\title{
Bursts Identification in Water Distribution Systems
}

\author{
Irina Borovik
}

\author{
PhD
}

August 2008 


\title{
Bursts Identification in Water Distribution Systems
}

\author{
Irina Borovik
}

Submitted in partial fulfilment of the requirements for the degree of Doctor of Philosophy

awarded by

De Montfort University

August 2008 


\section{Abstract}

The presented thesis investigates the identification of burst locations in water distribution systems (WDS) by analysis of field and simulation experimental data. This required the development of a new hybrid method of burst detection and sizing, and also a burst location identification algorithm. Generally, existing practice relies on a combination of some simple procedure and experience of the involved staff and cannot be easily automated. The practical methods are based on direct manifestation of burst on the surface or on systematically surveying suspected areas e.g. by using listening sticks, such methods are very time consuming. The proposed burst location algorithm is based on comparing data by means of statistical analysis of field data with results of water network simulation. An extended network hydraulic simulator is used to model pressure dependent leakage terms. The presence of a burst changes the flow pattern and also pressure at network nodes which may be used to estimate the burst size and its location. The influence of such random factors as demand flows and background leakage on the process of burst detection is also considered. The field data is from a generalised fixed area and variable area (FAVOR) test where inlet pressure is being stepped up and down and the following variables are measured: inlet flow, inlet pressure (head) and pressure at a number of selected sensitive nodes. The method has three stages and uses two different models, one is inlet flow model (IFM) to represent the total inlet flow and another is the extended hydraulic model to simulate different burst locations. Initially the presence of a potential burst is investigated. If this is confirmed precise values of the demand, background leakage flow and burst flow in IFM are subsequently estimated. They are used to identify the burst site at the third stage of the method. The method can be easily adapted for practical use. It requires data from experiments carried out at night between 1am and 5am and involves placing typically about 20 temporary loggers to collect the measurements during this period. It also requires the availability of a hydraulic model which normally is in the possession of a water company. The program has been implemented in the Matlab package and is easy to use. The current methodology is tuned to identify a single burst but can be generalised to identify locations of multiple bursts. 


\section{Acknowledgement}

The author would like to thank Prof. Bogumil Ulanicki for his guidance and members of the De Montfort University Water Software Systems research group for their help in preparation of the present research.

The author would like also to thank John May and South Staffordshire Water company for providing experimental data and for taking part in informative discussions. 


\section{Contents}

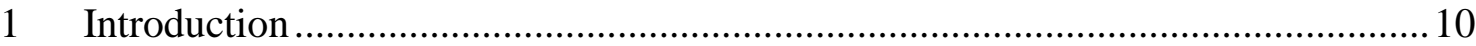

$1.1 \quad$ Aims and objectives of the research............................................................ 10

1.2 Summary of personal achievements............................................................. 13

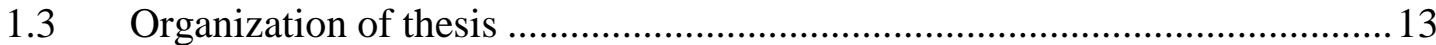

$1.4 \quad$ Leakage characteristics ........................................................................ 14

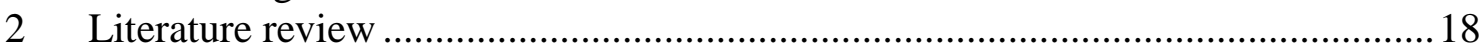

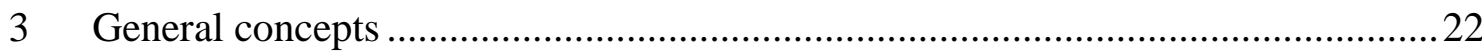

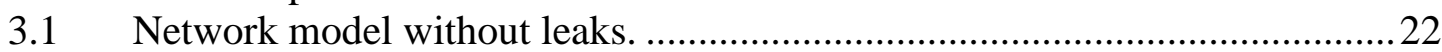

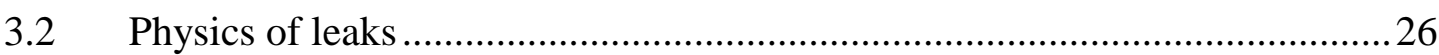

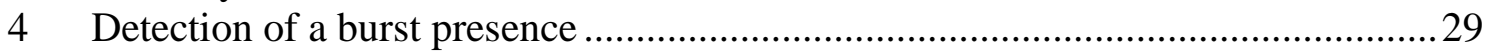

4.1 Validation of the proposed experimental method .............................................29

4.2 Simulating leakage including background leakage and bursts ..........................33

4.2.1 Background leakage estimation .............................................................

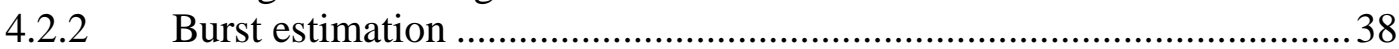

4.2.3 Burst leakage presence indication....................................................... 45

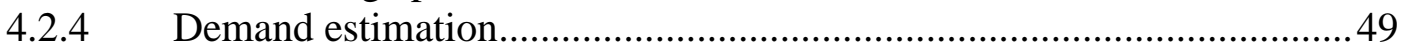

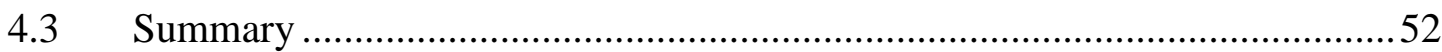

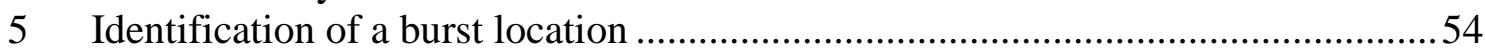

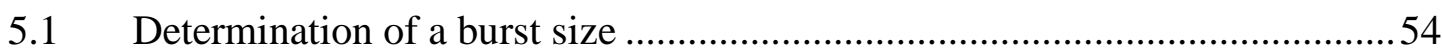

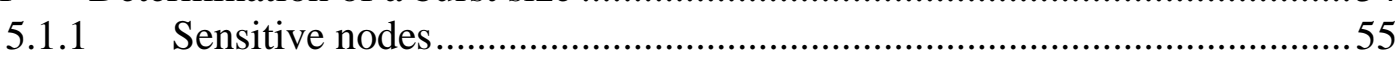

5.1.2 Determination of the IFM coefficients..................................................58

5.1.3 Method of statistical analysis for determination of the burst size............65

5.1.4 Hybrid method of burst detection ......................................................... 70

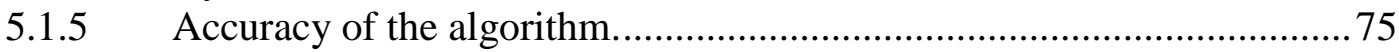

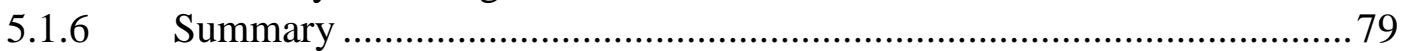

5.2 Effects of a burst on pressure in a DMA....................................................... 80

5.2.1 Influence of burst presence to pressure change in a network................... 80

5.2.2 The burst area location.............................................................................. 86

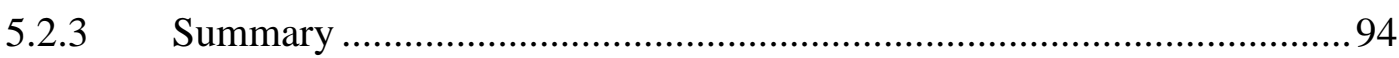

5.3 Algorithm for the burst location identification ..............................................95

5.3.1 Application of statistical analysis.........................................................96

5.3.2 Influence of sensitive nodes selection................................................. 104

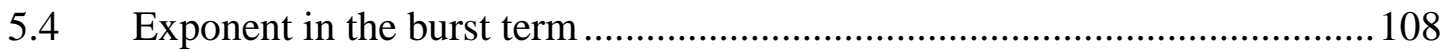

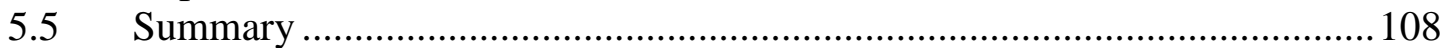

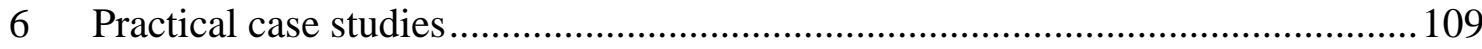

6.1 General condition of performing the experiment..........................................109

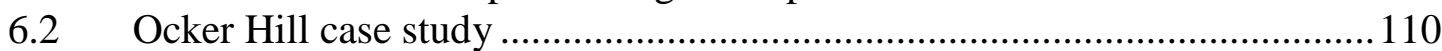

6.3 Shenstone case study............................................................................. 114

$6.4 \quad$ E054 - Drury Lane case study ................................................................... 118

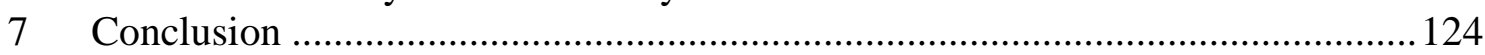

Appendix A - FAVOR Test Data.......................................................................... 128

Appendix B - Node and Element Data for the Frizinghall DMA ……………………....132

Appendix C - Node and Element Data for the Ocker Hill DMA ....................................136

Appendix D - Node and Element Data for the Shenstone DMA ...................................... 143

Appendix E - Node and Element Data for the E054 DMA............................................. 148

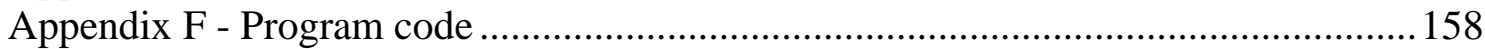




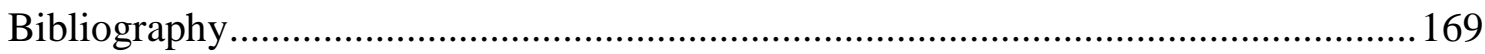

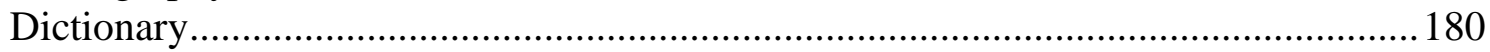

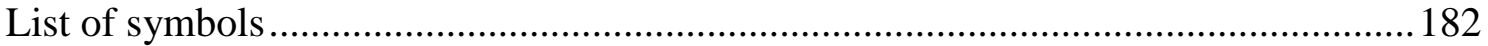




\section{Lists of tables}

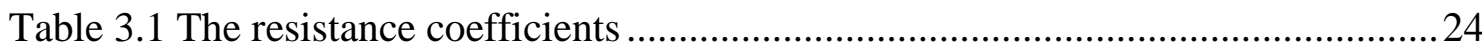

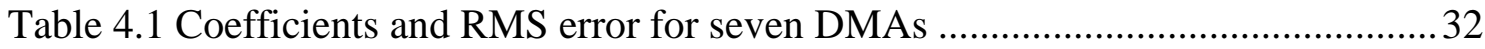

Table 4.2 Background leakage coefficients (for inlet pressure) …................................ 35

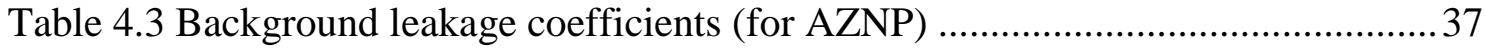

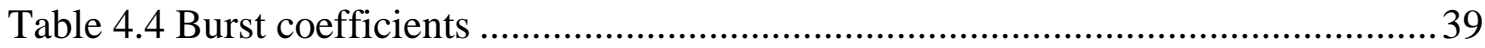

Table 4.5 Simulated (set) and estimated flows ......................................................... 40

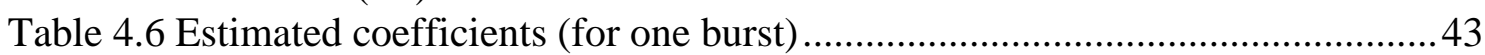

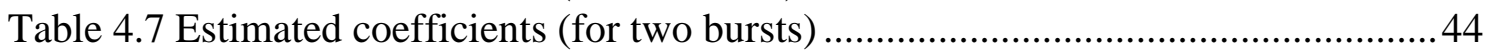

Table 4.8 Results of simulation (network without burst) .............................................. 46

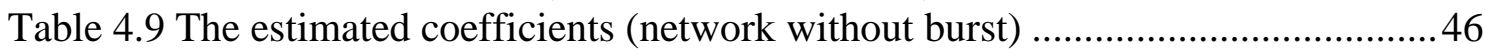

Table 4.10 The result of calculation (network without burst) .........................................46

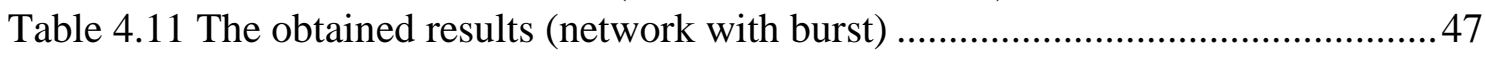

Table 4.12 The estimated coefficients (network with burst)............................................4

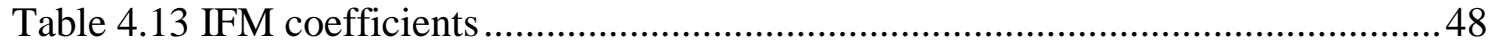

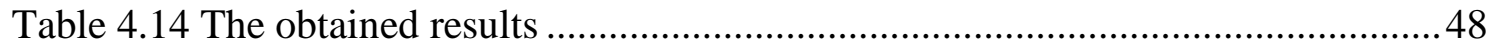

Table 4.15 Frequency of occurrence of the demand ....................................................49

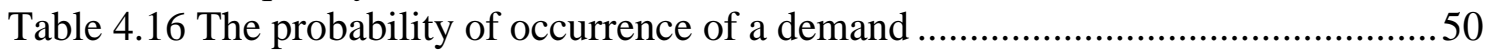

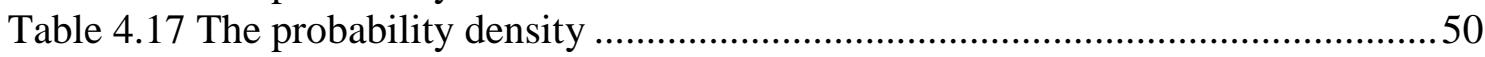

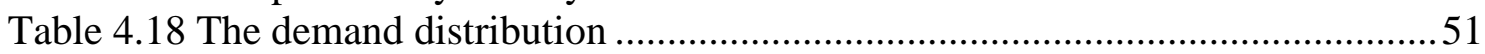

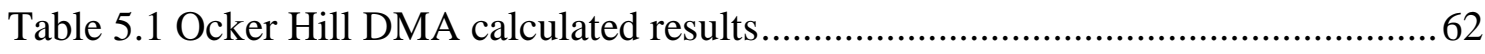

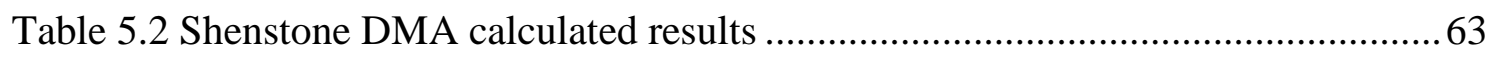

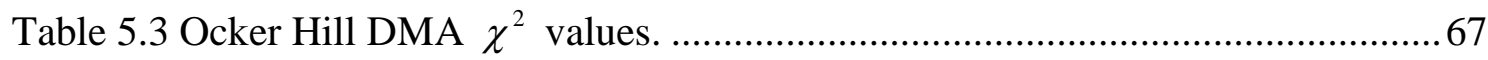

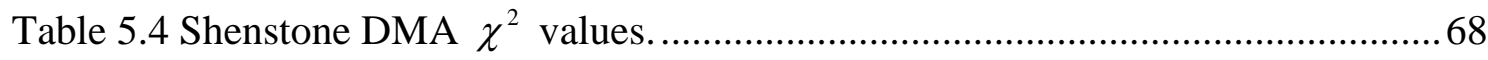

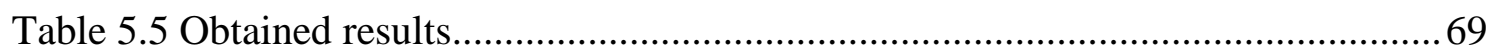

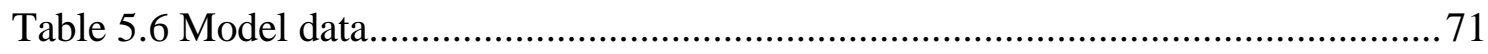

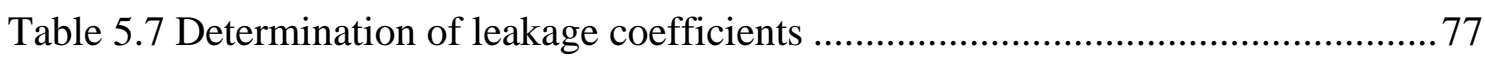

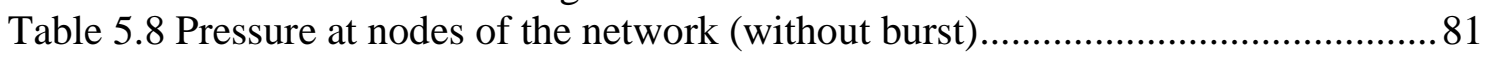

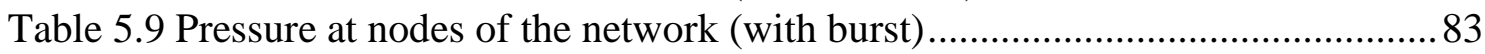

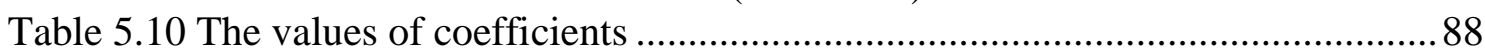

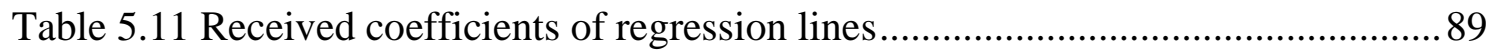

Table 5.12 Ocker Hill DMA calculated results........................................................... 91

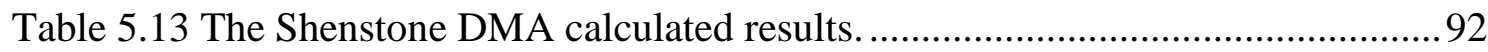

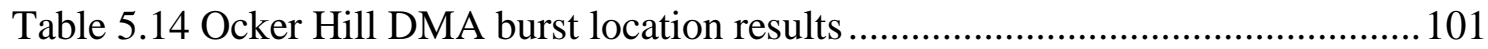

Table 5.15 Shenstone DMA burst location results...................................................... 101

Table 5.16 The results of experiments with other "Sensitive nodes" ........................... 106

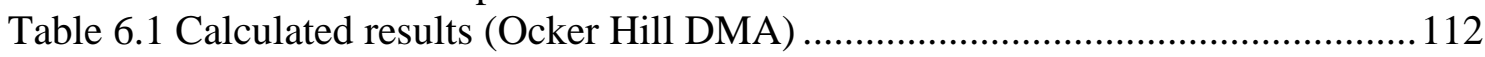

Table 6.2 Results of the burst location identification algorithm (Ocker Hill DMA) .... 113

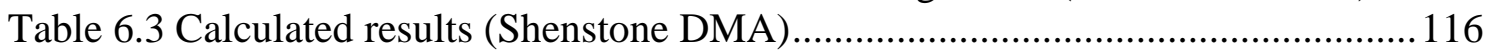

Table 6.4 Results of the burst location identification algorithm (Shenstone DMA) ....117

Table 6.5 Calculated results (First part of experiment)...........................................119

Table 6.6 Results of the burst location identification algorithm (First part of experiment)

.

Table 6.7 Calculated results (Second part of experiment) ......................................... 122

Table 6.8 Results of the burst location identification algorithm (Second part of

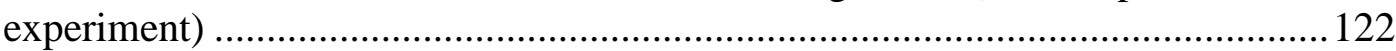


Table B.0.1 Node Data for Frizinghall DMA

Table B.0.2 Element Data for the Frizinghall DMA..................................................... 134

Table C.0.1 Complete nodes data for the Ocker Hill DMA...........................................136

Table C.0.2 Complete element data for Ocker Hill DMA ............................................... 141

Table D.0.1 Complete nodes data for the Shenstone DMA.............................................143

Table D.0.2 Complete element data for Shenstone DMA ………………………........ 146

Table E.0.1 Complete nodes data for the E054 DMA ……………………………....... 148

Table E.0.2 Complete element data for E054 DMA ………………………………...... 154 


\section{Lists of figures}

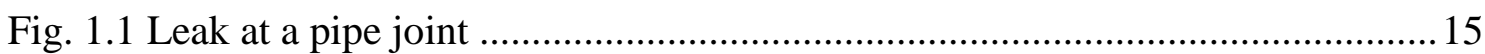

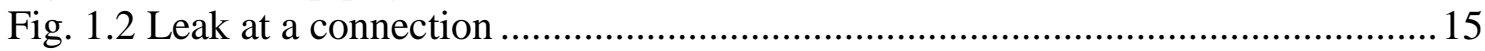

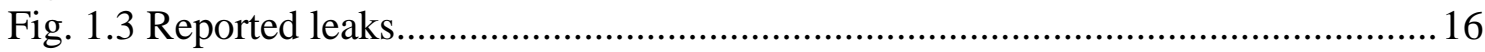

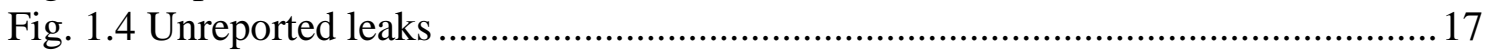

Fig. 3.1 Input-output models (conceptual model) of a water network ..........................22

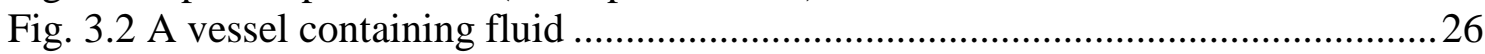

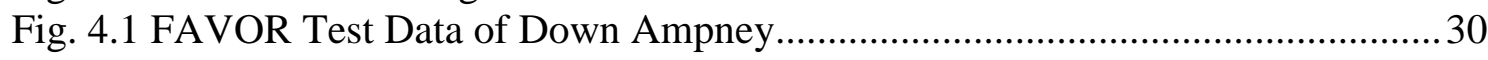

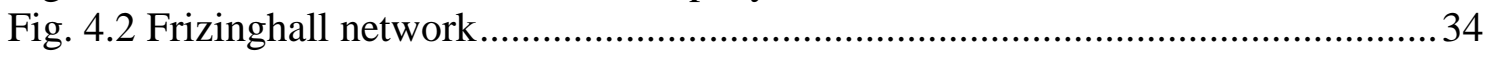

Fig. 4.3 Estimated background leakage coefficients using inlet pressure ...................... 35

Fig. 4.4 Relationship between AZNP and inlet pressure .......................................... 36

Fig. 4.5 Background leakage coefficient using AZNP. ............................................. 37

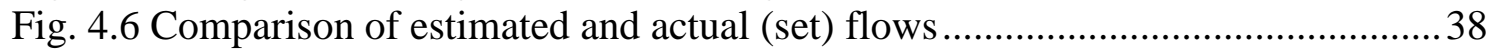

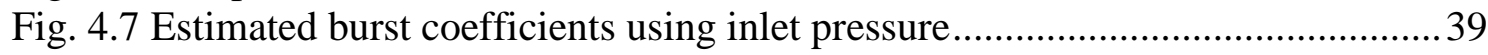

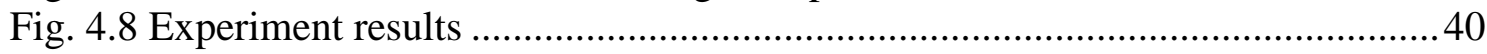

Fig. 4.9 Estimated burst coefficients using AZNP pressure ..................................... 41

Fig. 4.10 Estimated burst coefficients using inlet pressure (burst at node 352) ............ 41

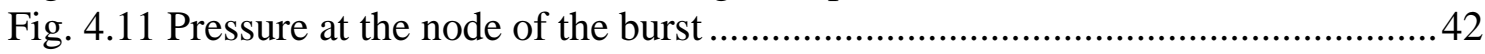

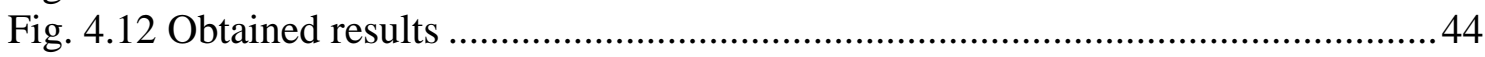

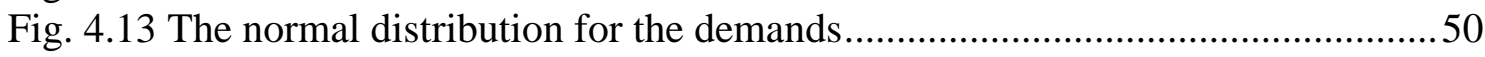

Fig. 4.14 Second section of Cirencester area ........................................................... 51

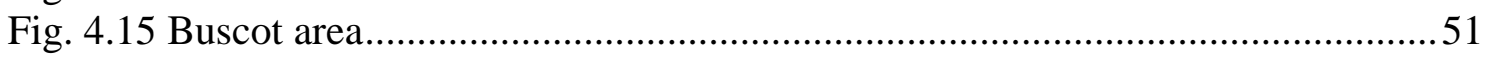

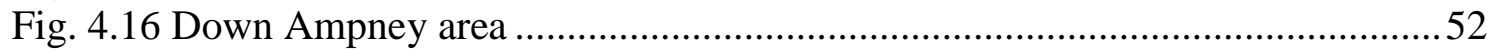

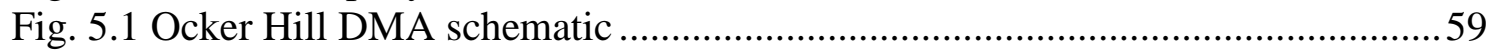

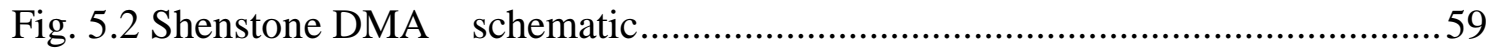

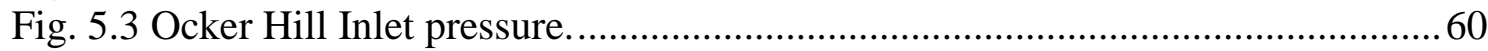

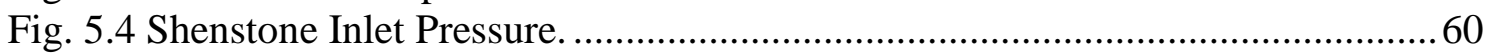

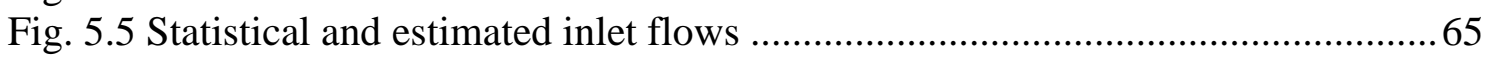

Fig. 5.6 File data.xls - Experimental data for the Shenstone network ........................... 72

Fig. 5.7 A flowchart of a burst size estimation algorithm......................................... 74

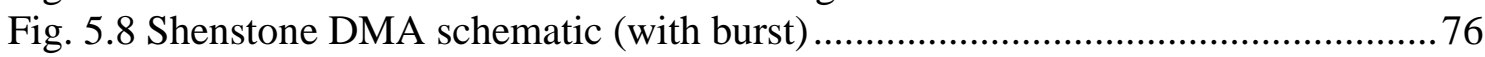

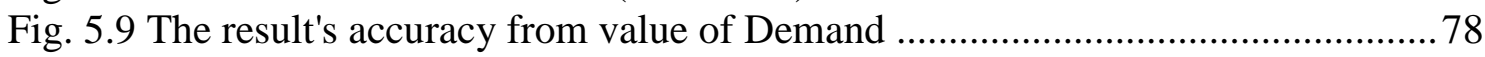

Fig. 5.10 The result's accuracy from value of the burst ............................................ 78

Fig. 5.11 The result's accuracy from value of the background leakage's flow ............... 78

Fig. 5.12 Diagram of pressure change at nodes of the network (without burst) .............82

Fig. 5.13 Diagram of pressure change in the network nodes (with burst) ...................... 83

Fig. 5.14 Ocker Hill DMA schematic (pressure measurement points) ............................84

Fig. 5.15 Diagram of pressure change in the network nodes ...................................... 84

Fig. 5.16 Diagram of pressure change in the network nodes ...................................... 85

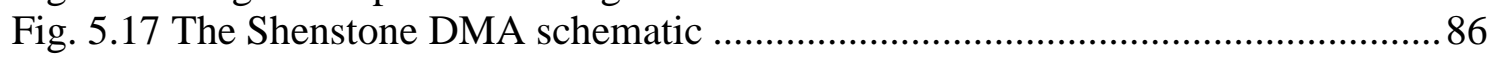

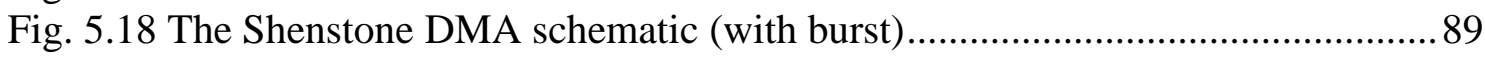

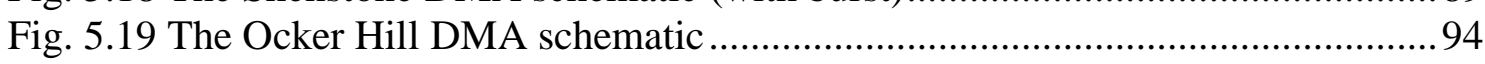

Fig. 5.20 A flowchart for burst location identification ............................................ 100

Fig. 5.21 Location of measurement points at the Shenstone DMA …......................... 105

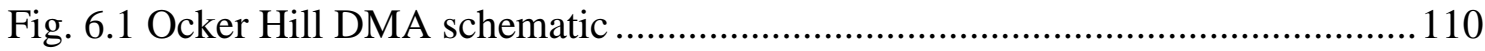

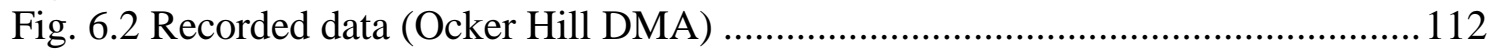

Fig. 6.3 Fixed area burst leakage in Ocker Hill DMA ................................................ 114 


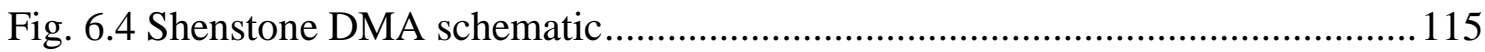

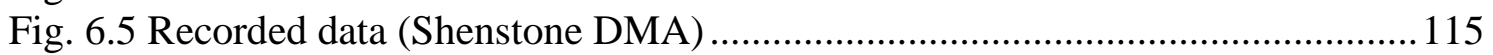

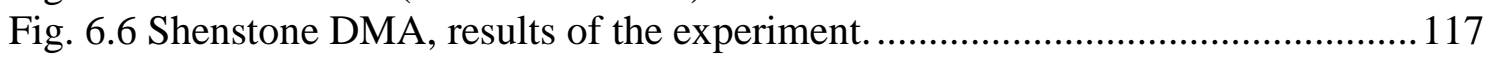

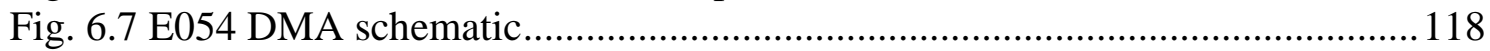

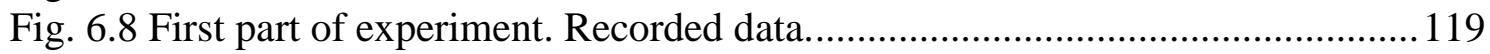

Fig. 6.9 E054 DMA. Results of first part of experiment. ............................................ 120

Fig. 6.10 Second part of experiment. Recorded data............................................... 121

Fig. 6.11 E054 DMA. Results of second part of experiment..................................... 123

Fig. A.0.1 FAVOR Test Data. Ashbury DMA. ..................................................... 128

Fig. A.0.2 FAVOR Test Data. Buscot DMA.......................................................... 129

Fig. A.0.3 FAVOR Test Data. Cirencester DMA.................................................... 129

Fig. A.0.4 FAVOR Test Data. Farringdon DMA. ................................................... 130

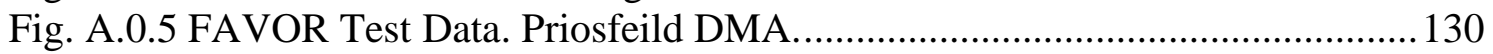

Fig. A.0.6 FAVOR Test Data. Shellingford DMA.................................................... 131 


\section{Introduction}

\subsection{Aims and objectives of the research}

Water is the most widespread substance in nature (hydrosphere occupies $71 \%$ of the Earth surface). It plays the most important role in the geological history of our planet and the existence of humanity without water would be impossible (about $65 \%$ of the human body consists of water). Water is an essential component of practically all technological processes. For this reason high emphasis is given to the matter of water supply without which further development of civilized society and modern production becomes impossible.

The current state and fast growth of urban water supply systems, expansion in a number of simultaneously used sources of water supply, in pump plants and in storage capacities are calling for improvement in analysis and control methods for water distribution systems (WDS). WDS are rather complicated entities of special constructions, interconnected by their parameters and operational condition. They provide, with sufficient reliability, water extraction from water sources, water treatment, accumulation and storage, water supply to the point of consumption, as well as distribution of the water among consumers. The systems are constructed in different environments using standard projects and serially manufactured for this purpose consisting of equipment, pipes and building constructions. Usually a WDS serves a rather wide circle of water consumers, who are dispersed over a wide area. In such complex conditions to take rational decisions about separate matters of water supply is difficult and requires the use of computer technology. One of the most important tasks is rational management of water resources. The UK water industry is addressing the major challenge of leakage management for WDS, driven by a mixture of economic, political and social factors (WRc 1994a, and b) and (Lambert et al. 1998). The water companies are making major investments to reduce leakage through traditional solutions and the evaluation and application of new technology. The savings arising from reduced leakage must be balanced against the cost of implementation of leakage detection schemes and the notion of an economic or optimum level of leakage at the distribution network scale is widely accepted throughout the industry. 
The leakage reduction problem as a whole is complex and requires co-ordinated actions in different areas of water network management, such as:

- Direct detection and repair of existing bursts

- General pipe rehabilitation programmes

- Operational pressure control

Water companies undertake a mixture of these complementary actions. General pipe rehabilitation is the most costly and long term action, but is undertaken to improve a number of different factors including leakage and water quality. Operational pressure control is a cost-effective action for reducing leakage over whole sub-networks, and for reducing the risk of further leaks by smoothing pressure variations and is the subject of ongoing research (Vairavamoorthy and Lumbers 1998), (Ulanicki et al. 1999), (Ulanicki and Prescott 2000). Detection and repair actions are targeted at sub-networks where bursts are present. Benefits of quick burst repair include reduced water losses, reduced disruption to traffic, reduced consequential losses (e.g. from flooding), and also reduced disruption to customers' supplies, which is an important water industry performance measure.

There are a number of procedures for detecting bursts. Water from some bursts appears on the surface but the water does not necessarily emerge at the point of the burst. Many bursts remain invisible with the water draining away and never reaching the surface. Undetected bursts cause significant damage to the network and urban infrastructure. Listening sticks and leak noise correlation methods are frequently used by water companies (Cascetta and Vigo 1992). This involves systematically surveying areas suspected of having bursts. These areas are identified from the night flow or from historical records of bursts and pipe condition. Leak noise correlation involves teams in the field surveying mains in sections, it is time consuming and costly. Some companies are now considering permanently installed leak noise monitors. Generally, burst detection requires a combination of activities depending upon the burst itself and the experience of the staff performing the tasks.

Recently UK water companies have heavily invested into restructuring water networks into smaller sub-networks known as Demand Management Areas (DMAs). A DMA is a sub-network where the boundary flow is monitored in order to assess leakage. Its boundary is closed except for inputs and outputs with flow and pressure metres. This facilitates leakage management in terms of pressure control and bursts detection. 
The first internationally applicable concept is the bursts and background estimates (BABE) which was developed by Allan Lambert for the UK National Leakage Control Initiative. The findings of this Initiative have been published in 'Managing Leakage' Reports (WRc- UK Water Industry, 1994). In BABE analysis, components of Real Losses are considered to consist of background leakage, reported and unreported leaks and bursts. Pressure in a water distribution system varies with demands during 24 hours a day (through the 24-hour day). For systems served by gravity from reservoirs, pressure is normally the highest at night, between $02.00 \mathrm{hrs}$ and $04.00 \mathrm{hrs}$, when consumption is at its lowest. The minimum flow, measured during the night when the flow is at its lowest, is generally used in the BABE analysis as the initial basis for calculating losses from the system. When a new burst occurs it causes a noticeable increase in night boundary flow - such bursts should be located and repaired as quickly as possible. This approach is effective only for detecting new bursts and not for their localisation. DMAs which are supplied by a small number of mains can be investigated by successively closing valves across the DMA and observing the corresponding changes in flow. This allows the operator to narrow the search to a small area where leak noise correlation methods can be applied. This common sense procedure can be developed further into formal estimation techniques for burst detection (Pudar and Liggett 1992) but so far, there is no firm practical evidence that this approach is fully effective. This can be attributed to the fact that the method is based on passive identification and inaccurate models, which do not reflect the true nature of leakage. Attempts were made to use the transient response of a network to detect bursts (Covas and Ramos 1999), although the model is complicated and the effectiveness of the approach is questionable especially for looped networks.

The hypothesis behind this research is that a truly effective method for burst detection can be formulated by exploiting different behaviour of background leakage and bursts under varying pressure (May 1994). The first step of the method is to perform an active identification experiment which involves changing inlet pressure and observing corresponding changes in the inlet flow and in pressure at a number of internal nodes. 


\subsection{Summary of personal achievements}

The following are personal contributions that represent significant and original advances over existing work:

- Development and validation of the concept that the different behaviour of background leakage and bursts under varying pressure can be used for burst detection.

- Verification that it is possible to precisely define the level of background leakage and presence of bursts in a network.

- Verification that it is possible to estimate the total water demand from night flow as well as demand distribution.

- Creating a hybrid method for burst size determination.

- The investigation of the effects of burst presence on pressure changes in the network and validation of the hypothesis that this can be used for the burst location identification.

- Creating a burst location identification algorithm together with the criterion to evaluate its accuracy.

- Investigation of the sensitivity of the burst location identification algorithm to different logger placement strategies.

- Validation of the developed methodology on two practical case studies

- Participation in Moscow University conference "Information and Control Systems in XXI century" (Borovik \& Pavlov 2000) and publication of reports (Borovik \& Pavlov 2007, Borovik \& Yanov 2007).

\subsection{Organization of thesis}

The thesis comprises six chapters representing the development of the research. The content of individual chapters is as follows:

- Chapter 2 contains a review of the literature in the leakage management area.

- Chapter 3 contains general equations of main physical laws and phenomena governing water distribution systems. 
- Chapter 3 consists of two sections, Chapter 3.1 is dedicated to the description of a network mathematical model and Chapter 3.2 to the physics of leaks.

- Chapter 4 is dedicated to verification of the hypothesis that the different behaviour of background leakage and bursts under varying pressure can be used to develop a method for burst detection. It consists of three parts: validation of the FAVOR test, high precision leakage modelling studies, and the formulation of a burst presence identification algorithm.

- Chapter 5 is dedicated to the task of finding burst location and is divided into three main parts: development of the hybrid method to quantify the leakage flows ( Chapter 5.1), investigation of sensitive indicators of burst presence (Chapter 5.2) and finally the development of the burst location identification algorithm in Chapter 5.3. The approach is based on calculating parameter estimates using the least squares method followed by statistical analysis based on the chi-square criterion. Chapter 5.1.1 describes an algorithm for selecting sensitive nodes where pressure loggers are to be placed, while the effects of different placing strategies are investigated in Chapter 5.3.2. Special emphasis is placed on the definition of a criterion which is able to assess the reliability of the obtained results.

- Chapter 6 describes three practical case studies in order to validate the proposed approach.

- Conclusions and an outline for future research are outlined in Chapter 7.

\subsection{Leakage characteristics}

There are numerous types of leaks, each one with different typical flow ranges. The AWWA manual, Water Audits and Leak Detection, describes six such categories (Manual of Water Supply Practices AWWA M36 1990). Hirner also uses six categories for causes of leaks identified in a German city network (Hirner 1997):

- Bad and defective materials, whether of the pipes and joints or in the bedding and surroundings, due to insufficient planning.

- Pipe breaks resulting from poor workmanship in their laying - bridging pipes, stones in contact with pipes, non-adherence to required joint gaps, damage arising from heavy traffic, excessive joint deflection within sockets. 
- Operational errors - excess pressure, filling pipelines too rapidly, closing valves too rapidly, water hammer.

- Corrosion - internal due to aggressive water, external due to insufficient corrosion protection of metallic materials from aggressive soil and groundwater.

- Leaking fittings (valves, air valves, saddles, hydrants), leaking stuffing boxes, leaking gate seating with stones in the seating, encrustation, old valves with inadequate construction, broken spindles caused by excessive force during operation, badly located saddle clamps.

- Accidental or deliberate damage to hydrants and taps removed from standpipes.

Examples of leaks from a joint between two pipes and from a connection are shown in Fig.1.1 and Fig.1.2 respectively.

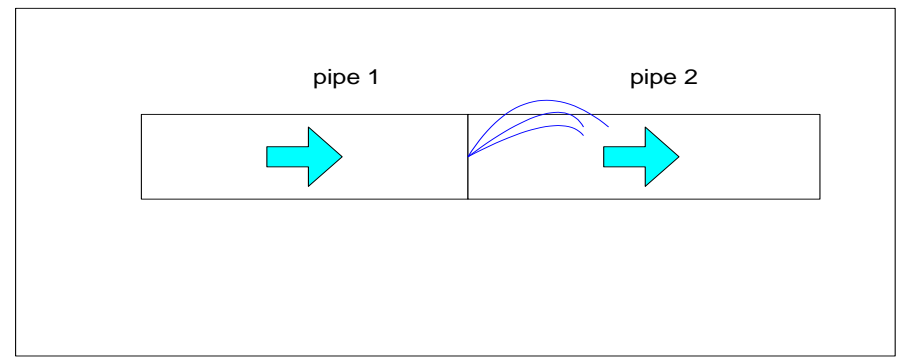

Fig. 1.1 Leak at a pipe joint

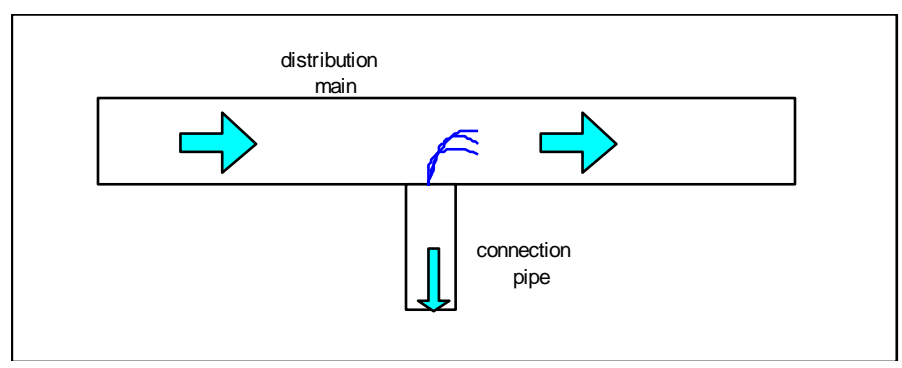

Fig. 1.2 Leak at a connection

The flow rates of individual leaks depend on the size of the hole, split or crack, and network pressure. They cover a wide range from a few litres/hour to many thousands of litres/hour. In Hirner (1997) categorization of the causes of leaks, all the items under the heading of operational faults such as excess pressure, filling pipelines too rapidly, closing valves too rapidly, water hammer - are associated with operating pressures, either directly or indirectly. 
For the purposes of practical calculations and modelling it is appropriate to aggregate the numerous categories of leaks into a smaller number of broader groupings. The choice of groupings needs to reflect the fact that the total annual volume of losses from leakage depends not only on frequencies, flow rates and average duration of different types of leak but also on the practicalities of becoming aware of, and locating, the leaks. The following groupings are now widely used in the UK, with some variation in terminology (Lambert et al. 1998).

- Reported leaks generally have such high flow rates that they cause visible flows at the ground surface, loss of supply or low pressure for consumers. They are therefore normally reported to the water company by third parties soon after they occur.

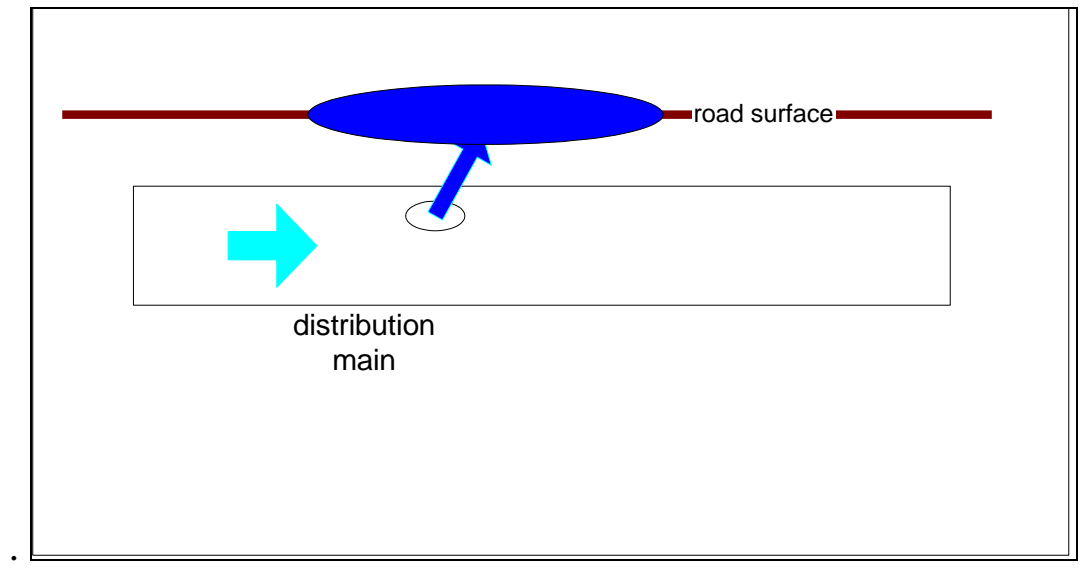

Fig. 1.3 Reported leaks

Reported leaks tend to have quite high individual flow rates, typically between 500 and 50,000 litres/hr, but average duration of only a few hours or days if repairs are carried out promptly.

- Unreported leaks have flow rates, which are generally less than those for reported leaks, but because they are only found through special investigations, they can run for months or even a year, and cause larger losses of water than reported leaks. 


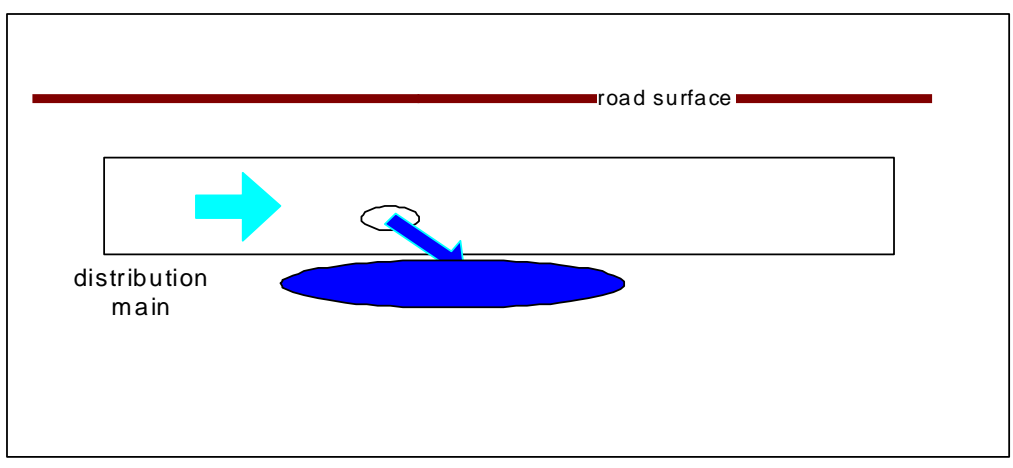

Fig. 1.4 Unreported leaks

However, some leaks are so small, so deep below ground, or come from pipes or fittings constructed of materials with poor sound conductivity (e.g. plastic pipes) that they cannot be detected at all. These relatively small undetectable leaks give rise to a third category of leakage.

- Background leakage for which individual flow rates are quite low - from less than 10 litres/hour to several hundred litres/hour - but they can account for a considerable proportion of the annual volume of losses, because they run continuously. They occur mainly at joints and fittings, and in the initial stages of development of small corrosion holes.

The unreported and reported leaks are combined into one group called bursts (or fixed area leakage) and the following categorization is proposed:

- flow of an individual burst is from 0.1 litres/second to 10 litres/second

- flow of an individual background leak is from 0.005 litres/second to 0.05 litres/second

for the purpose of numerical and practical experiments.

The main task of the research is to detect the location of a possible burst in water distribution systems. 


\section{Literature review}

At the present time the water loss due to leaks in water distribution systems is a major problem for water companies. The economic cost related to water pipe bursts depends on frequency of pipe breaks which decreases overall hydraulic performance of WDS. For example, current water losses in WDS in Serbia and Montenegro are $40 \%$ or more of delivered water (Babich, Prodanovich and Ivetich 2005). In Italy real losses represent $27 \%$ of the entire supplied volume, but in many cases they reach and exceed $50 \%$ and similar conditions are common in many other countries (Magini, Pallavicini \& Verde 2007). Leakage makes up a large part, sometimes more than $70 \%$ of the total water losses (WHO 2001). As a consequence of these economic and water-quality related issues, the interest of the scientific community in leak detection methodologies increased, with many papers on this topic published in recent years.

In general, two approaches of solving the problem of water loss due to leaks are available. The first one is prevention of leak occurrences. Usually a combination of factors and conditions influences the probability of leak occurrences (Ragani and Tesfamariam 2005), both static (e.g., pipe material, size, age, soil type) (Economou et al 2007) and dynamic (e.g., climate, cathodic protection, pressure zone changes) (Kleiner \& Rajani 2007). Skipworth (2001) and Unwin (2003) showed an increase in the burst rate with pipe age, where the relationship depends on material types. Various modelling approaches are used for prediction of the failures, depending upon the failure type, the nature and complexity of the network and the availability, scope and reliability of relevant data (Kleiner \& Rajani 2001; Giustolisi \& Berardi 2007; Berardi L., Giustolisi O., Primativo F. 2007; Boxall at al 2005). Predictions create a possibility of preventing burst occurrences by carrying out jobs on reconstruction and renewal of pipes (Hetenyi, Tolnai and Zimmer 2007). An economic analysis of this problem was performed in pioneering works on the subject (Shamir \& Howard 1979, Walski \& Pellicia 1982). Renewal works are needed which ensure the continuity of the service access, but where the strategy of renovation needs to take into account economic, technical and social criteria (Nafi \& Werey 2007). During development of a multi-objective strategy different algorithms are used for solving the task of planning optimisation and 
renovation: a genetic algorithm (Giustolisi, Laucelli and Savic 2005, Dandy and Engelhardt 2001), a fuzzy rule based, non-homogeneous Markov process (Kleinner et al 2004, 2005), the method of Cullinane (Trifunovich, Umar 2003), statistical methods (Mays, 2000), a nonsorting genetic algorithm (Devi \& Nam-Sik 2004), a Strength Pareto Evolutionary Algorithm (SPEA) (Cheung et al. 2003), a Non-Sorting Genetic Algorithm II (Deb et al 2000). At present the pipe rehabilitation practice and theory is being actively developed, new materials for pipes are investigated and new factors influencing the probability of burst occurrences are investigated, but it needs sufficient time, efforts and resources to be fully realized, that is why the problem of water losses will remain important in the near future.

In this context the detection of leaks is of high importance and both methodologies of the prediction of pipe failures and the detection of leaks are based on analysis of statistical data of already detected leaks (Berardi, Savic \& Giustolisi 2005).

The detection of a burst and identification of its size and location is not possible without system monitoring providing information about flow changes (Burnell 2003) and pressure changes (Stephens et al. 2005). The quality of collected information from monitors depends on the placement of pressure loggers in a water distribution system. To solve the problem of optimal placement of pressure loggers various methods based on Genetic Algorithms (Xi, Bin, Jie \& Fang 2007), cluster analysis (Huang \& Cong 2001, Zhou \& Hu 2005) and regression analysis (Guo, Liu \& Chen 2004) are suggested, but the essence of all these methods is in discovering sensitive nodes in the network, which represent behaviour of all other nodes. The matter of selection of sensitive nodes is examined in detail in Chapter 5.1.1.

There were different leak detection methods proposed in 1990s which are reviewed in (Simpson and Vitkovsky 1997, Vitkovsky and Simpson 1997), for example, a leak detection method by means of solving the inverse steady-state problem was introduced by Pudar and Liggett (Pudar \& Liggett 1992). More recently, several techniques for leaks detection based on transient models have been investigated. For instance, (Brunone \& Ferrante 2001, Covas at al. 2003, Covas et al. 2004, Al-Khomairi 2005) have developed methods based on time analysis of a travelling wave. (Zecchin et al. 2005), (Mpesha et al. 2000, Stoianov et al. 2002, Ferrante \& Brunone 2003, Wang et al. 2002) have investigated similar ideas in the frequency domain. Inverse transient analyses have been proposed by (Soares, Covas \& Reis 2007, Liggett \& Chen 1994, 
Nash \& Karney 1999, Vitkovsky et al. 2000, Kapelan et al. 2003). The basic idea is to deliberately generate transient waves or impulses and to measure the responses with highly sensitive pressure transducers. Optimisation (search) methods such as genetic algorithms are used for the burst location (Wu \& Sage 2007). The burst is placed at different nodes of the WDS model to minimize the difference between the simulated and measured transient pressure (Vitkovsky et al. 1999). The overwhelming majority of research papers concerned with this methodology have been applied for the single pipeline cases and not to real distribution systems. The main shortcoming of the approach is that the transient wave is heavily damped throughout a WDS due to storage tanks, junctions, network cross connections and various demands. It is unlikely that it will be possible to measure transient pressure accurately enough to be used for inverse analysis. In general such methods are not suitable for leak detection in DMAs.

Currently, other methods for burst detection are appearing. This is linked to the increase in computer power and consequently with the possibility of fast information processing in large databases and with the availability of new numerical methods for WDS analysis (Tabesh \& Delavar 2003, Giustolisi \& Laucelli 2007) e.g. modeling pressure dependent leakage.

The burst finding pilot study using the Calibration Module of SynerGEE ${ }^{\circledR}$ Water (Deagle etal. 2007) has been successful and it has proven that network models can be employed to identify system anomalies and areas of interest within the distribution network. However, according to the authors of the paper the required period of observation over the real network is very long: "A plot of a DMA inflows over a number of months prior to study and for the 24 hour period during the study and pressure data for a full 24-hour period for all pressure logger points are required".

There are other methods, which require continuous monitoring of the concerned area. For instance, (Garcia, Cabrera, Cabrera 2006) have developed a method based on the observation of the minimum night flow (MNF), (Mounce, Boxall \& Machell 2007) used the Artificial Neural Networks/Fuzzy Logic approach to analyze a DMA inflow including MNF, (Buchberger \& Nadimpalli 2004) have developed the leak screening method based on repeatedly computing the mean and standard deviation of the measured inlet night flows. An annual balance method has been proposed by (Tabesh et al. 2005). (Araujo, Coelho \& Ramos 2003) have developed a method for estimating distributed pressure-dependent leakage and consumer demands. Typical limitations of 
the above methods are that they identify only new burst events whilst the existing leaks may go undetected and they estimate the total water losses rather than precise location of a burst.

Puust (Puust et al. 2006) proposed a methodology which is based on the Shuffled Complex Evolution Metropolis (SCEM-UA) algorithm and is capable of estimating the posterior probability density functions for unknown leak areas and their respective locations in an artificial network case-study. It seems that this approach is similar to the hybrid method presented in this report, but it has not been developed completely and unfortunately comparative analysis of these methods cannot be carried out. 


\section{General concepts}

In the epoch of computer technology the solution to many engineering tasks is accomplished by computer algorithms which use mathematical models of physical phenomena occurring in the examined system. In this chapter the equations governing WDS are given, which underlie the method developed by the author.

\subsection{Network model without leaks.}

At the present time there are a number of packages for computer simulation of WDS, such as: GINAS (Coulbeck 1989), EPANET (Rossman 2000), FINESSE (WSS 1999) and InfoWorks WS (Wallingford Software 2008).

All of them are based on the hydraulic laws (in Greek language hydro means water, aulos - pipe, chute) - the science, that began to develop in the ancient period (250 years B.C.). A conceptual model of a WDS can be presented as an input-output system illustrated in Figure 3.1.

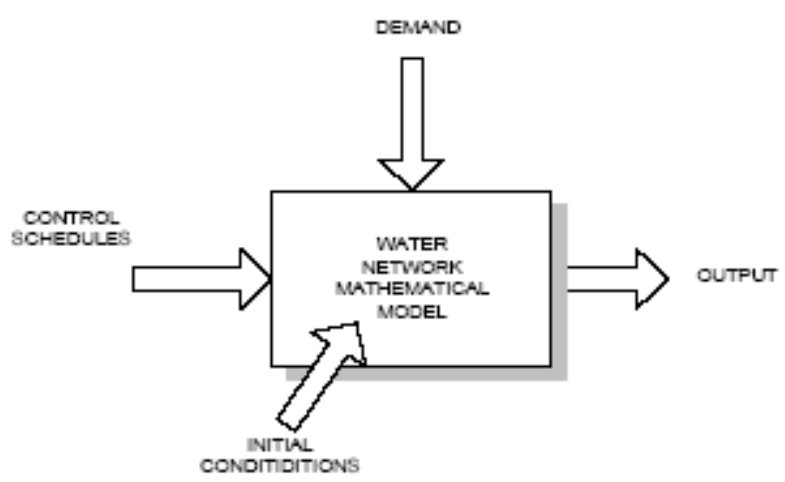

Fig. 3.1 Input-output models (conceptual model) of a water network

The following terms are associated with the model:

Control Schedules are pump, valve and source schedules.

Demands are node outflows representing water consumption.

Initial Conditions are the initial reservoir levels.

Output comprises heads at nodes, flows in elements, and operating costs.

Water Network Mathematical Model is the set of mathematical equations simulating behaviour of the physical system. 
Topology describes connections between components.

A computer model of a water distribution system is a collection of links connected to nodes. The links represent pipes, pumps and control valves. Nodes are points in the network where links join together and where water enters or leaves the network. It is useful to distinguish between the basic two terminal components with regular characteristics and the complex components with local control loops that potentially have irregular (non-monotonic, non-smooth) characteristics.

The two terminal components are described by an equation relating component flow $q$ and the head loss $\Delta h$ : e.g. $\Delta h-r(q) q=0$ where $r(q)$ is flow dependent resistance.

For complex components the origin and destination heads may appear explicitly as separate variables, e.g. $f\left(q, h_{\text {origin }}, h_{\text {destination }}\right)=0$.

The basic components are reservoirs, pipes, simple valves, pumps, and demands. The components with local control loops are control elements such as pressure reducing valves (PRVs), pressure sustaining valves (PSVs), pressure control pumps (PCPs), etc. In a computer implementation, a water network model is represented by a set of network data (network topology, water demands and components data) and a set of equations (that define physical operation of the model).

The fundamental model is formulated using laws of physics. Three physical laws are employed for water network models: conservation of mass - flow continuity (Kirchhoff's I law), conservation of energy - head-loss continuity (Kirchhoff's II law), and component equations (head/flow law).

The hydraulic head loss caused by water flowing in a pipe due to friction can be computed using one of two different formulas:

- Hazen-Williams formula

The Hazen-Williams equation is an empirical formula which relates the flow of water in a pipe with the physical properties of the pipe and the pressure drop caused by friction.

- Darcy-Weisbach formula

The Darcy-Weisbach equation is an important and widely used phenomenological equation in hydraulics. It relates the head loss or pressure loss due to friction along a given length of pipe to the average velocity of the fluid flow. 
Each formula uses the following equation to compute head-loss between the origin and destination node of the pipe:

$\Delta h=R q^{B}$

where $\Delta h$ is head-loss (Length), $q$ - flow rate (Volume/Time), $R$ - resistance coefficient, and $B$ - flow exponent. The table 3.1 lists expressions for the resistance coefficient for each of the formulas (Streeter \& Wylie 1998).

Table 3.1 The resistance coefficients

\begin{tabular}{|l|c|}
\hline \multicolumn{1}{|c|}{ Formula } & $\begin{array}{c}\text { Resistance Coefficient } \\
(\mathrm{R})\end{array}$ \\
\hline Hazen-Williams & $10.075 \times C^{-1.852}(d[m])^{-4.87} L[m]$ \\
\hline $\begin{array}{l}\text { Darcy-Weisbach } \\
(\text { Colebrook -White })\end{array}$ & $f \times 0.082627 \times(d[m])^{-5} \times L[m]$ \\
\hline
\end{tabular}

where

$C$ - Hazen-Williams roughness coefficient

$d$-pipe diameter $[\mathrm{m}]$,

$L$ - pipe length $[\mathrm{m}]$

$f$ - friction factor is a combination of geometric factors such as the Reynolds number and (outside the laminar regime) the relative roughness of the pipe (the ratio of the roughness height to the hydraulic diameter) and is obtained by solving the Colebrook equation $\frac{1}{f^{0.5}}=-2.0 \log \left(\frac{e / d}{3.7}+\frac{2.51}{\operatorname{Re} \times f^{0.5}}\right)$, where

$e$ - Darcy-Weisbach roughness coefficient [m]

$d$ - pipe diameter $[\mathrm{m}]$,

$q$ - flow rate $\left[\mathrm{m}^{\wedge} 3 / \mathrm{s}\right]$

$R e$ - the Reynolds Number of the flow (Reynolds numbers are used to characterize different flow regimes, such as laminar or turbulent flow: laminar flow occurs at low Reynolds numbers, where viscous forces are dominant, and is characterized by smooth, constant fluid motion, while turbulent flow occurs at high Reynolds numbers and is dominated by inertial forces, which tend to produce random eddies, vortices and other flow fluctuations.) 
The pipe headloss formulas for full flow:

- Hazen-Williams formula

$\Delta h[m]=R q^{1.852}=10.075 \times C^{-1.852}(d[m])^{-4.87} L[m](q[l / s])^{1.852}$

- Darcy-Weisbach (Colebrook -White) formula

$\Delta h[m]=R q^{2}=f \times 0.082627 \times(d[m])^{-5} \times L[m] \times(q[l / s])^{2}$

The Darcy-Weisbach equation are considered to be the most accurate model for estimating frictional head loss in steady pipe flow, but it is difficult to use. That is why an alternative empirical head loss calculation like the Hazen-Williams equation may be preferred. The Hazen-Williams equation can be expressed in slightly different units commonly used by hydraulic engineers:

$$
\Delta h[m]=1.21216 \times 10^{10} C^{-1.852}(d[m m])^{-4.87} L[m](q[l / s])^{1.852}
$$

For convenience of calculations in this thesis the above network equation can be expressed using a vector-matrix notation, as given below:

$$
\begin{array}{ll}
\frac{d h_{f}}{d t}=-S^{-1} q_{f}(t) & \text { reservoir dynamics } \\
R(q) q=\Lambda^{T} h & \text { component equations } \\
\Lambda_{c} q=-d & \text { mass balance at connection nodes } \\
\Lambda_{f} q=q_{f}+q_{s} & \text { mass balance at the reservoir nodes }
\end{array}
$$

where

$S \quad$ is a diagonal matrix of the reservoir cross-sectional areas

$h=\left[\begin{array}{l}h_{f} \\ h_{c}\end{array}\right] \quad$ is the vector of node heads, $h_{f}$ is the vector of heads at reservoir nodes (fixed grade nodes) and $h_{c}$ is the vector of heads at the connection nodes.

$q$ is the vector of branch flows.

$q_{f}$ and $q_{s} \quad$ are nodal flows, the vector of reservoir flows and the vector of source flows respectively.

$d \quad$ is the vector of nodal demands.

$\Lambda_{c}, \Lambda_{f} \quad$ are the node branch incidence matrices for connection nodes and reservoir nodes respectively.

$R(q) \quad$ is the component resistance matrix: 
$R(q)=\left[\begin{array}{ccc}r_{1}\left(q_{1}\right) & 0 \ldots & 0 \\ 0 & r_{2}\left(q_{2}\right) & 0 \ldots \\ 0 & 0 \ldots & r_{b}\left(q_{b}\right)\end{array}\right]$

$r_{i}\left(q_{i}\right)$ is a resistance for $q_{i}$ flow from component headloss function $\Delta h_{i}=R_{i}\left|q_{i}\right|^{0.852} q_{i}=r_{i}\left(q_{i}\right) q_{i}$

$b$ is a number of branches.

The system of equations (3.1) to (3.4) can be classified as a system of differential algebraic equations (DAEs) where equation 3.1 represents the differential part and equations (3.2) to (3.4) the algebraic part. Variables $h_{c}, q, h_{f}, q_{f}$ are internal variables of the model, vector $h_{f}$ is called a differential variable and $h_{c}, q, q_{f}$ are called algebraic variables.

\subsection{Physics of leaks}

Initially, a model must be obtained which includes standard hydraulic data and additionally leakage information. It is standard industrial practice that the leakage flow is aggregated together with demands. Germanopoulos (1985), using results of field experiments, proposed a non-linear formula relating leakage flow to pressure. May (1994) suggested an approach to leakage representation, which has a direct physical interpretation and can be incorporated into a simulation algorithm comparatively easily. Consider a vessel containing fluid with an opening in its wall depicted in Fig. 3.2.

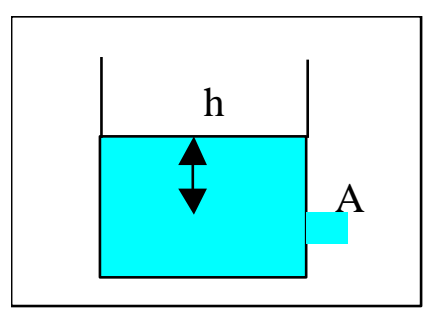

Fig. 3.2 A vessel containing fluid

Speed of the water through the opening is $v=\sqrt{2 g h}$ and the flow $q=c_{d} A \sqrt{2 g h}=c_{d} A(2 g h)^{0.5}$, where $c_{d}$ is the discharge coefficient, $A$ is the orifice area, $g$ is the acceleration due to gravity and $h$ is the pressure head. 
A slightly more general form of this power law will be applied to express the leak flow in pipes:

$$
q=c p^{\alpha},
$$

where $c$ is the leak coefficient (equivalent area of the leak), $\alpha$ is the leak exponent and $p$ is the pressure which is the difference between the head and the node elevation.

May's theory demonstrated that the cross-sectional area of certain types of leakage paths - holes, tears or breaks in pipes, joints and fittings - vary with pressure, while the velocity of flow continued to vary in proportion to the square root of pressure. This would give rise to different types of leakage paths in which the flow rates vary with pressure as follows:

- fixed areas (in case of a burst) to the power 0.5

The burst flow is calculated as $q=c_{1} p^{0.5}$, where $c_{l}$ is the burst coefficient.

- areas which vary along a single axis (in the case of the background leakage) to the power 1.5

The background leakage's flow is calculated as $q=c_{2} p^{1.5}, \quad$ where $\quad c_{2}$ is the background leakage coefficient.

In the UK large scale water distribution systems are decomposed into zones and the zones are decomposed into district metering areas (DMA). The concept of DMA management was first introduced to the UK water industry in the early 1980s (WAA 1980) where a district is an area of a distribution system which is specifically defined, e.g. by the closure of valves, and in which the quantities of water incoming and going out of the district are metered (Morrison 2004). Assessments of the aggregate water losses for the whole WDS are derived indirectly from water balance calculations, as the difference between a measured volume of input and aggregate, and measured or estimated volume of output over the same period of time. It is possible to write an equation for the balance of water in a DMA as follows:

Flow $_{\text {inlet }}=$ Demand + Leakage

The corresponding equation for the estimation of the inlet flow can be written as follows:

$q=$ Demand + Leakage $=d+c_{1} p_{1}^{0.5}+c_{2} p_{2}^{1.5}$

where $p_{1}$ and $p_{2}$ are appropriate pressures which will be discussed in detail later. 
A simulation model including hydraulic equations and pressure dependent leakage has been created and implemented in the advanced modelling environment GAMS (Brooke, Kendrick, \& Meeraus 1992). Such a model provides freedom to model different scenarios, for example simulating just background leakage, which cannot be tested in a physical network. The effects of bursts on flows and heads throughout the system can be observed and sensitive indicators of the presence of bursts can be derived. Because precision is of paramount importance, the Darcy-Weisbach (Colebrook -White) formula has been used rather than the Hazen-Williams model (Streeter and Wylie 1998). The standard hydraulic equations (3.1)-(3.4) have been complemented with additional terms representing pressure dependent leakage $q=c p^{\alpha}$, where the leakage exponent $\alpha$ is equal to 0.5 for a burst and 1.5 for the background leakage. The value of $c$ for each node is estimated by distributing the total background leakage flow between nodes. This equation constitutes the basis for further investigation. 


\section{Detection of a burst presence}

The aim of this part of the research is to formulate and verify a method for identification of the burst presence using the fixed and variable orifice area (FAVOR) test proposed by May (1994) as a starting point. The investigation will progress in three stages: validation of the FAVOR test, high precision leakage simulating studies and formulation of a burst presence identification algorithm. Leakage has two components the burst leakage through larger holes and the background leakage predominantly through pipe connections and joints. These two terms respond differently to varying pressure. A power law with exponent 0.5 governs flow through fixed areas (bursts). Flows through small holes and pipe-joints are governed by a power law with exponent 1.5. There are two possible explanations for this: the elasticity of pipes and/or inherent properties of fluid flowing through very small orifices.

The hypothesis is that applying step pressure changes to a DMA input and monitoring boundary flows can be used to separate the two terms of leakage in a DMA. This active identification experiment provides measurements from which equivalent constant and varying areas of the bursts and background leakage respectively can be evaluated. Hydraulic simulations are an important part of the method.

\subsection{Validation of the proposed experimental method}

The fixed and variable orifice area (FAVOR) test is based on Fixed and Variable Area Discharge (FAVAD) concept (May 1994), which describes the leakage and pressure relationship considering bursts as a fixed area discharge whereas background loss is considered as a variable area discharge. This concept is integrated with BABE methodology (Breaks and Background Estimates (BABE) 2008). In this concept, certain relationship between pressure and leakage exist depending on the leakage paths. Losses from fixed area leakage paths vary according to the square root of the system pressure, whilst discharges from variable area paths vary according to pressure to the power of 1.5. As there will be a mixture of fixed and variable area leaks in any distribution system, loss rates vary with pressure to a power that normally lies between the limits of 0.5 and 1.5. The simplest versions of the FAVAD concept, suitable for most practical 
predictions, are Leakage flow $Q(1 / \mathrm{s})$ which varies with Pressure according to an exponent $N 1\left(P^{N 1}\right)$ or

$$
\frac{Q_{1}}{Q_{0}}=\left(\frac{P_{1}}{P_{0}}\right)^{N 1}
$$

So, if pressure is reduced from $P_{0}$ to $P_{1}$, flow rates through existing leaks change from $Q_{0}$ to $Q_{1}$, and the extent of the change depends on the exponent N1. The higher the N1 value, the more sensitive existing leakage flow rates will be to changes in pressures. The FAVAD concepts have for the first time allowed accurate forecasting of the increase or decrease of Real Losses due to a change in pressure. The N1 values might be in the order of 0.5 to 1.5 , depending upon the type(s) of leak present (Thornton, Lambert 2005).

With the help of collaborating water companies seven single-input Demand Management Areas (DMAs) were selected by Water Software System research group (DMU). Multiple-input areas were tested as well. A typical FAVOR test was carried out by DMU during the night between 1 a.m. and 5 a.m. During the period of recordings, the inlet pressure was changed stepwise over a typical range of values at 20-minute or 30-minute intervals. The recorded variables with 10 -seconds or 20-seconds intervals were the inlet pressure and flow (Fig.4.1 for Down Ampney and Appendix A for other six DMA).

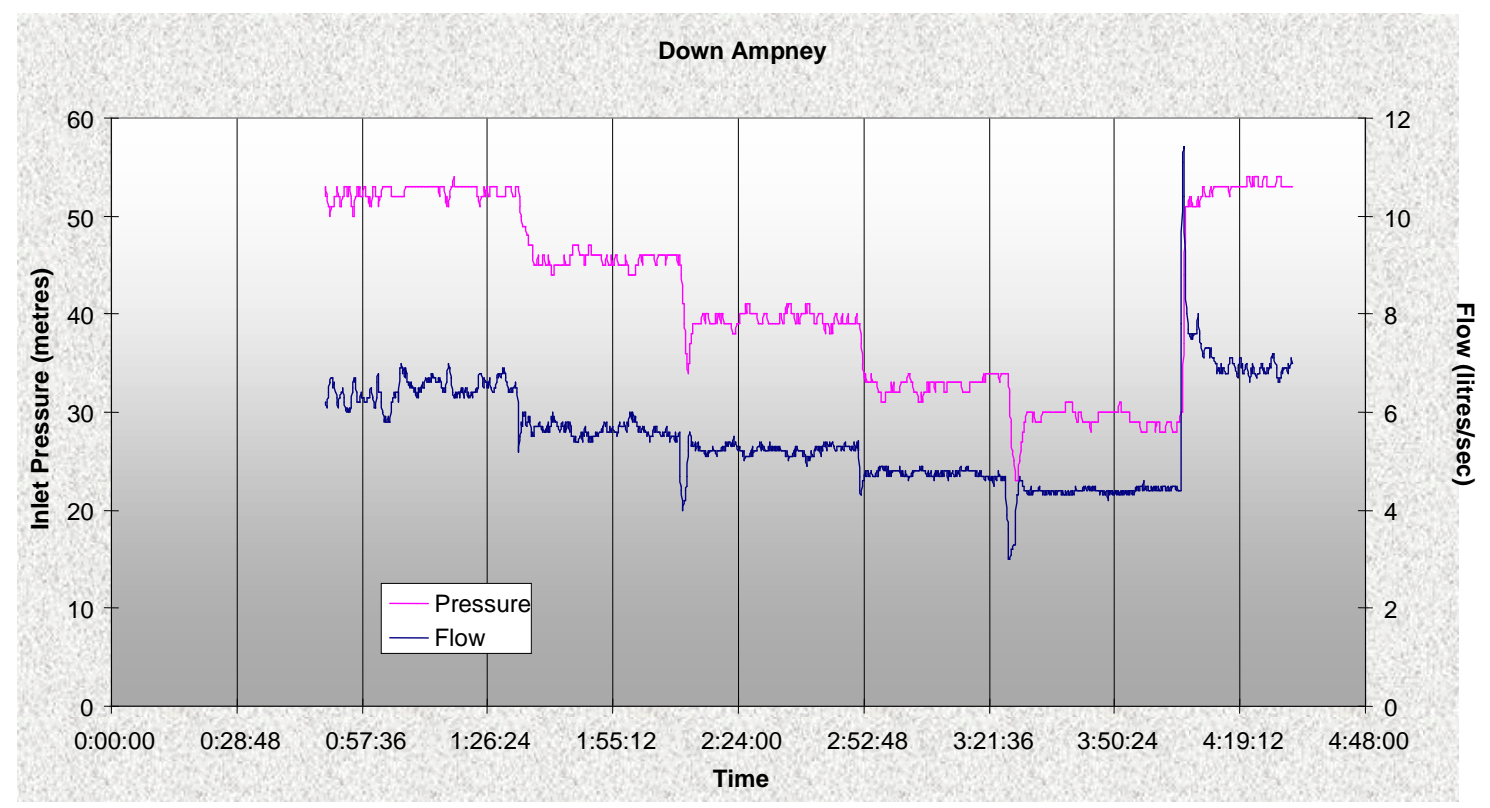

Fig. 4.1 FAVOR Test Data of Down Ampney 
It can be observed from the data (Fig.4.1) that when the inlet pressure is changed stepwise, the flow changes in a similar manner. The data from the transient phase between steady states should be neglected to decrease errors.

A three term inlet flow model (IFM) is fitted to this data.

$q=d+c_{1} p_{1}^{0.5}+c_{2} p_{2}^{1.5}$

It is assumed that the demand variation within half an hour is insignificant. $d$ is the average total demand that can be assumed to be irrespective of pressure. The total demand at night consists of the sum of small customers demands. Some customers demands (such as washing hands, cleaning plates and dishes and so on) are independent of pressure, as they have (controllers of water rates) possibility to control water head, while the other customers demands of automated devices (such as washing mechines, toilet cisterns, etc.) depend on pressure, because the time period of direct water demand depends on water head and on tank volume. But the ratio of time period of direct water demand by separate devices to the whole period of observation (about 4 hours) is insignificant. Variation of a specific demand, resulting from a pressure change at the given point of time can be considered only as a deviation from average demand at the same point of time. The average total demand is the sum of consumers demands at each specific point of time averaged for the whole night period of observation and can be assumed to be independent of pressure.

From a data set it is possible to find the coefficients $d, c_{1}$ and $c_{2}$. For the purpose of this investigation pressures $p_{1}$ and $p_{2}$ were assumed to be related to the average zonal night pressure (AZNP) (Maksimovic et al 2003). The average zonal night pressure taking account of the zonal demand distribution, $p_{A Z N P}$, as herein defined as

$p_{\text {AZNP }}=\frac{\sum_{i \in \text { Nodes }} p_{i} \cdot \text { Demand_Allocation_Factor }_{i}}{\sum_{i \in \text { Nodes }} \text { Demand_Allocation_Factor }_{i}}$

where $p_{i}$ is pressure at each node of network with demand and Demand_Allocation_Factor ${ }_{i}$ is proportion of total demand $d$ applied to node $i$.

Coefficients have been determined by a least squares method. The method of least squares is often applied in statistical contexts. Least squares can be interpreted as a method of fitting data. The best fit in the least-squares sense is that instance of the 
model for which the sum of squared residuals has its least value, a residual being the difference between an observed value and the value given by the model.

$\sum_{1}^{n}\left[q-\left(d+c_{1} p^{0.5}+c_{2} p^{1.5}\right)\right]^{2} \rightarrow \min$

where $q$ - measured inlet flow

$p$ - measured inlet pressure including AZNP correction

$n$ - the number of measurements

and coefficients $d \geq 0, c_{1} \geq 0, c_{2} \geq 0$, because the water cannot enter a network through leakages and cracks.

The suitability of a linear relationship between leakage and pressure has also been investigated. Coefficients and the root-mean square error for seven DMAs for the linear model and the three-term model are shown in Table 4.1 below.

Table 4.1 Coefficients and RMS error for seven DMAs

\begin{tabular}{|l|c|c|c|c|c|c|c|c|}
\hline \multirow{2}{*}{ DMA } & $\begin{array}{c}\text { Num of } \\
\text { measu- } \\
\text { rements }\end{array}$ & \multicolumn{3}{|c|}{$\begin{array}{c}\text { Inlet flow linear model } \\
q=d+c p\end{array}$} & \multicolumn{3}{c|}{$\begin{array}{c}\text { Inlet flow three term model } \\
q=d+c_{1} p^{0.5}+c_{2} p^{1.5}\end{array}$} \\
\hline & $\mathrm{n}$ & $d$ & $c$ & $\begin{array}{c}\text { The root- } \\
\text { mean } \\
\text { square } \\
\text { error }\end{array}$ & $c_{2}$ & $c_{1}$ & \multicolumn{3}{c|}{$\begin{array}{c}\text { The root- } \\
\text { mean } \\
\text { square } \\
\text { error }\end{array}$} \\
\hline Ashbury & 1255 & 3.517943 & 0.081812 & 1.374553 & 0.0053 & 0 & 5.8816 & 1.034893 \\
\hline Buscot & 1288 & 0.80247 & 0.003861 & 3.042027 & 0.0058 & 0 & 0.2311 & 1.66811 \\
\hline Down Ampney & 1332 & 6.106428 & 0.32282 & 1.506813 & 0.0348 & 0 & 10.3239 & 1.171579 \\
\hline Cirencester & 1613 & 5.942036 & 0.397712 & 5.331473 & 0.0387 & 0 & 11.8231 & 2.777965 \\
\hline Farringdon & 1593 & 1.594479 & 0.3 & 9.292015 & 0.0519 & 0 & 0 & 2.667019 \\
\hline Priorsfield & 1536 & 6.934208 & 0.305279 & 5.854758 & 0.0244 & 0.9412 & 6.8909 & 2.174472 \\
\hline Shellingford & 1458 & 4.747 & 0.229928 & 2.641694 & 0.0119 & 1.6835 & 0 & 1.777046 \\
\hline
\end{tabular}

The root-mean square error in the three-term model, observed in the table, is smaller than the error from the linear model, therefore the three-term model can be used in the subsequent considerations. For the time being it is impossible to comment on the values of the coefficients in the table without further research. 


\subsection{Simulating leakage including background leakage and bursts}

The general purpose environment GAMS (Brooke, Kendrick, \& Meeraus 1992) was used for simulating leakages for this stage of the research. The water network model simulation program realized in GAMS was provided by Water Software System research group (DMU). A GAMS simulation model provides freedom to model different scenarios that cannot be tested in a physical network. The effects of bursts on flows and heads throughout the system can be observed and sensitive indicators of the presence of bursts can be derived by using the GAMS simulation model. The pipe equation is represented by the Darcy-Weisbach (Colebrook -White) pipe formula (Streeter and Wylie 1998).

The Frizinghall network shown Fig. 4.2 is used for the experiments. In this network there is one inlet node (node 5), by which water enters the network, and some demands at nodes 20, 30, 40, 50, 65, 75, 80, 95, 105, 110, 115, 120, 125, 140, 145, 165, 175, 180, 195, 225, 226, 230, 241, 250, 255, 265, 305, 310, 320, 335, 345, 350, 360, 365, 375, 380, 385 (Appendix B). 


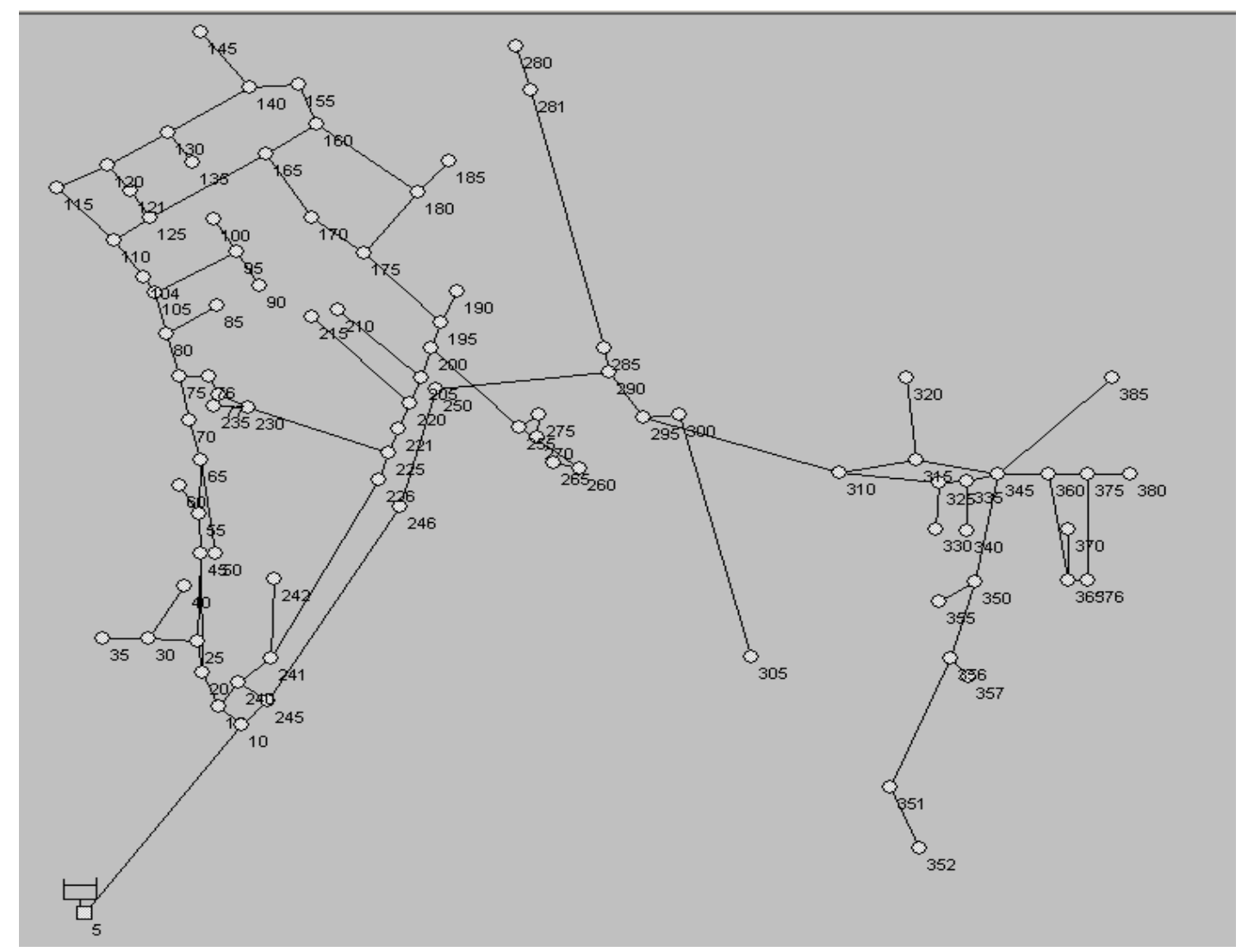

Fig. 4.2 Frizinghall network

The input parameters of the simulation program were: inlet pressure, value of total demand (in $1 / \mathrm{s}$ ), value of background leakage coefficient, and location of background leakages, and value of burst coefficient and location of burst. The values of inlet flow and flow and head at all nodes were output parameters of the simulation program.

\subsubsection{Background leakage estimation}

Initially, only background leakage was introduced to the model of the network and simulations were carried out for seven different nodal values of total background leakage coefficient to generate the 'experimental' data. In each experiment the inlet pressure was changed stepwise and the inlet flow obtained. The value of total demand was set to 1.798 litres/second. From the generated data the coefficients of the inlet flow model were estimated using a least square method and compared with the set values (input simulation values).

The inlet pressure was changed from 50 to 102 metres in steps of 4 metres. This was repeated for each value of the total background leakage coefficient. 
The nodes with background leakage were: $20,30,40,50,65,75,80,95,105,110,115$, $120,125,140,145,165,175,180,195,225,226,230,241,250,255,265,320,335$, $345,350,360,365,375,380,385$.

The inlet flow model equation (4.1) was adapted by removing the second term (the burst term) and assuming that pressure $p_{2}$ represents the DMA inlet pressure. Comparison of the set and estimated values of the total background leakage coefficients are given in Table 4.2 below.

Table 4.2 Background leakage coefficients (for inlet pressure)

Set value of background leakage coefficient for every node (for seven experiments)

\begin{tabular}{|c|c|c|c|c|c|c|}
\hline 0.000309 & 0.00144 & 0.00288 & 0.0144 & 0.0308571 & 0.0514286 & 0.085371 \\
\hline Set value of total background leakage coefficient (35 nodes * set value) \\
\hline 0.0108 & 0.0504 & 0.1008 & 0.504 & 1.08 & 1.8 & 2.988 \\
\hline
\end{tabular}

The values of the inlet flow for each experiment can be found by substituting obtained coefficients into the IFM equation. The total flow is the same for both the set up and the estimated values but demand flow and background leakage flow differ from the estimated ones. Because these differences have the same magnitude the total flow is the same. The coefficients of background leakage are not linearly correlated as illustrated in Fig. 4.3.

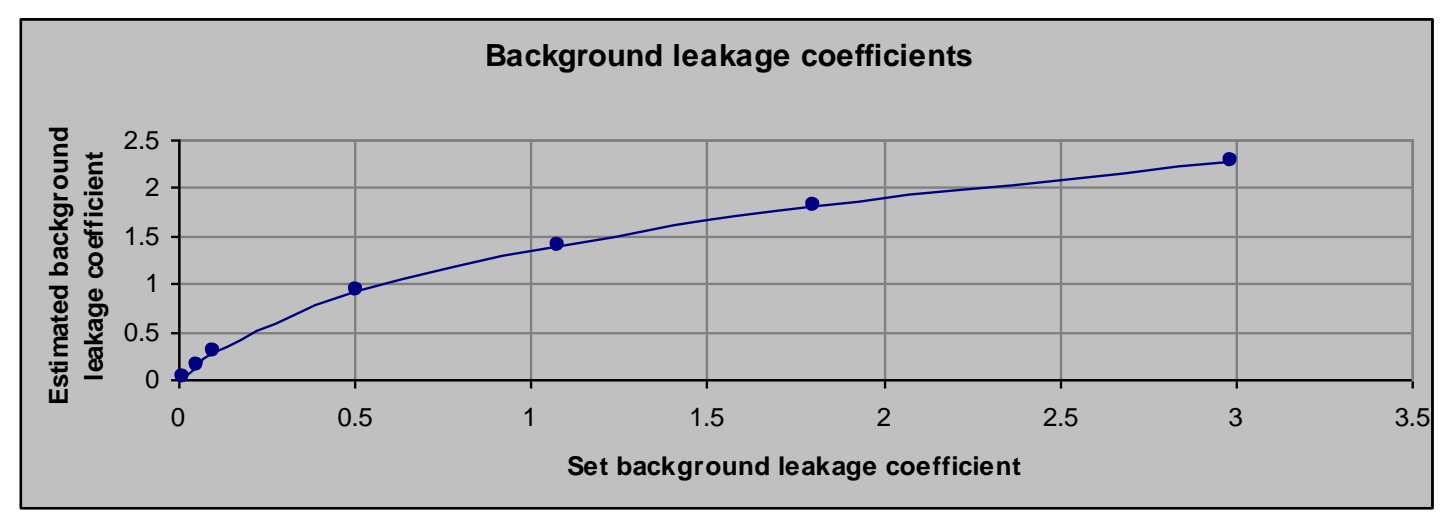

Fig. 4.3 Estimated background leakage coefficients using inlet pressure

This outcome can be explained because of an unsuitable choice of pressure variable for the inlet flow model (IFM). In this model the inlet pressure was used to represent the 
pressure at all background leakage nodes, it would be better to use the average zonal night pressure $p_{A Z N P}$ defined as

$p_{\text {AZNP }}=\frac{\sum_{i \in \text { Nodes }} p_{i} \cdot \text { Demand_Allocation_Factor }_{i}}{\sum_{i \in \text { Nodes }} \text { Demand_Allocation_Factor }_{i}}$

where $p_{i}$ is pressure at each node of network with demand and Demand_Allocation_Factor ${ }_{i}$ is proportion of total demand $d$ applied to node $i$.

Let's test this hypothesis using the simulation model developed in GAMS; Demand_Allocation_Factors and inlet pressure are input data. The inlet pressure was changed from 52 to 96 metres in steps of 4 metres. The pressures $p_{i}$ are received from the simulation program. The average zonal night pressure is calculated from equation 4.3:

\begin{tabular}{|c|c|c|c|c|c|c|c|c|c|c|c|c|}
\hline $\begin{array}{c}\text { Inlet } \\
\text { Pressure } \\
\text { (metres) }\end{array}$ & 52 & 56 & 60 & 64 & 68 & 72 & 76 & 80 & 84 & 88 & 92 & 96 \\
\hline $\begin{array}{c}\text { AZNP } \\
\text { (metres) }\end{array}$ & 101.60 & 105.59 & 109.58 & 113.58 & 117.57 & 121.56 & 125.55 & 129.55 & 133.54 & 137.53 & 141.52 & 145.52 \\
\hline
\end{tabular}

The results are depicted in Figure 4.4.

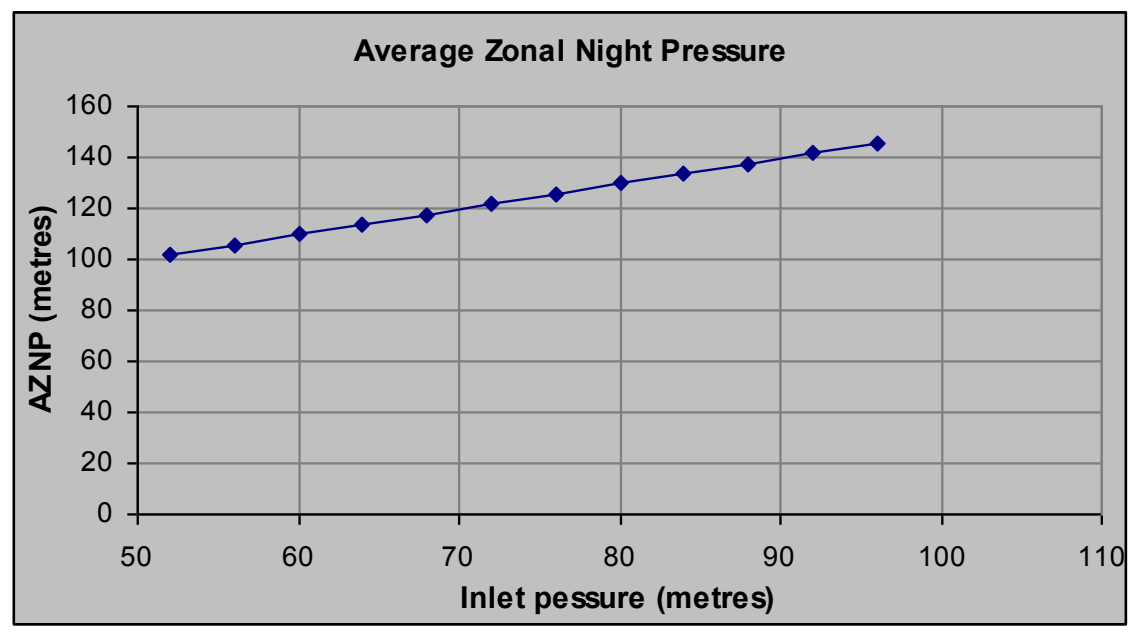

Fig. 4.4 Relationship between AZNP and inlet pressure

It can be observed from the chart that this is an affined relationship and can be described by a straight line equation:

$p_{\text {AZP }}=a+b \cdot p_{\text {input }}$ 
where $a$ and $b$ are coefficients, which can be calculated by regression analysis, and for the selected network:

$a=49.7 \quad b=0.998078 \quad$ with the RMS error $=0.00000721$

The experiment with background leakage only and step changing inlet pressure was repeated again but this time the average zonal night pressure was used in the IFM. The following results shown in Table 4.3 were obtained:

Table 4.3 Background leakage coefficients (for AZNP)

Set value of Background leakage coefficient for every node (for seven experiments)

\begin{tabular}{|}
\hline 0.0003 & 0.0014 & 0.0028 & 0.014 & 0.03 & 0.05 & 0.083 \\
\hline Set value of total background leakage coefficient (35 nodes * set value) \\
\hline 0.0108 & 0.0504 & 0.1008 & 0.504 & 1.08 & 1.8 & 2.988 \\
\hline \\
Estimated value of total background leakage coefficient (for seven experiments) \\
\hline 0.01019 & 0.04724 & 0.09317 & 0.42703 & 0.86817 & 1.39947 & 2.26402 \\
\hline
\end{tabular}

Coefficients of the background leakage are linearly correlated (Fig. 4.5)

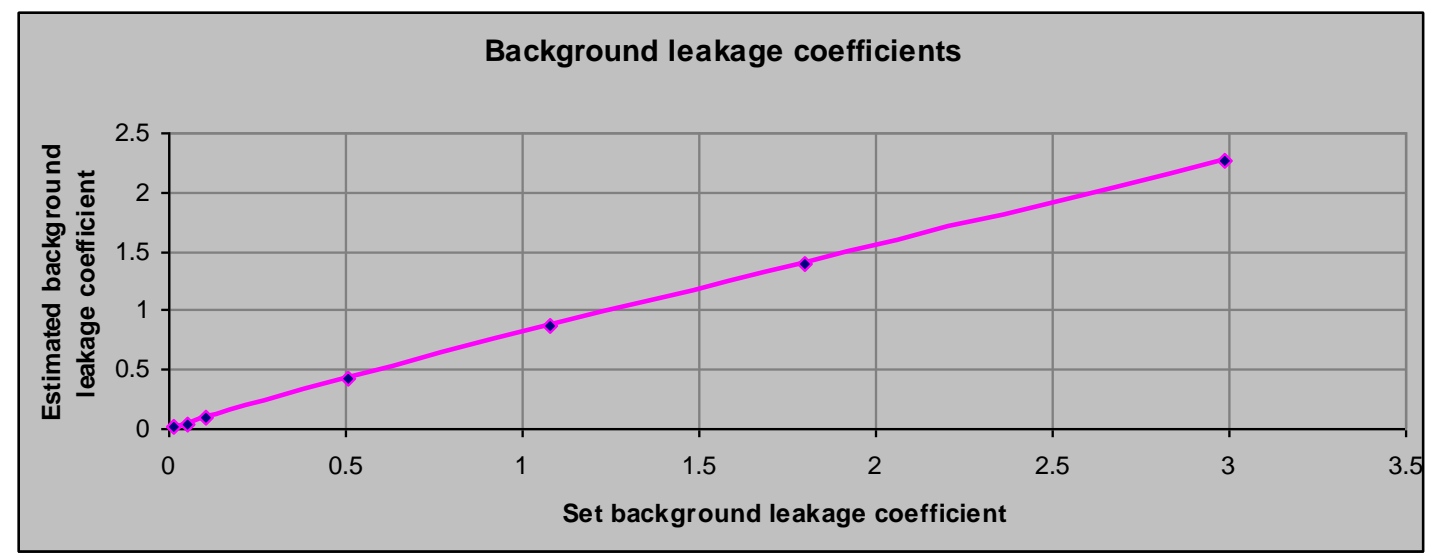

Fig. 4.5 Background leakage coefficient using AZNP.

By substituting the obtained coefficients in the equation of the IFM the flows for each experiment are determined. The total flow, flow of the background leakage and the demand coincides with the given ones (Fig. 4.6). 


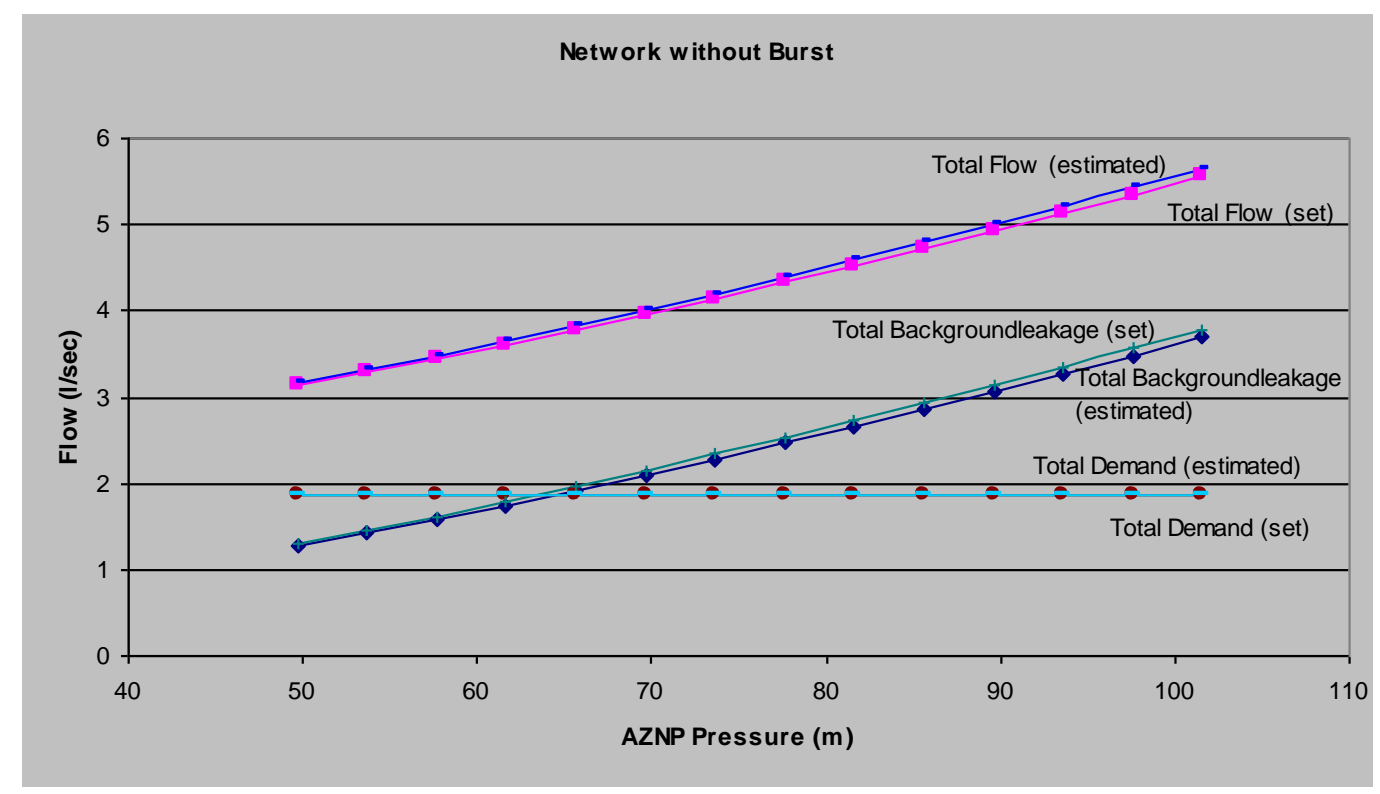

Fig. 4.6 Comparison of estimated and actual (set) flows

The outcome of the experiment proves that it is better to use the Average Zone Night Pressure for $p_{2}$ in IFM (equation 4.1) to represent background leakage.

\subsubsection{Burst estimation}

Now it is time to focus on an investigation of properties of the leakage flow caused by bursts. It is necessary to test the hypothesis that the burst is represented by the power term $c_{1} p^{0.5}$, and consider which pressure should be used, inlet pressure, AZNP as in the case of the background leakage or something else. With the help of the GAMS simulation program the network from Fig.4.2, with the known demand $(d=1.736 \mathrm{l} / \mathrm{s})$ and with a burst at node 246 but without the background leakage, was simulated.

Eight different values of the burst coefficient were selected and, for each value of burst coefficient, the inlet pressure was changed from 50 to 98 metres stepwise and the inlet flow was recorded.

The inlet flow model is reduced to two terms:

$q=d+c_{1} p_{1}^{0.5}$

where $q$ is the inlet flow, $p_{1}$ is the inlet pressure and $d$ is the demand value.

Comparison of the set and estimated by the method of least square values of the burst coefficients is presented below in Table 4.4 and in Fig.4.7. 
Table 4.4 Burst coefficients

\begin{tabular}{|l|l|l|l|l|l|l|l|}
\hline \multicolumn{6}{|l|}{ Set value of burst coefficient (for eight experiments) } \\
\hline 0 & 0.02651 & 0.13245 & 0.26447 & 0.39561 & 0.65438 & 1.26551 & 2.28602 \\
\hline Estimated value of burst coefficient using least square analysis of simulated results \\
\hline 0 & 0.01 & 0.05 & 0.1 & 0.15 & 0.25 & 0.5 & 1 \\
\hline
\end{tabular}

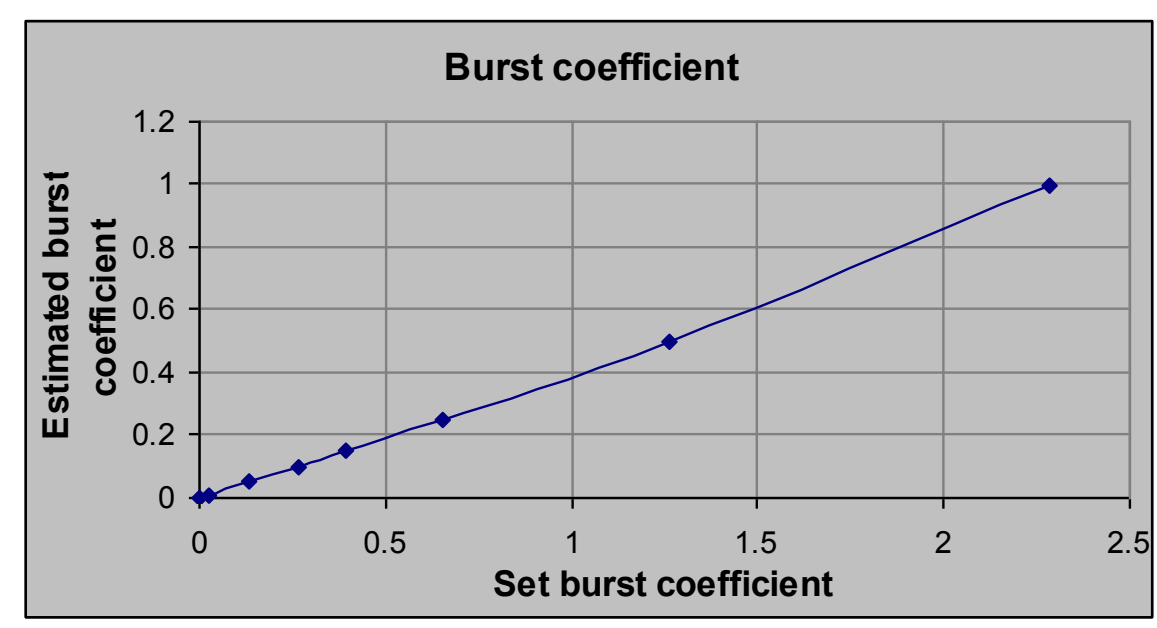

Fig. 4.7 Estimated burst coefficients using inlet pressure

One can note that at small values of the coefficient (that correspond to a burst flow of 24 litres/seconds) the relationship is linear but as the burst flow increases the burst flow is underestimated.

The comparison between simulated (set) and estimated flows is presented in Fig.4.8, it is worth noticing that although the estimated burst coefficients are not accurate the corresponding flow components are estimated accurately. 


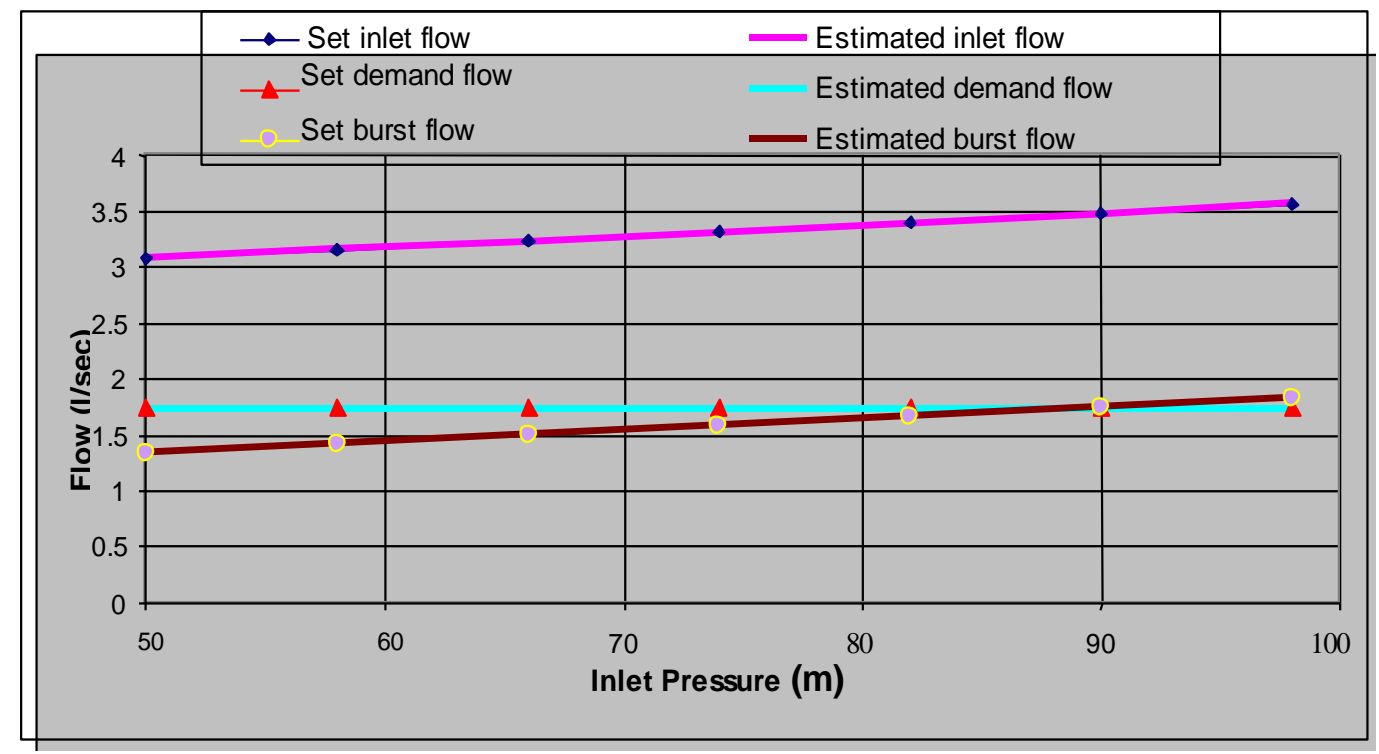

Fig. 4.8 Experiment results

Table 4.5 Simulated (set) and estimated flows

\begin{tabular}{|l|c|c|c|c|c|c|c|}
\hline Set inlet flow (l/sec) & 3.571 & 3.486 & 3.403 & 3.32 & 3.24 & 3.16 & 3.082 \\
\hline Estimated inlet flow (l/sec) & 3.57 & 3.49 & 3.40 & 3.32 & 3.24 & 3.16 & 3.08 \\
\hline Set burst flow (l/sec) & 1.836 & 1.750 & 1.666 & 1.584 & 1.504 & 1.425 & 1.346 \\
\hline Estimated burst flow (l/sec) & 1.84 & 1.75 & 1.67 & 1.58 & 1.50 & 1.42 & 1.35 \\
\hline Set demand flow (l/sec) & 1.736 & 1.736 & 1.736 & 1.736 & 1.736 & 1.736 & 1.736 \\
\hline Estimated demand flow (l/sec) & 1.74 & 1.74 & 1.74 & 1.74 & 1.74 & 1.74 & 1.74 \\
\hline
\end{tabular}

The outcomes of the repeated experiment using AZNP for calculations are not very successful either. The set of simulated and estimated coefficients of burst have a nonlinear relationship presented in Fig. 4.9. The demand flow $d$ is now bigger than the pre-set demand. This means that the burst has a constant component, which in the estimation model now contributes to the demand. 


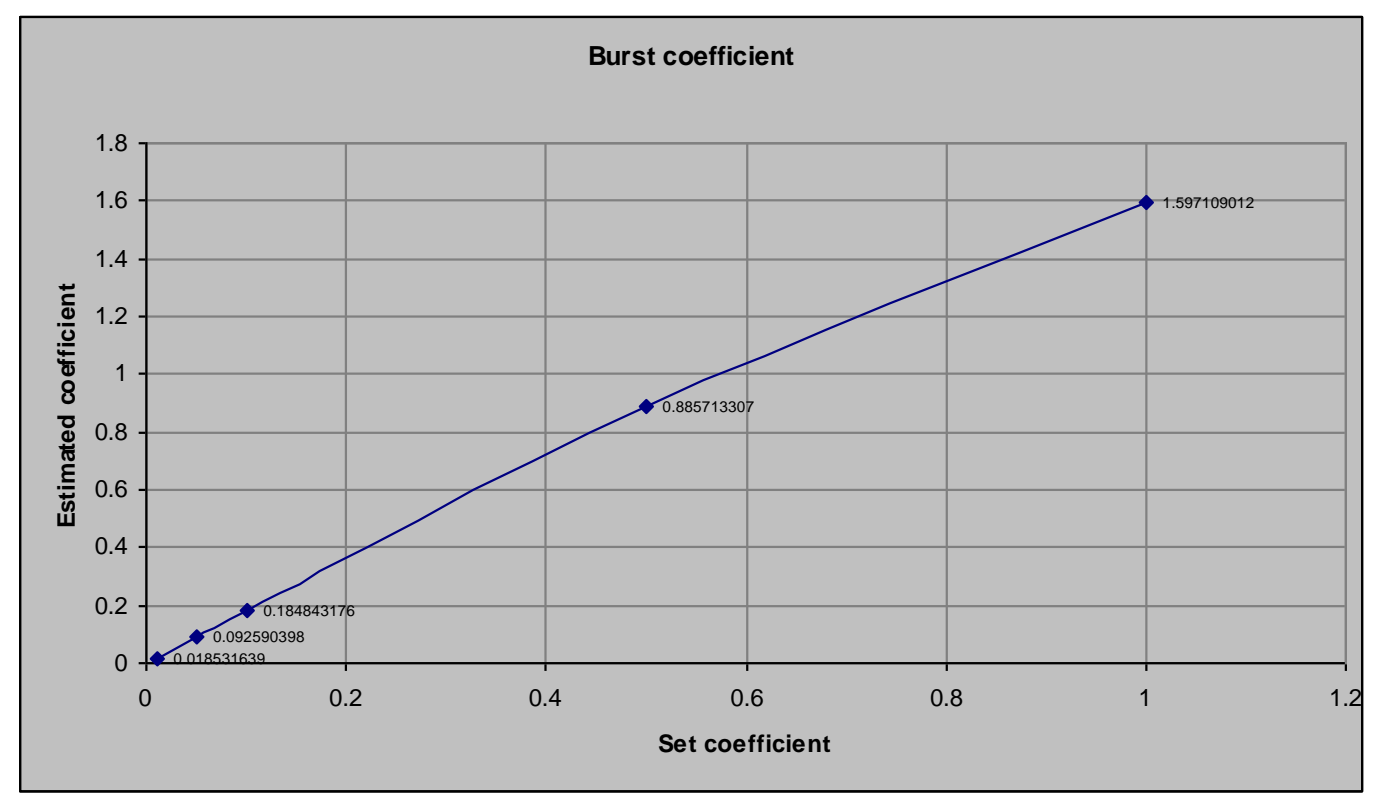

Fig. 4.9 Estimated burst coefficients using AZNP pressure

To check again the use of the inlet pressure in the IFM for the burst term, the previous experiment is repeated with the burst at node 352 . The inlet pressures, coefficient of the burst and the demand remain the same. The estimated coefficient differs significantly from the simulation (pre-set) one (Fig.4.10).

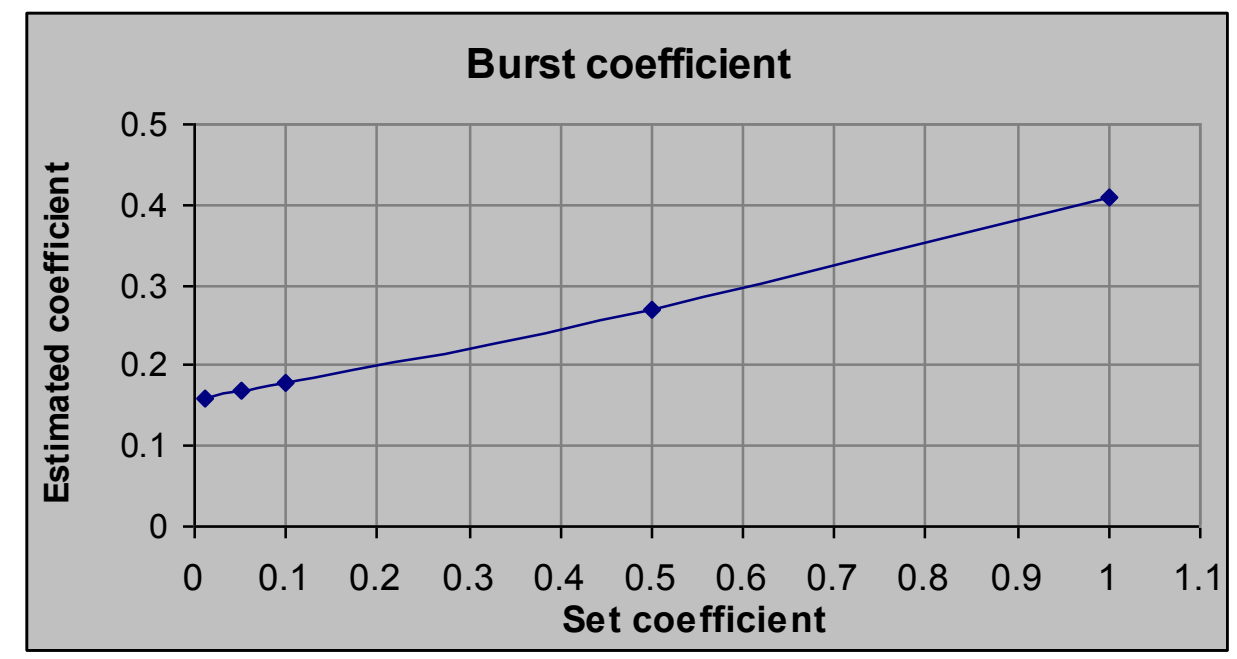

Fig. 4.10 Estimated burst coefficients using inlet pressure (burst at node 352)

Although the estimated total inlet flow is equal to the simulated one, the estimated demand is higher than that specified in the simulation program and consequently the estimated burst leakage flow is smaller than the simulated one. This implies, that the use 
of the inlet pressure in the burst term in the IFM does not necessarily lead to an accurate representation of the real burst flow.

In the first experiment the results with the inlet pressure shown in Fig. 4.8 are relatively good, because the burst node 246 is very near to the inlet node and has a comparable value to the burst node pressure.

Repeating the experiment with AZNP instead of the inlet pressure gives the similar negative outcome, but with a smaller error.

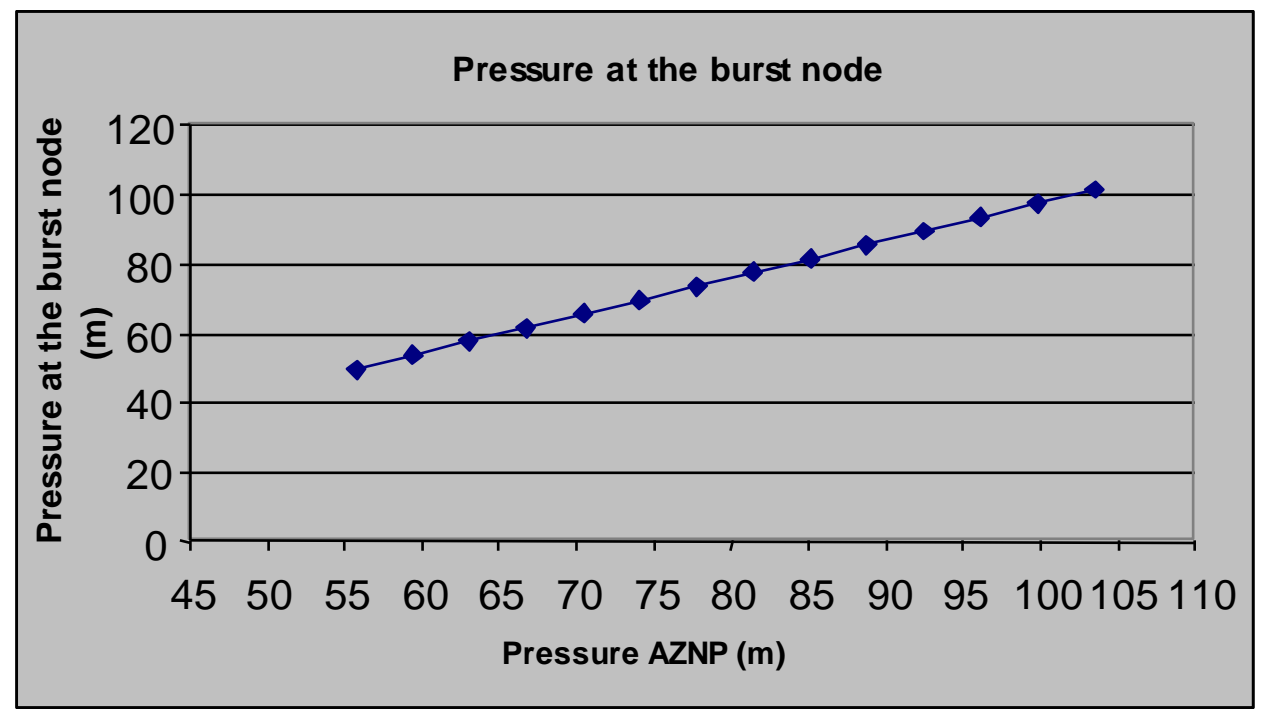

Fig. 4.11 Pressure at the node of the burst

Further investigation of pressures in a network has indicated a linear relationship between pressure at a node and AZNP (Fig. 4.11)

$p_{\text {node }}=a+b \cdot p_{\text {AZNP }} \quad$ where $a$ and $b$ are the regression coefficients.

In fact, the burst term should be represented by the pressure at the burst as it is indicated in the equation below but unfortunately the burst node and consequently the burst pressure are not known in advance

$q=d+c_{1} p_{\text {burst_node }}^{0.5}=d+c_{1} \cdot\left(a+b \cdot p_{\text {AZNP }}\right)^{0.5}$

where $a$ depends on the elevation of the burst node.

The data described by the model above can be approximated by the different model, which uses AZNP

$q=\hat{d}+\hat{c}_{1} \cdot p_{A Z N P}^{0.5}$,

this results in the overestimation of the demands $\hat{d} \geq d$ due to the contribution of the constant $a$. 
Let's apply the three-term IFM to the network where the background leakage and a burst are present:

$q=\hat{d}+\hat{c}_{1} \cdot p_{A Z N P}^{0.5}+c_{2} \cdot p_{A Z N P}^{1.5}$

The arrangements are: the inlet pressure changes from 50 to 102 metres in steps of 4 metres. There is a burst at node 352 . The burst coefficient for the simulation is set to 0.5 corresponding to the burst flow of $3-4 l / s e c$. The background leakage is present at the following nodes $20,30,40,50,65,75,80,95,105,110,115,120,125,140,145,165$, $175,180,195,225,226,230,241,250,255,265,320,335,345,350,360,365,375$, 380,385 . The aggregate coefficient of the background leakage is set up as 0.0036 , corresponding to the background leakage flow of $2-3 l / s e c$ and finally the demand is equal to $0.852 l / s e c$.

The network is simulated using the GAMS program and the inlet flow is recorded for each value of the inlet pressure. The AZNP is calculated for the given inlet pressure data. The coefficients $a$ and $b$ of the equation $p_{A Z N P}=a+b \cdot p_{\text {input }}$ were known from the previous simulation experiment in Section 4.2.1.

Coefficients $d, c_{1}, c_{2}$ are calculated by the method of least squares and are collected in Table 4.6.

Table 4.6 Estimated coefficients (for one burst)

\begin{tabular}{|c|c|c|}
\hline $\begin{array}{c}\text { Coefficients } \\
\text { of model }\end{array}$ & $\begin{array}{c}\text { Set } \\
\text { coefficients }\end{array}$ & $\begin{array}{c}\text { Estimated } \\
\text { coefficients }\end{array}$ \\
\hline$d$ & 0.852 & 1.6896 \\
\hline$c_{1}$ & 0.5 & 0.4029 \\
\hline$c_{2}$ & 0.0036 & 0.0038 \\
\hline
\end{tabular}

The calculated coefficients are substituted into the three-term model and flows for each step of the inlet pressure are obtained. The following graphs depicted in Fig. 4.12 are plotted from this experiment. 


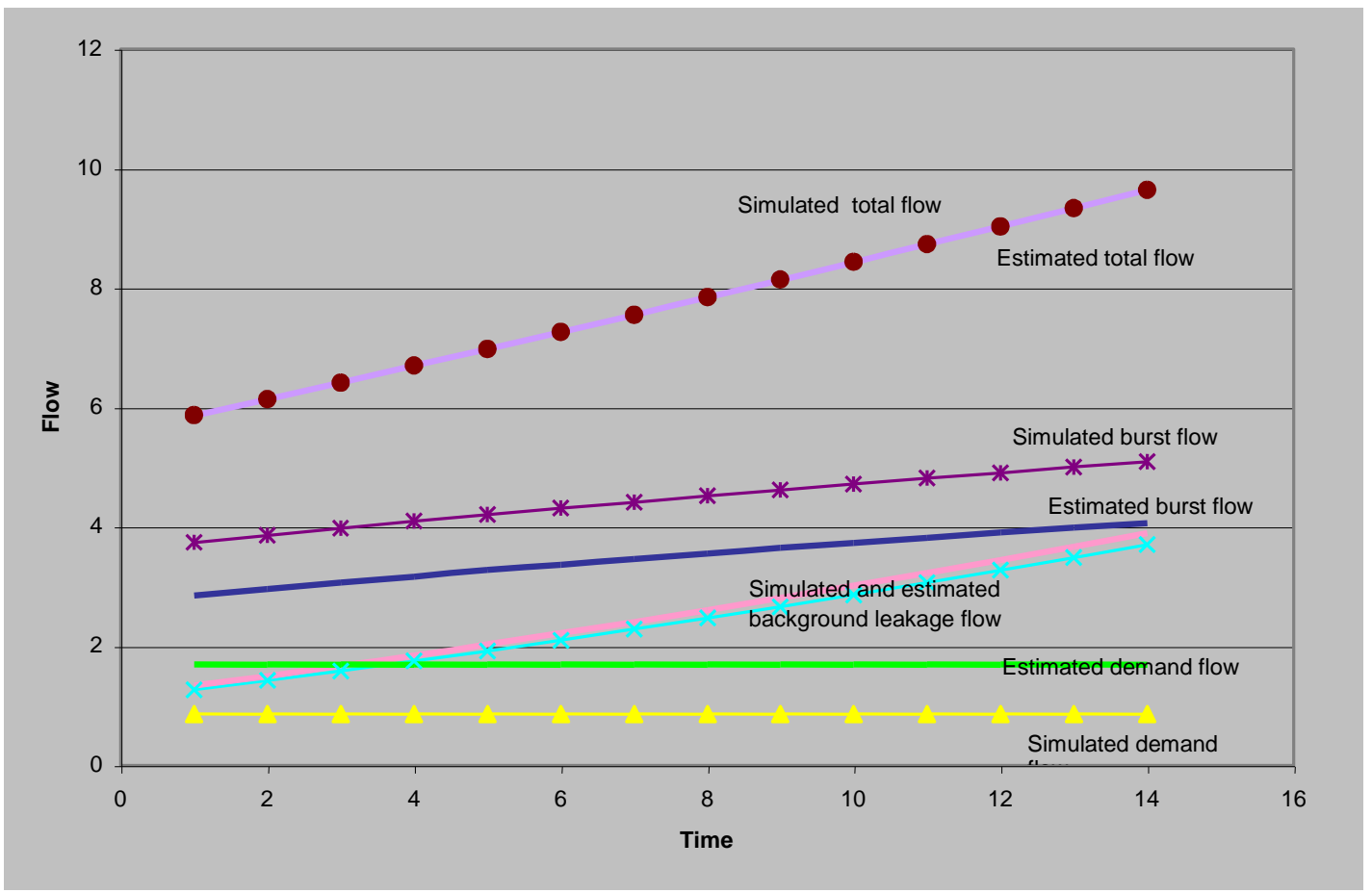

Fig. 4.12 Obtained results

It can be observed from the charts in Fig.4.12 that the extra component of the burst flow is added to the demand flow, but the background leakage flow is determined precisely.

If there is more than one burst in the network the coefficients of bursts are added together.

$q=d+c_{1, \text { burst_1 }} p_{\text {AZNP }}^{0.5}+c_{1, \text { burst_2 }} p_{\text {AZNP }}^{0.5}+c_{2} p_{\text {AZNP }}^{1.5}=d+c_{1} p_{\text {AZNP }}^{0.5}+c_{2} p_{\text {AZNP }}^{1.5}$

The formula above is applied to a network with two bursts, both with $c_{1}=0.5$. The experiment is also carried out under the same conditions as the previous experiment with one burst and the corresponding IFM coefficients are obtained using the leastsquare method:

Table 4.7 Estimated coefficients (for two bursts)

\begin{tabular}{|c|c|c|c|}
\hline $\begin{array}{c}\text { Coefficients of } \\
\text { model }\end{array}$ & Set coefficients & For two bursts & For one burst \\
\hline$d$ & 0.852 & 2.535 & 1.6896 \\
\hline$c_{1}$ & $\begin{array}{c}\text { two bursts } \\
\text { both with 0.5 }\end{array}$ & 0.8246 & 0.4029 \\
\hline$c_{2}$ & 0.0036 & 0.0039 & 0.0038 \\
\hline
\end{tabular}


It follows from the Table 4.7 that the coefficient of the bursts has increased twice and the coefficient of background leakage has remained the same. The true value of the demand is equal to 0.852 so it can be observed that the constant element from the bursts contributes again to the demand:

- for one burst

$$
\begin{gathered}
d=\text { demand }+ \text { burst_constant } \Rightarrow \text { burst_constant }=d-\text { demand }= \\
=1.6896-0.852=0.8376
\end{gathered}
$$

- for two equal bursts

$$
\begin{gathered}
d=\text { demand }+ \text { first_burst_constant }+ \text { second_burst_constant }= \\
=0.852+0.8376+0.8376=2.53
\end{gathered}
$$

More experiments have been carried out with two bursts and then three bursts and the similar pattern has been confirmed.

\subsubsection{Burst leakage presence indication.}

The real value of the burst flow is the sum of the 'constant' part of the burst flow (resulting from the difference between the pressure at the burst node and the AZNP) and variable part of the burst flow. This can be interpreted that $\hat{c}_{1}>0$ (equation 4.5 ) is a good indicator of a burst presence and the reminder of this section is dedicated to investigating this hypothesis. The following multiple squared correlation coefficient $R^{2}$ (Borovkov 1976) will be used,

$$
R^{2}=\frac{\sum_{n}(\text { Flow_estimated }- \text { Flow_estimated_average })^{2}}{\sum_{n}(\text { Flow_data }- \text { Flow_data_average })^{2}}
$$

where $R^{2}$ is a number from 0 to 1 , to assess how well the estimated values match the actual data,

$n$ - number of measurements,

Flow_estimated_average $=\frac{\sum_{n} \text { Flow_estimated }}{n}-$ the average value of estimated flow values, 
Flow_data_average $=\frac{\sum_{n} \text { Flow_data }}{n}-$ the average value of simulated (actual) flow values.

The degree of usefulness of the $\hat{c}_{1} \cdot p_{A Z N P}^{0.5}$ term in the IFM as an indicator of the burst presence can be assessed with the help of this criterion. The term is more indicative for $R^{2}$ being close to 1 .

The network without bursts is simulated by applying 14 steps of the inlet pressure and the IFM coefficients are determined by the method of the least squares. The results of simulation are presented in Table 4.8 and the estimated coefficients obtained by the least-square method are in Table 4.9.

Table 4.8 Results of simulation (network without burst)

\begin{tabular}{|c|c|c|c|c|c|c|c|c|c|c|c|c|c|c|}
\hline $\begin{array}{c}\text { Total boundary } \\
\text { flow 1/sec }\end{array}$ & 2.056 & 2.204 & 2.358 & 2.517 & 2.682 & 2.852 & 3.027 & 3.207 & 3.392 & 3.581 & 3.775 & 3.974 & 4.176 & 4.383 \\
\hline $\begin{array}{c}\text { Pressure } \\
\text { AZNP }\end{array}$ & 48.89 & 52.84 & 56.79 & 60.74 & 64.69 & 68.63 & 72.58 & 76.52 & 80.46 & 84.41 & 88.35 & 92.29 & 96.23 & 100.17 \\
\hline
\end{tabular}

Table 4.9 The estimated coefficients (network without burst)

\begin{tabular}{|c|c|c|}
\hline & $\begin{array}{c}\text { Estimated } \\
\text { coefficients }\end{array}$ & $\begin{array}{c}\text { Simulated } \\
\text { (set) } \\
\text { coefficients }\end{array}$ \\
\hline$\hat{d}$ & 0.84976314 & 0.85 \\
\hline$\hat{c}_{1}$ & 0 & 0 \\
\hline$c_{2}$ & 0.00352307 & 0.0035 \\
\hline
\end{tabular}

Coefficient $\hat{c}_{1}$ is equal to zero, the total flow is calculated from the IFM as the sum of the demand and the background leakage flow $q=\hat{d}+c_{2} p_{\text {AZNP }}^{1.5}$ and is displayed in Table 4.10 .

Table 4.10 The result of calculation (network without burst)

\begin{tabular}{|c|c|c|c|c|c|c|c|c|c|c|c|c|c|c|}
\hline $\begin{array}{c}\text { Pressure } \\
\text { AZNP }\end{array}$ & 48.89 & 52.84 & 56.79 & 60.74 & 64.69 & 68.63 & 72.58 & 76.52 & 80.46 & 84.41 & 88.35 & 92.29 & 96.23 & 100.17 \\
\hline $\begin{array}{c}\text { Estimated } \\
\text { boundary } \\
\text { flow }\end{array}$ & 2.05 & 2.20 & 2.36 & 2.52 & 2.68 & 2.85 & 3.03 & 3.21 & 3.39 & 3.58 & 3.78 & 3.97 & 4.18 & 4.38 \\
\hline
\end{tabular}


The average value of the simulated flow is

$$
\frac{\sum_{1}^{14} \text { Flow_data }}{14}=3.156
$$

$$
\frac{\sum_{1}^{14} \text { Flow_estimated }}{14}=3.1557
$$

The parameter $R^{2}$ is determined using the previously defined formula as $R^{2}=0.99$ which is a very high value.

A similar experiment is repeated with presence of a burst. In the first stage the burst term is removed from the IFM $q=\hat{d}+c_{2} p_{A Z P}^{1.5}$ and the following results are obtained. The flows are presented in Table 4.11 and the IFM coefficients in Table 4.12.

Table 4.11 The obtained results (network with burst)

\begin{tabular}{|c|c|c|c|c|c|c|c|c|c|c|c|c|c|c|}
\hline Pressure AZNP & 48.89 & 52.84 & 56.79 & 60.74 & 64.69 & 68.63 & 72.58 & 76.52 & 80.46 & 84.41 & 88.35 & 92.29 & 96.23 & 100.17 \\
\hline $\begin{array}{c}\text { Total boundary flow } \\
\text { 1/sec }\end{array}$ & 16.25 & 16.86 & 17.46 & 18.05 & 18.63 & 19.21 & 19.79 & 20.36 & 20.92 & 21.49 & 22.05 & 22.60 & 23.16 & 23.71 \\
\hline $\begin{array}{c}\text { Calculated boundary } \\
\text { flow 1/sec }\end{array}$ & 16.53 & 17.00 & 17.50 & 18.01 & 18.53 & 19.07 & 19.63 & 20.20 & 20.79 & 21.39 & 22.01 & 22.64 & 23.28 & 23.94 \\
\hline
\end{tabular}

Table 4.12 The estimated coefficients (network with burst)

\begin{tabular}{|c|c|c|}
\hline & $\begin{array}{c}\text { Estimated } \\
\text { coefficients }\end{array}$ & $\begin{array}{c}\text { Simulated (set) } \\
\text { coefficients }\end{array}$ \\
\hline$\hat{d}$ & 12.696134 & 0.85 \\
\hline$\hat{c}_{1}$ & 0 & 2 \\
\hline$c_{2}$ & 0.011216 & 0.0035 \\
\hline
\end{tabular}

Furthermore, the parameter $R^{2}$ is calculated as $R^{2}=0.8$ indicating that the accuracy of the flow approximation has significantly decreased. Then, the coefficients of the IMF are recalculated including the burst term.

$q=\hat{d}+\hat{c}_{1} \cdot p_{A Z P}^{0.5}+c_{2} \cdot p_{A Z P}^{1.5}$

The IMF coefficients and the corresponding flows are given in Table 4.13 and Table 4.14 respectively. 
Table 4.13 IFM coefficients

\begin{tabular}{|c|c|c|}
\hline & $\begin{array}{c}\text { Estimated } \\
\text { coefficients }\end{array}$ & $\begin{array}{c}\text { Simulated (set) } \\
\text { coefficients }\end{array}$ \\
\hline$\hat{d}$ & 3.9142 & 0.85 \\
\hline$\hat{c}_{1}$ & 1.5604 & 2 \\
\hline$c_{2}$ & 0.0042 & 0.0035 \\
\hline
\end{tabular}

Table 4.14 The obtained results

\begin{tabular}{|l|c|c|c|c|c|c|c|c|c|c|c|c|c|c|}
\hline Pressure AZNP & 48,89 & 52,84 & 56,79 & 60,74 & 64,69 & 68,63 & 72,58 & 76,52 & 80,46 & 84,41 & 88,35 & 92,29 & 96,23 & 100,17 \\
\hline $\begin{array}{l}\text { Simulated total } \\
\text { boundary flow 1/sec }\end{array}$ & 16,25 & 16,86 & 17,46 & 18,05 & 18,63 & 19,21 & 19,79 & 20,36 & 20,92 & 21,49 & 22,05 & 22,60 & 23,16 & 23,71 \\
\hline $\begin{array}{l}\text { Estimated boundary } \\
\text { flow 1/sec }\end{array}$ & 16,26 & 16,87 & 17,47 & 18,06 & 18,65 & 19,23 & 19,80 & 20,38 & 20,94 & 21,51 & 22,07 & 22,63 & 23,19 & 23,74 \\
\hline
\end{tabular}

The parameter $R^{2}$ is calculated as $R^{2}=0.99999$ so the accuracy of approximation is very high. The standard deviation of the estimated flow for both cases (with and without the burst term) is given below:

- a model without the burst term

$$
\delta^{2}=\frac{\sum_{n}(\text { Flow_estimated }- \text { Flow_data })^{2}}{n}=0.0196591, \delta=\sqrt{\delta^{2}}=0.14021 .
$$

- a model with the burst term

$$
\delta^{2}=\frac{\sum_{n}(\text { Flow_estimated }- \text { Flow_data })^{2}}{n}=0.000388205, \delta=\sqrt{\delta^{2}}=0.019702
$$

Similar experiments were performed with a burst of different magnitude and at different locations and the obtained results have been very similar to that presented above. From a practical point of view the hypothesis that the coefficient $\hat{c}_{1}$ can be used as an indicator of burst presence has been confirmed. 


\subsubsection{Demand estimation}

If the demand is known, then it is possible to evaluate the magnitude of the burst flow from $q_{\text {burst }}=\hat{d}-d+\hat{c}_{1} \cdot p_{A Z N P}^{0.5}$. If a DMA has no bursts and only the background leakage it is possible to evaluate the instantaneous demand flow from the formula $d=q_{\text {in }}-q_{\text {background }}=q_{\text {in }}-c_{2} p_{\text {AZNP }}^{1.5}$.

The demand can be calculated at different time instances and a deeper statistical analysis of this demand can be carried out.

Each field test has a series of pressure steps thirty minutes apart. During each step a portion of the total flow is the demand, which is pressure independent and is random due to numerous customers in the DMA using random volumes of water at random time intervals (Buchberger and $\mathrm{Wu}$ 1995). It is assumed here that the demand has a normal distribution, the assumption often used in existing literature, e.g. by Pallavicini \& Magini (2007). The normal distribution law is characterized by the exponential formula: $f(x)=\frac{1}{\delta \sqrt{2 \pi}} \cdot e^{-\frac{(x-m)^{2}}{2 \delta^{2}}}$ where $m=$ expected value (mean) and $\delta=$ standard deviation.

There are data available from a number of FAVOR tests carried out for physical DMAs without bursts. For instance, for the first section of the Cirencester area the obtained frequencies are shown in Table 4.15.

Table 4.15 Frequency of occurrence of the demand

\begin{tabular}{|l|l|l|l|l|l|l|l|l|l|l|l|l|l|}
\hline $\begin{array}{l}\text { Demand }\left(x_{I}\right) \\
{[1 / \mathrm{s}]}\end{array}$ & 6 & 7 & 8 & 9 & 10 & 11 & 12 & 13 & 14 & 15 & 16 & 17 & 18 \\
\hline $\begin{array}{l}\text { Frequency of } \\
\text { occurrence of } \\
\text { the demand }\left(n_{I}\right)\end{array}$ & 0 & 11 & 0 & 0 & 0 & 202 & 0 & 0 & 99 & 86 & 0 & 0 & 12 \\
\hline
\end{tabular}

The experimental probability $p\left(x_{i}\right)$ for each value of the demand is determined from the formula $p\left(x_{i}\right)=\frac{n_{i}}{\sum_{i} n_{i}}$ and recorded in Table 4.16. 
Table 4.16 The probability of occurrence of a demand

\begin{tabular}{|l|c|c|c|c|c|c|c|c|c|c|c|c|c|}
\hline $\begin{array}{l}\text { Demand }\left(x_{i}\right) \\
{[1 / \mathrm{s}]}\end{array}$ & 6 & 7 & 8 & 9 & 10 & 11 & 12 & 13 & 14 & 15 & 16 & 17 & 18 \\
\hline $\begin{array}{l}\text { Probability } \\
p\left(x_{i}\right)\end{array}$ & 0 & 0.027 & 0 & 0 & 0 & 0.49 & 0 & 0 & 0.24 & 0.21 & 0 & 0 & 0.03 \\
\hline
\end{tabular}

The estimates for the mean and the standard deviation are $m=\sum_{i} x_{i} \cdot p\left(x_{i}\right)=12.66$ and $\delta^{2}=\sum_{i} p\left(x_{i}\right) \cdot\left(x_{i}-m\right)^{2}=4.634, \delta=\sqrt{\delta^{2}}=2.15$ respectively.

The theoretical probability density $f(x)$ can now be calculated for each demand level from the estimated model $f(x)=\frac{1}{\delta \sqrt{2 \pi}} \cdot e^{-\frac{(x-m)^{2}}{2 \delta^{2}}}$ as illustrated in Table 4.17.

Table 4.17 The probability density

\begin{tabular}{|l|c|c|c|c|c|c|c|c|c|c|c|c|c|}
\hline $\begin{array}{l}\text { Demand } \\
\left(x_{i}\right) \\
{[1 / \mathrm{s}]}\end{array}$ & 6 & 7 & 8 & 9 & 10 & 11 & 12 & 13 & 14 & 15 & 16 & 17 & 18 \\
\hline $\begin{array}{l}\text { Probability } \\
\text { density } \\
\mathrm{f}\left(\mathrm{x}_{\mathrm{i}}\right)\end{array}$ & 0.002 & 0.006 & 0.018 & 0.044 & 0.086 & 0.138 & 0.177 & 0.183 & 0.153 & 0.103 & 0.056 & 0.024 & 0.009 \\
\hline
\end{tabular}

This estimated distribution for the demands is shown in Fig. 4.13 below and compared with the recorded data.

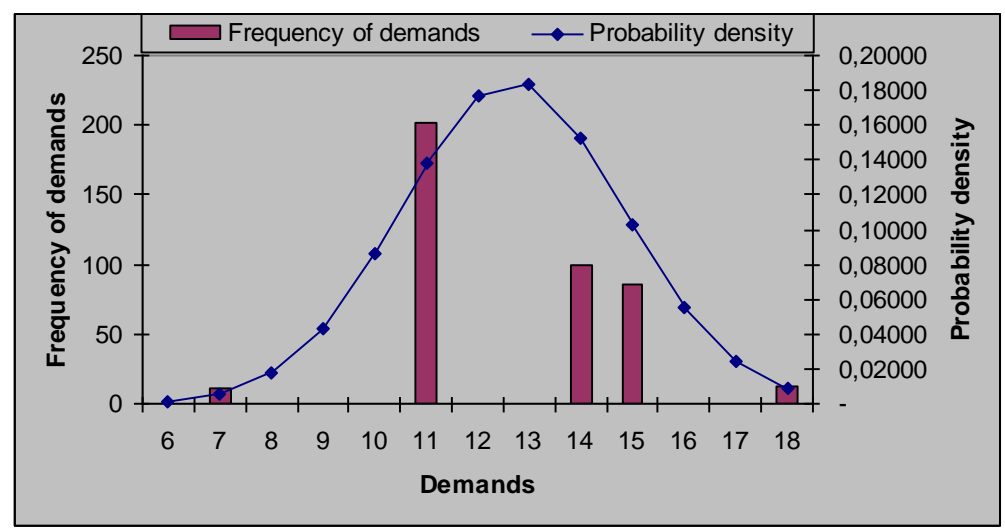

Fig. 4.13 The normal distribution for the demands

From the model distribution, the probability of the demands falling within a particular range can be calculated, examples are given in Table 4.18. 
Table 4.18 The demand distribution

\begin{tabular}{|c|cc|}
\hline Probability (\%) & \multicolumn{2}{|c|}{ Section of demand value } \\
\hline $99.7 \%$ & 6.2 & 19.12 \\
\hline $95 \%$ & 8.3557 & 16.966 \\
\hline $68 \%$ & 10.5 & 14.8 \\
\hline
\end{tabular}

Similar calculations have been performed for other water distribution zones. The density distribution for the second section of the Cirencester area is depicted in Fig.4.14.

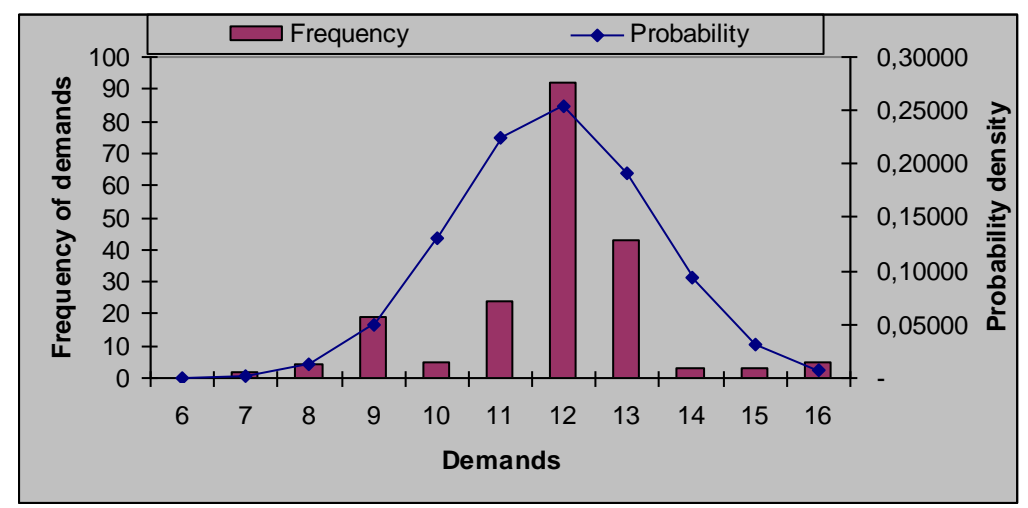

Fig. 4.14 Second section of Cirencester area

The frequency distribution for the Buscot area and the Down Ampney area are presented in Fig.4.15 and Fig.4.16 respectively.

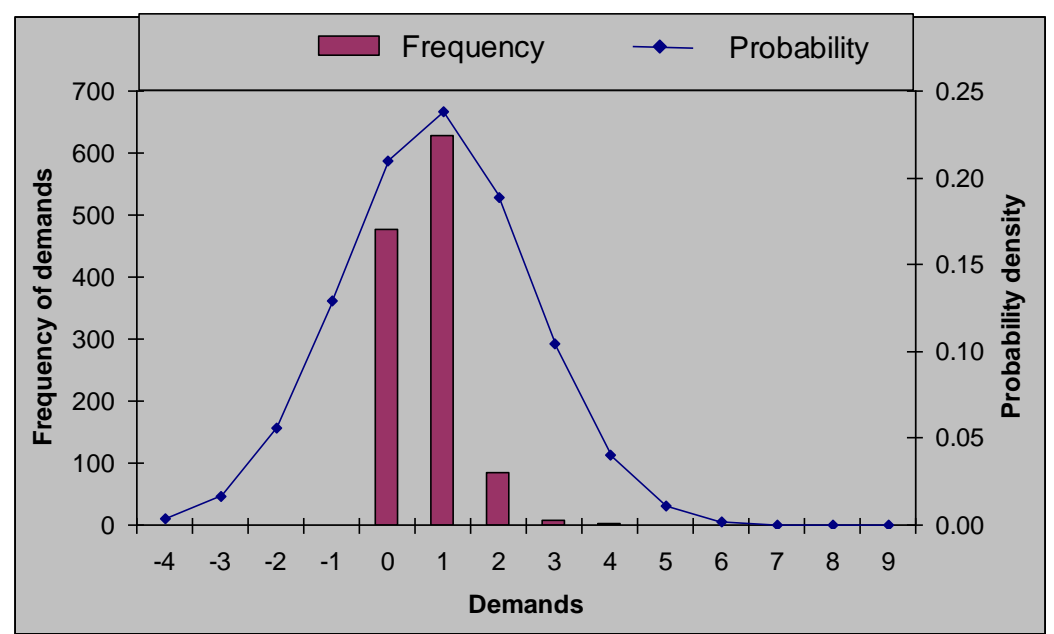

Fig. 4.15 Buscot area 


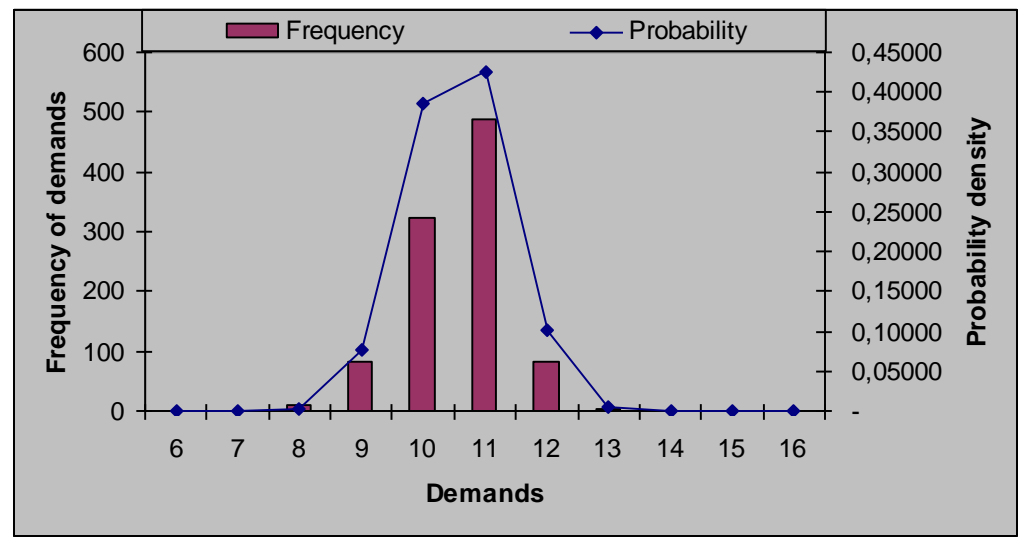

Fig. 4.16 Down Ampney area

The mean value of the demand in each case is equal to the demand value in the IFM.

\subsection{Summary}

The following conclusions can be made resulting from the carried out research: Applying step pressure changes to a DMA input and monitoring boundary flows can be used to separate the three terms in the inlet flow: demand, the burst flow and the background leakage flow.

- Background leakage in a network can be accurately represented by a pressure dependent term where the Average Zone Night Pressure (AZNP) is raised to the power of 1.5 .

- Burst flow is represented by a pressure dependent power term in which it is necessary to use the pressure at the burst node for accurate representation. The use of AZNP in this term creates an additional constant term which incorrectly increases the total demand term. It is impossible on the basis of input data only (inlet flow, inlet pressure and AZNP pressure) to find out precisely the burst size, but it is possible to discover its presence.

- The demand flow has random character with a normal distribution. The probability of a demand falling within a particular range and the demand distribution curves have been estimated from the experimental data. However, for the reasons mentioned in the previous point it is impossible to estimate the demand accurately using only input data (inlet flow and inlet pressure). 
But applying step pressure changes to a DMA input and monitoring boundary flows (FAVOR test) only for the detection of the presence of leaks does not make sense. Many Water Companies successfully use the BABE test (WRc- UK Water Industry, 1994) for this purpose. That is why in order to solve the posed problem of identification of a burst size and its location it is necessary to continue the research. 


\section{Identification of a burst location}

The main aim of this chapter is to formulate an identification procedure to estimate the burst coefficient (an equivalent burst area) and the burst location more precisely than is currently possible by other methods. This is a complementary approach to the traditional methods of acoustic monitoring and closing sections of the network and can assist water companies in their leakage management activities.

Two case studies are described in this chapter. The first one is based on numerical experiments where the data are generated from a simulation model of a DMA. This demonstrates the applicability of the method and its susceptibility to noise. In the course of carrying out numerical experiments it has been assumed that the burst exponent was 0.5. A number of field studies have shown that the exponent can be considerably larger than 0.5 , and typically varies between 0.5 and 2.5 (Farley \& Trow 2003, Van Zyl \& Clayton 2005, Ulanicki, Prescott and May 2006). The proposed approach can be adapted to other burst exponent values and this topic is discussed in Chapter 5.4.

The second case study is based on data, obtained by S. Prescott (WSS) out of field experiments performed on a physical DMA.

It is worth recalling that the whole approach is based on an active identification experiment and allows detection of existing bursts, which is a significant advantage compared to other methods.

\subsection{Determination of a burst size}

The proposed experimental method is based on the FAVOR test, originally developed by May (1994). This involves adjusting the pressure at the inlet to a DMA and monitoring the corresponding changes in inlet flow. The recorded pressure/flow relationship can be used to separate the inlet flow into three components:

- Demand - assumed to be constant over the recording period (between $1 \mathrm{am}-$ $5 \mathrm{am})$.

- Fixed area leakage - the leakage flow which is governed by the power law with the exponent of 0.5. This model is applicable for a reasonably large burst.

- Variable area leakage - the leakage flow is governed by the power law with the exponent of 1.5 due to changes in the effective leakage area caused by the 
pressure changes. This applies to minor drips, dribbles and seepages through joints and connections often referred to as 'background leakage'.

$$
q=d+q_{\text {burst }}+q_{\text {background }}=d+c_{1} p_{i}^{0.5}+\sum_{j} c_{2 j} p_{j}^{1.5}
$$

where

$\begin{array}{ll}q & \text { inlet flow } \\ d & \text { demand flow } \\ q_{\text {burst }} & \text { burst flow at node } i \\ q_{\text {background }} & \text { background leakages flow } \\ c_{1} & \text { the burst coefficient } \\ p_{i} & \text { pressure at the burst node } \\ c_{2 j} & \text { background leakage coefficients } \\ p_{j} & \text { pressures at background leakages nodes }\end{array}$

It is assumed that the demand flow does not depend on pressure variations in a DMA and the average value of demand is constant over the considered period between 1 am $5 \mathrm{am}$. The total background leakage flow represents the sum of all separate background leaks in a network and it is possible to use a single (common) coefficient of the background leakage $c_{2}$ and the Average Zone Night Pressure $p_{A Z N P}$ to evaluate this flow as has been investigated in Chapter 4. However, as is known from Chapter 4 replacement of the pressure at the burst node by the inlet pressure or by the Average Zone Night Pressure leads to an underestimation of the burst size. This is why for accurate burst coefficient (burst flow) identification more measurements are required, for instance, pressure measurements at a number of internal nodes of the DMA. Extended FAVOR (e-FAVOR) test is where additionally pressure (head) at a number of selected internal nodes of a DMA is measured.

\subsubsection{Sensitive nodes}

It is impossible to monitor all nodes in a DMA due to economic and practical limitations, namely the number of loggers required and the availability of access points (hydrants) for measurements. It is therefore essential to use a comparatively low number 
of loggers and place them at representative nodes so called 'sensitive nodes' which would allow for identifying the burst flow and the burst location.

The experiment described in Chapter 4.2.2 was revised as follows. The burst was at node 246 and the inlet pressure was used in the IFM to represent this burst with good results but only because the burst node was very close to the inlet.

Looking at the topology of this model, it was easy to observe that a change of pressure at one network node causes similar changes at the neighbourhood nodes. After further investigation of pressure distribution in the network with bursts present, it has been observed that some nodes which are on the path between the source and the burst react more to the bursts than other nodes, and such nodes can be called "sensitive nodes". In the course of further experiments it has been found that if the pressure of the node, which is near to burst, was used for the calculation of the burst flow, instead of the pressure at the burst node, the error does not exceed $0.5 \%$.

The procedure of finding sensitive nodes has been formalised and is presented below. Once the sensitive nodes have been identified from the model, pressure loggers can be placed at these nodes during the field experiment subject to hydrant availability.

One of the methods of determining sensitive nodes is splitting a network into homogenous areas and choosing a number of nodes inside each area. An area should contain nodes which are strongly hydraulically linked and have a similar reaction to a burst inside the area. The sensitive nodes can be selected by evaluating the root-meansquare deviation of the pressure $p_{\mathrm{i}}$ at each node reaction due to the bursts located at different points of the area, i.e. the most sensitive pressure node is selected for each burst node.

$$
\sqrt{\frac{\sum_{1}^{n}\left(p_{i}-\frac{\sum_{1}^{n} p_{i}}{n}\right)^{2}}{(n-1)}} \rightarrow \max
$$

where

$n \quad$ number of burst locations

$p_{i} \quad$ pressure at node $i$

This method has some shortcomings. The choice of areas directly depends on the topology of a network and for each network the number of areas can be quite different. 
The maximum of root-mean-square deviations, as the experiment has shown, are at the extremities of a network, and this may result in a not quite precise identification of bursts, which are in the centre of the network.

The other method of determining sensitive nodes has been developed by Prescott and Ulanicki (2006). They were guided by the idea that the placement of loggers is of paramount importance to ensure that as much information as possible about the network and its operation is collected during data collection. The technique is related to that proposed by Bush and Uber (1998) and uses the sensitivity matrix of the hydraulic model (Jacobian matrix) to determine how the pressure at potential measurement nodes is affected by a burst at any node across the network. This matrix has dimension $m \times n$, where $m$ is the number of potential pressure measurement points and $n$ is the number of nodes in the network (possible burst location).

The sensitivity matrix can be calculated directly from the network equations (Chapter 3.1) and it is obtained directly from the simulator.

The algorithm of detection of sensitive nodes works as follows:

1. A network model is simulated and a sensitivity matrix constructed. The matrix has size $m \times n$ where $m$ (e.g. 100) is the number of all potential measurement points (location of hydrants) and $n$ (e.g. 530) is the number of nodes. The elements of this matrix are derivatives of the measured head at node $m$ with respect to the area of a burst at node $n$.

The sensitivity matrix is given by

$$
S=\left(\begin{array}{cccc}
\frac{d h_{1}}{d c_{1}} & \frac{d h_{2}}{d c_{1}} & \ldots & \frac{d h_{m}}{d c_{1}} \\
\frac{d h_{1}}{d c_{2}} & \frac{d h_{2}}{d c_{2}} & \ldots & \frac{d h_{m}}{d c_{2}} \\
\ldots & \ldots & \ldots & \ldots \\
\frac{d h_{1}}{d c_{n}} & \frac{d h_{2}}{d c_{n}} & \ldots & \frac{d h_{m}}{d c_{n}}
\end{array}\right)
$$

2. The desired number of measurement nodes is selected, which may depend for instance, on the number of available loggers (e.g. 20).

3. The location with the highest total sensitivity over all the network nodes is selected as a measurement point. 
4. All nodes that are both within a given proximity, and within a given head difference, of the selected point are eliminated as possible measurement points. These rejected nodes are collated with the chosen measurement point to from a node group.

5. From the remaining available locations, the one with the highest total sensitivity over all the network nodes is selected as the next measurement point.

6. Steps 3, $4 \& 5$ are repeated until all measurement points are either used or discarded.

7. The network coverage is determined by setting the proximity and head difference limits at step 3. If the number of chosen nodes is different from the desired number, then these limits are adjusted accordingly and the process is repeated from step 2 .

This procedure provides a list of measurement points, which ensure that all parts of the network have a measurement nearby. The algorithm has been implemented in MATLAB by Prescott and Ulanicki (2006) and subsequently has been used in the present research.

\subsubsection{Determination of the IFM coefficients.}

To corroborate the hypothesis, that from the additional measurements of pressure values at sensitive nodes of a network, it is possible to calculate with sufficient accuracy burst size, a number of numerical experiments have been carried out. To generate data, namely the values of the inlet flow and the pressure at sensitive nodes, a WDS simulation program specially developed by Prescott in the MATLAB package has been used (Prescott and Ulanicki 2006). This program has been implemented to provide more flexibility in performing numerical experiments, it is simple to use, includes pressure dependent leakage, has facilities for setting up different simulation scenarios and can be easily modified depending on the requirements of the experiments. There are other WDS simulation packages that could be used, such as, FINESSE (WSS 1999), EPANET (Rossman 2000) or the one which was implemented in GAMS (Brooke, Kendrick, \& Meeraus 1992). All of them have some drawbacks, GAMS input and output data format is inconvenient for their further processing within the framework of 
the present experiment. The other packages have the same disadvantage using their own data formats and additionally they don't model pressure dependent leakage: For carrying out the planned research experiments it is important to manipulate data easily as well as having the possibility of modifying the simulation algorithm at different stages of the experiments. In order to validate the simulation algorithm the program results have been compared with the results obtained from the previously used programs, the one implemented in GAMS and the FINESSE package.

A model of the Frizinghall network has been selected for validating the simulation program, the model which has already been available in the GAMS and in the FINESSE format. In order to validate the simulation results the same values of inlet pressure, demands and parameters of burst have been used by the three simulation programs. The testing has been carried out by changing parameters of the burst including size and location. Values of the pressure at nodes and values of the calculated inlet flow have been compared and they agree with good accuracy therefore the code has been accepted for further research.

Two DMAs with different characteristics, Ocker Hill and Shenstone, shown in Fig.5.1 and Fig.5.2 respectively have been chosen to investigate the benefits of more measurements being available. Node and element data for Ocker Hill are shown at Appendix C and for Shenstone are shown at Appendix D.

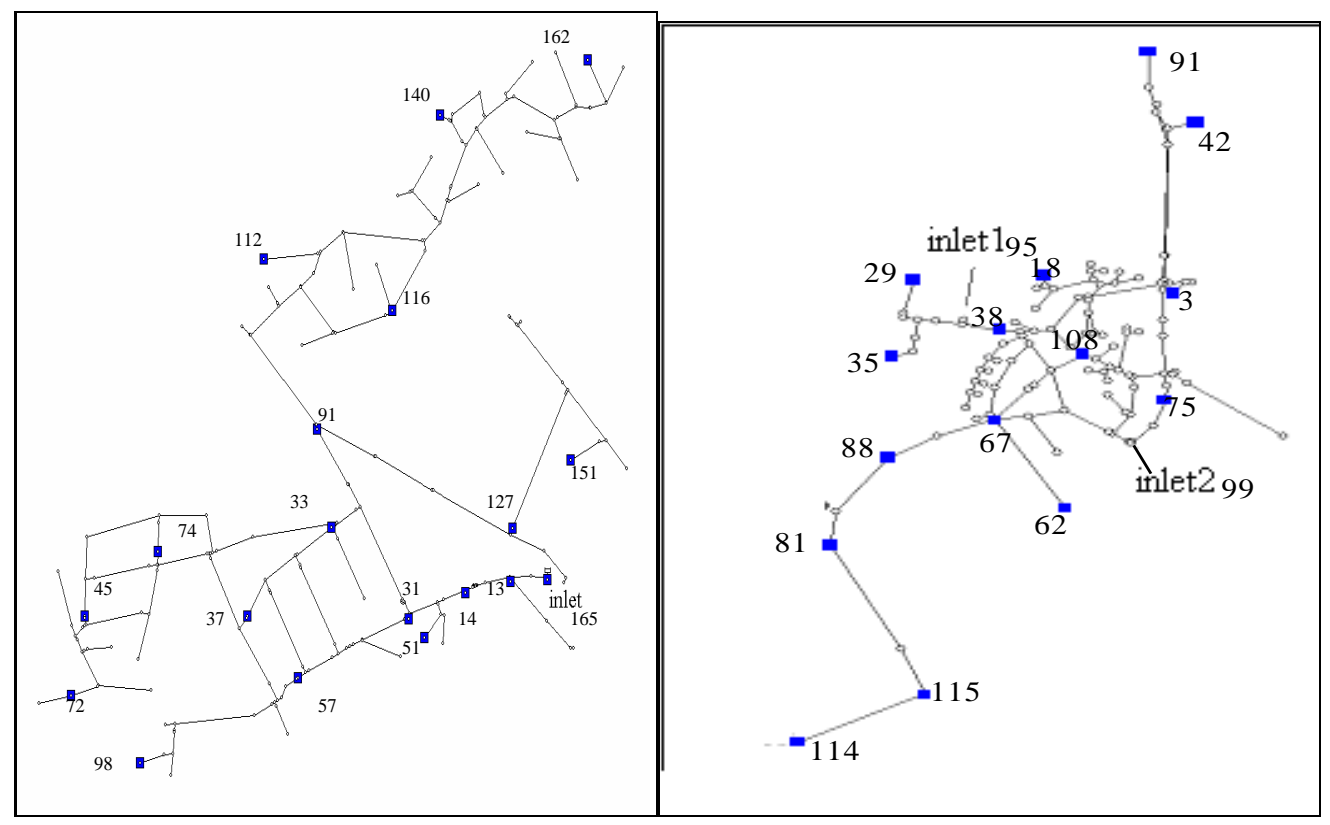

Fig. 5.1 Ocker Hill DMA schematic

Fig. 5.2 Shenstone DMA schematic 
Ocker Hill is a mostly domestic single-feed DMA supplying 1850 properties (1825 domestic, 25 commercial). The inlet is through a 6" Rollseal PRV and there is a disused PRV (4" Bermad) about $150 \mathrm{~m}$ downstream of this. Shenstone is currently fed through two PRV inlets and supplies 1008 consumers (917 domestic, 91 commercial). The PRVs are 4" Bermad (St John) and 4" Rollseal (Lynn).

Sensitive nodes which have been obtained from the program described in Chapter 5.1.1 are marked in the DMA schematics. The pressure values at the marked nodes are used as initial indicators for calculating the burst size.

The set up of the experiment is described below:

- the inlet pressure is changed in steps in Ocker Hill from $18.94 \mathrm{~m}$ to $50.47 \mathrm{~m}$ (node 165) (Figure 5.3) and in Shenstone from $40.9 \mathrm{~m}$ to $65.9 \mathrm{~m}$ at Inlet 1 (node 95 ) and from $33.26 m$ to $58.26 m$ at Inlet 2 (node 99) (Figure 5.4).

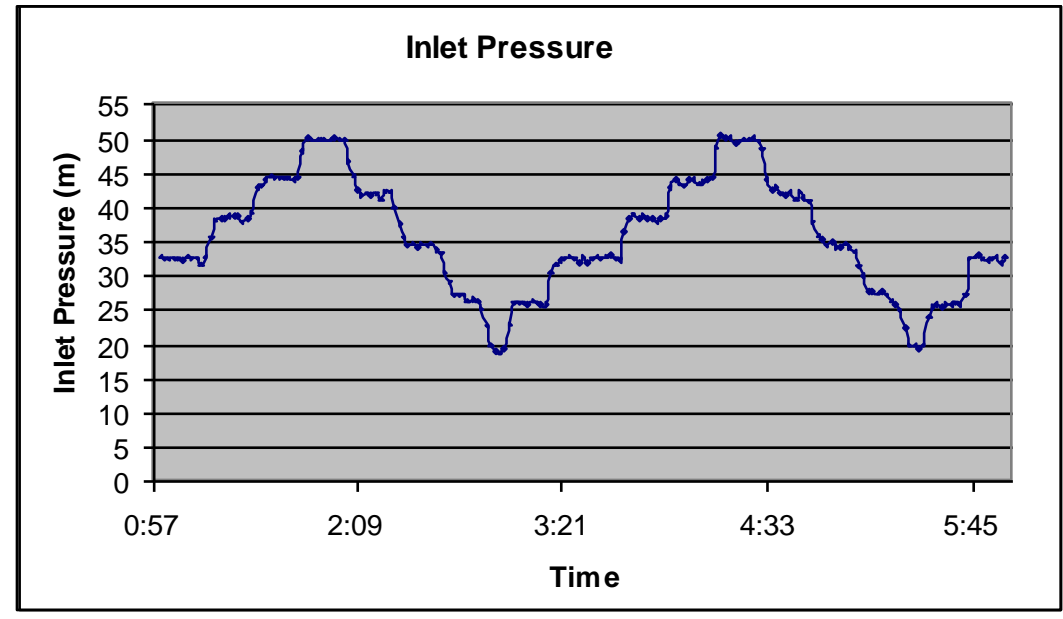

Fig. 5.3 Ocker Hill Inlet pressure.

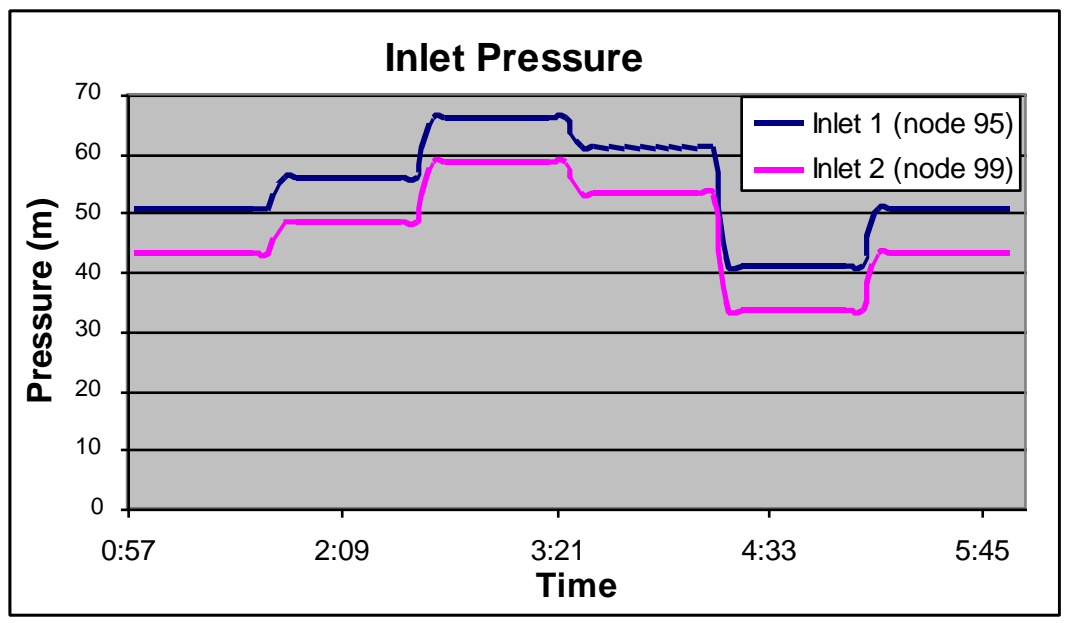

Fig. 5.4 Shenstone Inlet Pressure. 
- The total demand is set within the limits from 2 to $4 \mathrm{l} / \mathrm{s}$ and distributed among the demand nodes in proportion to the number of consumers.

- The value of the total background leakage coefficient is set within the limits from 0 to $0.02 l / s / m \sqrt{m}$ and random distributed among demand nodes of the network.

- The value of the burst coefficient is set within the limits from 0.2 to 0.5 $l / s / \sqrt{m}$ at a selected node of the network (a different burst coefficient value for each experiment).

- The selected values are entered into the network simulation program as input parameters. The observed output variables are: the total inlet flow and the pressure values at sensitive nodes of the network.

- Using the least squares method defined by Equation (4.2) the coefficients of the IFM are calculated, where the Average Zone Night Pressure is used in the background leakage term and pressure at a sensitive node is used to represent the burst term.

Some results of the experiments are given in Tables 5.1 and Table 5.2 below. The assumed demand and leak coefficients have been used in the simulation program to generate data whilst values of other variables have been estimated by the least squares method separately for each sensitive node.

Tables 5.1 and Table 5.2 are highlighted in yellow for the rows containing the largest values of the burst coefficients. 
Table 5.1 Ocker Hill DMA calculated results

\begin{tabular}{|c|c|c|c|c|c|c|c|}
\hline \multicolumn{4}{|c|}{$\begin{array}{l}\text { Set values: Demand flow }=41 / \mathrm{s} \\
\text { Burst coefficient at node } 59=0.5 \\
\text { Total background leakage coefficient }=0.006525\end{array}$} & \multicolumn{4}{|c|}{$\begin{array}{l}\text { Set values: Demand flow }=31 / \mathrm{s} \\
\text { Burst coefficient at node } 141=0.37 \\
\text { Total background leakage coefficient }=0.01613\end{array}$} \\
\hline $\begin{array}{l}\text { Sensitive } \\
\text { node }\end{array}$ & $\begin{array}{l}\text { Demand } \\
\text { flow }\end{array}$ & $\begin{array}{c}\text { Burst } \\
\text { coefficient }\end{array}$ & $\begin{array}{c}\text { Background } \\
\text { leakage } \\
\text { coefficient }\end{array}$ & $\begin{array}{l}\text { Sensitive } \\
\text { node }\end{array}$ & $\begin{array}{l}\text { Demand } \\
\text { flow }\end{array}$ & $\begin{array}{c}\text { Burst } \\
\text { coefficient }\end{array}$ & $\begin{array}{c}\text { Background } \\
\text { leakage } \\
\text { coefficient }\end{array}$ \\
\hline 165 & 4.058089 & 0.478309 & 0.006348 & 165 & 3.269832 & 0.305609 & 0.015863 \\
\hline 37 & 3.80658 & 0.533508 & 0.006317 & 37 & 3.054222 & 0.3395 & 0.01604 \\
\hline 45 & 4.175571 & 0.482332 & 0.006583 & 45 & 3.284707 & 0.30811 & 0.016206 \\
\hline 91 & 3.341031 & 0.588109 & 0.006037 & 91 & 2.774552 & 0.377206 & 0.015912 \\
\hline 13 & 4.465427 & 0.424752 & 0.006732 & 13 & 3.520386 & 0.269926 & 0.016199 \\
\hline 31 & 4.451922 & 0.436145 & 0.006792 & 31 & 3.480549 & 0.278997 & 0.016327 \\
\hline 51 & 4.172598 & 0.474184 & 0.006536 & 51 & 3.311559 & 0.303062 & 0.016131 \\
\hline 72 & 4.380813 & 0.451963 & 0.006749 & 72 & 3.413617 & 0.28941 & 0.016309 \\
\hline 74 & 3.989204 & 0.508653 & 0.006444 & 74 & 3.16787 & 0.324317 & 0.016121 \\
\hline 151 & 3.38793 & 0.582463 & 0.006067 & 151 & 2.804813 & 0.373748 & 0.015939 \\
\hline 98 & 4.148603 & 0.48765 & 0.00656 & 98 & 3.26764 & 0.31053 & 0.01619 \\
\hline 162 & 2.850417 & 0.645874 & 0.005789 & 162 & 2.460468 & 0.415558 & 0.015782 \\
\hline 14 & 4.454542 & 0.429002 & 0.006744 & 14 & 3.504668 & 0.273175 & 0.016233 \\
\hline 127 & 3.76789 & 0.534242 & 0.006296 & 127 & 3.049977 & 0.342568 & 0.016081 \\
\hline 140 & 3.005157 & 0.628148 & 0.005865 & 140 & 2.560595 & 0.404035 & 0.015829 \\
\hline 112 & 3.177482 & 0.607924 & 0.005953 & 112 & 2.671365 & 0.390698 & 0.015879 \\
\hline 33 & 3.711359 & 0.543539 & 0.006249 & 33 & 3.000119 & 0.346666 & 0.015998 \\
\hline 57 & 4.267668 & 0.469709 & 0.006652 & 57 & 3.343708 & 0.299688 & 0.016246 \\
\hline 116 & 2.792038 & 0.652447 & 0.00576 & 116 & 2.422476 & 0.419613 & 0.015762 \\
\hline
\end{tabular}


Table 5.2 Shenstone DMA calculated results

\begin{tabular}{|c|c|c|c|c|c|c|c|}
\hline \multicolumn{4}{|c|}{$\begin{array}{l}\text { Set values: Demand flow }=3.81 / \mathrm{s} \\
\text { Burst coefficient at node } 98=0.2 \\
\text { Total background leakage coefficient }=0.002406\end{array}$} & \multicolumn{4}{|c|}{$\begin{array}{l}\text { Set values: Demand flow }=21 / \mathrm{s} \\
\text { Burst coefficient at node } 29=0.4 \\
\text { Total background leakage coefficient }=0\end{array}$} \\
\hline $\begin{array}{l}\text { Sensitive } \\
\text { node }\end{array}$ & $\begin{array}{l}\text { Demand } \\
\text { flow }\end{array}$ & $\begin{array}{c}\text { Burst } \\
\text { coefficient }\end{array}$ & $\begin{array}{c}\text { Background } \\
\text { leakage } \\
\text { coefficient }\end{array}$ & $\begin{array}{l}\text { Sensitive } \\
\text { node }\end{array}$ & $\begin{array}{l}\text { Demand } \\
\text { flow }\end{array}$ & $\begin{array}{c}\text { Burst } \\
\text { coefficient }\end{array}$ & $\begin{array}{l}\text { Background } \\
\text { leakage } \\
\text { coefficient }\end{array}$ \\
\hline 95 & 3.236225 & 0.260706 & 0.002156 & 95 & 1.898237 & 0.401441 & 0 \\
\hline 99 & 3.593154 & 0.222397 & 0.002291 & 99 & 2.425762 & 0.347515 & 0.000168 \\
\hline 18 & 3.286523 & 0.257139 & 0.002183 & 18 & 1.935232 & 0.398993 & 0 \\
\hline 91 & 3.440365 & 0.241165 & 0.002237 & 91 & 2.159354 & 0.377021 & $6.28 \mathrm{E}-05$ \\
\hline 42 & 3.437983 & 0.241385 & 0.002237 & 42 & 2.155902 & 0.377425 & $6.14 \mathrm{E}-05$ \\
\hline 3 & 3.147278 & 0.271559 & 0.002136 & 3 & 1.780036 & 0.40958 & 0 \\
\hline 114 & 3.861908 & 0.190836 & 0.002427 & 114 & 2.815415 & 0.300705 & 0.00035 \\
\hline 115 & 3.836697 & 0.194077 & 0.002413 & 115 & 2.776174 & 0.305679 & 0.00033 \\
\hline 81 & 3.585625 & 0.224361 & 0.002296 & 81 & 2.385865 & 0.352186 & 0.000151 \\
\hline 88 & 3.663002 & 0.215375 & 0.002329 & 88 & 2.506131 & 0.338376 & 0.000202 \\
\hline 108 & 3.885163 & 0.188002 & 0.002439 & 108 & 2.850187 & 0.296228 & 0.000368 \\
\hline 62 & 3.485124 & 0.235644 & 0.002254 & 62 & 2.230019 & 0.369494 & $8.91 \mathrm{E}-05$ \\
\hline 67 & 3.50643 & 0.233287 & 0.002263 & 67 & 2.263157 & 0.365866 & 0.000102 \\
\hline 38 & 3.378799 & 0.246559 & 0.00221 & 38 & 2.07937 & 0.385877 & $3.27 \mathrm{E}-05$ \\
\hline 75 & 3.53757 & 0.229522 & 0.002272 & 75 & 2.325583 & 0.358828 & 0.000127 \\
\hline 35 & 3.344375 & 0.249648 & 0.002194 & 35 & 2.043496 & 0.393223 & $1.69 \mathrm{E}-05$ \\
\hline 29 & 3.315828 & 0.252624 & 0.002184 & 29 & 2 & 0.4 & 0 \\
\hline \multicolumn{4}{|c|}{$\begin{array}{l}\text { Set values: Demand flow }=21 / \mathrm{s} \\
\text { Burst coefficient at node } 67=0.2 \\
\text { Total background leakage coefficient }=0.00239\end{array}$} & \multicolumn{4}{|c|}{$\begin{array}{l}\text { Set values: Demand flow }=41 / \mathrm{s} \\
\text { Burst coefficient at node } 80=0.24 \\
\text { Total background leakage coefficient }=0.002216\end{array}$} \\
\hline $\begin{array}{c}\text { Sensitive } \\
\text { node }\end{array}$ & $\begin{array}{l}\text { Demand } \\
\text { flow }\end{array}$ & $\begin{array}{c}\text { Burst } \\
\text { coefficient }\end{array}$ & $\begin{array}{c}\text { Background } \\
\text { leakage } \\
\text { coefficient }\end{array}$ & $\begin{array}{l}\text { Sensitive } \\
\text { node }\end{array}$ & $\begin{array}{c}\text { Demand } \\
\text { flow }\end{array}$ & $\begin{array}{c}\text { Burst } \\
\text { coefficient }\end{array}$ & $\begin{array}{c}\text { Background } \\
\text { leakage } \\
\text { coefficient }\end{array}$ \\
\hline 95 & 1.793312 & 0.220055 & 0.002301 & 95 & 3.65718 & 0.273442 & 0.002071 \\
\hline 99 & 2.094677 & 0.18765 & 0.002415 & 99 & 4.031559 & 0.233282 & 0.002213 \\
\hline 18 & 1.821443 & 0.217637 & 0.002321 & 18 & 3.716929 & 0.269285 & 0.002101 \\
\hline 91 & 1.949842 & 0.204158 & 0.002365 & 91 & 3.876757 & 0.252068 & 0.002158 \\
\hline 42 & 1.949871 & 0.204019 & 0.002367 & 42 & 3.874481 & 0.25247 & 0.002158 \\
\hline 3 & 1.706537 & 0.229054 & 0.002284 & 3 & 3.570119 & 0.284088 & 0.002053 \\
\hline 114 & 2.310342 & 0.162332 & 0.002525 & 114 & 4.321251 & 0.199451 & 0.002359 \\
\hline 115 & 2.288989 & 0.165062 & 0.002514 & 115 & 4.294801 & 0.202867 & 0.002345 \\
\hline 81 & 2.076462 & 0.190582 & 0.002416 & 81 & 4.031286 & 0.234779 & 0.002221 \\
\hline 88 & 2.141971 & 0.183006 & 0.002444 & 88 & 4.11251 & 0.225311 & 0.002256 \\
\hline 108 & 2.327863 & 0.15972 & 0.002534 & 108 & 4.345177 & 0.196395 & 0.002372 \\
\hline 62 & 1.991531 & 0.200079 & 0.002381 & 62 & 3.925762 & 0.246665 & 0.002177 \\
\hline 67 & 2.009589 & 0.198089 & 0.002388 & 67 & 3.948126 & 0.244182 & 0.002186 \\
\hline 38 & 1.907202 & 0.208534 & 0.002346 & 38 & 3.81245 & 0.258423 & 0.00213 \\
\hline 75 & 2.040366 & 0.193994 & 0.002396 & 75 & 3.975472 & 0.240345 & 0.002193 \\
\hline 35 & 1.883588 & 0.210778 & 0.002333 & 35 & 3.771283 & 0.261826 & 0.002112 \\
\hline 29 & 1.859498 & 0.213293 & 0.002325 & 29 & 3.741332 & 0.264948 & 0.002101 \\
\hline
\end{tabular}


The estimated coefficients in the IFM are very close to the preset values. The average differences between the estimated and the preset values are as follows:

- The average difference for the demand flow is $5 \%$, with the difference ranging from 0.1 to 0.5 litres/sec.

- The average difference for the burst coefficient is $7 \%$, with the difference ranging from 0.01 to 0.06 .

- The average difference for the background leakage coefficient is $2 \%$, with the difference ranging from 0.00005 to 0.0003 .

It is inexpedient to select average values, because the precision of burst size prediction can be low. A question arises as to what method should be used to select particular coefficient values from the obtained range?

The task is to find out an exact size of the burst. Taking inspiration from the algorithm by Prescott and Ulanicki (2006), describing the procedure of selecting sensitive nodes, the maximum value of the burst coefficient $c_{l}=\max$ could be considered. When this suggestion is used the following estimation accuracies have been obtained:

- For the demand $d$, the average error of estimating the demand is $11 \%$, and the absolute error increases with increasing demands, reaching about 0.2 litres/sec for the demand of 2 litres/sec and 1.2 litres/sec for the demand of 4 litres/sec.

- For the burst coefficient, the average error of estimating the burst coefficient $c_{1}$ is $12 \%$, which corresponds to about 0.4 litres/sec (from 0.07 litres/sec up to 0.91 litres/sec depending on the set burst size).

- For the background leakage, the average error of estimating the background leakage coefficient $c_{2}$ is $5 \%$, which corresponds to about 0.1 litres/sec.

The results are not encouraging. The maximum value of the burst coefficient corresponds to the assumption of the presence of a burst at the sensitive node. Where the sensitive node is located in an area of the network the most distant from the source (i.e. on the end of the branch where the burst has been preset). Also the difference between the inlet pressure and the end node pressure (in the presents of leaks) is rather small. Such distant sensitive nodes are: node 116 at the Ocker Hill DMA and node 3 at the Shenstone DMA. So the hypothesis of identifying the burst node through the biggest value of the burst coefficients is not correct. The solution can be found by applying a proper statistical analysis to the generated data. 


\subsubsection{Method of statistical analysis for determination of the burst size.}

All the obtained coefficients (within the limits of a separate experiment) have been received by means of the least squares method and correspond to an average flow/pressure relationship. However, it is difficult to be satisfied with the flow values, i.e. the demand flow, the burst flow and the background leakage flow. Some of these flows depend on pressures at nodes of the network and, as a consequence, on the inlet pressure. The inlet flow is the result of summation of all the flows. The question of selecting from the set of obtained coefficient values which are close to true values should be answered by considering flows in the network and consequently the inlet flow.

Let's assume, that the inlet flow is described by means of a certain theoretical IFM:

$q_{i}=d_{i}+c_{1 i} p_{i}^{0.5}+c_{2 i} p_{A Z N P}^{1.5}$

where

$q_{i} \quad$ inlet flow

$d_{i} \quad$ demand

$c_{1 i} \quad$ burst coefficient

$c_{2 i} \quad$ background leakage coefficient

$p_{i} \quad$ pressure at a sensitive node

$p_{\text {AZNP }} \quad$ Average Zone Night Pressure

$i \quad$ identification number of sensitive nodes (number of a theoretical IFM)

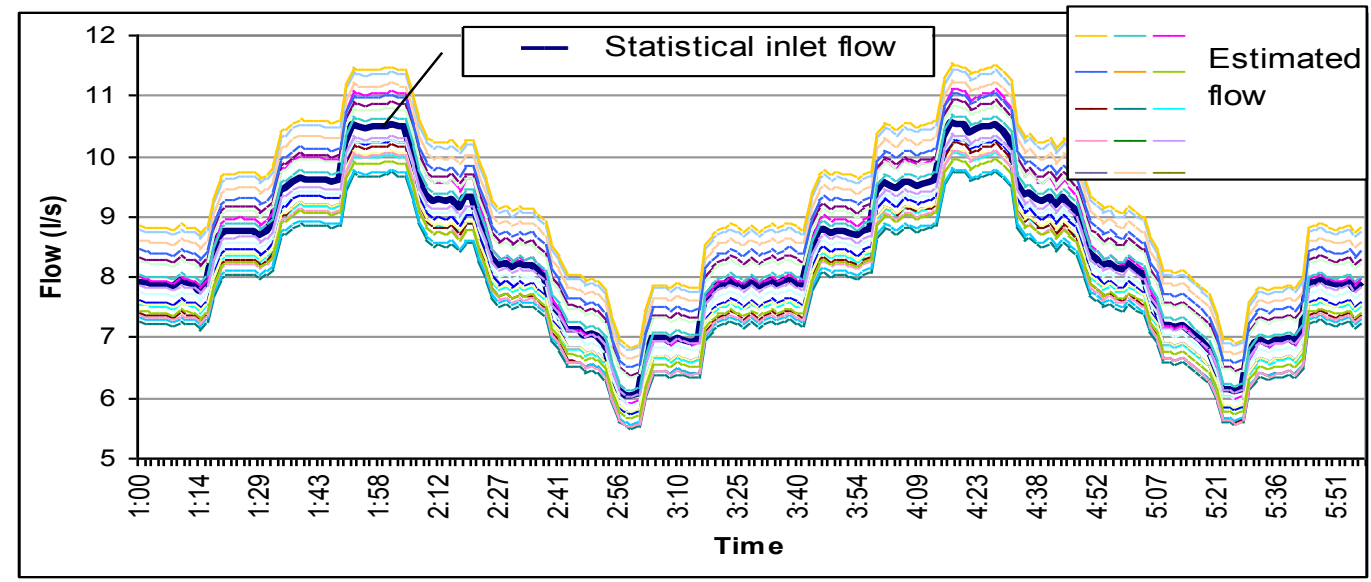

Fig. 5.5 Statistical and estimated inlet flows

No matter how well the IFM has been selected, there will be a difference between the statistical (obtained from simulation) and the estimated (calculated from equation 5.4) 
data (Fig.5.5). The question arises whether these divergences are random fluctuations, related to a limited number of observations, instability of demands or inaccuracy of measurements, or they are deterministic and related to an incorrect model. The question can be answered by the so called 'goodness-of-fit' test in which on the basis of given statistical material a hypothesis $H$ shall be verified, if a random variable $X$ follows a certain law of distribution. This law can be set in one or another form, for example in the form of a distribution function, either in a continuous or discrete form.

In order to accept or reject the hypothesis $H$, it is necessary to choose a measure of a difference between the theoretical and statistical distributions. It is possible to use different measures, e.g. the sum of squares of deviations of the theoretical probabilities from corresponding frequencies of statistical probabilities, or the sum of the same squares with some weight coefficients, or the maximum deviation between the theoretical and statistical distribution. In any case this measure will be a random variable and the distribution law of this random variable depends on the distribution of $X$ and on the number of experiments.

In order to verify the hypothesis and in our case - the compliance of the statistical and estimated values of the inlet flow, it is proposed here to use the chi-square $\left(\chi^{2}\right)$ criterion. A chi-square test (also chi-squared or $\chi^{2}$ test) is a statistical hypothesis test in which the test statistic has a chi-square distribution when the null hypothesis is true, or in which the probability distribution of the test statistic (assuming the null hypothesis is true) can be made to approximate a chi-square distribution as closely as desired by making the sample size large enough. In probability theory and statistics, the chi-square distribution (also chi-squared or $\chi^{2}$ distribution) is one of the most widely used theoretical probability distributions in inferential statistics, e.g., in statistical significance tests (Chernoff \& Lehmann 1954, Plackett 1983). The chi-square statistic is calculated by finding the difference between each observed and theoretical frequency for each possible outcome, squaring them, dividing each by the theoretical frequency, and taking the sum of the results.

$$
\chi^{2}=\sum_{i} \frac{\left(Y_{i}^{\prime}-Y_{i}\right)^{2}}{Y_{i}^{\prime 2}}
$$

where

$Y_{i}^{\prime} \quad$ estimated data 
$Y_{i} \quad$ statistical data

As a result of comparison of statistical values of the inlet flow obtained from simulations, with the estimated values based on Equation 5.4, the following values of $\chi^{2}$ depicted in Tables 5.3 and 5.4 have been obtained.

Table 5.3 Ocker Hill DMA $\chi^{2}$ values.

\begin{tabular}{|c|c|c|c|}
\hline \multicolumn{2}{|c|}{ Burst at node 141. } & \multicolumn{2}{c|}{ Burst at node 59. } \\
\hline $\begin{array}{c}\text { Sensitive } \\
\text { node }\end{array}$ & $\begin{array}{c}\text { The value of } \\
\chi^{2}\end{array}$ & Sensitive node & $\begin{array}{c}\text { The value of } \\
\chi^{2}\end{array}$ \\
\hline 165 & $1.45 \mathrm{E}-05$ & 165 & $9.01 \mathrm{E}-07$ \\
\hline 37 & $6.14 \mathrm{E}-06$ & 37 & $5.85 \mathrm{E}-07$ \\
\hline 45 & $1.19 \mathrm{E}-05$ & 45 & $1.24 \mathrm{E}-06$ \\
\hline 91 & $2.51 \mathrm{E}-06$ & 91 & $5.85 \mathrm{E}-06$ \\
\hline 13 & $2.64 \mathrm{E}-05$ & 13 & $1.21 \mathrm{E}-05$ \\
\hline 31 & $2.16 \mathrm{E}-05$ & 31 & $9.83 \mathrm{E}-06$ \\
\hline 51 & $1.39 \mathrm{E}-05$ & 51 & $1.69 \mathrm{E}-06$ \\
\hline 72 & $1.73 \mathrm{E}-05$ & 72 & $6.12 \mathrm{E}-06$ \\
\hline 74 & $8.53 \mathrm{E}-06$ & 74 & $7.77 \mathrm{E}-09$ \\
\hline 151 & $2.74 \mathrm{E}-06$ & 151 & $5.17 \mathrm{E}-06$ \\
\hline 98 & $1.14 \mathrm{E}-05$ & 98 & $9.24 \mathrm{E}-07$ \\
\hline 162 & $6.93 \mathrm{E}-07$ & 162 & $1.4 \mathrm{E}-05$ \\
\hline 14 & $2.46 \mathrm{E}-05$ & 14 & $1.11 \mathrm{E}-05$ \\
\hline 127 & $5.96 \mathrm{E}-06$ & 127 & $7.42 \mathrm{E}-07$ \\
\hline 140 & $1.09 \mathrm{E}-06$ & 140 & $1.14 \mathrm{E}-05$ \\
\hline 112 & $1.69 \mathrm{E}-06$ & 112 & $8.47 \mathrm{E}-06$ \\
\hline 33 & $5.3 \mathrm{E}-06$ & 33 & $1.27 \mathrm{E}-06$ \\
\hline 57 & $1.42 \mathrm{E}-05$ & 57 & $2.92 \mathrm{E}-06$ \\
\hline 116 & $5.78 \mathrm{E}-07$ & 116 & $1.51 \mathrm{E}-05$ \\
\hline
\end{tabular}

Where the values highlighted in yellow correspond to the minimum values of $\chi^{2}$. 
Table 5.4 Shenstone DMA $\chi^{2}$ values.

\begin{tabular}{|c|c|c|c|c|c|c|c|}
\hline \multicolumn{2}{|c|}{ Burst at node 98. } & Burst at node 29. & Burst at node 67. & \multicolumn{2}{c|}{ Burst at node 80. } \\
\hline $\begin{array}{c}\text { Sensitive } \\
\text { node }\end{array}$ & $\begin{array}{c}\text { The value } \\
\text { of } \chi^{2}\end{array}$ & $\begin{array}{c}\text { Sensitive } \\
\text { node }\end{array}$ & $\begin{array}{c}\text { The value } \\
\text { of } \chi^{2}\end{array}$ & $\begin{array}{c}\text { Sensitive } \\
\text { node }\end{array}$ & $\begin{array}{c}\text { The value } \\
\text { of } \chi^{2}\end{array}$ & $\begin{array}{c}\text { Sensitive } \\
\text { node }\end{array}$ & $\begin{array}{c}\text { The value } \\
\text { of }\end{array}$ \\
\hline 95 & $1.3 \mathrm{E}-07$ & 95 & $9.3 \mathrm{E}-07$ & 95 & $1.3 \mathrm{E}-08$ & 95 & $2.8 \mathrm{E}-08$ \\
\hline 99 & $2.58 \mathrm{E}-08$ & 99 & $8.15 \mathrm{E}-08$ & 99 & $7.23 \mathrm{E}-09$ & 99 & $1.17 \mathrm{E}-09$ \\
\hline 18 & $1.18 \mathrm{E}-07$ & 18 & $3.24 \mathrm{E}-07$ & 18 & $9.7 \mathrm{E}-09$ & 18 & $2.13 \mathrm{E}-08$ \\
\hline 91 & $7.1 \mathrm{E}-08$ & 91 & $9.92 \mathrm{E}-09$ & 91 & $5.45 \mathrm{E}-10$ & 91 & $4.27 \mathrm{E}-09$ \\
\hline 42 & $7.12 \mathrm{E}-08$ & 42 & $9.47 \mathrm{E}-09$ & 42 & $5.12 \mathrm{E}-10$ & 42 & $4.54 \mathrm{E}-09$ \\
\hline 3 & $1.65 \mathrm{E}-07$ & 3 & $4.85 \mathrm{E}-06$ & 3 & $2.47 \mathrm{E}-08$ & 3 & $4.35 \mathrm{E}-08$ \\
\hline 114 & $5.03 \mathrm{E}-09$ & 114 & $4.35 \mathrm{E}-07$ & 114 & $9.13 \mathrm{E}-08$ & 114 & $7.63 \mathrm{E}-08$ \\
\hline 115 & $1.92 \mathrm{E}-09$ & 115 & $3.77 \mathrm{E}-07$ & 115 & $7.61 \mathrm{E}-08$ & 115 & $6.18 \mathrm{E}-08$ \\
\hline 81 & $2.93 \mathrm{E}-08$ & 81 & $6.47 \mathrm{E}-08$ & 81 & $4.36 \mathrm{E}-09$ & 81 & $8.28 \mathrm{E}-10$ \\
\hline 88 & $1.29 \mathrm{E}-08$ & 88 & $1.23 \mathrm{E}-07$ & 88 & $1.49 \mathrm{E}-08$ & 88 & $7.63 \mathrm{E}-09$ \\
\hline 108 & $9.28 \mathrm{E}-09$ & 108 & $4.91 \mathrm{E}-07$ & 108 & $1.1 \mathrm{E}-07$ & 108 & $9.14 \mathrm{E}-08$ \\
\hline 62 & $5.59 \mathrm{E}-08$ & 62 & $2.08 \mathrm{E}-08$ & 62 & $4.99 \mathrm{E}-12$ & 62 & $1.44 \mathrm{E}-09$ \\
\hline 67 & $4.99 \mathrm{E}-08$ & 67 & $2.77 \mathrm{E}-08$ & 67 & $2.26 \mathrm{E}-10$ & 67 & $6.03 \mathrm{E}-10$ \\
\hline 38 & $8.64 \mathrm{E}-08$ & 38 & $2.54 \mathrm{E}-09$ & 38 & $2.6 \mathrm{E}-09$ & 38 & $9.8 \mathrm{E}-09$ \\
\hline 75 & $4.1 \mathrm{E}-08$ & 75 & $4.43 \mathrm{E}-08$ & 75 & $1.68 \mathrm{E}-09$ & 75 & $2.13 \mathrm{E}-11$ \\
\hline 35 & $9.58 \mathrm{E}-08$ & 35 & $6.74 \mathrm{E}-10$ & 35 & $4.06 \mathrm{E}-09$ & 35 & $1.34 \mathrm{E}-08$ \\
\hline 29 & $1.05 \mathrm{E}-07$ & 29 & $1.61 \mathrm{E}-26$ & 29 & $6.05 \mathrm{E}-09$ & 29 & $1.69 \mathrm{E}-08$ \\
\hline
\end{tabular}

Where the values highlighted in yellow correspond to the minimum values of $\chi^{2}$.

In the ideal situation of full consistency between the statistical and the theoretical data, the value of the criteria should be equal to 0 . In our experiment the pressure at a sensitive node instead of the pressure at the burst node was used and consequently $\chi^{2}>0$. In general the minimum value of $\chi^{2}$ identifies the demand, the burst and the background leakage, that most correctly describe flows in a network and such cases are collected in Table 5.5 for different input data scenarios.

The accuracy of the results is influenced by the considered scenario; the simulated demand, the total background leakage and the size and the location of the burst. This will be closer investigated in Chapter 5.1.5. 
Table 5.5 Obtained results

\begin{tabular}{|c|c|}
\hline Set values & $\begin{array}{l}\text { The values, obtained as a result of } \\
\text { calculations }\end{array}$ \\
\hline \multicolumn{2}{|c|}{ Ocker Hill DMA } \\
\hline Demand flow $=4 \mathrm{l} / \mathrm{s}$ & Demand flow $=3.98921 / \mathrm{s}$ \\
\hline Burst coefficient at node $59=0.5$ & Burst coefficient at node $74=0.508653$ \\
\hline Total background leakage coefficient $=0.006525$ & Total background leakage coefficient $=0.006444$ \\
\hline Demand flow $=3 \mathrm{l} / \mathrm{s}$ & Demand flow $=2.422476 \mathrm{l} / \mathrm{s}$ \\
\hline Burst coefficient at node $141=0.37$ & Burst coefficient at node $116=0.419613$ \\
\hline Total background leakage coefficient $=0.01613$ & Total background leakage coefficient $=0.015762$ \\
\hline \multicolumn{2}{|c|}{ Shenstone DMA } \\
\hline Demand flow $=3.8 \mathrm{l} / \mathrm{s}$ & Demand flow $=3.836697 \mathrm{l} / \mathrm{s}$ \\
\hline Burst coefficient at node $98=0.2$ & Burst coefficient at node $115=0.194077$ \\
\hline Total background leakage coefficient $=0.002406$ & Total background leakage coefficient $=0.002413$ \\
\hline Demand flow $=21 / \mathrm{s}$ & Demand flow $=21 / \mathrm{s}$ \\
\hline Burst coefficient at node $29=0.4$ & Burst coefficient at node $29=0.4$ \\
\hline Total background leakage coefficient $=0$ & Total background leakage coefficient $=0$ \\
\hline Demand flow $=21 / \mathrm{s}$ & Demand flow $=1.991531 \mathrm{l} / \mathrm{s}$ \\
\hline Burst coefficient at node $67=0.2$ & Burst coefficient at node $62=0.200079$ \\
\hline Total background leakage coefficient $=0.00239$ & Total background leakage coefficient $=0.002381$ \\
\hline Demand flow $=4 \mathrm{l} / \mathrm{s}$ & Demand flow $=3.9754721 / \mathrm{s}$ \\
\hline Burst coefficient at node $80=0.24$ & Burst coefficient at node $75=0.240345$ \\
\hline Total background leakage coefficient $=0.002216$ & Total background leakage coefficient $=0.002193$ \\
\hline
\end{tabular}

A summary of all experiments carried out by the author (about 30 experiments) including those which have not been described here is given below.

- For the demand $d$ the average error was $1.5 \%$ (the absolute average error of 0.1 $1 / \mathrm{s}$ for the demand of $3 \mathrm{l} / \mathrm{s}$ ).

- For the burst coefficient $c_{1}$ the average error was $0.8 \%$ (the absolute average error in the terms of the burst flow $0.031 / \mathrm{s}$ ).

- For the background leakage coefficient $c_{2}$ the average error was $0.8 \%$ (the absolute average error in the terms of the background flow $0.015 \mathrm{l} / \mathrm{s}$ ).

This level of accuracy of determining the IFM coefficients is sufficiently high from the practical point of view and one should remember that the pressures to estimate the IFM coefficients were from a sensitive node and not from the exact burst node. 


\subsubsection{Hybrid method of burst detection}

The considerations in the previous chapter allow the formulation of a hybrid method for burst detection which is based on applying a least squares method followed by a chisquare test. The description of the method is given in the following steps: data requirements including a hydraulic model and the data obtained from the field experiment, verbal description of the algorithms and the algorithm flowchart.

The following input data are required to determine the size of a burst in a network:

\section{Hydraulic model data}

The model of the Shenstone network used by the author is stored in a separate excel file model.xls (Table 5.6 and full data are contained in Appendix D) with the following fields:

A - Node number - a unique label used to identify the node.

B - Type of node - a binary value that describes the role of a node in a network: 0 for a connection node or 1 for a source node (reservoir node or PRV OUTLET node).

$\mathrm{C}$ - Demand factor - number of average water users allocated to a node.

D - Elevation (m) - elevation in metres above a common reference of a node. The elevation in used in the program only to compute the pressure at the node.

E - Coefficient of a burst - value of coefficient $c_{1}$ for a specific node is set in case of presence in a network of already known burst with specified characteristics.

$\mathrm{F}$ - Exponent of the burst term in the IFM=0.5.

$\mathrm{G}$ - Coefficient of known background leakages - value of coefficient $c_{2}$ for a specific node is set up in case of presence in a network with already known background leakages with specified characteristics.

$\mathrm{H}-$ Exponent of the background leakage term in the IFM $=1.5$.

I, J - horizontal and vertical co-ordinates of a node on the map. They do not affect any other variable. 
Table 5.6 Model data

\begin{tabular}{|c|c|c|c|c|c|c|c|c|c|}
\hline A & B & C & D & $E$ & $\mathbf{F}$ & $\mathbf{G}$ & $\mathbf{H}$ & I & $\mathbf{J}$ \\
\hline 1 & 0 & 2 & 91 & 0 & 0.5 & 0 & 1.5 & 411362848 & 304925728 \\
\hline 2 & 0 & 2 & 91 & 0 & 0.5 & 0 & 1.5 & 411382531 & 304927213 \\
\hline 3 & 0 & 8 & 91 & 0 & 0.5 & 0 & 1.5 & 411304768 & 304868015 \\
\hline 4 & 0 & 0 & 91.08 & 0 & 0.5 & 0 & 1.5 & 411296376 & 304921239 \\
\hline 5 & 0 & 0 & 91.4 & 0 & 0.5 & 0 & 1.5 & 411280256 & 305070883 \\
\hline$\ldots$ & $\ldots$ & $\ldots$ & $\ldots$ & $\ldots$ & $\ldots$ & $\ldots$ & $\ldots$ & $\ldots$ & $\ldots$ \\
\hline 91 & 0 & 100 & 97 & 0 & 0.5 & 0 & 1.5 & 411217951 & 306164501 \\
\hline 92 & 0 & 5 & 100.714 & 0 & 0.5 & 0 & 1.5 & 411142464 & 304066560 \\
\hline 93 & 0 & 16 & 102.76 & 0 & 0.5 & 0 & 1.5 & 410760043 & 304351731 \\
\hline 94 & 0 & 0 & 98 & 0 & 0.5 & 0 & 1.5 & 411219601 & 305974799 \\
\hline 95 & 1 & 0 & 94.1 & 0 & 0.5 & 0 & 1.5 & 410509041 & 304723406 \\
\hline 96 & 0 & 24 & 103.797 & 0 & 0.5 & 0 & 1.5 & 410916992 & 304578976 \\
\hline 97 & 0 & 0 & 103.8 & 0 & 0.5 & 0 & 1.5 & 410779338 & 304376098 \\
\hline 98 & 0 & 33 & 105.2 & 0 & 0.5 & 0 & 1.5 & 411156736 & 304418880 \\
\hline 99 & 1 & 0 & 100.74 & 0 & 0.5 & 0 & 1.5 & 411148846 & 304062094 \\
\hline 100 & 0 & 0 & 105.357 & 0 & 0.5 & 0 & 1.5 & 410269088 & 302952832 \\
\hline$\ldots$ & .. & $\ldots$ & $\ldots$ & $\ldots$ & $\ldots$ & $\ldots$ & $\ldots$ & $\ldots$ & $\ldots$ \\
\hline 120 & 0 & 15 & 111.712 & 0 & 0.5 & 0 & 1.5 & 411059714 & 304321608 \\
\hline
\end{tabular}

Reservoirs represent boundary inlet points to a network in which measurements of the inlet flow and the inlet pressure are made.

\section{Experimental data.}

The variables which are measured during the E-FAVOR test include the pressure and flow at the inlet to a DMA and also pressure at selected sensitive nodes inside the DMA. The following should be decided before carrying out the test:

- Number of pressure measurement points - this is limited by practical aspects such as number of available loggers and number of available access points (hydrants).

- Inlet pressure stepping - it is beneficial to have many pressure steps and each step with a significant amplitude. This is again constrained by practicalities in the field, pressure of $15 \mathrm{~m}$ has to be maintained at each node of the network to meet the OFWAT regulations and the pressure can only go as high as the inlet pressure to the PRV (PRV fully open).

After the experiment the measurements are stored in another excel file data.xls, which contains the following information (Figure 5.6):

- inlet node IDs $(95,99)$; 
- nodes which are near to the inlet nodes $(19,92)$;

- list of sensitive nodes, at which the measurements have been made $(18,91,42$, $3,114,155, \ldots)$;

- inlet head in metres which is manipulated (stepped) during the experiment.

- inlet flow in litres per second resulting from the changes in the inlet pressure

- pressure at the sensitive nodes in metres, which subsequently will be transformed into head at sensitive nodes (pressure + elevation)

The algorithm of determination of burst size in a network has been implemented in the MATLAB package and progresses through the following steps:

1. Read in the Excel files containing the hydraulic model data and the experimental data.

2. Prepare the matrix of pressures at the sensitive nodes and calculate the values of the Average Zonal Night Pressure.

3. In case of a network with many inlets, add all inlet flows together to form a total inlet flow. It has been found that the use of the total flow is a good compromise between the burst location accuracy and the calculation speed of the algorithm.

\begin{tabular}{|c|c|c|c|c|c|c|c|c|c|c|c|c|c|c|c|}
\hline & A & $B$ & & A & $B$ & C & D & $E$ & $F$ & G & $\mathrm{H}$ & 1 & $J$ & K & L \\
\hline 1 & 95 & 99 & 1 & 95 & 99 & 18 & 91 & 42 & 3 & 114 & 115 & 81 & 88 & 108 & \\
\hline 2 & 145 & 144 & 2 & 197 & 92 & 0 & 0 & 0 & 0 & 0 & 0 & 0 & 0 & 0 & \\
\hline 3 & 145 & 144 & 3 & 3.7974 & 2.509 & 142.66 & 142.74 & 142.69 & 142.69 & 142.83 & 142.83 & 142.83 & 142.83 & 142.78 & 142 \\
\hline 4 & 145 & 144 & 4 & 3.7974 & 2.509 & 142.66 & 142.74 & 142.69 & 142.69 & 142.83 & 142.83 & 142.83 & 142.83 & 142.78 & 142 \\
\hline 5 & 145 & 144 & 5 & 3.7974 & 2.509 & 142.66 & 142.74 & 142.69 & 142.69 & 142.83 & 142.83 & 142.83 & 142.83 & 142.78 & 142 \\
\hline 6 & 145 & 144 & 6 & 3.7974 & 2.509 & 142.66 & 142.74 & 142.69 & 142.69 & 142.83 & 142.83 & 142.83 & 142.83 & 142.78 & 142 \\
\hline 7 & 145 & 144 & 7 & 3.7974 & 2.509 & 142.66 & 142.74 & 142.69 & 142.69 & 142.83 & 142.83 & 142.83 & 142.83 & 142.78 & 142 \\
\hline 8 & 145 & 144 & 8 & 3.7974 & 2.509 & 142.66 & 142.74 & 142.69 & 142.69 & 142.83 & 142.83 & 142.83 & 142.83 & 142.78 & 142 \\
\hline 9 & 145 & 144 & 9 & 3.7974 & 2.509 & 142.66 & 142.74 & 142.69 & 142.69 & 142.83 & 142.83 & 142.83 & 142.83 & 142.78 & 142 \\
\hline 10 & 145 & 144 & 10 & 3.7974 & 2.509 & 142.66 & 142.74 & 142.69 & 142.69 & 142.83 & 142.83 & 142.83 & 142.83 & 142.78 & 142 \\
\hline 11 & 145 & 144 & 11 & 3.7974 & 2.509 & 142.66 & 142.74 & 142.69 & 142.69 & 142.83 & 142.83 & 142.83 & 142.83 & 142.78 & 142 \\
\hline 12 & 150 & 149 & 12 & 3.7974 & 2.509 & 142.66 & 142.74 & 142.69 & 142.69 & 142.83 & 142.83 & 142.83 & 142.83 & 142.78 & 142 \\
\hline 13 & 150 & 149 & 13 & 3.8994 & 2.6121 & 147.55 & 147.65 & 147.58 & 147.58 & 147.73 & 147.73 & 147.74 & 147.74 & 147.68 & 147 \\
\hline 14 & 150 & 149 & 14 & 3.8994 & 2.6121 & 147.55 & 147.65 & 147.58 & 147.58 & 147.73 & 147.73 & 147.74 & 147.74 & 147.68 & 147 \\
\hline 15 & 150 & 149 & 15 & 3.8994 & 2.6121 & 147.55 & 147.65 & 147.58 & 147.58 & 147.73 & 147.73 & 147.74 & 147.74 & 147.68 & 147 \\
\hline 16 & 150 & 149 & 16 & 3.8994 & 2.6121 & 147.55 & 147.65 & 147.58 & 147.58 & 147.73 & 147.73 & 147.74 & 147.74 & 147.68 & 147 \\
\hline 17 & 150 & 149 & 17 & 3.8994 & 2.6121 & 147.55 & 147.65 & 147.58 & 147.58 & 147.73 & 147.73 & 147.74 & 147.74 & 147.68 & 147 \\
\hline 18 & 150 & 149 & 18 & 3.8994 & 2.6121 & 147.55 & 147.65 & 147.58 & 147.58 & 147.73 & 147.73 & 147.74 & 147.74 & 147.68 & 147 \\
\hline 19 & 150 & 149 & 19 & 3.8994 & 2.6121 & 147.55 & 147.65 & 147.58 & 147.58 & 147.73 & 147.73 & 147.74 & 147.74 & 147.68 & 147 \\
\hline 20 & 150 & 149 & 20 & 3.8994 & 2.6121 & 147.55 & 147.65 & 147.58 & 147.58 & 147.73 & 147.73 & 147.74 & 147.74 & 147.68 & 147 \\
\hline 21 & 150 & 149 & 21 & 3.8994 & 2.6121 & 147.55 & 147.65 & 147.58 & 147.58 & 147.73 & 147.73 & 147.74 & 147.74 & 147.68 & 147 \\
\hline 22 & 160 & 159 & 22 & 3.8994 & 2.6121 & 147.55 & 147.65 & 147.58 & 147.58 & 147.73 & 147.73 & 147.74 & 147.74 & 147.68 & 147 \\
\hline 23 & 160 & 159 & 23 & 4.1067 & 2.8191 & 157.31 & 157.44 & 157.35 & 157.35 & 157.53 & 157.53 & 157.53 & 157.53 & 157.47 & 157 \\
\hline 24 & 160 & 159 & 24 & 4.1067 & 2.8191 & 157.31 & 157.44 & 157.35 & 157.35 & 157.53 & 157.53 & 157.53 & 157.53 & 157.47 & 157 \\
\hline 25 & 160 & 159 & 25 & 4.1067 & 2.8191 & 157.31 & 157.44 & 157.35 & 157.35 & 157.53 & 157.53 & 157.53 & 157.53 & 157.47 & 157 \\
\hline 26 & 160 & 159 & 26 & 4.1067 & 2.8191 & 157.31 & 157.44 & 157.35 & 157.35 & 157.53 & 157.53 & 157.53 & 157.53 & 157.47 & 157 \\
\hline 27 & 160 & 159 & 27 & 4.1067 & 2.8191 & 157.31 & 157.44 & 157.35 & 157.35 & 157.53 & 157.53 & 157.53 & 157.53 & 157.47 & 157 \\
\hline 28 & 160 & 159 & 28 & 4.1067 & 2.8191 & 157.31 & 157.44 & 157.35 & 157.35 & 157.53 & 157.53 & 157.53 & 157.53 & 157.47 & 157 \\
\hline 29 & 160 & 159 & 29 & 4.1067 & 2.8191 & 157.31 & 157.44 & 157.35 & 157.35 & 157.53 & 157.53 & 157.53 & 157.53 & 157.47 & 157 \\
\hline 30 & 160 & 159 & 30 & 4.1067 & 2.8191 & 157.31 & 157.44 & 157.35 & 157.35 & 157.53 & 157.53 & 157.53 & 157.53 & 157.47 & 157 \\
\hline 31 & 160 & 159 & 31 & 4.1067 & 2.8191 & 157.31 & 157.44 & 157.35 & 157.35 & 157.53 & 157.53 & 157.53 & 157.53 & 157.47 & 157 \\
\hline 32 & 155 & 154 & 32 & 4.1067 & 2.8191 & 157.31 & 157.44 & 157.35 & 157.35 & 157.53 & 157.53 & 157.53 & 157.53 & 157.47 & 157 \\
\hline & & & & & & & & & & & & & & & \\
\hline
\end{tabular}

Fig. 5.6 File data.xls - Experimental data for the Shenstone network

4. Solve the least squares problem for each sensitive node $i \in K$ :

$$
\min \left\|C_{i}^{\prime} P^{\prime}-Q_{i n}^{*}\right\|^{2},
$$

where 
$Q_{i n}^{*}=\left[\begin{array}{c}q_{i n, 1}^{*} \\ q_{i n, 2}^{*} \\ \ldots \\ q_{i n, n}^{*}\end{array}\right]$

is the vector of the measured inlet flow with dimension $n \times 1$ ( $n$ is the number of measurements in time);

$C_{i}=\left[\begin{array}{l}d \\ c_{1} \\ c_{2}\end{array}\right] \quad$ is the vector $3 \times 1$ of the coefficients of the IFM equation $q=d+c_{1} p_{i}^{0.5}+c_{2} p_{A Z N P}^{1.5}$

$P=\left[\begin{array}{ccc}1 & p_{i 1}^{0.5} & p_{\text {AZNP1 }}^{1.5} \\ 1 & p_{i 2}^{0.5} & p_{A Z N P 2}^{1.5} \\ \cdots & \cdots & \cdots \\ 1 & p_{i n}^{0.5} & p_{A Z N P n}^{1.5}\end{array}\right]$

is the matrix of the pressures with dimension $n \times 3$ ( $n$ is the number of measurements in time).

As a result the matrix of the demand and leakage coefficients is formed

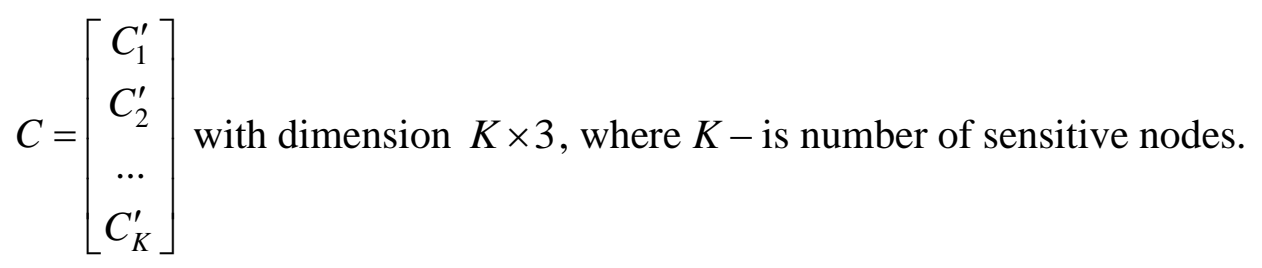

5. Choose the solution which corresponds to the sensitive node which gives the minimum value of the chi-square criterion using the following procedure. Estimated values of the inlet flow are obtained using the coefficients found in Step 4 and compared with the measured inlet flow using the $\chi^{2}$ criterion (5.5). In this way the vector $V$ of the $\chi^{2}$ values is created which can serve as a measure of how good the description of the experimental flow is compared to the estimated (theoretical) one.

The outputs of the algorithm are the values of the IFM coefficients and the resulting theoretical inlet flows and the vector $V$ of the $\chi^{2}$ criterion values.

The flowchart of the Hybrid Algorithm for burst detection is given in Fig.5.7 and programme code is given in Appendix F 


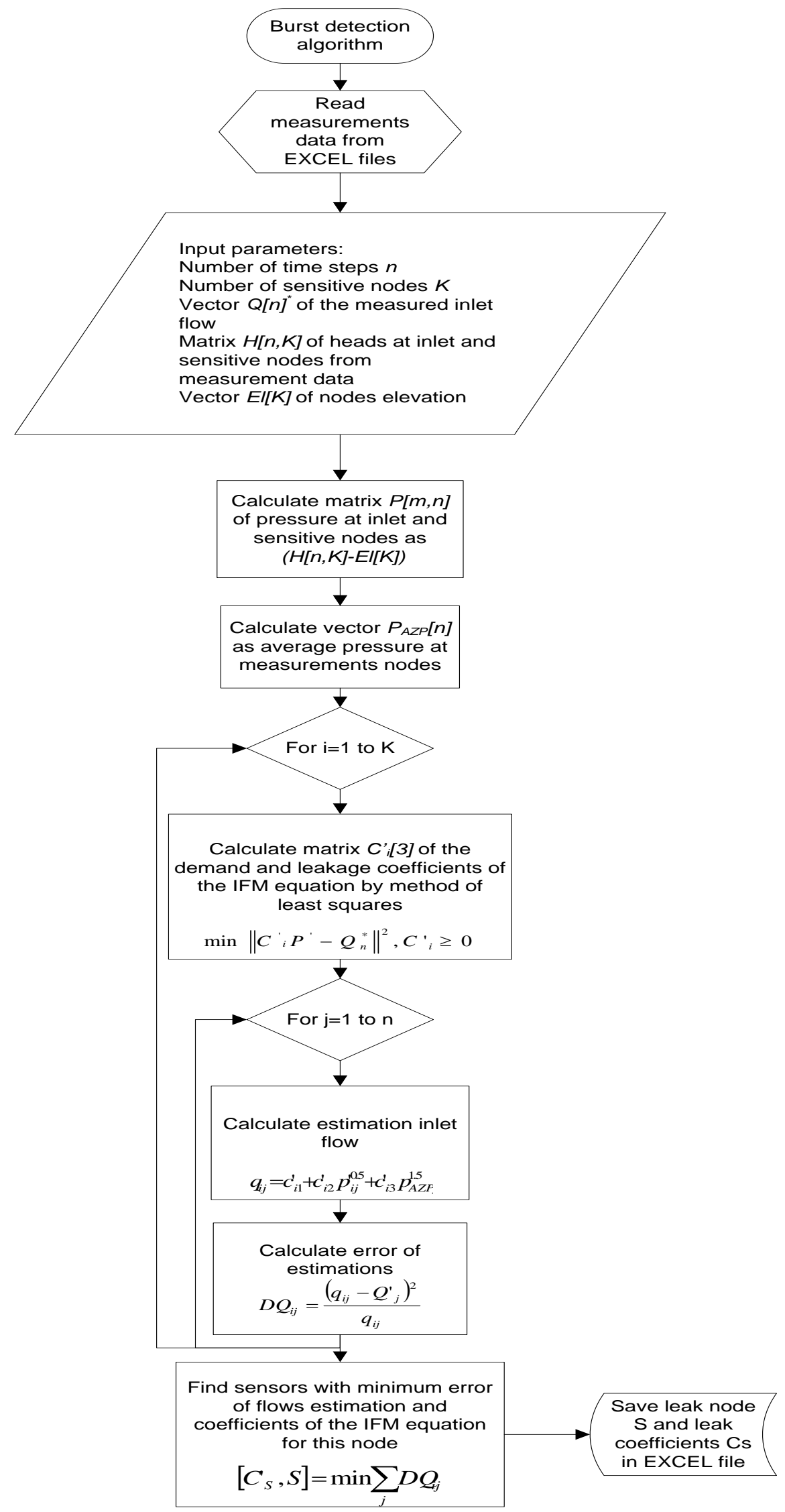

Fig. 5.7 A flowchart of a burst size estimation algorithm 


\subsubsection{Accuracy of the algorithm.}

It was observed in the experiments described in Chapter 5.1.3, that the accuracy of the estimation of the burst size is influenced by the magnitude of the flows corresponding to the IFM three terms: the demand, the fixed area flow (burst flow) and the variable area flow (background leakage flow) and also on proportions between these flows. This issue is investigated further in this chapter.

In the above consideration the terms of the IFM have been varied within the following limits:

- Total demand flow varied from 2 1/s to 4 1/s.

- The coefficient of the fixed area leakage is varied from 0.15 to $0.4 l / s / \sqrt{m}$.

- The coefficient of the variable area leakage is varied from 0 to $0.002 \mathrm{l} / \mathrm{s} / \mathrm{m} \sqrt{\mathrm{m}}$ at an individual node.

It is important to know how the algorithm would behave for other coefficient values. It is also important to investigate limiting proportions between the flow components for which the accuracy of the obtained results is satisfactory.

From the literature and from other case studies provided by Water Software Systems (De Montfort University) it has been found out, that the possible values of the demand and the leakage coefficients for different DMAs can be within the following limits:

- The total demand flow: $0.2-11$ 1/s.

- The coefficient of the fixed area leakage (burst coefficient): $0.1-1.6 l / s / \sqrt{m}$.

- The coefficient of the variable area leakage (background leakage coefficient):

$$
0.005-0.05^{l / s} / m \sqrt{m} .
$$

The Shenstone DMA (Figure 5.8) has been selected for these investigations because the model was already available in an electronic format and the network is well understood by the author. Additionally the accuracy of the results for typical values of the IFM coefficients is known and can be used as a benchmark to compare the accuracy for extreme flow values.

The network has two inlets, node 95 and node 99 and altogether comprises of 116 nodes. The E-FAVOR test is simulated using the model, inlet pressure has been changed in steps from $40.9 \mathrm{~m}$ to $65.9 \mathrm{~m}$ at Inlet 1 (node 95) and from $33.26 \mathrm{~m}$ to 58.26 
$m$ at Inlet 2 (node 99). The simulated pressure data ('measurements') are collected from 15 sensitive nodes (they are depicted in Figure 5.8 by dark blue rectangles) and the simulated inlet flow ('measurements') are collected from nodes 99 and 95.

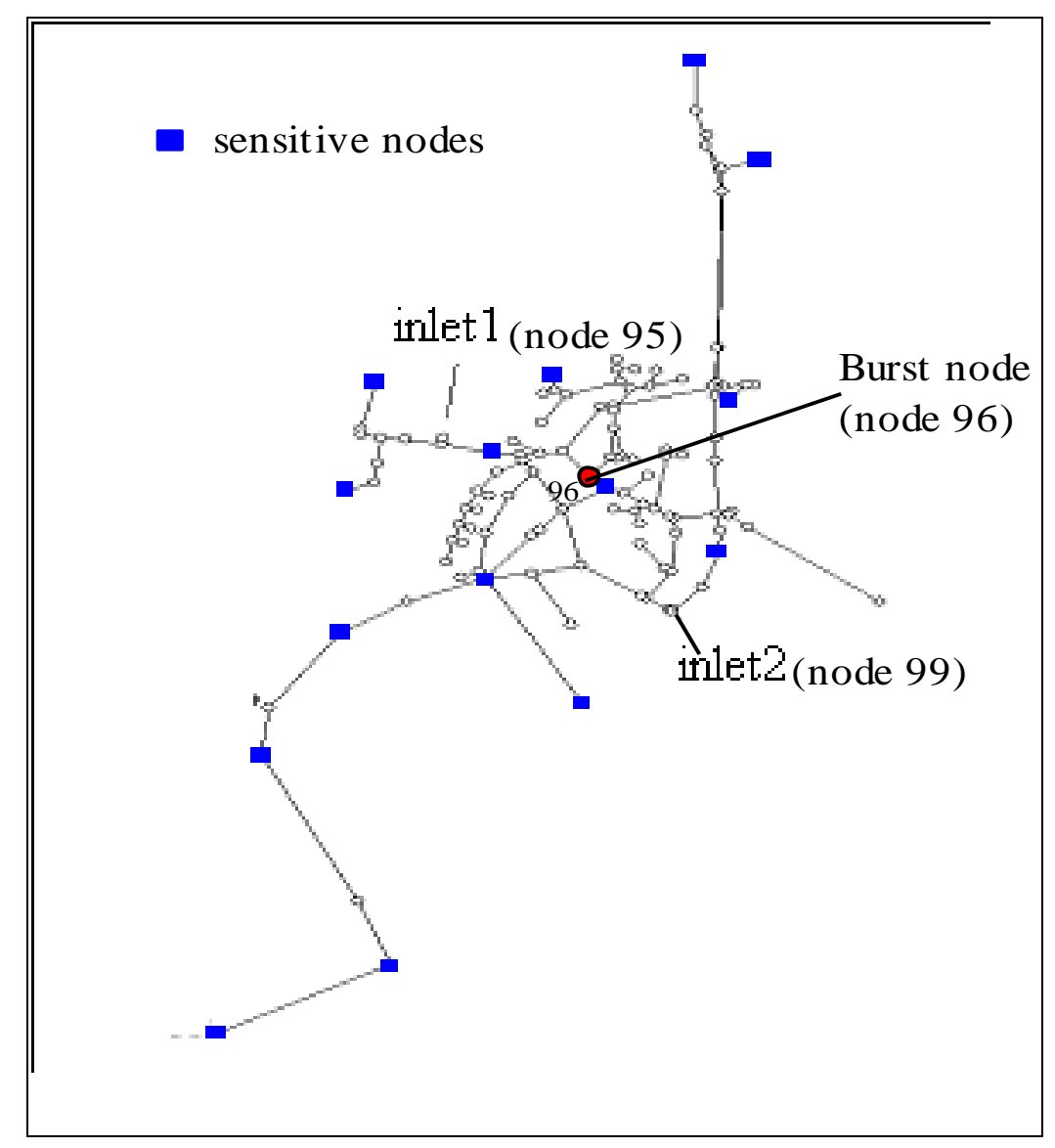

Fig. 5.8 Shenstone DMA schematic (with burst)

Node 96 is chosen as a burst node since it is equidistant from the two inlet nodes and is in the centre of the network so it should be strongly affected by the variables manipulated in the experiments.

The accuracy for this wide range of parameter values is compared to the accuracy of the method for the following average values of the parameters

- $d_{a v r}=5.5 \mathrm{l} / \mathrm{s}-$ the average value of total demand;

- $c_{1 \_a v r}=0.8-$ the average value of the burst coefficient;

- $\quad c_{2 \_a v r}=0.0229-$ the average value of the background leakage coefficient.

The inlet pressure has been changed in steps resulting in the total inlet flow change from $13 \mathrm{l} / \mathrm{s}$ to $22 \mathrm{l} / \mathrm{s}$.

Applying the developed algorithm the following estimates have been obtained:

- $d_{\text {avr }}=4.85 \mathrm{l} / \mathrm{s}$; 
- $c_{1 \_a v r}=0.9$

- $\quad c_{2 \_a v r}=0.022$

Further experiments have been carried out for different values of the parameters and the results are collected in Table 5.7.

Table 5.7 Determination of leakage coefficients

\begin{tabular}{|c|c|c|c|c|c|c|}
\hline \multicolumn{5}{|c|}{ Simulated parameters } & \multicolumn{3}{c|}{ Estimated results } \\
\hline $\begin{array}{l}\text { Total Inlet } \\
\text { Flow (1/s) }\end{array}$ & $\mathrm{d} 1 / \mathrm{s}$ & $\mathrm{c}_{1}$ & $\mathrm{c}_{2}$ & $\mathrm{~d} 1 / \mathrm{s}$ & $\mathrm{c}_{1}$ & $\mathrm{c}_{2}$ \\
\hline $17.5-28.7$ & 11 & 0.8 & 0.023 & 10.8 & 0.84 & 0.022 \\
\hline $16.0-28.6$ & 5.5 & 0.8 & 0.05 & 1.6 & 1.5 & 0.044 \\
\hline $20.0-34.0$ & 11 & 0.8 & 0.05 & 7.2 & 1.48 & 0.044 \\
\hline $21.5-36.0$ & 11 & 1.6 & 0.05 & 9.2 & 2 & 0.043 \\
\hline $1.8-2.5$ & 0.2 & 0.1 & 0.005 & 0.16 & 0.11 & 0.0049 \\
\hline $2.0-3.0$ & 0.2 & 0.15 & 0.005 & 0.11 & 0.16 & 0.0049 \\
\hline $7.0-11.0$ & 5.5 & 0.15 & 0.005 & 5.45 & 0.15 & 0.0049 \\
\hline $12.5-19$ & 11 & 0.15 & 0.005 & 11 & 0.15 & 0.005 \\
\hline $5.8-11.2$ & 0.2 & 0.15 & 0.023 & 0.005 & 0.26 & 0.02 \\
\hline $9.6-18.6$ & 0.2 & 0.15 & 0.047 & 0 & 0.34 & 0.042 \\
\hline
\end{tabular}

More experiments have been performed and they have been divided into groups where only one parameter has been varied in a group. The level of accuracy was calculated from the equation below:

$\varphi=\left(1-\frac{\sum_{n} \frac{\left|x_{m}-x_{c}\right|}{x_{m}}}{n}\right) \cdot 100 \%$

where $x_{m}$ and $x_{c}$ are the simulated parameter value and the estimated parameter value, respectively and $n$ is the number of experiments inside each group. The best accuracy corresponds to $\phi=100 \%$.

The results are presented in Figs 5.9, 5.10 and 5.11 respectively. 


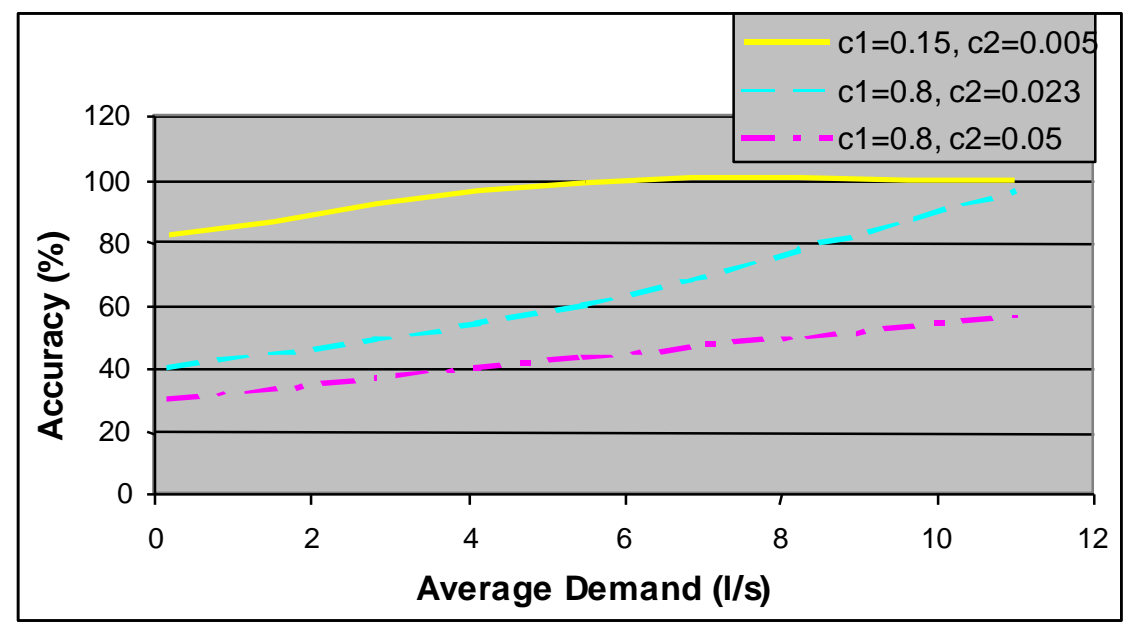

Fig. 5.9 The result's accuracy from value of Demand

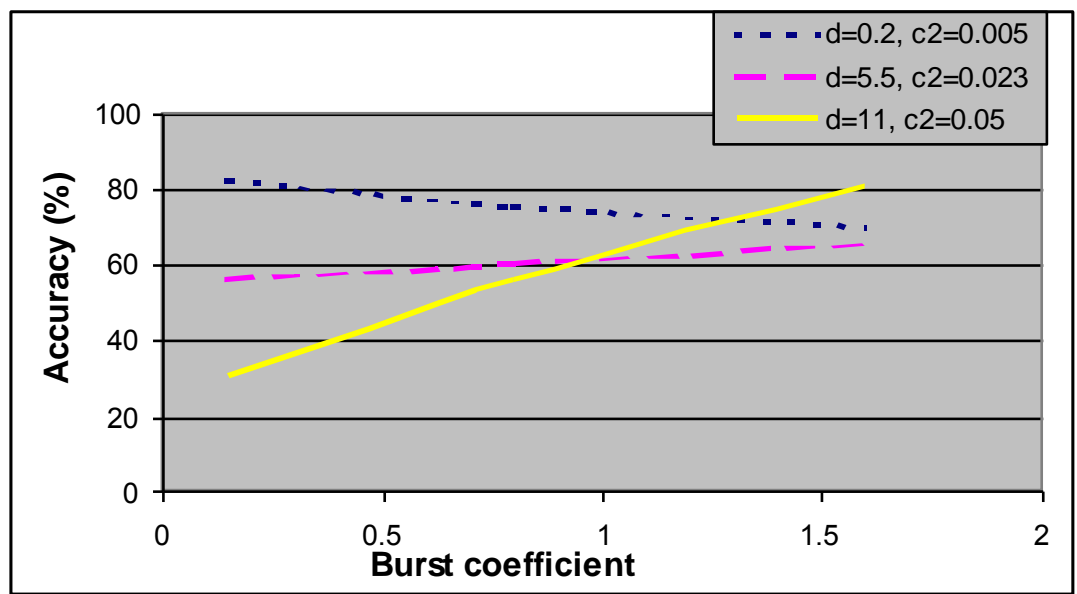

Fig. 5.10 The result's accuracy from value of the burst

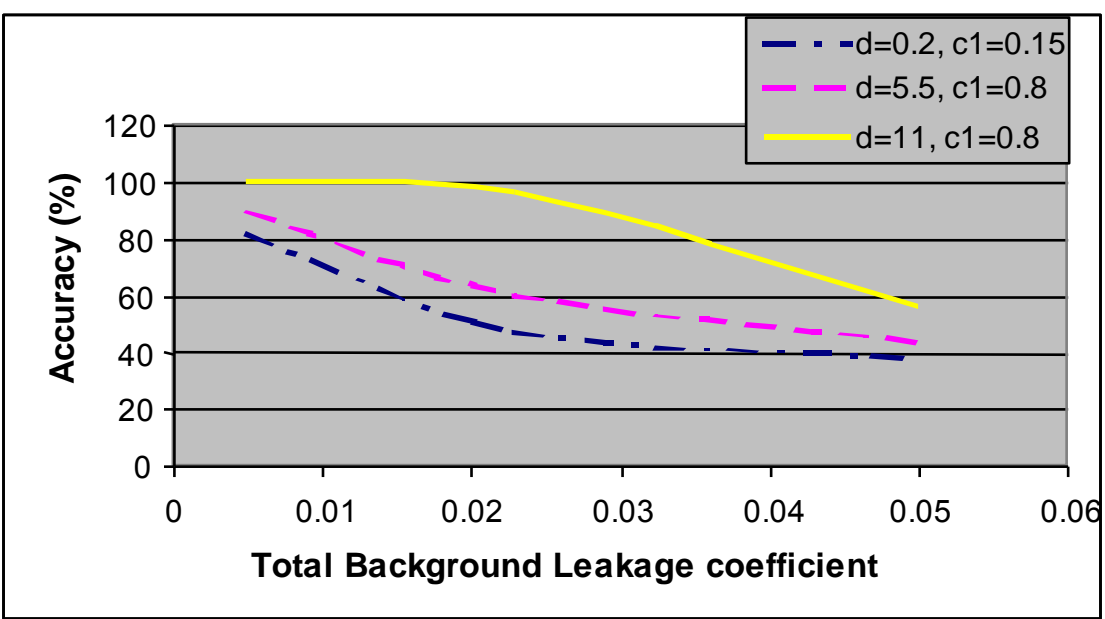

Fig. 5.11 The result's accuracy from value of the background leakage's flow

The observations from the experiments are collected below: 
1. For small values of the leakage flows an increase in the demand improves the accuracy of the algorithm as shown in Fig. 5.9. For bigger values of the leakage flows an increase in the demand has also a positive effect on accuracy. In both cases the improvement in accuracy is moderate and stays slightly above $80 \%$.

2. The leakage flows depend on pressure through different exponents, 0.5 for a burst and 1.5 for the background leakage respectively. The burst coefficient is estimated with higher accuracy for bigger burst flows as can be observed in Fig. 5.10. The opposite can be observed for the background leakage coefficient where the accuracy gets lower for bigger background leakage coefficients as illustrated in Figure 5.11.

3. Ratios between the terms in the IFM also influence the accuracy of the coefficient estimates. For small values of the background leakage the accuracy of the algorithm is high enough (> $80 \%$ ) and depends only on the ratio between the demand and the burst terms. An increase in the demand causes an increase of the estimation accuracy for the background leakage coefficient. The increase in the value of the background leakage coefficient with the two terms remaining constant reduces the estimation accuracy.

From the numerous experiments where the values of coefficients were within the limits $0.2-11 \mathrm{l} / \mathrm{s}$ for total demand flow, $0.1-1.6^{l / s} / \sqrt{m}$ for burst coefficient and $0.005-0.05^{l / s} / m \sqrt{m}$ for background leakage coefficient, it is observed that the estimation of a burst is effective if the burst is sufficiently big in comparison with the background leakage flow:

Variable area flow (background leakage) $\leq \frac{1}{2}$ fixed area flow (burst leakage).

\subsubsection{Summary}

The following conclusions can be made resulting from the carried out research:

- The least squares method has been used to calculate the coefficients of the IFM, where the Average Zone Night Pressure has been substituted in the background 
leakage term, and the pressure at a sensitive node was used to represent the burst term.

- A burst was provisionally allocated to different sensitive nodes and the solution was selected which gives the minimum value of the chi-square criterion applied to the total inlet flow. This is the essence of the hybrid method of burst detection algorithm.

- The hybrid method helps to determine accurate values of the IFM parameters, the total demand and fixed and variable area leakage terms using the recorded data of the inlet pressure and flow and pressure at the sensitive nodes of a network.

- The accuracy of the results of determining the burst size and the burst location is influenced by the magnitude of the three flows (demand, fixed area flow and variable area flow) and by the proportions between them.

\subsection{Effects of a burst on pressure in a DMA}

The hybrid method of determination of burst size was based on studying flow changes in a DMA caused by the fixed area and the variable area leakage. However, the flow changes in a DMA cause a redistribution of pressure at nodes of the network. This may provide a good signature for the identification of the burst location. The remainder of this chapter is dedicated to develop this idea.

\subsubsection{Influence of burst presence to pressure change in a network.}

A DMA consists mainly of pipes, a head-loss along a pipe is:

$\Delta h=R q^{B}$,

where $\Delta h$ is the head-loss, $q$ is the flow rate, $R$ is the resistance coefficient, and $B$ is flow exponent. In the Hazen-Williams formula the exponent $B=1.852$ and subsequently $\Delta h=R q^{1.852}$ 
It has been demonstrated before that the inlet flow can be separated into the three components: the total average demand $d$, the fixed area flow $q=c_{1} p^{0.5}$ and the variable area flow $q=c_{2} p_{\text {AZNP }}^{1.5}$.

In the absence of the demand and the leakage flows the pressure in the network is distributed uniformly and $\Delta h=0$ for any pipe. When the demand only is present, the pressure drop along a pipe is pressure independent and for a constant demand is constant $\Delta h=f(d)$. This should be true when performing the e-FAVOR test for such a network. Let's use the Ocker Hill which has one inlet for simulation experiments.

The inlet head (node 165) has been changed linearly from $156 \mathrm{~m}$ up to $191 \mathrm{~m}$ (which corresponds to the change in pressure from $18.5 \mathrm{~m}$ up to $53.5 \mathrm{~m}$ ) and the demand $d$ is set to $1 \mathrm{l} / \mathrm{s}$. The corresponding values of pressures at all nodes of the network have been recorded and are depicted in Table 5.8.

Table 5.8 Pressure at nodes of the network (without burst)

\begin{tabular}{|c|c|c|c|c|c|c|c|c|}
\hline \multirow{2}{*}{$\begin{array}{c}\text { Node } \\
\text { number }\end{array}$} & \multicolumn{7}{|c|}{ Measurement number $(\mathrm{n})$} & \multirow{2}{*}{$\Delta p(n=1)-p(n=176)$} \\
\hline & 1 & 2 & 3 & $\ldots$ & 174 & 175 & 176 & 35 \\
\hline 2 & 18.50 & 18.70 & 18.90 & $\ldots$ & 53.10 & 53.30 & 53.50 & 35 \\
\hline 2 & 19.89 & 20.09 & 20.29 & $\ldots$ & 54.49 & 54.69 & 54.89 & 35 \\
\hline 3 & 18.50 & 18.70 & 18.90 & $\ldots$ & 53.10 & 53.30 & 53.50 & 35 \\
\hline 4 & 18.50 & 18.70 & 18.90 & $\ldots$ & 53.10 & 53.30 & 53.50 & 35 \\
\hline 5 & 18.50 & 18.70 & 18.90 & $\ldots$ & 53.10 & 53.30 & 53.50 & 35 \\
\hline 6 & 16.99 & 17.19 & 17.39 & $\ldots$ & 51.59 & 51.79 & 51.99 & 35 \\
\hline 7 & 15.97 & 16.17 & 16.37 & $\ldots$ & 50.57 & 50.77 & 50.97 & 35 \\
\hline 8 & 15.46 & 15.66 & 15.86 & $\ldots$ & 50.06 & 50.26 & 50.46 & 35 \\
\hline 9 & 15.95 & 16.15 & 16.35 & $\ldots$ & 50.55 & 50.75 & 50.95 & 35 \\
\hline 10 & 15.95 & 16.15 & 16.35 & $\ldots$ & 50.55 & 50.75 & 50.95 & $\ldots$ \\
\hline$\ldots$ & $\ldots$ & $\ldots$ & $\ldots$ & $\ldots$ & $\ldots$ & $\ldots$ & $\ldots$ & 35 \\
\hline 75 & 21.69 & 21.89 & 22.09 & $\ldots$ & 56.29 & 56.49 & 56.69 & 35 \\
\hline 76 & 19.39 & 19.59 & 19.79 & $\ldots$ & 53.99 & 54.19 & 54.39 & 35 \\
\hline 77 & 20.05 & 20.25 & 20.45 & $\ldots$ & 54.65 & 54.85 & 55.05 & $\ldots$ \\
\hline$\ldots$ & $\ldots$ & $\ldots$ & $\ldots$ & $\ldots$ & $\ldots$ & $\ldots$ & $\ldots$ & 35 \\
\hline 165 & 18.50 & 18.70 & 18.90 & $\ldots$ & 53.1 & 53.3 & 53.5 & \\
\hline
\end{tabular}

The pressure at each node of the network increases linearly with the increase of the inlet pressure, and this can be seen in Figure 5.12. 


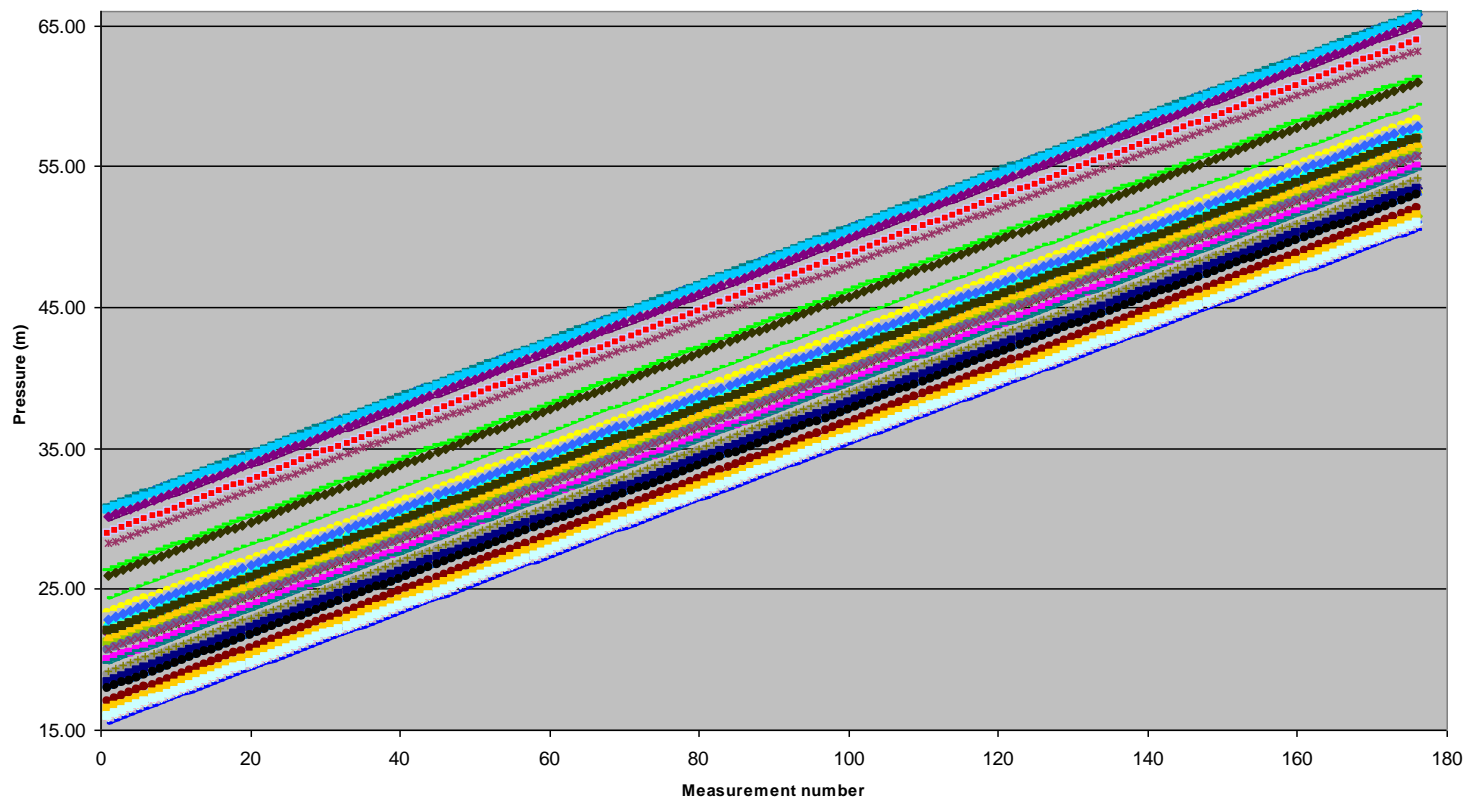

Fig. 5.12 Diagram of pressure change at nodes of the network (without burst)

If a burst is present in the network, the pressure at the burst node drops and the burst flow depends on the pressure and the size of the break in the pipe.

In the numerical experiments the inlet head (node 165) has been varied from $156 \mathrm{~m}$ up to $191 \mathrm{~m}$ (that corresponds to a change of pressure from $18.5 \mathrm{~m}$ up to $53.5 \mathrm{~m}$ ), the average total demand is $11 / \mathrm{s}$ and the burst at node 76 has the burst coefficient $c l=0.9$. By means of simulation the pressure values at all nodes of the network have been calculated and are presented in Table 5.9. 
Table 5.9 Pressure at nodes of the network (with burst)

\begin{tabular}{|c|c|c|c|c|c|c|c|c|}
\hline \multirow{2}{*}{$\begin{array}{c}\text { Node } \\
\text { number }\end{array}$} & \multicolumn{7}{|c|}{ Measurement number $(t)$} & \multirow{2}{*}{$\Delta p(t=1)-p(t=176)$} \\
\hline 1 & 18.49 & 18.69 & 18.89 & $\ldots$ & 53.07 & 53.27 & 53.47 & 34.98 \\
\hline 2 & 18.26 & 18.45 & 18.63 & $\ldots$ & 50.74 & 50.93 & 51.12 & 32.86 \\
\hline 3 & 18.49 & 18.69 & 18.89 & $\ldots$ & 53.09 & 53.29 & 53.49 & 34.99 \\
\hline 4 & 18.49 & 18.69 & 18.89 & $\ldots$ & 53.07 & 53.27 & 53.47 & 34.98 \\
\hline 5 & 18.49 & 18.69 & 18.88 & $\ldots$ & 53.07 & 53.27 & 53.47 & 34.98 \\
\hline 6 & 16.76 & 16.96 & 17.16 & $\ldots$ & 51.08 & 51.27 & 51.47 & 34.71 \\
\hline 7 & 15.48 & 15.67 & 15.87 & $\ldots$ & 49.43 & 49.63 & 49.83 & 34.35 \\
\hline 8 & 14.76 & 14.95 & 15.15 & $\ldots$ & 48.45 & 48.65 & 48.84 & 34.08 \\
\hline 9 & 15.19 & 15.38 & 15.58 & $\ldots$ & 48.79 & 48.98 & 49.18 & 33.99 \\
\hline 10 & 15.16 & 15.36 & 15.55 & $\ldots$ & 48.74 & 48.93 & 49.12 & 33.96 \\
\hline$\ldots$ & $\ldots$ & $\ldots$ & $\ldots$ & $\ldots$ & $\ldots$ & $\ldots$ & $\ldots$ & $\ldots$ \\
\hline 75 & 18.72 & 18.89 & 19.07 & $\ldots$ & 49.16 & 49.34 & 49.51 & 30.79 \\
\hline 76 & 16.09 & 16.27 & 16.44 & $\ldots$ & 46.01 & 46.18 & 46.36 & 30.26 \\
\hline 77 & 16.96 & 17.13 & 17.30 & $\ldots$ & 47.21 & 47.39 & 47.56 & 30.61 \\
\hline$\ldots$ & $\ldots$ & $\ldots$ & $\ldots$ & $\ldots$ & $\ldots$ & $\ldots$ & $\ldots$ & $\ldots$ \\
\hline 165 & 18.50 & 18.70 & 18.90 & $\ldots$ & 53.1 & 53.3 & 53.5 & 35 \\
\hline
\end{tabular}

Now, the pressure at the burst node and the nearby nodes follows a different law than the pressure at the inlet node and remaining nodes. A general diagram of pressure changes at all the nodes of the network is given in Figure 5.13 below.

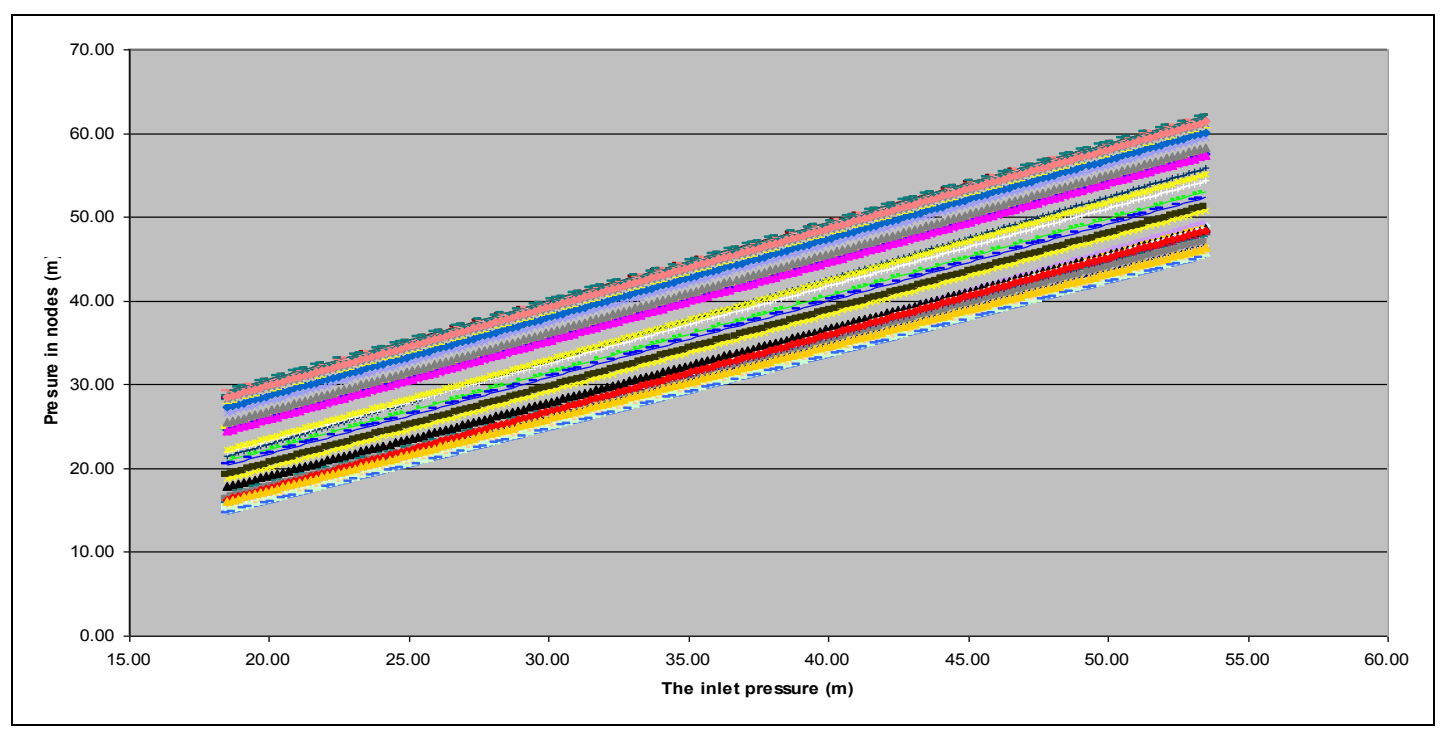

Fig. 5.13 Diagram of pressure change in the network nodes (with burst)

The diagram suggests that the pressure changes at the nodes can be approximated by straight lines. Let's consider these changes in more detail for some selected nodes. The following the network nodes have been chosen for inspection: node 3 which is adjacent to the actual input node (node 165), node 76 which is the burst node, node 75 which is 
in immediate proximity to the burst, node 62 which is on the same branch as the burst and nodes 93 and 28 which are in other parts of the network (Figure 5.14).

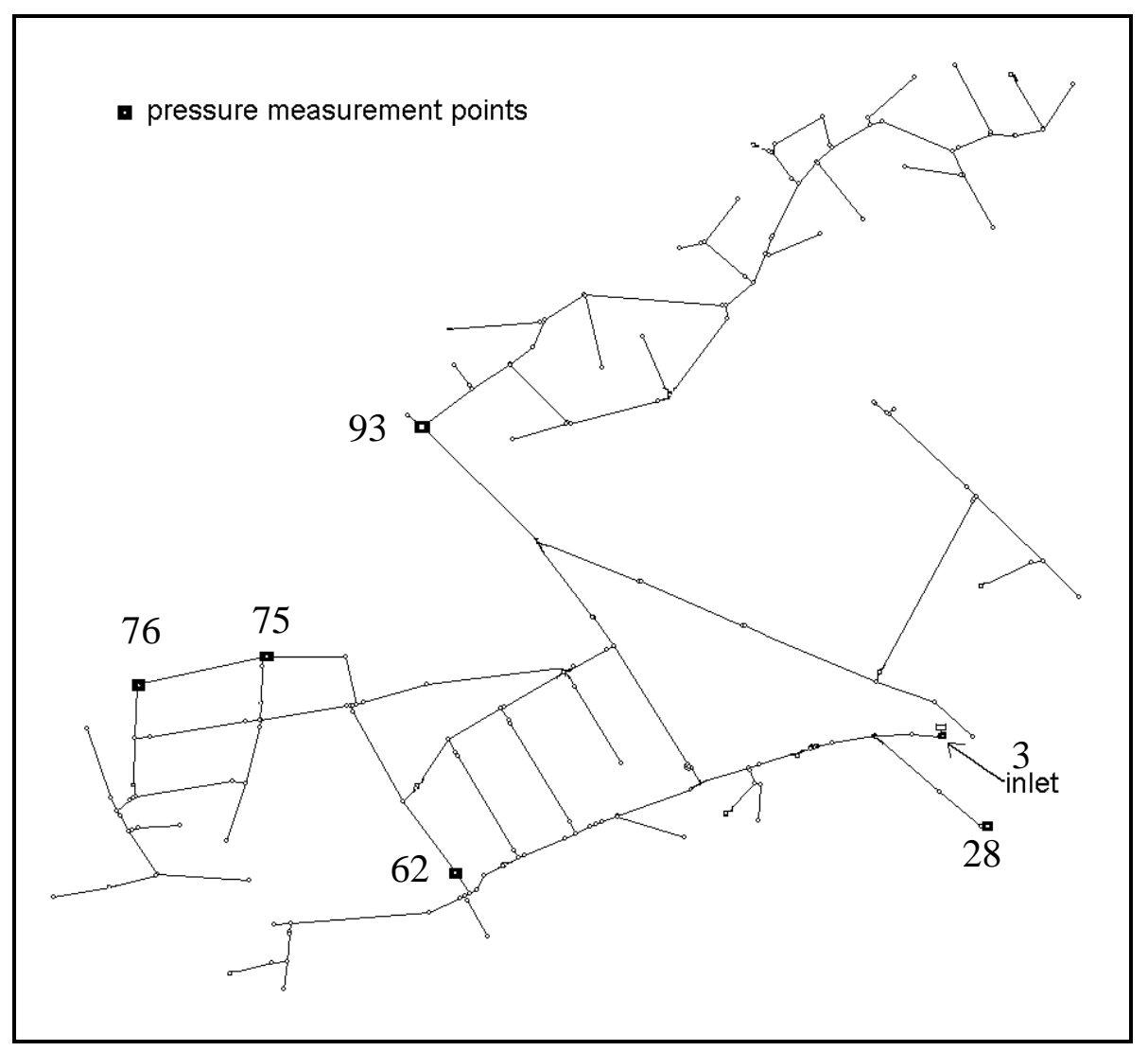

Fig. 5.14 Ocker Hill DMA schematic (pressure measurement points)

The pressure changes at the selected nodes are illustrated Figure 5.15.

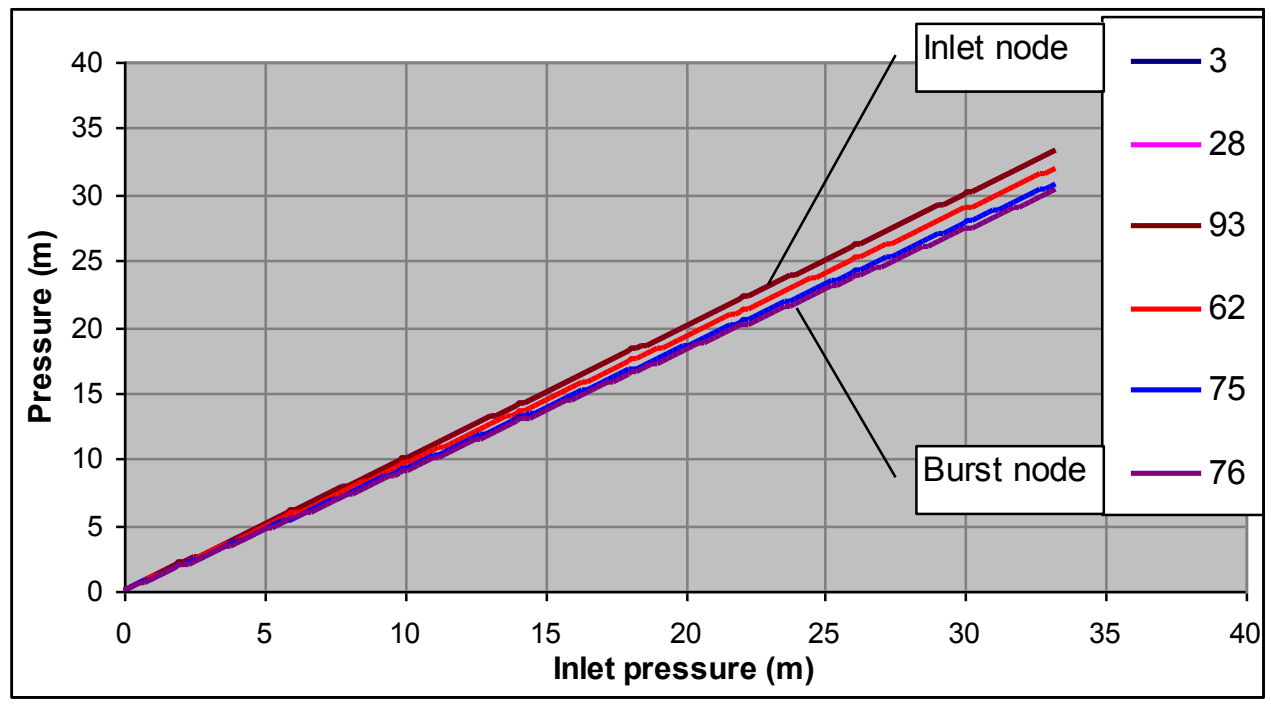

Fig. 5.15 Diagram of pressure change in the network nodes 
In the diagram (Figure 5.15) differences between the gradients of the pressure lines for different nodes are quite evident. The smallest gradient is observed for the straight line representing the burst node. Also the nodes 75 and 62 which are close to the burst node have small gradients. For the remaining nodes 93 and 28 the pressure line approximation completely coincides with the pressure line approximation for the inlet node 3 (node 3 is directly connected with PRV OUTLET at node 165), which indicates that these nodes are not affected by the burst.

If a small background leakage, with the background leakage coefficient equal to 0.015 , is added the general picture does not change qualitatively as is shown in Figure 5.16, the order in the gradient values is the same as previously with the smallest gradient for the burst node and the biggest gradient for the inlet node.

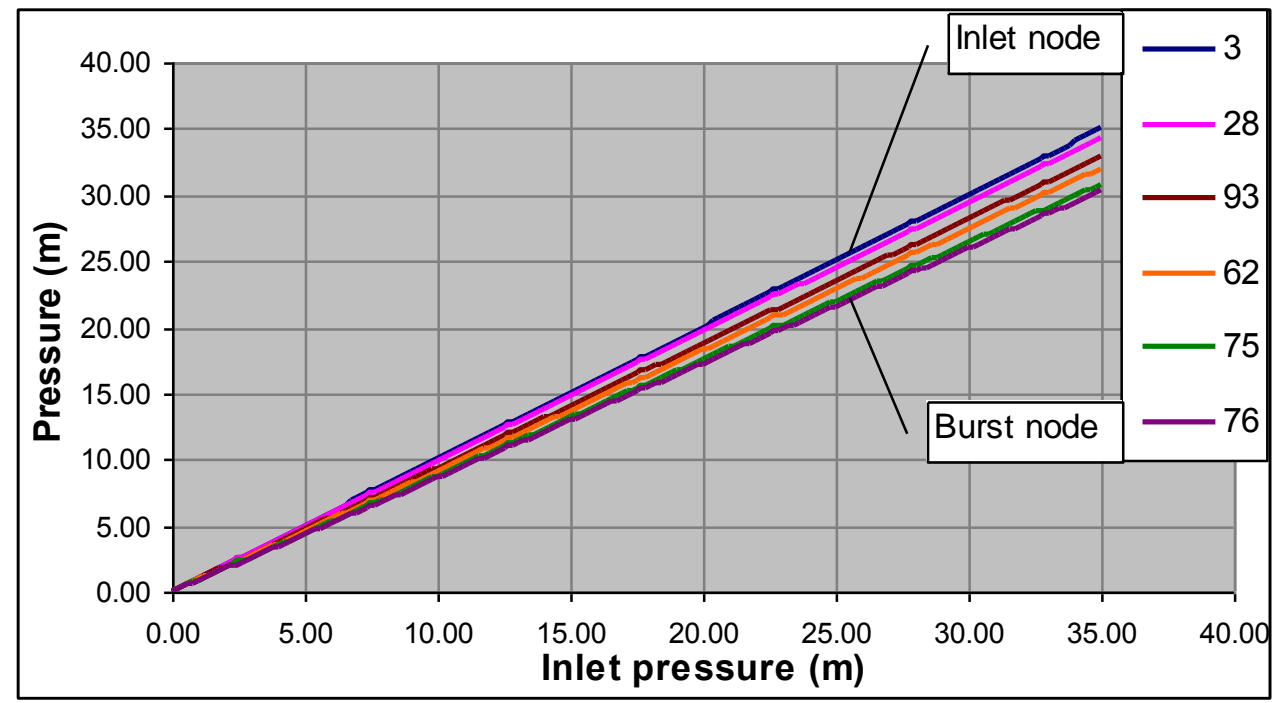

Fig. 5.16 Diagram of pressure change in the network nodes

The gradient values of the pressure approximation lines for all the nodes apart from the inlet node have been reduced but the order between the lines remained the same. The observation can be made that the gradient of the pressure approximation lines can be used to identify the burst location and that the presence of small background leakage does not invalidate this hypothesis. Further experiments have been performed which are not described in this report which independently have confirmed that by analysing the pressure lines it is possible to identify a burst location in a network. 


\subsubsection{The burst area location.}

At the burst node the pressure changes with smaller steps compared to other nodes and potentially by measuring the pressure at all nodes it would be possible to find the burst node. In reality during a field experiment it is impossible to $\log$ all the nodes in a network for economical and technical reasons and only selected nodes can be monitored. A natural question arises as to whether it is possible to identify a burst location by investigating the pressure patterns at the sensitive nodes (Chapter 5.1.1).

Numerical experiments have been performed on the Shenstone DMA with the following set up: a hydraulic network model available in Matlab is used, the head at Inlet 1 (node 95) has been stepped from $135 \mathrm{~m}$ up to $160 \mathrm{~m}$ and at Inlet 2 (node 99) has been stepped from $134 \mathrm{~m}$ up to $159 \mathrm{~m}$, the total demand flow was $3 \mathrm{l} / \mathrm{s}$, the total coefficient of the background leakage is 0.0024 .

The demand is distributed among nodes of the network according to the number of properties (houses) allocated to each node and the background leakage is distributed in a similar way. The results from the simulation program have been the pressure values at the sensitive nodes: $18,91,42,3,114,115,81,88,108,62,67,38,75,35,29$, and the values of inlet flows.

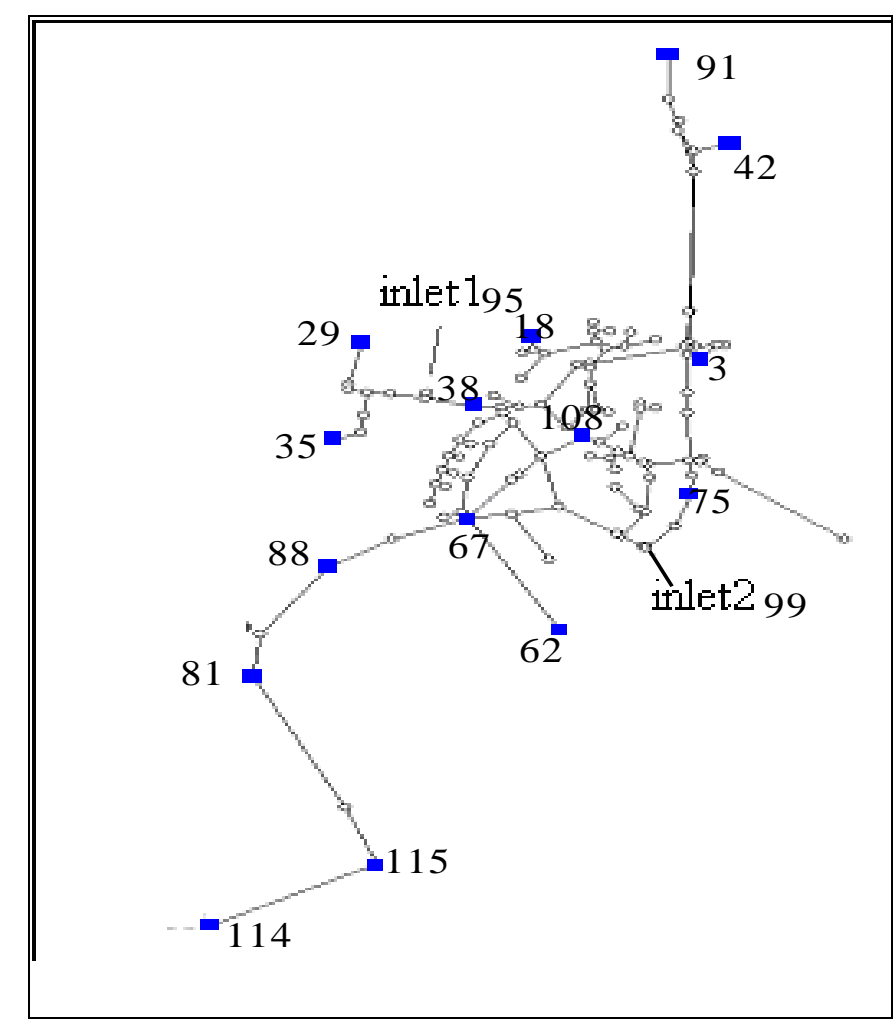

Fig. 5.17 The Shenstone DMA schematic 
The simulation results have been entered as input data to the program of the burst size determination, based on the Hybrid Algorithm described in Chapter 5.1.4 and the following values are calculated:

- total demand

- burst coefficient

- total coefficient of the background leakage 0.002412 .

The following equation is used for approximating the pressure changes at each sensitive node:

$p=a+b p_{\text {inlet }}$

where

$p \quad$ pressure at a sensitive node

a constant coefficient of the regression line

$b \quad$ gradient of the regression line

$p_{\text {inlet }} \quad$ inlet pressure

The regression coefficients have been found by the least squares method to minimise deviations of the approximating straight line from the experimental data:

$U=\sum_{i=1}^{N}\left[p_{i}-\left(a+b p_{\text {inlet } \__{-}}\right)\right]^{2}=\min$, where $N$ is number of measurements.

Equating the respective partial derivatives to zero and simplifying gives

$\frac{d U}{d a}=\sum_{i=1}^{N}\left[p_{i}-\left(a+b p_{\text {inlet_i }_{-}}\right)\right]=0$

$\frac{d U}{d b}=\sum_{i=1}^{N}\left[\left\{p_{i}-\left(a+b p_{\text {inlet_}_{-}}\right)\right\} p_{\text {inlet_i }_{-}}\right]=0$

which leads to a system of simultaneous linear equations with respect to $a$ and $b$ :

$$
\begin{aligned}
& a N+b \sum_{i=1}^{N} p_{\text {inlet_ } i}=\sum_{i=1}^{N} p_{i} \\
& a \sum_{i=1}^{N} p_{\text {inlet_ } i}+b \sum_{i=1}^{N} p_{\text {inlet_ } i}^{2}=\sum_{i=1}^{N} p_{i} p_{\text {inlet_ } i},
\end{aligned}
$$

The equations can be solved analytically as:

$a=\frac{1}{N}\left(\sum_{i=1}^{N} p_{i}-b \sum_{i=1}^{N} p_{\text {inlet_}_{-} i}\right)$ 


$$
b=\frac{\sum_{i=1}^{N} p_{\text {inlet } \__{-} i} \sum_{i=1}^{N} p_{i}-N \sum_{i=1}^{N} p_{i} p_{\text {inlet }-i}}{\left(\sum_{i=1}^{N} p_{\text {inlet } \_} i\right)^{2}-N \sum_{i=1}^{N} p_{\text {inlet_ } i}^{2}}
$$

Applying these formulae to the simulated data the following coefficients shown in Table 5.10 are obtained.

Table 5.10 The values of coefficients

\begin{tabular}{|c|c|c|}
\hline $\begin{array}{c}\text { Node } \\
\text { number }\end{array}$ & $a$ & $b$ \\
\hline 95 & 0 & 1.0000 \\
\hline 99 & -7.64 & 1.0000 \\
\hline 18 & -0.62394 & 0.9922 \\
\hline 91 & -3.85902 & 0.9930 \\
\hline 42 & -3.80134 & 0.9925 \\
\hline 3 & 2.183803 & 0.9925 \\
\hline 114 & -13.3392 & 0.9929 \\
\hline 115 & -12.7394 & 0.9929 \\
\hline 81 & -7.01928 & 0.9929 \\
\hline 88 & -8.73966 & 0.9929 \\
\hline 108 & -13.8839 & 0.9932 \\
\hline 62 & -4.84889 & 0.9933 \\
\hline 67 & -5.30837 & 0.9933 \\
\hline 38 & -2.78493 & 0.9965 \\
\hline 75 & -6.18396 & 0.9965 \\
\hline 35 & -2.22599 & 0.9994 \\
\hline 29 & -1.62653 & 0.9994 \\
\hline
\end{tabular}

The gradients of the lines corresponding to the sensitive nodes are within the limits from 0.99 to 1 and are very close one to another. This confirms the first part of the hypothesis that the background leakage has little influence on the pressure at the sensitive nodes.

In order to verify the second part of the hypothesis, the numerical experiment is repeated for the same network model, with the same values of the inlet heads and demands. The background leakage is removed from the model and a burst is introduced at node 52 with burst coefficient $c_{1}=0.4$ as shown in Figure 5.18. 


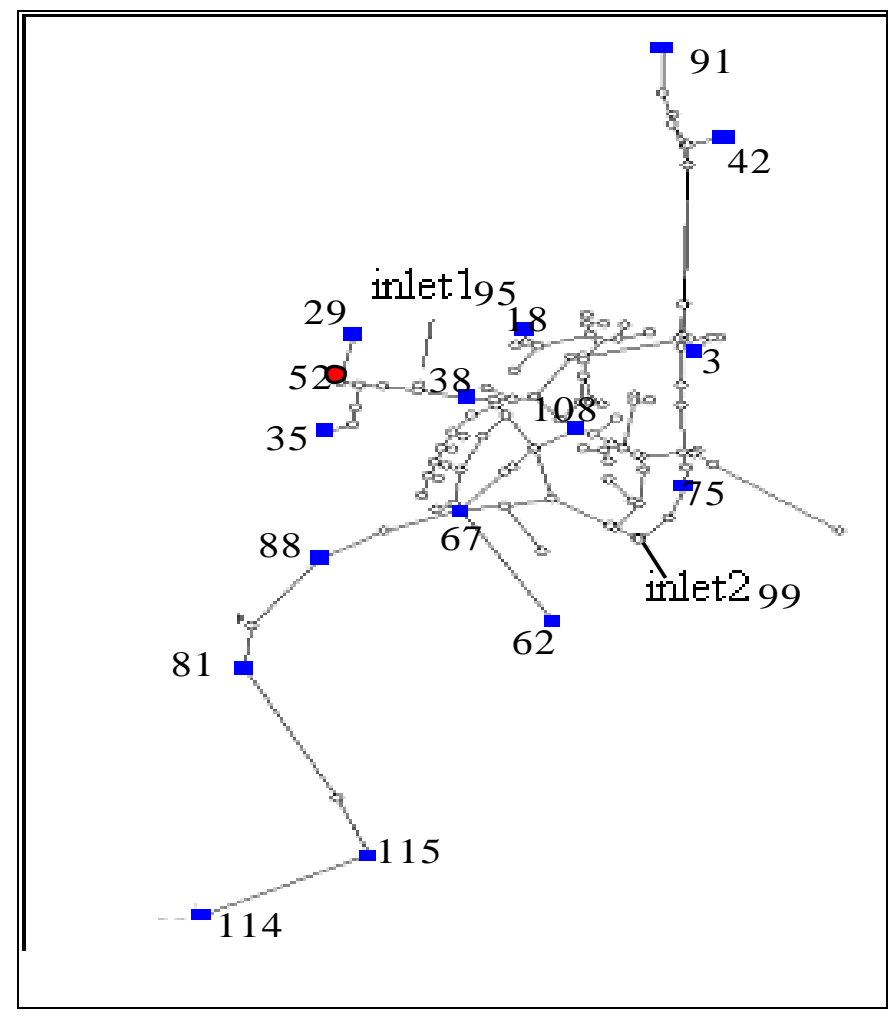

Fig. 5.18 The Shenstone DMA schematic (with burst)

Repeating the calculations has yielded the following $a$ and $b$ coefficients presented in Table 5.11.

Table 5.11 Received coefficients of regression lines

\begin{tabular}{|c|c|c|}
\hline $\begin{array}{c}\text { The number } \\
\text { of node }\end{array}$ & $a$ & $b$ \\
\hline 95 & 0 & 1.0000 \\
\hline 99 & -7.64 & 1.0000 \\
\hline 18 & -0.66244 & 0.9994 \\
\hline 91 & -3.91534 & 0.9999 \\
\hline 42 & -3.86885 & 0.9997 \\
\hline 3 & 2.118069 & 0.9997 \\
\hline 114 & -13.3933 & 0.9994 \\
\hline 115 & -12.7933 & 0.9994 \\
\hline 81 & -7.07294 & 0.9994 \\
\hline 88 & -8.79272 & 0.9994 \\
\hline 108 & -13.93 & 0.9995 \\
\hline 62 & -4.89169 & 0.9994 \\
\hline 67 & -5.35134 & 0.9994 \\
\hline 38 & -2.83102 & 0.9985 \\
\hline 75 & -6.222 & 0.9999 \\
\hline 35 & -2.34588 & 0.9820 \\
\hline 29 & -1.77288 & 0.9720 \\
\hline
\end{tabular}


It can be seen from Table 5.11, that the smallest gradient of the pressure line $b=0.97$ is observed at node 29 which is in the immediate proximity of the burst. Presence of the burst has also a significant impact on node $35(b=0.98)$, which is located in the same branch as the burst node. The burst has lesser impact on other nodes with the gradient values of about $b=0.999$. It confirms the second part of the hypothesis that the gradients of the pressure line at sensitive nodes can be used to identify the area with the burst.

The following observations can be made:

- Presence of a burst in a network affects the gradient of regression lines approximating the pressure changes at sensitive nodes which are close to the burst

- It is possible to identify the burst area by analysis of the regression lines

- Small background leakage in a network doesn't change the order between the regression lines.

A weak point of the hypothesis is an assumption about the small background leakage. For example, a background leakage concentrated in one particular area can lead to erroneous determination of the burst site. Further numerical investigations have been performed to answer this question. The Shenstone and the Ocker Hill DMA models have been used for the experiments and different values of demand, burst and background leakage have been simulated.

Some results of the experiments are given in Tables 5.12 and 5.13 below, where Burst area denotes sensitive nodes located near the burst. The estimated values of the gradients of the estimated sensitive nodes are highlighted in yellow. 
Table 5.12 Ocker Hill DMA calculated results.

\begin{tabular}{|c|c|c|c|c|c|c|}
\hline Parameter & Set values & $\begin{array}{l}\text { Estimated } \\
\text { values }\end{array}$ & \multicolumn{4}{|c|}{$\begin{array}{l}\text { Sensitive nodes and estimated values o } \\
\qquad \mathrm{b}\end{array}$} \\
\hline \multirow{2}{*}{\multicolumn{2}{|c|}{ burst node 59}} & & 98 & 0.87753 & 112 & 0.89546 \\
\hline & & & 57 & 0.88002 & 151 & 0.89593 \\
\hline \multirow{2}{*}{$d(l / s)$} & \multirow[t]{2}{*}{4} & \multirow[t]{2}{*}{3.9892} & 72 & 0.88223 & 127 & 0.89624 \\
\hline & & & 45 & 0.88232 & 91 & 0.89700 \\
\hline$c_{1}$ & 0.5 & 0.50865 & 74 & 0.88245 & 31 & 0.90762 \\
\hline \multirow[t]{2}{*}{$c_{2}$} & \multirow[t]{2}{*}{0.006525} & \multirow[t]{2}{*}{0.006444} & 37 & 0.88272 & 51 & 0.92618 \\
\hline & & & 33 & 0.89247 & 14 & 0.95076 \\
\hline \multirow{3}{*}{ Burst area } & \multirow{3}{*}{$57,98,37$} & \multirow{3}{*}{$\begin{array}{l}98,57,72 \\
45,74,37\end{array}$} & 162 & 0.89522 & 13 & 0.96887 \\
\hline & & & 140 & 0.89526 & 165 & 1.00000 \\
\hline & & & 116 & 0.89537 & & \\
\hline \multirow{2}{*}{\multicolumn{2}{|c|}{ burst node 141}} & & 162 & 0.81 & 98 & 0.84 \\
\hline & & & 140 & 0.81 & 37 & 0.84 \\
\hline \multirow{2}{*}{$d(l / s)$} & \multirow{2}{*}{3} & \multirow{2}{*}{2.422476} & 116 & 0.81 & 57 & 0.85 \\
\hline & & & 112 & 0.81 & 33 & 0.85 \\
\hline$c_{1}$ & 0.37 & 0.419613 & 151 & 0.82 & 31 & 0.86 \\
\hline \multirow{2}{*}{$c_{2}$} & \multirow{2}{*}{0.01613} & \multirow{2}{*}{0.015762} & 127 & 0.82 & 51 & 0.89 \\
\hline & & & 91 & 0.82 & 14 & 0.92 \\
\hline \multirow{3}{*}{ Burst area } & \multirow{3}{*}{$\begin{array}{l}140,162 \\
116,112\end{array}$} & \multirow{3}{*}{$\begin{array}{l}162,140 \\
116,112\end{array}$} & 72 & 0.84 & 13 & 0.95 \\
\hline & & & 45 & 0.84 & 165 & 1.00 \\
\hline & & & 74 & 0.84 & & \\
\hline
\end{tabular}


Table 5.13 The Shenstone DMA calculated results.

\begin{tabular}{|c|c|c|c|c|c|c|}
\hline Parameter & Set values & Estimated & \multicolumn{4}{|c|}{ Sensitive nodes and estimated values of $b$} \\
\hline \multirow{2}{*}{\multicolumn{2}{|c|}{ burst node 67}} & \multirow[b]{3}{*}{1.99} & 114 & 0.983 & 3 & 0.988 \\
\hline & & & 115 & 0.983 & 91 & 0.988 \\
\hline$d(l / s)$ & 2 & & 81 & 0.983 & 38 & 0.993 \\
\hline \multirow[b]{2}{*}{$c_{1}$} & \multirow{2}{*}{0.2} & \multirow{2}{*}{0.2} & 88 & 0.983 & 75 & 0.994 \\
\hline & & & 62 & 0.983 & 35 & 0.999 \\
\hline$c_{2}$ & 0.00239 & 0.00238 & 67 & 0.983 & 29 & 0.999 \\
\hline \multirow{3}{*}{ Burst area } & \multirow{3}{*}{$67,62,88$} & \multirow{3}{*}{$\begin{array}{c}114,115,81 \\
88,62,67\end{array}$} & 108 & 0.987 & 95 & 1.000 \\
\hline & & & 18 & 0.987 & 99 & 1.000 \\
\hline & & & 42 & 0.988 & & \\
\hline \multirow{2}{*}{\multicolumn{2}{|c|}{ burst node 80}} & & 18 & 0.979 & 67 & 0.982 \\
\hline & & & 42 & 0.980 & 91 & 0.982 \\
\hline$d(l / s)$ & 4 & 3.975 & 3 & 0.980 & 38 & 0.989 \\
\hline \multirow{2}{*}{$c_{1}$} & \multirow{2}{*}{0.24} & \multirow{2}{*}{0.24} & 108 & 0.981 & 75 & 0.991 \\
\hline & & & 114 & 0.982 & 35 & 0.999 \\
\hline \multirow[t]{2}{*}{$c_{2}$} & 0.002216 & 0.002193 & 115 & 0.982 & 29 & 0.999 \\
\hline & \multirow{3}{*}{108,38} & \multirow{3}{*}{$\begin{array}{c}18,42,3 \\
108\end{array}$} & 81 & 0.982 & 95 & 1.000 \\
\hline \multirow{2}{*}{ Burst area } & & & 88 & 0.982 & 99 & 1.000 \\
\hline & & & 62 & 0.982 & & \\
\hline \multirow{2}{*}{\multicolumn{2}{|c|}{ burst node 96}} & & 18 & 0.987 & 62 & 0.990 \\
\hline & & & 42 & 0.988 & 67 & 0.990 \\
\hline$d(l / s)$ & 0.2 & 0.11 & 3 & 0.988 & 38 & 0.994 \\
\hline \multirow{2}{*}{$c_{1}$} & \multirow{2}{*}{0.15} & \multirow{2}{*}{0.159} & 108 & 0.989 & 75 & 0.995 \\
\hline & & & 91 & 0.990 & 29 & 0.999 \\
\hline \multirow[t]{2}{*}{$c_{2}$} & 0.005 & 0.0049 & 114 & 0.990 & 35 & 0.999 \\
\hline & & 18.42 .3 & 115 & 0.990 & 95 & 1.000 \\
\hline Burst area & 108 & $18,42,3$ & 81 & 0.990 & 99 & 1.000 \\
\hline Durse area & & 108 & 88 & 0.990 & & \\
\hline burst & de 96 & & 42 & 0.834 & 62 & 0.874 \\
\hline & & & 3 & 0.836 & 67 & 0.875 \\
\hline$d(l / s)$ & 0.2 & 0.05 & 18 & 0.843 & 75 & 0.926 \\
\hline & 0.15 & 0.26 & 91 & 0.861 & 38 & 0.934 \\
\hline$c_{1}$ & 0.15 & 0.20 & 108 & 0.866 & 35 & 0.989 \\
\hline$c_{2}$ & 0.023 & 0.0215 & 114 & 0.871 & 29 & 0.989 \\
\hline & & $42 \quad 3.18 \quad 91$ & 115 & 0.871 & 95 & 1.000 \\
\hline Burst area & 108 & $42,3,18,91$ & 81 & 0.871 & 99 & 1.000 \\
\hline & & 108 & 88 & 0.871 & & \\
\hline
\end{tabular}




\begin{tabular}{|c|c|c|c|c|c|c|}
\hline Parameter & Set values & Estimated & \multicolumn{4}{|c|}{ Sensitive nodes and estimated values of $b$} \\
\hline \multirow{2}{*}{\multicolumn{2}{|c|}{ burst node 96}} & \multirow[b]{3}{*}{0} & 42 & 0.65 & 62 & 0.72 \\
\hline & & & 3 & 0.66 & 67 & 0.72 \\
\hline$d(l / s)$ & 0.2 & & 18 & 0.67 & 38 & 0.85 \\
\hline \multirow[b]{2}{*}{$c_{1}$} & \multirow[b]{2}{*}{0.15} & \multirow{2}{*}{0.34} & 114 & 0.70 & 75 & 0.85 \\
\hline & & & 115 & 0.70 & 29 & 0.96 \\
\hline \multirow[t]{2}{*}{$c_{2}$} & \multirow{2}{*}{0.04666} & \multirow{2}{*}{0.0419} & 81 & 0.70 & 35 & 0.96 \\
\hline & & & 88 & 0.70 & 95 & 1.00 \\
\hline \multirow{2}{*}{ Burst area } & \multirow{2}{*}{108} & \multirow{2}{*}{$42,3,18$} & 108 & 0.71 & 99 & 1.00 \\
\hline & & & 91 & 0.72 & & \\
\hline \multirow{2}{*}{\multicolumn{2}{|c|}{ burst node 96}} & & 18 & 0.96 & 62 & 0.97 \\
\hline & & & 42 & 0.96 & 67 & 0.97 \\
\hline$d(l / s)$ & 5.5 & 5.45 & 3 & 0.96 & 75 & 0.98 \\
\hline \multirow{2}{*}{$c_{1}$} & \multirow{2}{*}{0.15} & \multirow{2}{*}{0.15} & 108 & 0.96 & 38 & 0.98 \\
\hline & & & 91 & 0.96 & 35 & 1.00 \\
\hline$c_{2}$ & 0.005 & 0.00496 & 114 & 0.97 & 29 & 1.00 \\
\hline \multirow{3}{*}{ Burst area } & \multirow{3}{*}{108} & \multirow{3}{*}{$\begin{array}{c}18,42,3 \\
108,91\end{array}$} & 115 & 0.97 & 95 & 1.00 \\
\hline & & & 81 & 0.97 & 99 & 1.00 \\
\hline & & & 88 & 0.97 & & \\
\hline \multirow{2}{*}{\multicolumn{2}{|c|}{ burst node 96}} & & 18 & 0.94 & 62 & 0.95 \\
\hline & & & 42 & 0.94 & 67 & 0.95 \\
\hline$d(l / s)$ & 11 & 10.95 & 3 & 0.94 & 75 & 0.97 \\
\hline \multirow{2}{*}{$c_{1}$} & \multirow{2}{*}{0.15} & \multirow{2}{*}{0.15} & 108 & 0.94 & 38 & 0.97 \\
\hline & & & 91 & 0.95 & 35 & 1.00 \\
\hline \multirow[t]{2}{*}{$c_{2}$} & 0.005 & 0.00494 & 114 & 0.95 & 29 & 1.00 \\
\hline & & & 115 & 0.95 & 95 & 1.00 \\
\hline Burst area & 108 & 18,4 & 81 & 0.95 & 99 & 1.00 \\
\hline & & 108 & 88 & 0.95 & & \\
\hline burst & ode 98 & & 91 & 0.979 & 62 & 0.984 \\
\hline & & & 3 & 0.979 & 67 & 0.984 \\
\hline$d(l / s)$ & 3.8 & 10.95 & 42 & 0.979 & 75 & 0.989 \\
\hline$c_{1}$ & 0.2 & 0.15 & 18 & 0.981 & 38 & 0.992 \\
\hline & & & 108 & 0.982 & 35 & 0.999 \\
\hline$c_{2}$ & 0.0024 & 0.00494 & 114 & 0.984 & 29 & 0.999 \\
\hline & & & 115 & 0.984 & 95 & 1.000 \\
\hline Burst area & 108 & $91,3,42,18$ & 81 & 0.984 & 99 & 1.000 \\
\hline & & 108 & 88 & 0.984 & & \\
\hline
\end{tabular}

The performed experiments have confirmed that by investigating the pressure changes at the sensitive nodes it is possible to define an approximate area of the burst. The background leakage affects the gradients of the regression lines at the sensitive nodes but does not lead to erroneous identification of the burst area. It has been also observed 
that the accuracy of burst area identification depends on the topology of a network. The Ocker Hill DMA (Figure 5.19) has a branch topology, where the root is represented by the inlet and the water arrives at an extreme node along a unique path. In this case the accuracy of burst area identification depends on the number of loggers in a branch. The identification results are normally quite accurate for such a topology.

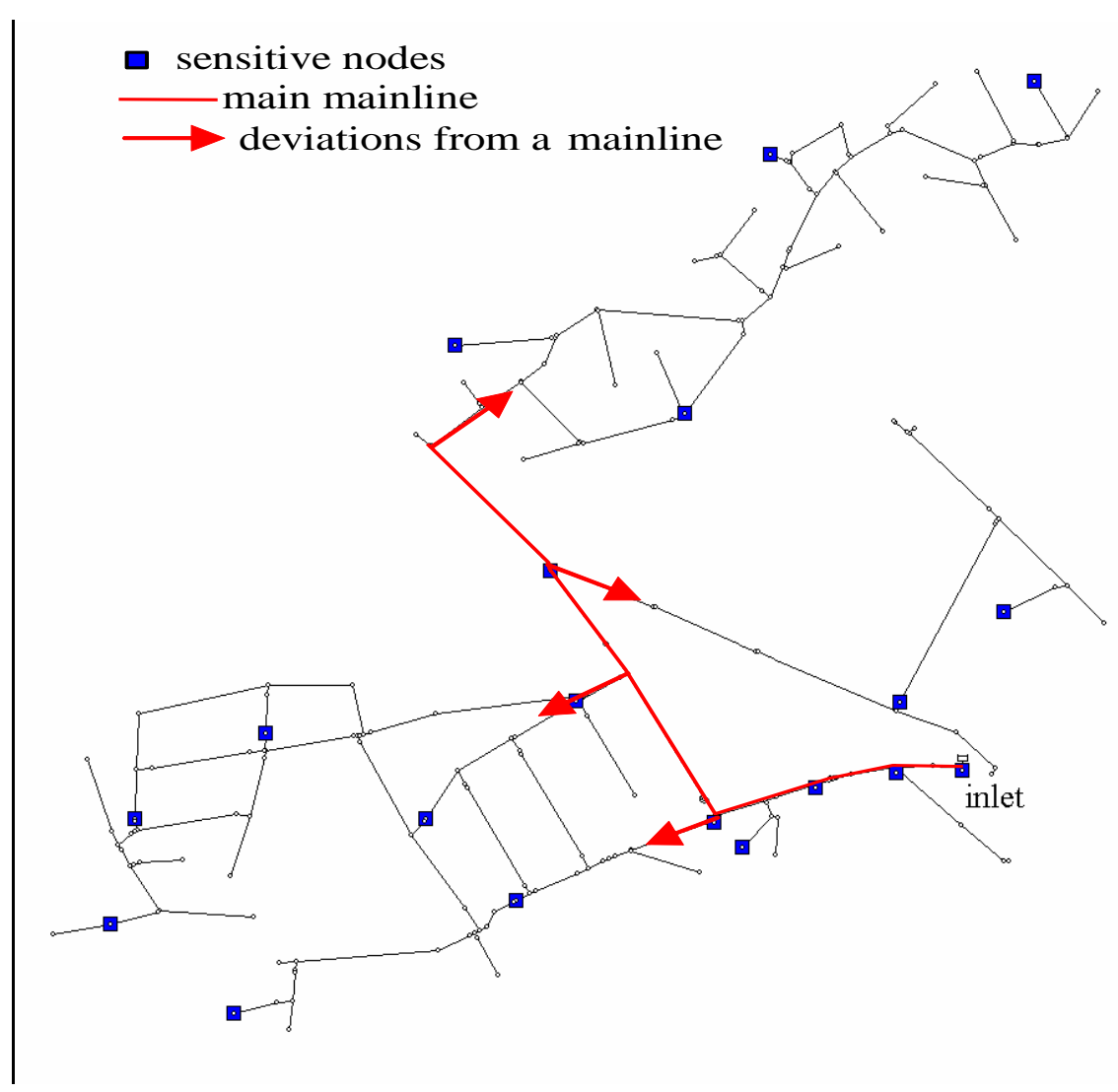

Fig. 5.19 The Ocker Hill DMA schematic

The Shenstone DMA has two inlet nodes in the network and each node is affected by both inlets which complicates the identification of the burst area. If the burst is located in the middle of the network, the burst area which is found tends to be quite big.

\subsubsection{Summary}

So the following conclusions have been made: 
- The pressure at DMA nodes depends on the inlet pressure. The gradient of a pressure line, a plot of the pressure at a node versus the inlet pressure, is smallest for the burst node or a node close to the burst node.

- By investigating the pressure changes at the sensitive nodes it is possible to define an approximate area of the burst.

- The background leakage affects the gradients of the regression lines at the sensitive nodes but does not lead to erroneous identification of the burst area. It has been also observed that the accuracy of burst area identification depends on the topology of a network.

\subsection{Algorithm for the burst location identification}

The results shown in the previous Chapter 5.2 are satisfactory but for identification of burst locations with higher precision further research is required which is presented in this chapter. Two lines of investigation are possible, a deterministic approach or a statistical analysis. The decision about the choice of the approach depends on the nature of the input data available. The following data are considered to be available for the burst location identification:

- model of a network

- inlet pressure which is stepped during the field experiment

- inlet flow

- list of sensitive nodes

- pressure measurements at the sensitive nodes

- the total average demand, the burst coefficient and the total background leakage coefficient which are calculated using the hybrid method for burst detection described in Chapter 5.1.4.

- gradients of the regression pressure lines for the sensitive nodes.

The availability of the input data is limited by the scope of the field test and by the number and accuracy of the available loggers. In this situation application of deterministic methods is unrealistic and statistical methods have been employed in this research. 


\subsubsection{Application of statistical analysis.}

Statistical methods calculate parameters of models to achieve the best match of the theoretical results and the physical processes.

First the discussion about the influence of bursts on pressure change at the sensitive nodes will be revisited. In Chapter 5.2.2 it was discovered that the regression line (approximating the pressure changes) with the minimum gradient indicates a burst in an immediate proximity. The burst affects also the pressure in nearby and hydraulically dependent nodes. Remote nodes are less affected by the burst and the gradient of the regression line is bigger and closer to 1 . If the burst location is changed it will affect the pressure distribution in the whole network although to a different degree. This observation is supported by the results discussed in Chapter 5.1.3 where it was demonstrated that moving a burst location changes the total inlet flow and also in Chapter 5.2.2 where the burst location method was discussed.

There are different sources of errors in the identification of burst locations, some are introduced at the stage of determining the IMF coefficients and some are introduced by measurement errors of the pressure at the sensitive nodes. In such a situation use of statistical methods is required. The main idea is to perform the pressure stepping field experiment and record the pressure changes at the sensitive nodes. A similar experiment is performed on the simulation model using data evaluated earlier; the demand, the background leakage flow and the burst flow. The burst is allocated to different nodes of the simulation model and the theoretical gradient of the pressure line at each sensitive node is compared with the measured gradient. The comparison is done with the help of the chi-square criterion

The precise formulation of the algorithm is given below:

1. A hydraulic model of the network is prepared.

2. The field experiment is carried out. It is enough to apply three different inlet pressure values to approximate the gradient of a pressure line.

3. The hydraulic model is updated. The total demand and the total background leakage, earlier calculated with the hybrid method, are distributed according to the number of consumers at each node. 
4. The burst, with the size which was calculated earlier by the hybrid method, is allocated alternately at each node of the network and the scenario is simulated.

5. Matrices of pressure changes at the sensitive nodes for each burst site are formed.

6. Gradients of the pressure lines at the sensitive nodes for each burst site are calculated.

7. The theoretical gradients of pressure lines are compared with the measured gradients at the sensitive nodes by applying the $\chi^{2}$ criterion. A vector which contains $\chi^{2}$ values for each theoretical burst site is constructed. The minimum value of $\chi^{2}$ points to the burst site.

The flowchart of the algorithm is given in Fig.5.20 and programme code is given in Appendix F. 


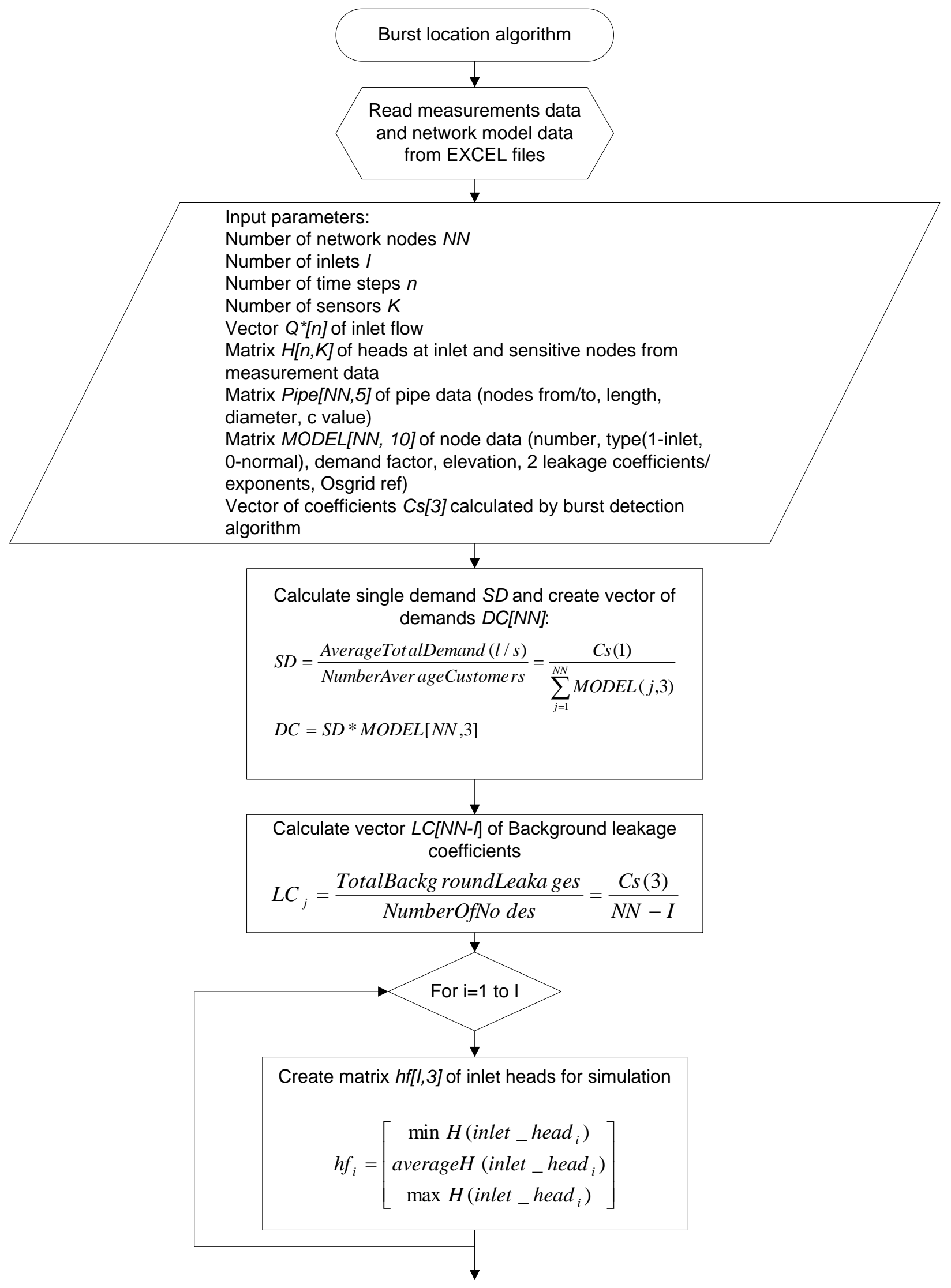




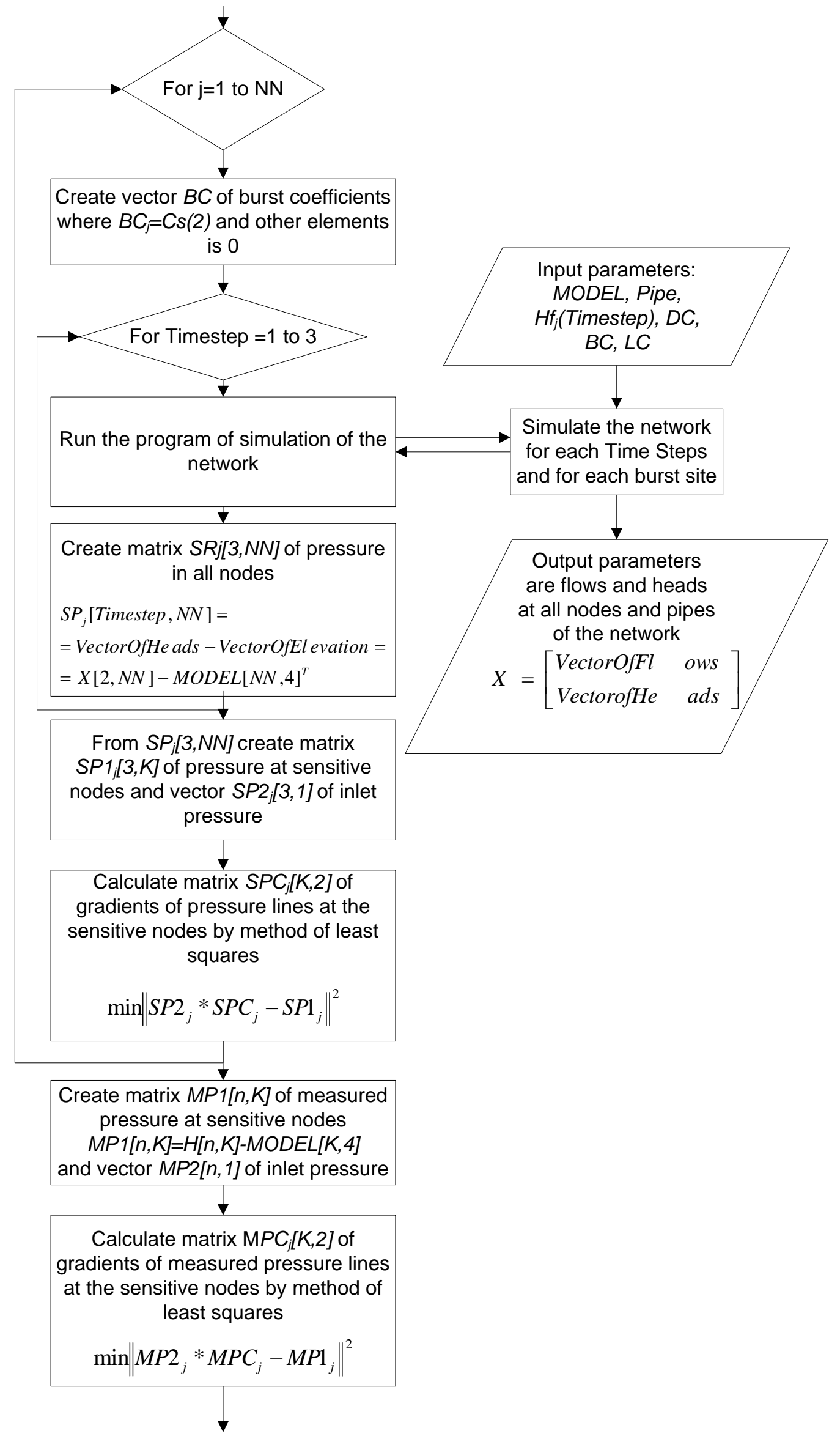




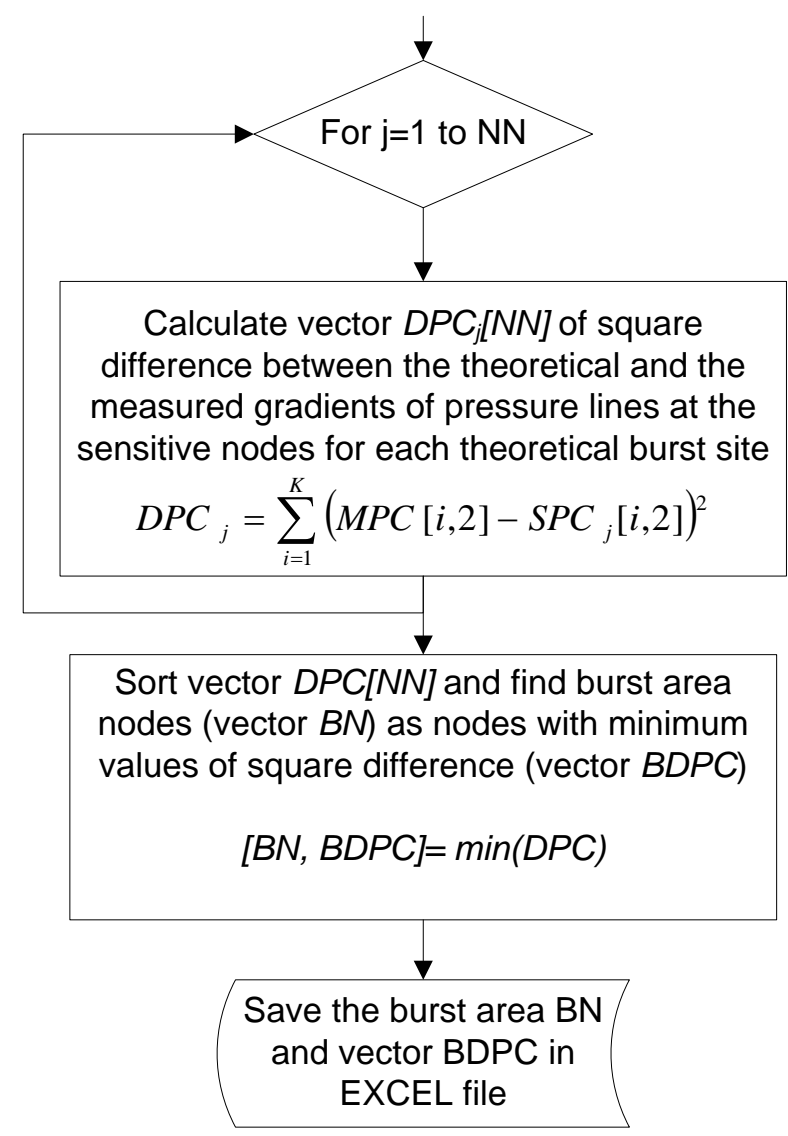

Fig. 5.20 A flowchart for burst location identification

The output from this algorithm is a set of network nodes at which a burst is most likely. The algorithm has been validated on the already considered case studies of the Shenstone and Ocker Hill DMAs shown in Figures 5.17 and 5.19.

The selected results of the experiments are given in Tables 5.14 and 5.15 below. For the Ocker Hill DMA model the inlet head (node 165) has been varied from $156 \mathrm{~m}$ to $191 \mathrm{~m}$ (which corresponds to the pressure changes from $18.5 \mathrm{~m}$ to $53.5 \mathrm{~m}$ ). For the Shenstone DMAs water network model the inlet head has been varied from $135 \mathrm{~m}$ to $160 \mathrm{~m}$ at Inlet 1 (node 95) and from $134 m$ to $159 m$ at Inlet 2 (node 99). 
Table 5.14 Ocker Hill DMA burst location results

\begin{tabular}{|c|c|c|c|}
\hline Parameter & Set values & \multicolumn{2}{|c|}{ Obtained results } \\
\hline \multirow{7}{*}{ burst node } & \multirow{7}{*}{59} & Node & The value of $\chi^{2}$ \\
\hline & & 57 & $2.66 \mathrm{E}-05$ \\
\hline & & 58 & $2.82 \mathrm{E}-05$ \\
\hline & & 55 & $3.27 \mathrm{E}-05$ \\
\hline & & 56 & 3.39E-05 \\
\hline & & 59 & $3.58 \mathrm{E}-05$ \\
\hline & & 88 & 4.17E-05 \\
\hline$d(l / s)$ & 4 & \multicolumn{2}{|r|}{3.9892} \\
\hline$c_{1}$ & 0.5 & \multicolumn{2}{|r|}{0.50865} \\
\hline$c_{2}$ & 0.006525 & \multicolumn{2}{|c|}{0.006444} \\
\hline \multirow{8}{*}{ burst node } & \multirow{8}{*}{141} & Node & $\begin{array}{c}\text { The value of } \\
\chi^{2}\end{array}$ \\
\hline & & 141 & $8.74 \mathrm{E}-05$ \\
\hline & & 140 & $8.77 \mathrm{E}-05$ \\
\hline & & 146 & $8.81 \mathrm{E}-05$ \\
\hline & & 147 & 8.92E-05 \\
\hline & & 139 & 8.92E-05 \\
\hline & & 144 & $8.93 \mathrm{E}-05$ \\
\hline & & 154 & $8.93 \mathrm{E}-05$ \\
\hline$d(l / s)$ & 3 & \multicolumn{2}{|r|}{2.422476} \\
\hline$c_{1}$ & 0.37 & \multicolumn{2}{|c|}{0.419613} \\
\hline$c_{2}$ & 0.01613 & \multicolumn{2}{|c|}{0.015762} \\
\hline
\end{tabular}

Table 5.15 Shenstone DMA burst location results

\begin{tabular}{|c|c|c|c|}
\hline Parameter & Set values & \multicolumn{2}{|c|}{ Obtained results } \\
\hline \multirow{6}{*}{ burst node } & \multirow{6}{*}{67} & Node & $\begin{array}{c}\text { The value of } \\
\chi^{2}\end{array}$ \\
\hline & & 67 & 8.44E-07 \\
\hline & & 63 & $8.49 \mathrm{E}-07$ \\
\hline & & 51 & $8.65 \mathrm{E}-07$ \\
\hline & & 56 & $1.86 \mathrm{E}-06$ \\
\hline & & 61 & 4.69E-06 \\
\hline$d(l / s)$ & 2 & \multicolumn{2}{|r|}{1.99} \\
\hline$c_{1}$ & 0.2 & \multicolumn{2}{|r|}{0.2} \\
\hline$c_{2}$ & 0.00239 & \multicolumn{2}{|c|}{0.00238} \\
\hline
\end{tabular}




\begin{tabular}{|c|c|c|c|}
\hline Parameter & Set values & \multicolumn{2}{|c|}{ Obtained results } \\
\hline \multirow{5}{*}{ burst node } & \multirow{5}{*}{80} & Node & $\begin{array}{c}\text { The value of } \\
\chi^{2}\end{array}$ \\
\hline & & 80 & $2.26 \mathrm{E}-06$ \\
\hline & & 69 & 7.20E-06 \\
\hline & & 33 & $8.27 \mathrm{E}-06$ \\
\hline & & 54 & $2.67 \mathrm{E}-05$ \\
\hline$d(l / s)$ & 4 & \multicolumn{2}{|r|}{3.975} \\
\hline$c_{1}$ & 0.24 & \multicolumn{2}{|r|}{0.24} \\
\hline$c_{2}$ & 0.002216 & \multicolumn{2}{|c|}{0.002193} \\
\hline \multirow{8}{*}{ burst node } & \multirow{8}{*}{96} & Node & $\begin{array}{c}\text { The value of } \\
\chi^{2}\end{array}$ \\
\hline & & 96 & $4.18 \mathrm{E}-06$ \\
\hline & & 108 & $5.42 \mathrm{E}-06$ \\
\hline & & 80 & $1.44 \mathrm{E}-05$ \\
\hline & & 86 & $2.57 \mathrm{E}-05$ \\
\hline & & 112 & $2.67 \mathrm{E}-05$ \\
\hline & & 33 & 2.74E-05 \\
\hline & & 69 & $3.04 \mathrm{E}-05$ \\
\hline$d(l / s)$ & 0.2 & \multicolumn{2}{|r|}{0.11} \\
\hline$c_{1}$ & 0.15 & \multicolumn{2}{|r|}{0.159} \\
\hline$c_{2}$ & 0.005 & \multicolumn{2}{|r|}{0.0049} \\
\hline \multirow{8}{*}{ burst node } & \multirow{8}{*}{96} & Node & $\begin{array}{c}\text { The value of } \\
\chi^{2}\end{array}$ \\
\hline & & 107 & $2.87 \mathrm{E}-03$ \\
\hline & & 108 & $2.96 \mathrm{E}-03$ \\
\hline & & 96 & $2.98 \mathrm{E}-03$ \\
\hline & & 97 & $2.98 \mathrm{E}-03$ \\
\hline & & 93 & $3.01 \mathrm{E}-03$ \\
\hline & & 72 & 3.03E-03 \\
\hline & & 61 & $3.06 \mathrm{E}-03$ \\
\hline$d(l / s)$ & 0.2 & \multicolumn{2}{|r|}{0} \\
\hline$c_{1}$ & 0.15 & \multicolumn{2}{|r|}{0.34} \\
\hline$c_{2}$ & 0.04666 & \multicolumn{2}{|c|}{0.0419} \\
\hline
\end{tabular}




\begin{tabular}{|c|c|c|c|}
\hline Parameter & Set values & \multicolumn{2}{|c|}{ Obtained results } \\
\hline \multirow{8}{*}{ burst node } & \multirow{8}{*}{96} & Node & $\begin{array}{c}\text { The value of } \\
\chi^{2}\end{array}$ \\
\hline & & 66 & $1.04 \mathrm{E}-05$ \\
\hline & & 70 & $1.04 \mathrm{E}-05$ \\
\hline & & 71 & $1.04 \mathrm{E}-05$ \\
\hline & & 87 & $1.18 \mathrm{E}-05$ \\
\hline & & 96 & $1.37 \mathrm{E}-05$ \\
\hline & & 111 & $1.47 \mathrm{E}-05$ \\
\hline & & 113 & $1.56 \mathrm{E}-05$ \\
\hline$d(l / s)$ & 5.5 & \multicolumn{2}{|r|}{5.45} \\
\hline$c_{1}$ & 0.15 & \multicolumn{2}{|r|}{0.15} \\
\hline$c_{2}$ & 0.005 & \multicolumn{2}{|c|}{0.00496} \\
\hline \multirow{8}{*}{ burst node } & \multirow{8}{*}{96} & Node & $\begin{array}{c}\text { The value of } \\
\chi^{2}\end{array}$ \\
\hline & & 87 & $1.55 \mathrm{E}-05$ \\
\hline & & 96 & $1.85 \mathrm{E}-05$ \\
\hline & & 71 & $1.91 \mathrm{E}-05$ \\
\hline & & 70 & $1.93 \mathrm{E}-05$ \\
\hline & & 66 & $1.96 \mathrm{E}-05$ \\
\hline & & 111 & $2.56 \mathrm{E}-05$ \\
\hline & & 104 & $2.68 \mathrm{E}-05$ \\
\hline$d(l / s)$ & 11 & \multicolumn{2}{|r|}{10.95} \\
\hline$c_{1}$ & 0.15 & \multicolumn{2}{|r|}{0.15} \\
\hline$c_{2}$ & 0.005 & \multicolumn{2}{|c|}{0.00494} \\
\hline \multirow{8}{*}{ burst node } & \multirow{8}{*}{98} & Node & $\begin{array}{c}\text { The value of } \\
\chi^{2}\end{array}$ \\
\hline & & 98 & $2.00 \mathrm{E}-06$ \\
\hline & & 104 & $3.51 \mathrm{E}-06$ \\
\hline & & 103 & 3.92E-06 \\
\hline & & 71 & $9.53 \mathrm{E}-06$ \\
\hline & & 70 & $9.54 \mathrm{E}-06$ \\
\hline & & 66 & $9.54 \mathrm{E}-06$ \\
\hline & & 111 & $1.15 \mathrm{E}-05$ \\
\hline$d(l / s)$ & 3.8 & \multicolumn{2}{|c|}{3.836697} \\
\hline$c_{1}$ & 0.2 & \multicolumn{2}{|c|}{0.194077} \\
\hline$c_{2}$ & 0.0024 & \multicolumn{2}{|c|}{0.002413} \\
\hline
\end{tabular}

The results of the above experiment show that, at least for the data of numerical experiments, the developed algorithm identifies the burst location very precisely. It was 
observed that the exponent (order) of the $\chi^{2}$ value depends on the accuracy of the IFM coefficients $(d, c 1, c 2)$, i.e. the more accurate the coefficients, the smaller the value of $\chi^{2}$ is achieved.

This exponent can be used as a criterion of accuracy of the burst location identification algorithm.

- If $\chi^{2}$ is of $10^{-6}$ order or smaller the burst node is located precisely;

- If $\chi^{2}$ is bigger than $10^{-6}$ the area of burst is determined (not the node) and a further investigation using different methods, for example listening sticks or noise correlation should be used.

\subsubsection{Influence of sensitive nodes selection.}

For the field experiment loggers can only be installed at available hydrants which do not necessarily overlap with the selected sensitive nodes. The effects of random distribution of loggers on the accuracy of the burst location identification algorithms are investigated here. A group of people who are not experts in water engineering have been asked to place 15 pressure loggers in the Shenstone DMA and placement results are depicted in Fig. 5.21. 


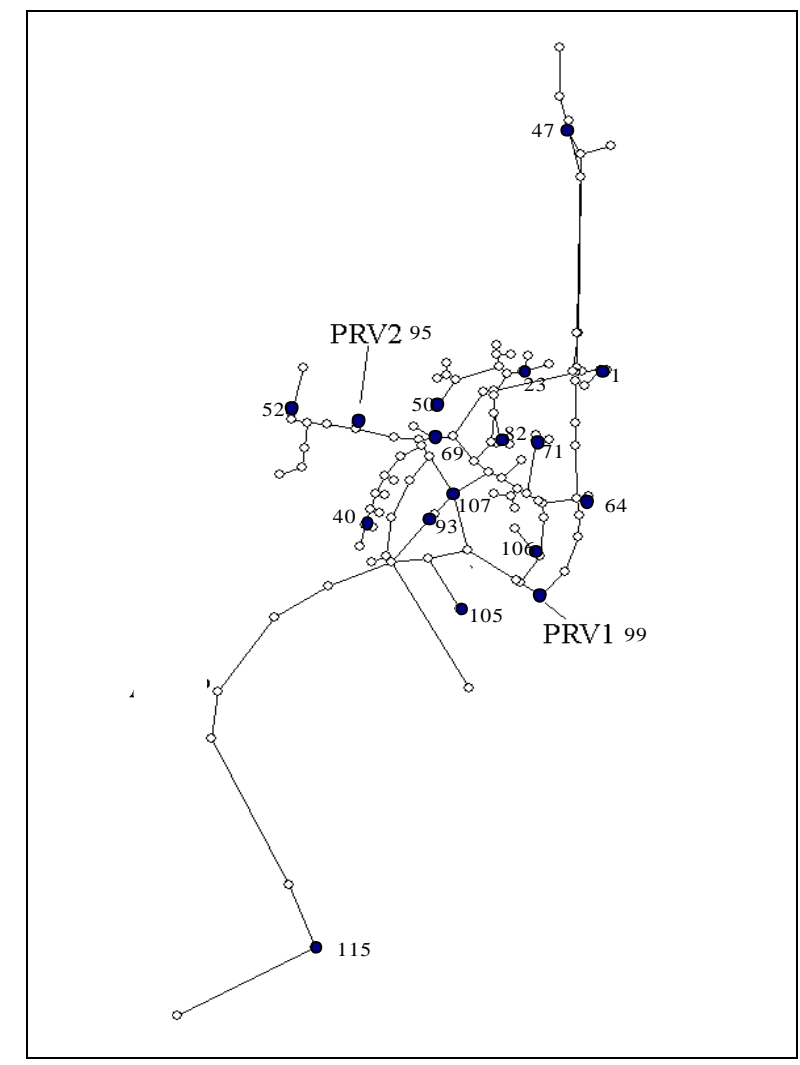

Fig. 5.21 Location of measurement points at the Shenstone DMA

The intuitive method resulted in uniform distribution of the loggers over all parts of the network.

The following conditions were set to obtain the 'experimental' data:

- inlet head has been varied from $135 \mathrm{~m}$ to $160 \mathrm{~m}$ on Inlet 1 (PRV 2 OUTLET node 95) and from $134 m$ to $159 m$ on Inlet 2 (PRV 1 OUTLET node 99);

- experimental data have been generated by the hydraulic simulations (the validity of this was investigated in Chapter 5.1.2);

- the simulations have been carried out for various values of the total demand, the various values of the total background leakage, and various burst sites;

- the following simulation results have been considered as the experimental data:

$\circ$ values of the inlet heads (nodes 99 and 95),

○ values of head at "sensitive nodes" (nodes 52, 69, 40, 82, 50, 71, 105, 64, $1,115,47,93,23,107,106)$,

○ values of inlet flows (nodes 99 and 95).

The generated experimental data have been initially processed by the hybrid method in order to obtain the estimated total demand, the estimated coefficient of the total background leakage and the estimated coefficient of the burst. Subsequently, the burst 
location identification algorithm has been used to find the site of the presumed burst. The estimation results of the experiments are compared to the set values in the hydraulic simulator. The results are given in Table 5.16 below.

Table 5.16 The results of experiments with other "Sensitive nodes"

\begin{tabular}{|c|c|c|c|}
\hline Parameter & Set values & \multicolumn{2}{|c|}{ Obtained results } \\
\hline \multirow{6}{*}{ burst node } & \multirow{6}{*}{34} & Node & $\begin{array}{c}\text { The value of } \\
\chi^{2}\end{array}$ \\
\hline & & 34 & $6.84 \mathrm{E}-07$ \\
\hline & & 42 & $1.10 \mathrm{E}-06$ \\
\hline & & 41 & $2.10 \mathrm{E}-06$ \\
\hline & & 47 & $3.82 \mathrm{E}-06$ \\
\hline & & 6 & $1.26 \mathrm{E}-04$ \\
\hline$d(l / s)$ & 2 & \multicolumn{2}{|c|}{2.01433} \\
\hline$c_{1}$ & 0.15 & \multicolumn{2}{|c|}{0.149735} \\
\hline$c_{2}$ & 0.002353 & \multicolumn{2}{|c|}{0.002348} \\
\hline \multirow{7}{*}{ burst node } & \multirow{7}{*}{67} & Node & $\begin{array}{c}\text { The value of } \\
\chi^{2}\end{array}$ \\
\hline & & 62 & $7.85 \mathrm{E}-07$ \\
\hline & & 67 & 7.87E-07 \\
\hline & & 63 & 7.95E-07 \\
\hline & & 51 & 8.44E-07 \\
\hline & & 56 & $8.68 \mathrm{E}-07$ \\
\hline & & 61 & $1.61 \mathrm{E}-06$ \\
\hline$d(l / s)$ & 2 & \multicolumn{2}{|c|}{1.996932} \\
\hline$c_{1}$ & 0.2 & \multicolumn{2}{|c|}{0.20195} \\
\hline$c_{2}$ & 0.00239 & \multicolumn{2}{|c|}{0.002384} \\
\hline \multirow{6}{*}{ burst node } & \multirow{6}{*}{96} & Node & $\begin{array}{c}\text { The value of } \\
\chi^{2}\end{array}$ \\
\hline & & 96 & $4.55 \mathrm{E}-04$ \\
\hline & & 108 & $2.01 \mathrm{E}-03$ \\
\hline & & 80 & $2.72 \mathrm{E}-03$ \\
\hline & & 112 & $3.52 \mathrm{E}-03$ \\
\hline & & 87 & $4.74 \mathrm{E}-03$ \\
\hline$d(l / s)$ & 5.5 & \multicolumn{2}{|c|}{4.851102} \\
\hline$c_{1}$ & 0.8 & \multicolumn{2}{|c|}{0.932311} \\
\hline$c_{2}$ & 0.0229 & \multicolumn{2}{|c|}{0.021861} \\
\hline
\end{tabular}




\begin{tabular}{|c|c|c|c|}
\hline Parameter & Set values & \multicolumn{2}{|c|}{ Obtained results } \\
\hline \multirow{6}{*}{ burst node } & \multirow{6}{*}{108} & Node & $\begin{array}{c}\text { The value of } \\
\chi^{2}\end{array}$ \\
\hline & & 108 & $2.80 \mathrm{E}-03$ \\
\hline & & 96 & $6.80 \mathrm{E}-03$ \\
\hline & & 112 & $1.06 \mathrm{E}-02$ \\
\hline & & 107 & $1.36 \mathrm{E}-02$ \\
\hline & & 85 & $1.63 \mathrm{E}-02$ \\
\hline$d(l / s)$ & 5.5 & \multicolumn{2}{|c|}{1.597663} \\
\hline$c_{1}$ & 0.8 & \multicolumn{2}{|c|}{1.507342} \\
\hline$c_{2}$ & 0.05 & \multicolumn{2}{|c|}{0.043888} \\
\hline \multirow{6}{*}{ burst node } & \multirow{6}{*}{78} & Node & $\begin{array}{c}\text { The value of } \\
\chi^{2}\end{array}$ \\
\hline & & 78 & $2.17 \mathrm{E}-03$ \\
\hline & & 68 & $5.53 \mathrm{E}-03$ \\
\hline & & 85 & 8.49E-03 \\
\hline & & 82 & $1.01 \mathrm{E}-02$ \\
\hline & & 84 & $1.49 \mathrm{E}-02$ \\
\hline$d(l / s)$ & 11 & \multicolumn{2}{|c|}{7.199524} \\
\hline$c_{1}$ & 0.8 & \multicolumn{2}{|c|}{1.481012} \\
\hline$c_{2}$ & 0.05 & \multicolumn{2}{|c|}{0.043619} \\
\hline \multirow{6}{*}{ burst node } & \multirow{6}{*}{76} & Node & $\begin{array}{c}\text { The value of } \\
\chi^{2}\end{array}$ \\
\hline & & 76 & 4.66E-04 \\
\hline & & 73 & $2.05 \mathrm{E}-03$ \\
\hline & & 64 & $3.25 \mathrm{E}-03$ \\
\hline & & 75 & 4.36E-03 \\
\hline & & 57 & 4.39E-03 \\
\hline$d(l / s)$ & 11 & \multicolumn{2}{|c|}{10.81651} \\
\hline$c_{1}$ & 0.8 & \multicolumn{2}{|c|}{0.838669} \\
\hline$c_{2}$ & 0.0229 & \multicolumn{2}{|c|}{0.021985} \\
\hline
\end{tabular}

The results show robustness of the burst location identification algorithm with respect to logger placements. 


\subsection{Exponent in the burst term}

Recent research (Ulanicki et al. 2006) indicated that the burst term in the IFM model (the relationship between leakage flow and water pressure) can have a higher exponent than 0.5 depending on the pipe material, fluid properties for different Reynolds number and on the surrounding soil (Noack and Ulanicki 2006) from 0.5 to 2.5. In such a situation the previously described algorithms require modification. The original IMF model had the following form:

$q=d+c_{1} p_{i}^{0.5}+c_{2} p_{A Z N P}^{1.5}$

The model is now modified to make the exponent of the burst term an unknown variable:

$q=d+c_{1} p_{i}^{e}+c_{2} p_{A Z N P}^{1.5}$

where $e, d, c 1, c 2$ are now the unknown parameters, which can be evaluated using Matlab. The estimated value of the exponent together with other coefficients are entered as input data to the burst detection algorithm.

So with such modification the algorithm became more universal and it will be applied in Chapter 6 where a real case study is presented.

\subsection{Summary}

The developed identification procedure for the burst location is more precise than other methods currently available.

The exponent of the value of $\chi^{2}$ can be used as a criterion of accuracy of the burst location identification algorithm. The given criterion specifies also the accuracy of the performed experiments.

The algorithm of burst location identification developed by the author allows for finding a potential burst site with quite high precision. 


\section{Practical case studies}

Data from real field experiments have been provided by the Water Software Systems group. It created the opportunity to test the developed algorithms in a real life model rather than purely by numerical experiments, the results are presented in this chapter.

\subsection{General condition of performing the experiment.}

The field tests have been an extension of the FAVOR test - apart from monitoring the inlet pressures and flows additional pressures were measured inside a DMA (e-FAVOR test).

There were several experimental parameters to be decided:

- Sampling interval - should be short enough to give a reasonable amount of data at each pressure level but large enough to avoid transients and measurement noise (e.g. flow measurement are averaged over the interval). Thirty seconds to 2 minutes has been found to be suitable.

- Accuracy of measurements - obviously the more accurate the better. They should be sufficiently accurate to record head losses across the network. The required accuracy of pressure gauges was $0.1 \mathrm{~m}$, and the required accuracy of flow meters was $0.1 \mathrm{l} / \mathrm{s}$.

- Number of measurements points - again, the more the better but there are practical limits. The precision of the burst location depends on pressure changes caused by the leakage flow pattern between loggers, so the identification will be more accurate if they are closer together.

- Pressure steps - it is beneficial to have a large range of inlet pressure changes but the experiment should not upset the water customers. A pressure of $15 \mathrm{~m}$ has to be maintained at each point in the network to meet the OFWAT requirements and the pressure can only go as high as the inlet pressure to the PRV (minus a small head loss of around $5 \mathrm{~m}$ across the PRV). 


\subsection{Ocker Hill case study}

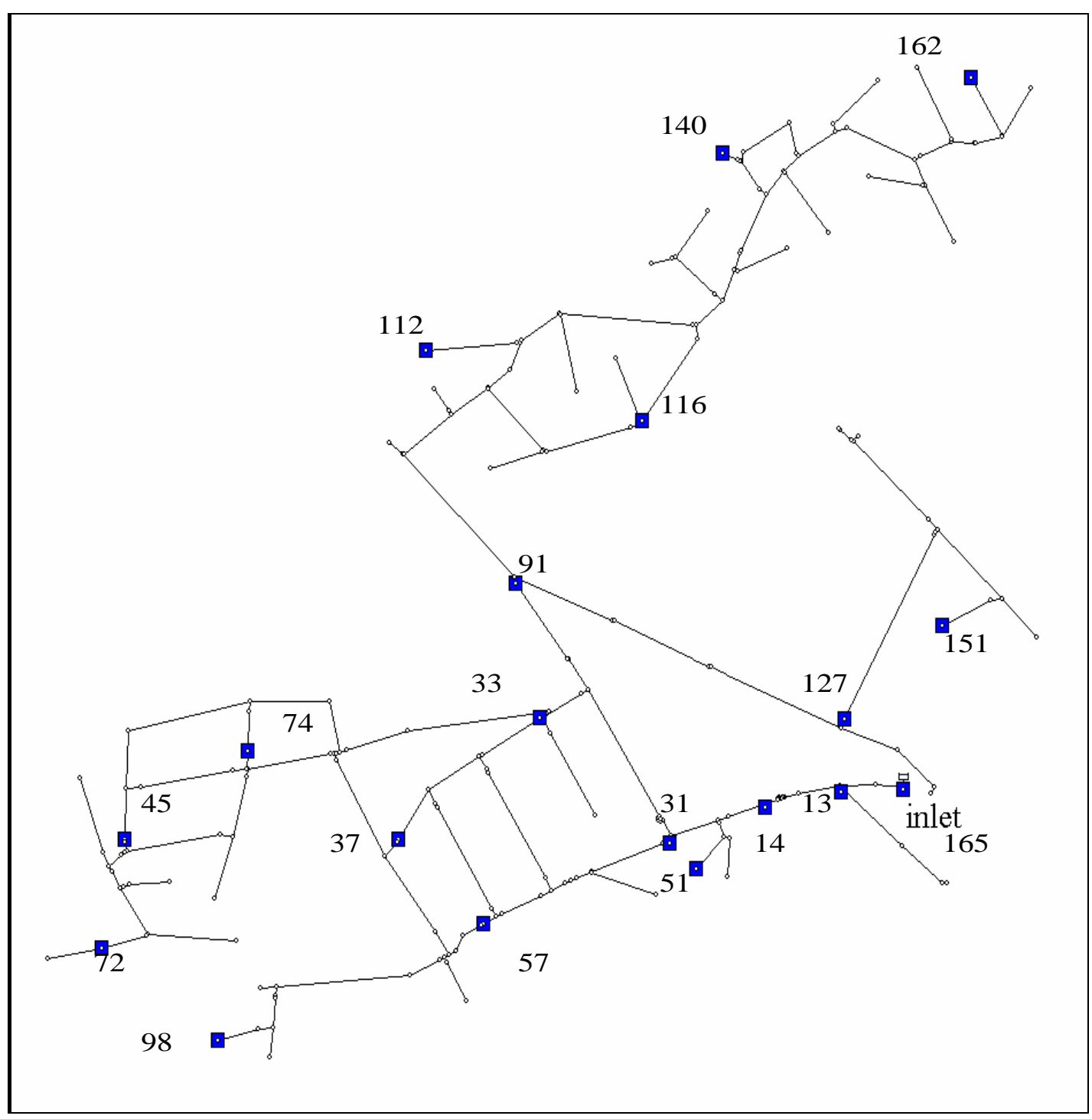

Fig. 6.1 Ocker Hill DMA schematic

Ocker Hill, shown in Fig. 6.1, is a single-feed DMA supplying 1850 domestic properties and 25 commercial customers. The inlet is through a 6" Rollseal PRV and there is one disused PRV (4" Bermad) about 150m downstream from the inlet. The experiment was performed by members of the Water Software System research group during the nights of 23rd and 24th March 2005 and consisted of a sequence of pre-programmed pressure steps, shown in Figure 6.2.

Data were recorded every 30 seconds and the measured variables were:

- Inlet flow 
- PRV inlet pressure

- PRV outlet pressure

- Pressure at the following hydrants

10 Kidd Croft

20 Hopton Close

41 Wooding Crescent

27 Jackson Close

80 Ocker Hill Road

Corner Gospel Oak Road \& Prospect St

8 The Coppice

37 Windsor Road

1 North Road

77 North Road

8 Dick Sheppard Avenue

5 Waring Road

9 Shelley Avenue

41 St Mark’s Road

1 Mott Close

2 Solari Close

Inlet of second PRV

Corner Spring Street \& Ocker Hill Road

The recorded data are shown in Figure 6.2. There is a clear correlation between the head and the flow measurements - when the head is decreased the flow decreases as well due to the volume of flow through leaks being reduced. The total flow reduction due to head drop of $30 \mathrm{~m}$ is around $4.51 / \mathrm{s}$. 

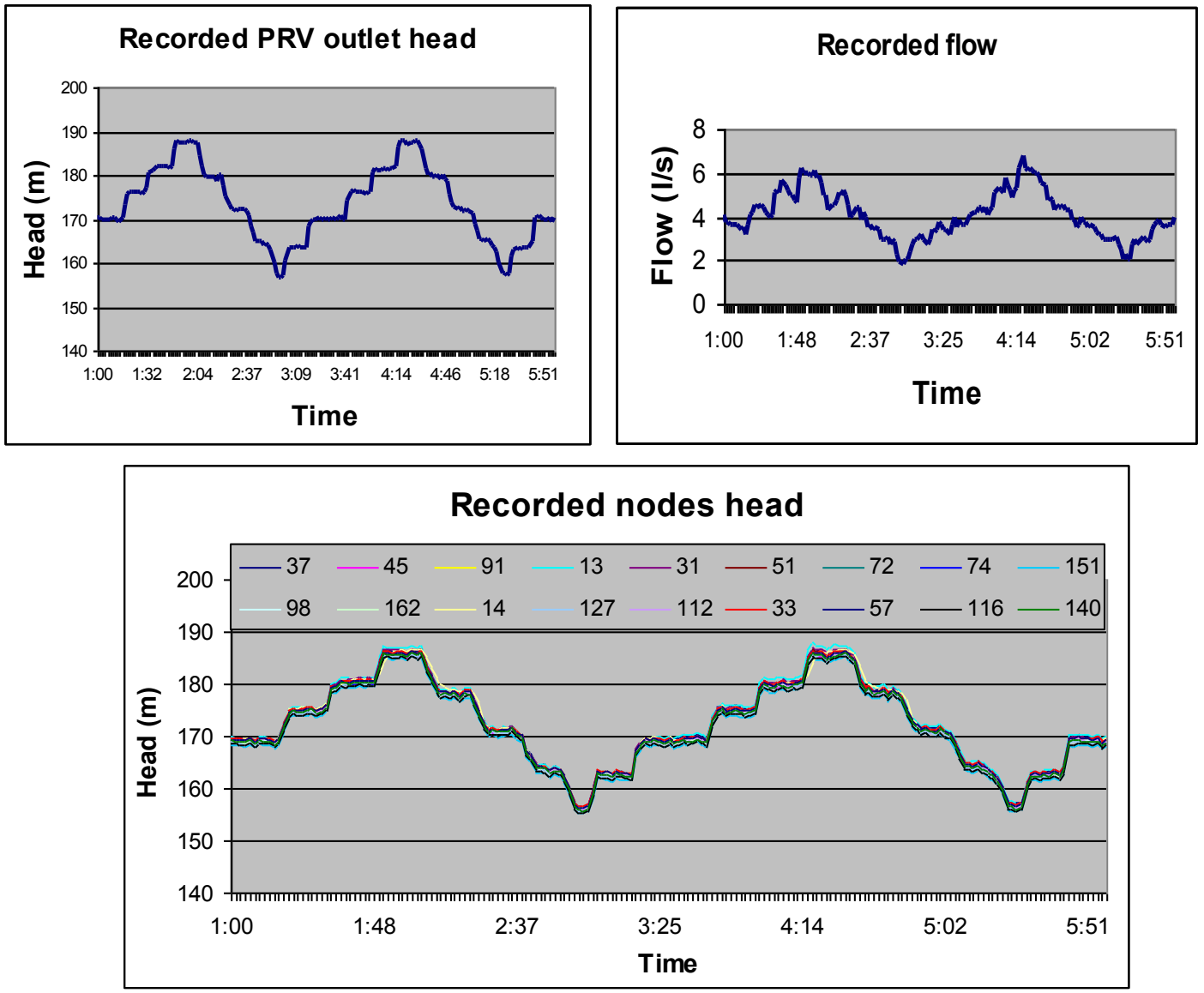

Fig. 6.2 Recorded data (Ocker Hill DMA)

The following terms of the IFM:

- demand

- fixed area burst leakage (burst coefficient) across the DMA

- variable area burst leakage (background leakage coefficient) across the DMA have been calculated by the hybrid algorithm described in Chapter 5.1.4.

Table 6.1 Calculated results (Ocker Hill DMA)

\begin{tabular}{|c|c|c|c|c|}
\hline $\begin{array}{c}\text { Sensitive } \\
\text { node }\end{array}$ & $\begin{array}{c}\text { Demand factor } \\
(1 / \mathrm{s})\end{array}$ & $\begin{array}{c}\text { Coefficient of } \\
\text { the burst }\end{array}$ & $\begin{array}{c}\text { Coefficient of the total } \\
\text { background leakage }\end{array}$ & $\begin{array}{c}\text { Value of } \chi^{2} \\
\text { (difference between calculated and } \\
\text { recorded inlet flows) }\end{array}$ \\
\hline \multicolumn{5}{|c|}{ The burst exponent $=1.44968$} \\
\hline 165 & 0.730393 & 0.021656 & 0 & 2.456042 \\
\hline 37 & 0.350676 & 0.016086 & 0.003627 & 2.704906 \\
\hline 45 & 0.590325 & 0 & 0.014098 & 2.715408 \\
\hline 91 & 0.590325 & 0 & 0.014098 & 2.715408 \\
\hline 13 & 0.978954 & 0.022717 & 0 & 2.496215 \\
\hline 31 & 0.853587 & 0.022649 & 0 & 2.670476 \\
\hline 51 & 0.683629 & 0.02253 & 0 & 2.677547 \\
\hline 72 & 0.590325 & 0 & 0.014098 & 2.715408 \\
\hline 74 & 0.590325 & 0 & 0.014098 & 2.715408 \\
\hline 151 & 0.590325 & 0 & 0.014098 & 2.715408 \\
\hline
\end{tabular}




\begin{tabular}{|c|c|c|c|c|}
\hline 98 & 0.590325 & 0 & 0.014098 & 2.715408 \\
\hline 162 & 0.590325 & 0 & 0.014098 & 2.715408 \\
\hline 14 & 0.590325 & 0 & 0.014098 & 2.715408 \\
\hline 127 & 0.590325 & 0 & 0.014098 & 2.715408 \\
\hline 140 & 0.082092 & 0.012493 & 0.005512 & 2.691486 \\
\hline 112 & 0.590325 & 0 & 0.014098 & 2.715408 \\
\hline 33 & 0.248723 & 0.018274 & 0.002202 & 2.687886 \\
\hline 57 & 0.590325 & 0 & 0.014098 & 2.715408 \\
\hline 116 & 0.590325 & 0 & 0.014098 & 2.715408 \\
\hline
\end{tabular}

The results in yellow indicate one area of concentrated leakage with the exponent of 1.44968 near the inlet (node 165) as depicted in Figure 6.3. By looking at the exponent of the burst term and the values of parameters at other sensitive nodes, it is possible to draw a conclusion about the presence of the head loss (background leakage but not bursts) in the network. As indicated in Table 6.1, the difference between the calculated and the measured flows is big and the obtained results should be treated with caution.

Application of the burst location identification algorithm produced the following results:

Table 6.2 Results of the burst location identification algorithm (Ocker Hill DMA)

\begin{tabular}{|c|c|}
\hline Burst node & $\begin{array}{c}\text { Value of } \chi^{2} \\
\text { (reflects an error in prediction of burst } \\
\text { location) }\end{array}$ \\
\hline 20 & $1.4648 \mathrm{E}-03$ \\
\hline 19 & $1.6372 \mathrm{E}-03$ \\
\hline 66 & $1.7134 \mathrm{E}-03$ \\
\hline 21 & $1.8493 \mathrm{E}-03$ \\
\hline
\end{tabular}




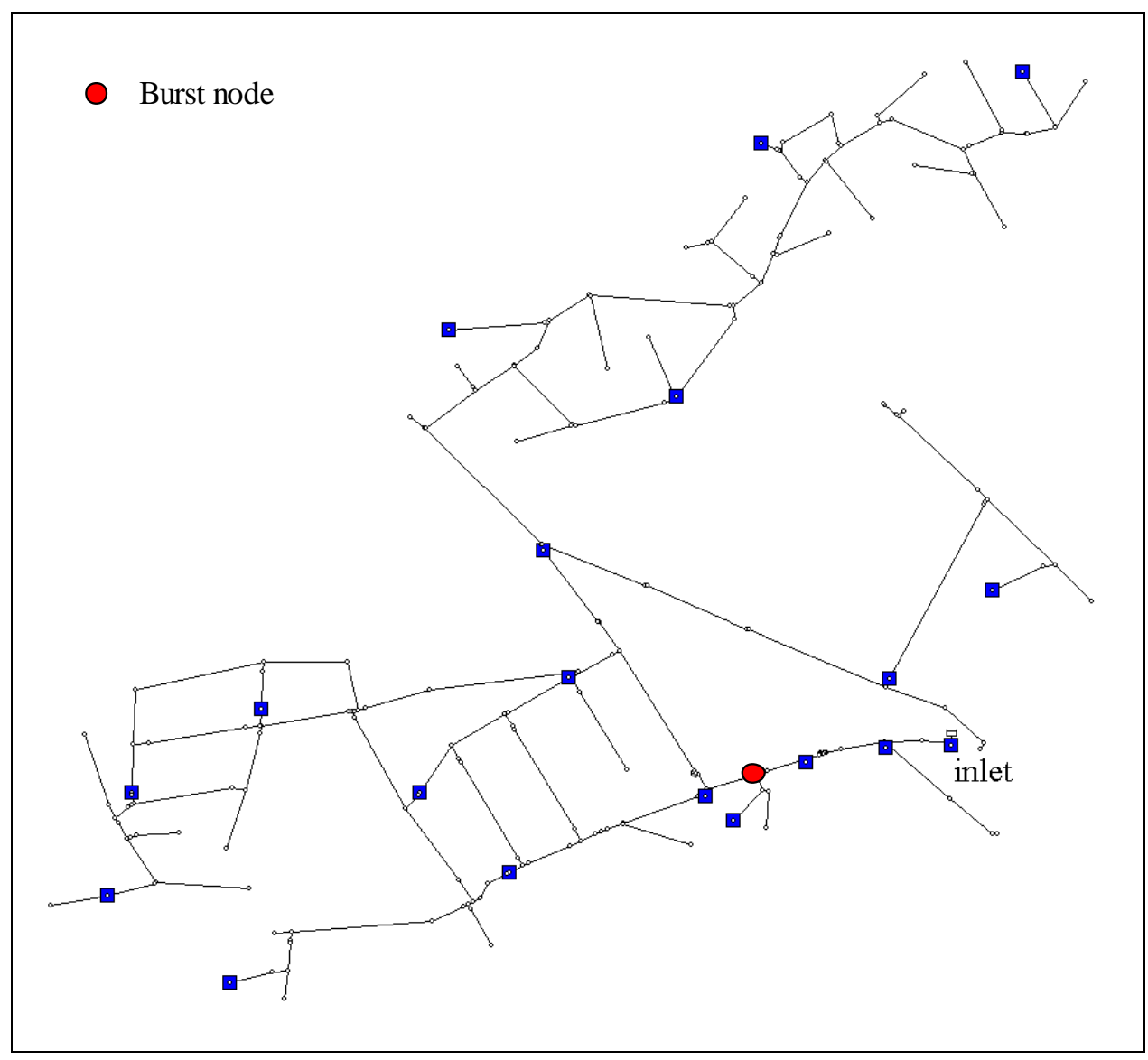

Fig. 6.3 Fixed area burst leakage in Ocker Hill DMA

The obtained results coincide with the results of the hybrid method algorithm, i.e. a small burst is indicated near the inlet, which most likely is explained by the presence of concentrated background leakage in this area.

\subsection{Shenstone case study}

Shenstone is fed through two PRV inlets (Figure 6.4) and supplies 1008 consumers (917 domestic and 91 commercial). The PRVs are 4" Bermad (St John) which is at the corner of St Johns Hill, and Bham Rd and 4" Rollseal (Lynn) which is in Lynne Lane. 


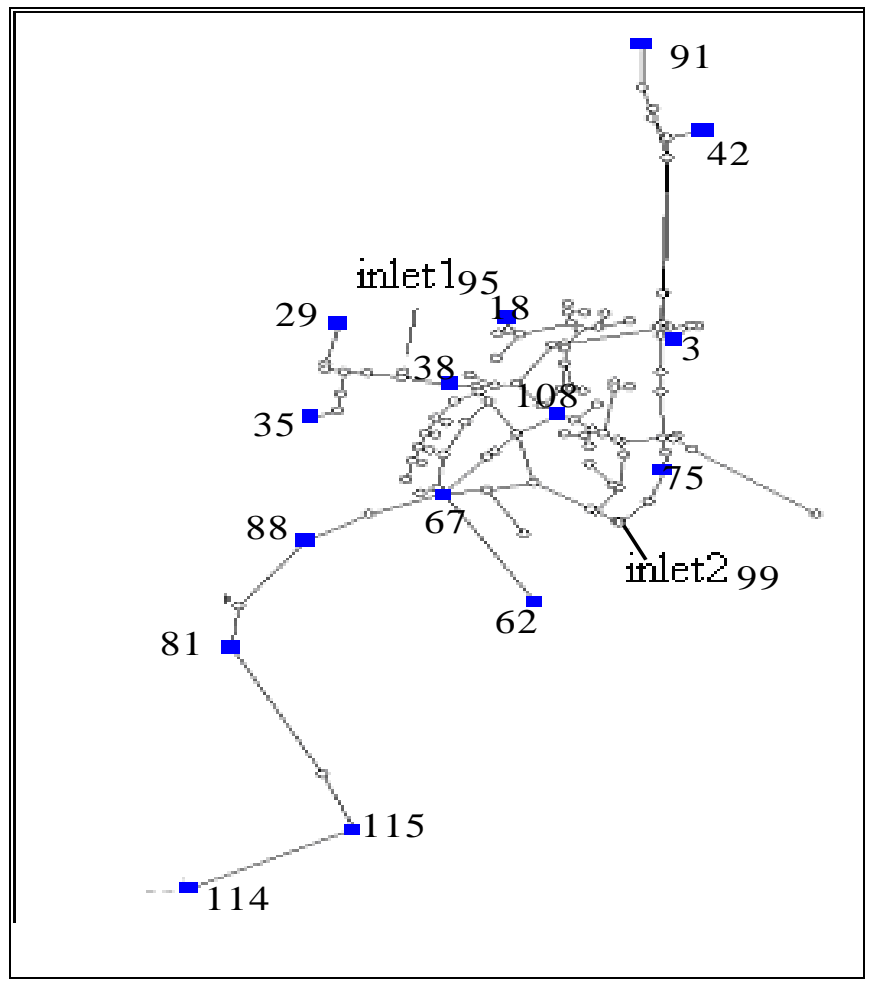

Fig. 6.4 Shenstone DMA schematic

The recorded data obtained during the field experiment are presented in Figure 6.5.
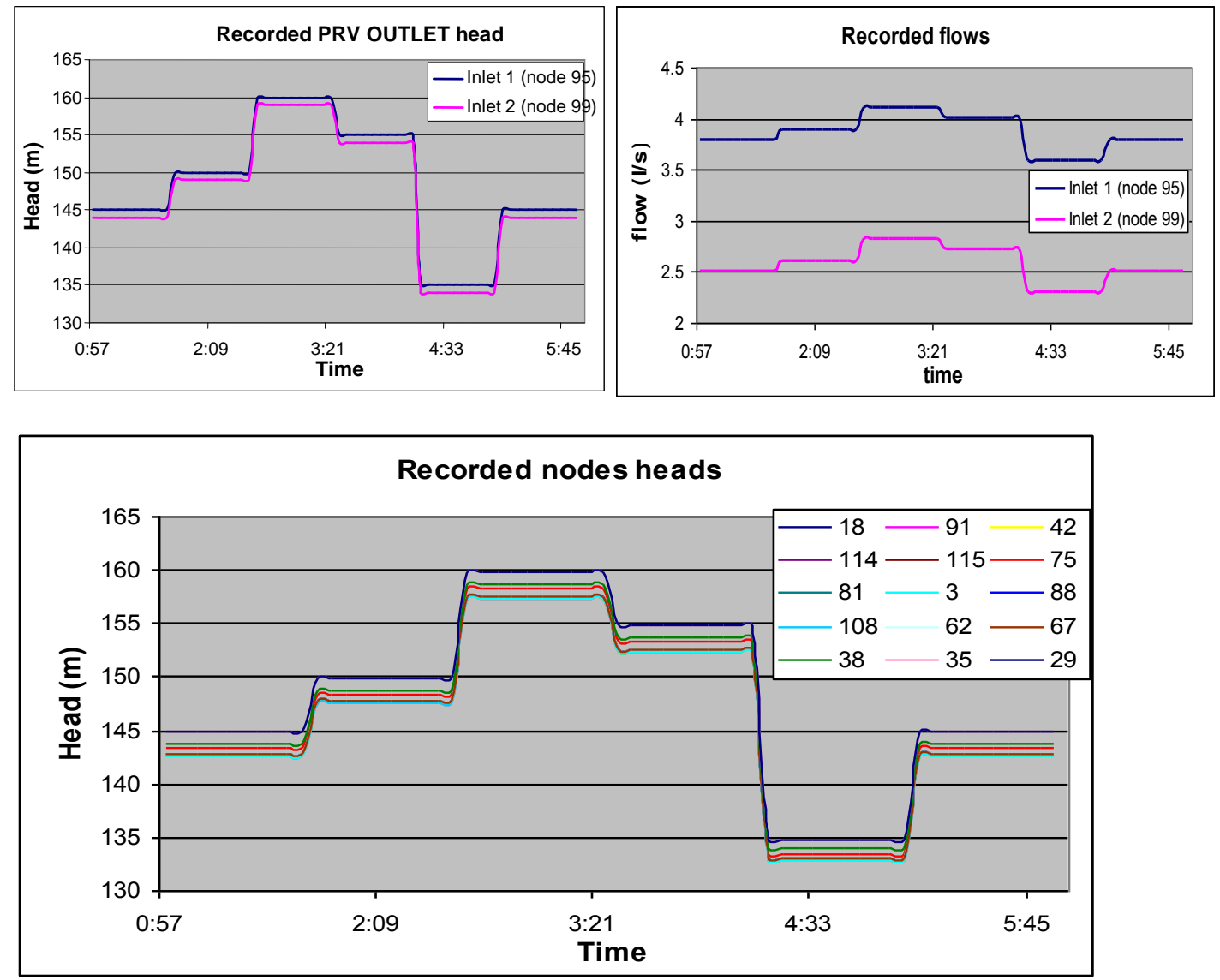

Fig. 6.5 Recorded data (Shenstone DMA) 
The following terms of the IFM:

- demand

- fixed area burst leakage (burst coefficient) across the DMA

- variable area burst leakages (background leakage coefficients) across the DMA have been calculated by the hybrid algorithm described in Chapter 5.1.4.

Table 6.3 Calculated results (Shenstone DMA)

\begin{tabular}{|c|c|c|c|c|}
\hline $\begin{array}{c}\text { Sensitive } \\
\text { node }\end{array}$ & $\begin{array}{c}\text { Demand factor } \\
(1 / \mathrm{s})\end{array}$ & $\begin{array}{c}\text { Coefficient of } \\
\text { the burst }\end{array}$ & $\begin{array}{c}\text { Coefficient of the } \\
\text { total background } \\
\text { leakage }\end{array}$ & $\begin{array}{c}\text { Value of } \chi^{2} \\
\text { (difference between calculated and } \\
\text { recorded inlet flows) }\end{array}$ \\
\hline \multicolumn{5}{|c|}{ The burst exponent $=0.512104$} \\
\hline 95 & 3.643539 & 0.284718 & 0.002128 & $4.99 \mathrm{E}-08$ \\
\hline 99 & 4.033422 & 0.242887 & 0.002276 & $9.31 \mathrm{E}-10$ \\
\hline 18 & 3.709304 & 0.279806 & 0.002165 & $3.93 \mathrm{E}-08$ \\
\hline 91 & 3.876389 & 0.261679 & 0.002224 & $5.94 \mathrm{E}-08$ \\
\hline 42 & 3.873712 & 0.262168 & 0.002225 & $1.79 \mathrm{E}-08$ \\
\hline 3 & 3.55773 & 0.294989 & 0.002115 & $7.11 \mathrm{E}-08$ \\
\hline 114 & 4.333455 & 0.208249 & 0.002425 & $6.74 \mathrm{E}-08$ \\
\hline 115 & 4.305799 & 0.211826 & 0.00241 & $2.08 \mathrm{E}-08$ \\
\hline 81 & 4.032276 & 0.244776 & 0.002283 & $1.54 \mathrm{E}-08$ \\
\hline 88 & 4.117065 & 0.234884 & 0.00232 & $1.16 \mathrm{E}-07$ \\
\hline 108 & 4.360773 & 0.204427 & 0.002443 & $6.8 \mathrm{E}-08$ \\
\hline 62 & 3.922307 & 0.257142 & 0.002238 & $1.01 \mathrm{E}-08$ \\
\hline 67 & 3.950318 & 0.253477 & 0.002255 & $1.81 \mathrm{E}-07$ \\
\hline 38 & 3.803718 & 0.269449 & 0.002187 & $1.6 \mathrm{E}-08$ \\
\hline 75 & 3.972916 & 0.250807 & 0.002251 & $1.97 \mathrm{E}-08$ \\
\hline 35 & 3.766198 & 0.271833 & 0.002176 & \\
\hline 29 & 3.735147 & 0.275068 & 0.002165 & \\
\hline
\end{tabular}

The results in yellow indicate both burst and background leakage in the network. The values of the $\chi^{2}$ criterion confirm the high accuracy of the estimated values of the demand and the coefficients of the fixed and variable leakage terms.

Application of the algorithm for burst location identification has detected a burst site in the network: 
Table 6.4 Results of the burst location identification algorithm (Shenstone DMA)

\begin{tabular}{|c|c|}
\hline Burst node & $\begin{array}{c}\text { Value of } \chi^{2} \\
\text { (reflects an error in prediction of burst } \\
\text { location) }\end{array}$ \\
\hline 80 & $3.2 \mathrm{E}-06$ \\
\hline 69 & $1.44 \mathrm{E}-05$ \\
\hline 33 & $1.67 \mathrm{E}-05$ \\
\hline
\end{tabular}

The obtained results especially the exponent of the $\chi^{2}$ criterion indicates a high degree of probability of the burst presence at node 80 . The value of the total demand flow is 4 $1 / \mathrm{s}$, the value of the coefficient of the fixed area leakage (burst) is 0.24 , the value of the coefficient of the total background leakage is 0.00227 .

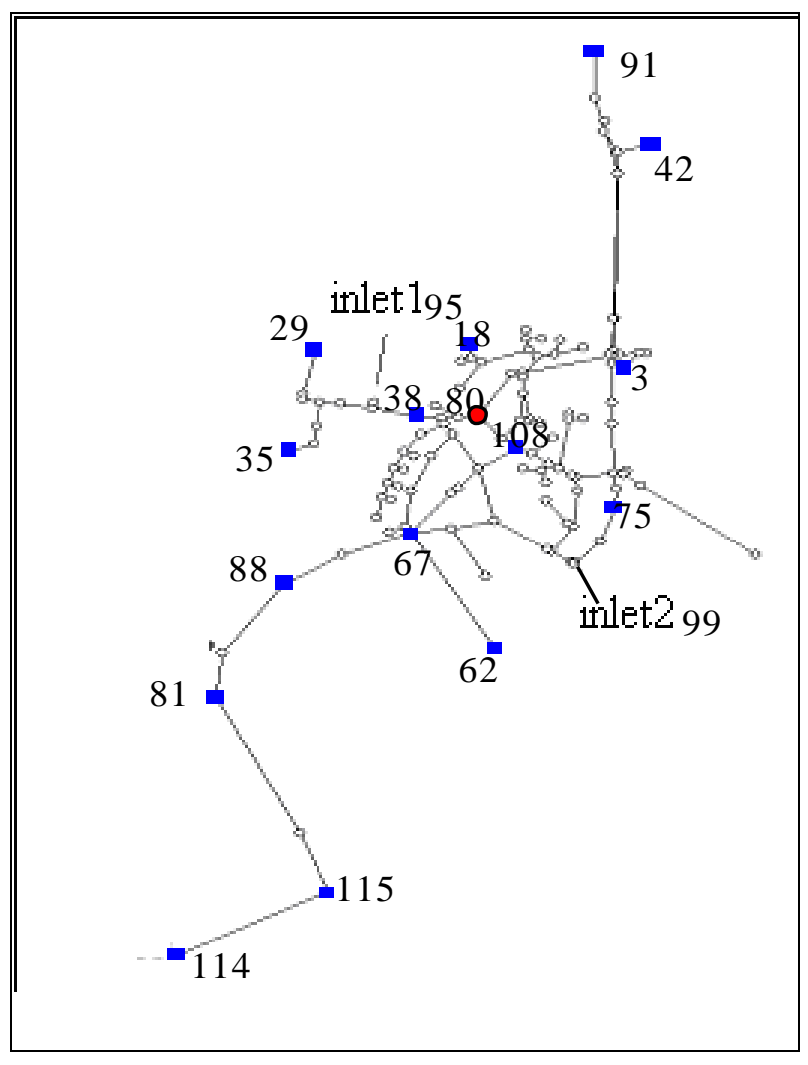

Fig. 6.6 Shenstone DMA, results of the experiment. 


\subsection{E054 - Drury Lane case study}

E054 is a single-feed DMA supplying 253 domestic properties and 18 commercial properties of which 43 have a demand greater than $200 \mathrm{~m}^{3} / y e a r$. The total mains length is $9 \mathrm{~km}$ whilst 5 boundary valves enclose the area. There is one PRV at Walton Park (Figure 6.7). There are no major metered customers within this DMA. The experiment consisted of a sequence of pre-programmed pressure steps. It is assumed that there are 10 Cello loggers installed in the DMA. Node and element data for E054 DMA are shown at Appendix E.

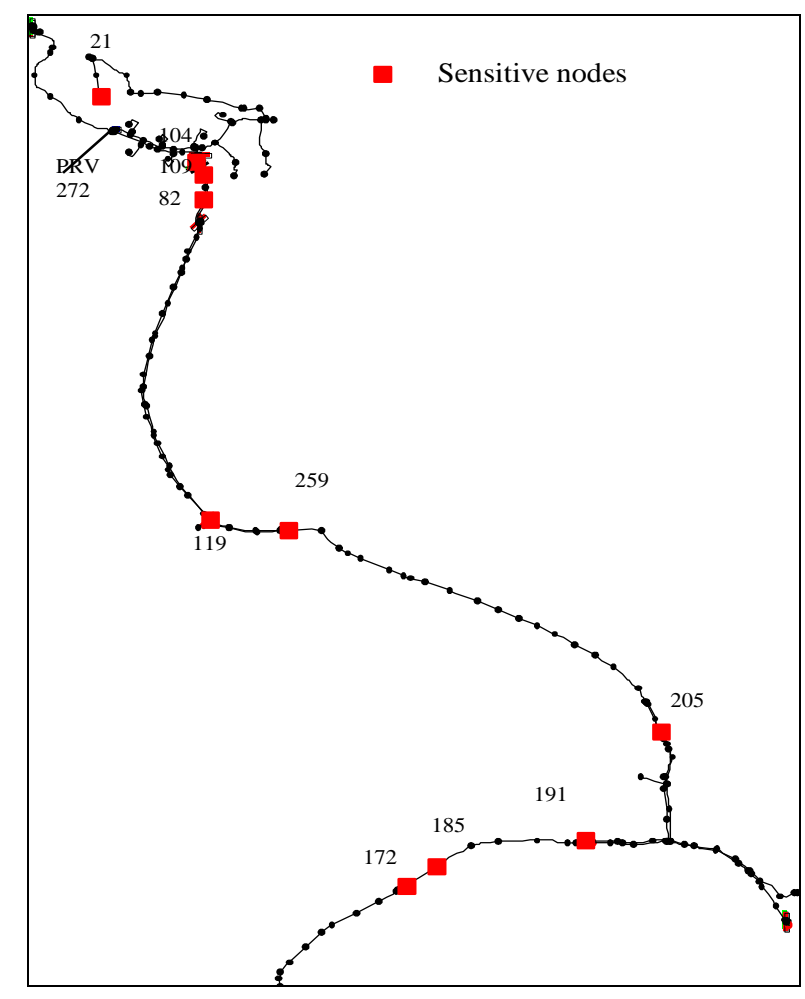

Fig. 6.7 E054 DMA schematic

The field measurements have not been available and therefore the experiment has been simulated using the program developed in Matlab and consists of two parts. The first part of the test was carried out between 22:00 hrs and 02:05 hrs. A single hydrant was opened at $5.0 \mathrm{l} / \mathrm{s}$ and the outlet pressure of the Walton Park PRV has been lowered via a number of pressure steps from $55 \mathrm{~m}$ to $40 \mathrm{~m}$ and then returned to $55 \mathrm{~m}$ using the same pressure step size. The recorded simulation data obtained during the experiment are presented in Figure 6.8. 

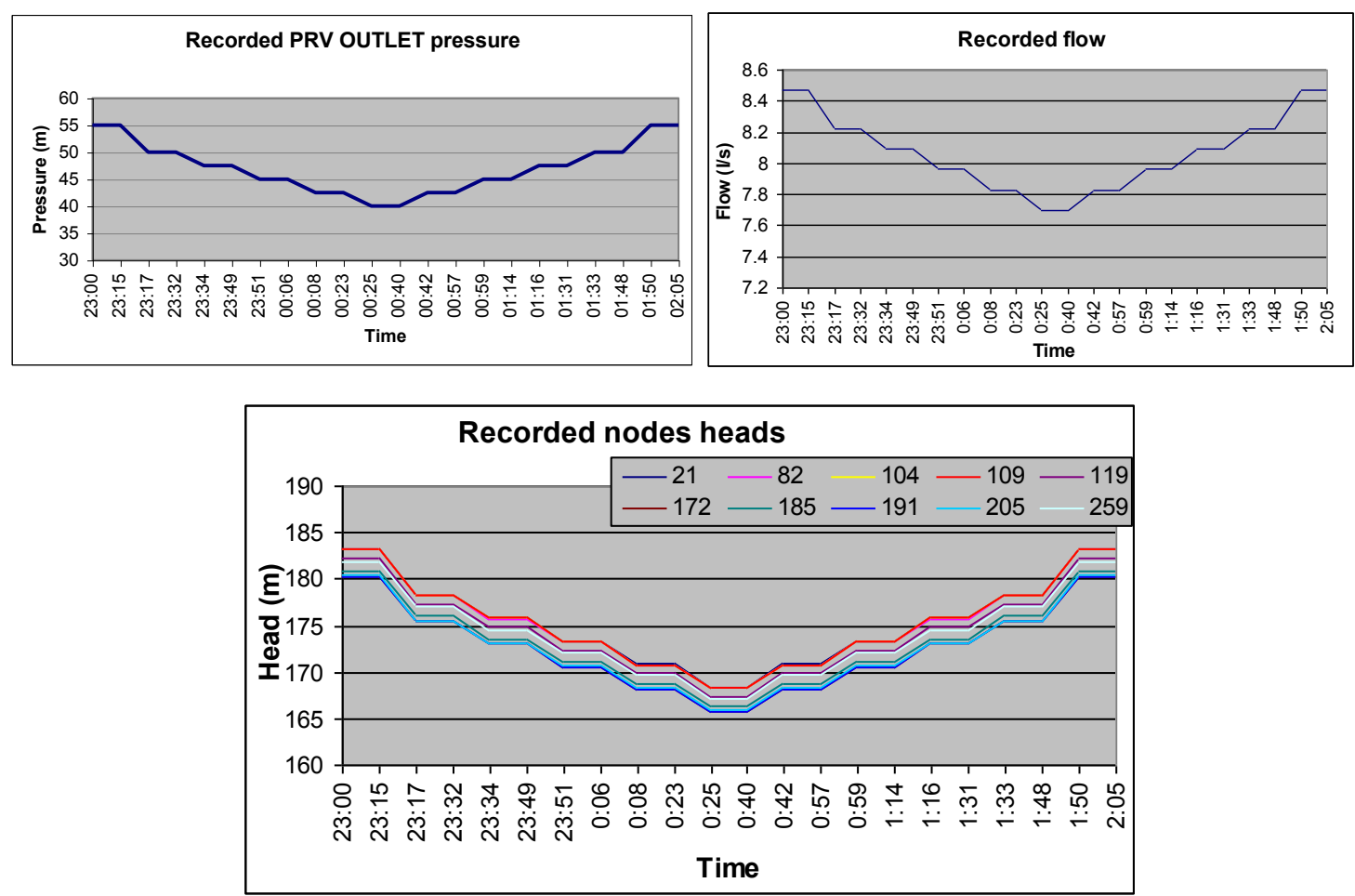

Fig. 6.8 First part of experiment. Recorded data.

The following terms of the IFM:

- demand

- fixed area burst leakages (burst coefficient) across the DMA

- variable area burst leakages (background leakage coefficients) across the DMA have been calculated by the hybrid algorithm described in Chapter 5.1.4.

Table 6.5 Calculated results (First part of experiment)

\begin{tabular}{|c|c|c|c|c|}
\hline $\begin{array}{c}\text { Sensitive } \\
\text { node }\end{array}$ & $\begin{array}{c}\text { Demand factor } \\
(1 / \mathrm{s})\end{array}$ & $\begin{array}{c}\text { Coefficient of } \\
\text { the burst }\end{array}$ & $\begin{array}{c}\text { Coefficient of the } \\
\text { total background } \\
\text { leakage }\end{array}$ & $\begin{array}{c}\text { Value of } \chi^{2} \\
\text { (difference between calculated and } \\
\text { recorded inlet flows) }\end{array}$ \\
\hline \multicolumn{5}{|c|}{ The burst exponent $=0.5$} \\
\hline 272 & 4.47715 & 0.427843 & 0.002017 & $1.21 \mathrm{E}-07$ \\
\hline 21 & 4.052519 & 0.472961 & 0.001863 & $6.45 \mathrm{E}-08$ \\
\hline 82 & 6.011171 & 0.218857 & 0.002941 & $1.86 \mathrm{E}-06$ \\
\hline 104 & 6.008423 & 0.21928 & 0.002938 & $1.85 \mathrm{E}-06$ \\
\hline 109 & 6.008558 & 0.21926 & 0.002938 & $1.85 \mathrm{E}-06$ \\
\hline 119 & 5.936531 & 0.233564 & 0.002869 & $1.93 \mathrm{E}-06$ \\
\hline 172 & 0 & 0.800822 & 0.001128 & $4.80 \mathrm{E}-08$ \\
\hline 185 & 3.866816 & 0.497848 & 0.001805 & $1.05 \mathrm{E}-09$ \\
\hline 191 & 2.139402 & 0.654995 & 0.001368 & $1.02 \mathrm{E}-09$ \\
\hline 205 & 2.132612 & 0.655379 & 0.001366 & $6.48 \mathrm{E}-07$ \\
\hline 259 & 5.526152 & 0.299596 & 0.002547 & \\
\hline
\end{tabular}


The results in yellow indicate both burst and background leakage in the network. The values of the $\chi^{2}$ criterion confirm the high accuracy of the estimated values of the demand and the coefficients of the fixed and variable leakage terms.

Application of the algorithm for burst location identification has detected a burst site in the network:

Table 6.6 Results of the burst location identification algorithm (First part of experiment)

\begin{tabular}{|c|c|}
\hline Burst node & $\begin{array}{c}\text { Value of } \chi^{2} \\
\text { (reflects an error in prediction of burst } \\
\text { location) }\end{array}$ \\
\hline 206 & $7.04 \mathrm{E}-06$ \\
\hline 205 & $1.34 \mathrm{E}-05$ \\
\hline 203 & $1.45 \mathrm{E}-05$ \\
\hline 202 & $1.60 \mathrm{E}-05$ \\
\hline 204 & $2.09 \mathrm{E}-05$ \\
\hline
\end{tabular}

The obtained results especially the exponent of the $\chi^{2}$ criterion indicate a high degree of probability of the burst presence close to node 206 (Figure 6.9). The value of the total demand flow is $2.133 \mathrm{l} / \mathrm{s}$, the value of the coefficient of the fixed area leakage (burst) is 0.655 (which corresponds to a burst flow of about $5 \mathrm{l} / \mathrm{s}$ ), the value of the coefficient of the total background leakage is 0.001366 .

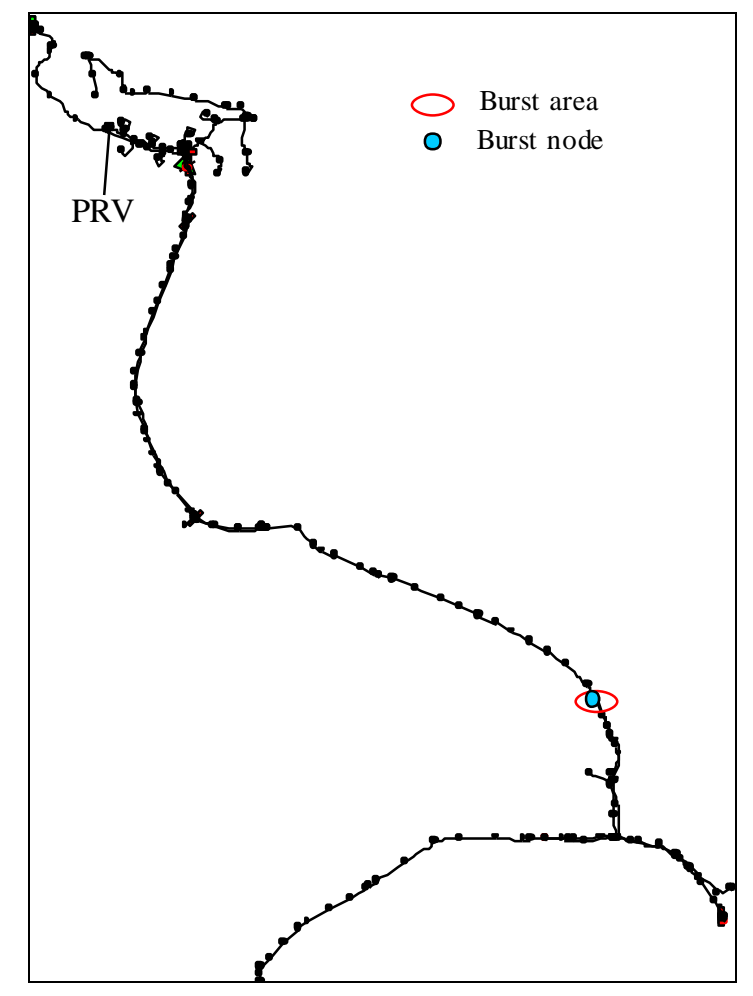

Fig. 6.9 E054 DMA. Results of first part of experiment. 
The second part of test was carried out between 02:30 hrs and 05:30 hrs. A single hydrant has been opened at $1 \mathrm{l} / \mathrm{s}$ and the outlet pressure of the Walton Park PRV has been lowered via a number of pressure steps from $55 \mathrm{~m}$ to $40 \mathrm{~m}$ and then returned to 55 $\mathrm{m}$ using the same pressure step sizes. The recorded data obtained during the experiment are presented in Figure 6.10.
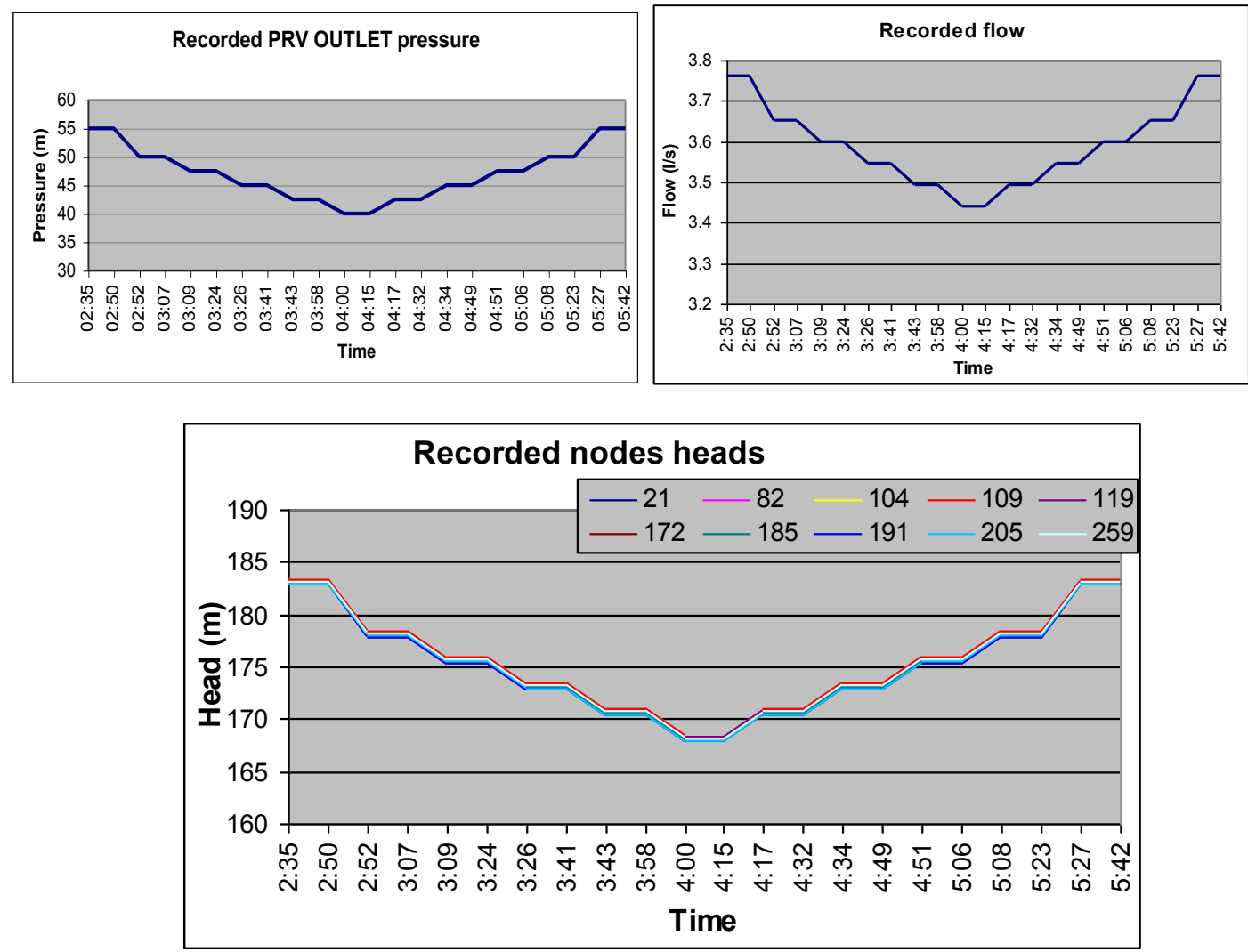

Fig. 6.10 Second part of experiment. Recorded data.

The following terms of the IFM:

- demand

- fixed area burst leakages (burst coefficient) across the DMA

- variable area burst leakages (background leakage coefficients) across the DMA have been calculated by the hybrid algorithm described in Chapter 5.1.4. 
Table 6.7 Calculated results (Second part of experiment)

\begin{tabular}{|c|c|c|c|c|}
\hline $\begin{array}{c}\text { Sensitive } \\
\text { node }\end{array}$ & $\begin{array}{c}\text { Demand factor } \\
(\mathrm{l} / \mathrm{s})\end{array}$ & $\begin{array}{c}\text { Coefficient of } \\
\text { the burst }\end{array}$ & $\begin{array}{c}\text { Coefficient of the } \\
\text { total background } \\
\text { leakage }\end{array}$ & $\begin{array}{c}\text { Value of } \chi^{2} \\
\text { (difference between calculated and } \\
\text { recorded inlet flows })\end{array}$ \\
\hline \multicolumn{5}{|c|}{ The burst exponent $=0.5$} \\
\hline 272 & 2.563226 & 0.074651 & 0.001529 & $1.80 \mathrm{E}-08$ \\
\hline 21 & 2.488546 & 0.082557 & 0.001502 & $1.20 \mathrm{E}-08$ \\
\hline 82 & 2.829353 & 0.038304 & 0.001685 & $1.57 \mathrm{E}-07$ \\
\hline 104 & 2.829267 & 0.038318 & 0.001685 & $1.57 \mathrm{E}-07$ \\
\hline 109 & 2.829271 & 0.038317 & 0.001685 & $1.57 \mathrm{E}-07$ \\
\hline 119 & 2.811203 & 0.04158 & 0.001668 & $6.01 \mathrm{E}-10$ \\
\hline 172 & 1.743729 & 0.14285 & 0.001351 & $9.69 \mathrm{E}-09$ \\
\hline 185 & 2.445957 & 0.086933 & 0.001489 & $2.68 \mathrm{E}-09$ \\
\hline 191 & 2.149506 & 0.11318 & 0.001416 & $2.67 \mathrm{E}-09$ \\
\hline 205 & 2.14837 & 0.113259 & 0.001416 & $6.00 \mathrm{E}-08$ \\
\hline 259 & 2.737868 & 0.053058 & 0.001614 & \\
\hline
\end{tabular}

The results in yellow indicate both burst and background leakage in the network. The values of the $\chi^{2}$ criterion confirm the high accuracy of the estimated values of the demand and the coefficients of the fixed and variable leakage terms.

Application of the algorithm for burst location identification has detected a burst site in the network:

Table 6.8 Results of the burst location identification algorithm (Second part of experiment)

\begin{tabular}{|c|c|}
\hline Burst node & $\begin{array}{c}\text { Value of } \chi^{2} \\
\text { (reflects an in prediction of burst } \\
\text { location) }\end{array}$ \\
\hline 200 & $1.78 \mathrm{E}-07$ \\
\hline 202 & $3.75 \mathrm{E}-07$ \\
\hline 203 & $3.95 \mathrm{E}-07$ \\
\hline 205 & $4.12 \mathrm{E}-07$ \\
\hline 196 & $4.51 \mathrm{E}-07$ \\
\hline 206 & $4.98 \mathrm{E}-07$ \\
\hline
\end{tabular}

The obtained results especially the exponent of $\chi^{2}$ criterion indicates a high degree of probability of the burst presence close to node 200 (Figure 6.11). The value of the total demand flow is $1.7 \mathrm{l} / \mathrm{s}$, the value of the coefficient of the fixed area leakage (burst) is 0.14 (which corresponds to a burst flow of about $1 \mathrm{l} / \mathrm{s}$ ), the value of the coefficient of the total background leakage is 0.00135 . 


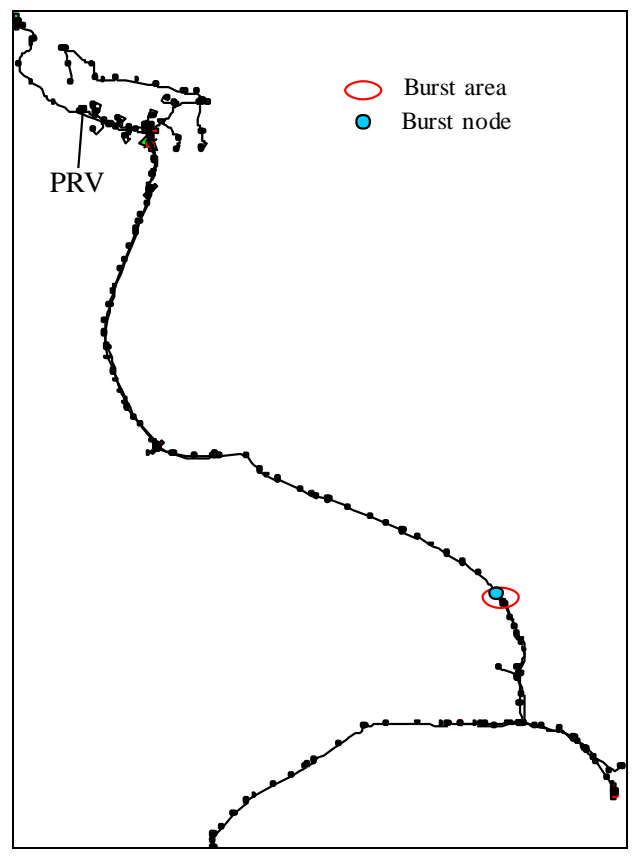

Fig. 6.11 E054 DMA. Results of second part of experiment.

The real burst for the above experiments on E054 DMA was set in the node 206 and this corresponds to the obtained results. 


\section{Conclusion}

The research has addressed the problem of the identification of burst locations, which is a very important aspect of leakage management. The solution should help water companies to estimate the presence, the size and the location of a burst and also the total background leakage through a simple field data analysis leading to reduced water losses, improved customer service and a reduction in socio-economic disruptions.

Some aspects of searching for solutions of such issues have been expressed by the author of the present thesis during discussions at the Moscow University conference "Information and Control Systems in XXI century" (Borovik \& Pavlov 2000) and have found their reflection in the published reports (Borovik \& Pavlov 2007, Borovik \& Yanov 2007).

The overall thesis has been that the different behaviors of background leakage and burst leakage under varying water pressure can be used to develop a method for burst detection and burst location identification which subsequently could be adopted into standard industrial practice.

Initial studies used the FAVOR test field experimental data provided by the collaborating water companies. The classical FAVOR test was performed by applying stepped pressure to the network inlet and recording the inlet flow(s). Later case studies used the e-FAVOR test experimental data. The e-FAVOR test is the same as the FAVOR test but in addition includes the pressure at internal nodes. The industrial partners provided case-study DMAs (models) and, wherever possible, the requested field measurements. However, the majority of the research had to be performed using numerical experiments and 'experimental' data generated by hydraulic simulators.

The research has been performed in three stages:

1. Detection of the presence of a burst in a network on the basis of measurements of inlet flow and inlet pressure.

2. Determination of the size of a potential burst using the measured data of inlet pressure, inlet flow and pressure at the sensitive nodes of the network.

3. Finding out burst locations in a network on the basis of measured data of inlet pressure, inlet flow and pressure changes at the sensitive nodes of a network. 
In the first stage described in Chapter 4 the measurements from the FAVOR test i.e. a set of inlet pressure and flow measurement to the DMA, are used to check for the presence of bursts. Data for six various networks (DMAs) have been made available to the author. It has been shown that it is possible to distinguish the following three terms in the total inlet flow: demand (which does not depend on the inlet pressure), the burst flow and the background leakage flow. A three term inlet flow model (IFM) has been created to represent this.

Additional research has been carried out, investigating individual terms in the IFM with the help of an hydraulic simulation program implemented in GAMS. The following conclusions have been reached:

- Background leakage in a network can be accurately represented by a pressure dependent term where the Average Zone Night Pressure (AZNP) is raised to the power of 1.5 .

- Burst flow is represented by a pressure dependent power term in which it is necessary to use the pressure at the burst node for accurate representation. The use of AZNP in this term creates an additional constant term which incorrectly increases the total demand term. It is impossible on the basis of input data only (inlet flow, inlet pressure and AZNP pressure) to find out precisely the burst size, but it is possible to discover its presence.

- The demand flow does not depend on the inlet pressure and has random character with a normal distribution. The probability of a demand falling within a particular range, and the demand distribution curves, have been estimated from the experimental data. However, for the reasons mentioned in the previous point it is impossible to estimate the demand accurately using only input data (inlet flow and inlet pressure).

In Stage 2 presented in Chapter 5.1 additional measurements, the pressure at sensitive nodes, have been added as input data to complement the inlet flow and pressure data. An algorithm for the selection of sensitive nodes developed by Prescott and Ulanicki (2006) has been adopted in these studies. During the research various hypotheses have been put forward and checked. Some of them, such as the hypothesis of burst size definition based on the maximal burst coefficient obtained from the ratio of inlet flow and pressure at sensitive nodes, have been rejected. 
The least squares method has been used to calculate the coefficients of the IFM, where the Average Zone Night Pressure has been substituted in the background leakage term, and the pressure at a sensitive node was used to represent the burst term.

A burst was allocated to a different sensitive node and the solution was selected which gives the minimum value of the chi-square criterion applied to the total inlet flow. This is the essence of the hybrid method of burst detection algorithm. The following observations have been made:

- The hybrid method helps to determine accurate values of the IFM parameters, the total demand and fixed and variable area leakage terms using the recorded data of the inlet pressure and flow and the pressure at the sensitive nodes of a network.

- The accuracy of the results of determining the burst size and the burst location is influenced by the magnitude of the three flows (demand, fixed area flow and variable area flow) and by the proportions between them.

The main aim of the third stage of the research presented in Chapter 5.2 and 5.3 has been to propose an identification procedure for the burst location which is more precise than other methods currently available. Initially in Chapter 5.2 it was observed that the pressure at DMA nodes depends on the inlet pressure. The gradient of a pressure line, a plot of the pressure at a node versus the inlet pressure, is smallest for the burst node or a node close to the burst node. Subsequently, in Chapter 5.3, this idea was formalised and a statistical method based on the $\chi^{2}$ criterion has been proposed, where the minimum value of $\chi^{2}$ points to the burst site.

- The exponent of the value of $\chi^{2}$ can be used as a criterion of accuracy of the burst location identification algorithm. The given criterion specifies also the accuracy of the performed experiments.

- The algorithm of burst location identification developed by the author allows for finding a potential burst site with quite high precision.

In order to validate the approach two real life case studies, Ocker Hill and Shenstone DMAs, have been analysed. In the former no burst was found but the results indicated a concentration of background leakage. In the latter case study the results were very 
accurate with a burst indicated at node 80 with a high precision of $\chi^{2}=3.2 \times 10^{-6}$. These results have not been verified by the industrial partner.

An additional case study for the E054 DMA was planned, but unfortunately the field data is not currently available and numerical experiments have been carried out instead by generating data from a simulation model.

The research has developed a number of sensitive indicators to evaluate the presence, the magnitude and the location of a burst. In further research this approach can be generalized to identify the location of many bursts. At the moment a single burst is allocated to a node and the scenario is simulated, this process needs to be repeated for all nodes of the network. This process could be automated and some search algorithm (e.g. based on an evolutionary approach) could be adopted for this purpose. 


\section{Appendix A - FAVOR Test Data}

Seven single-input Demand Management Areas (DMAs) were tested as well. A typical FAVOR test was carried out during the night between 1 a.m. and 5 a.m. During the period of recordings, the inlet pressure was changed stepwise over a typical range of values at 20-minute or 30-minute intervals. The inlet pressure and flow were recorded at 20 -seconds intervals. The results of the FAVOR Test are shown below.

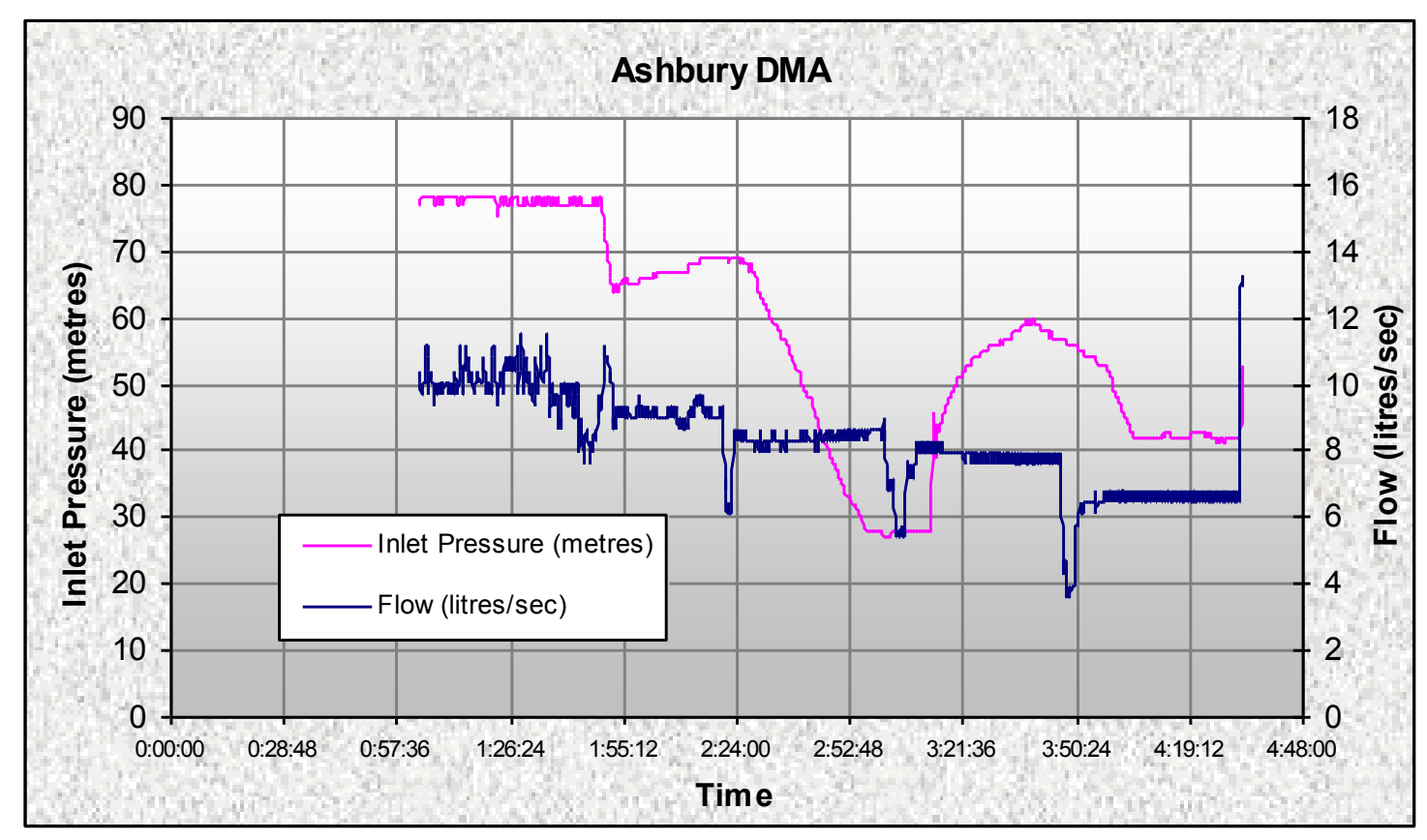

Fig. A.0.1 FAVOR Test Data. Ashbury DMA. 


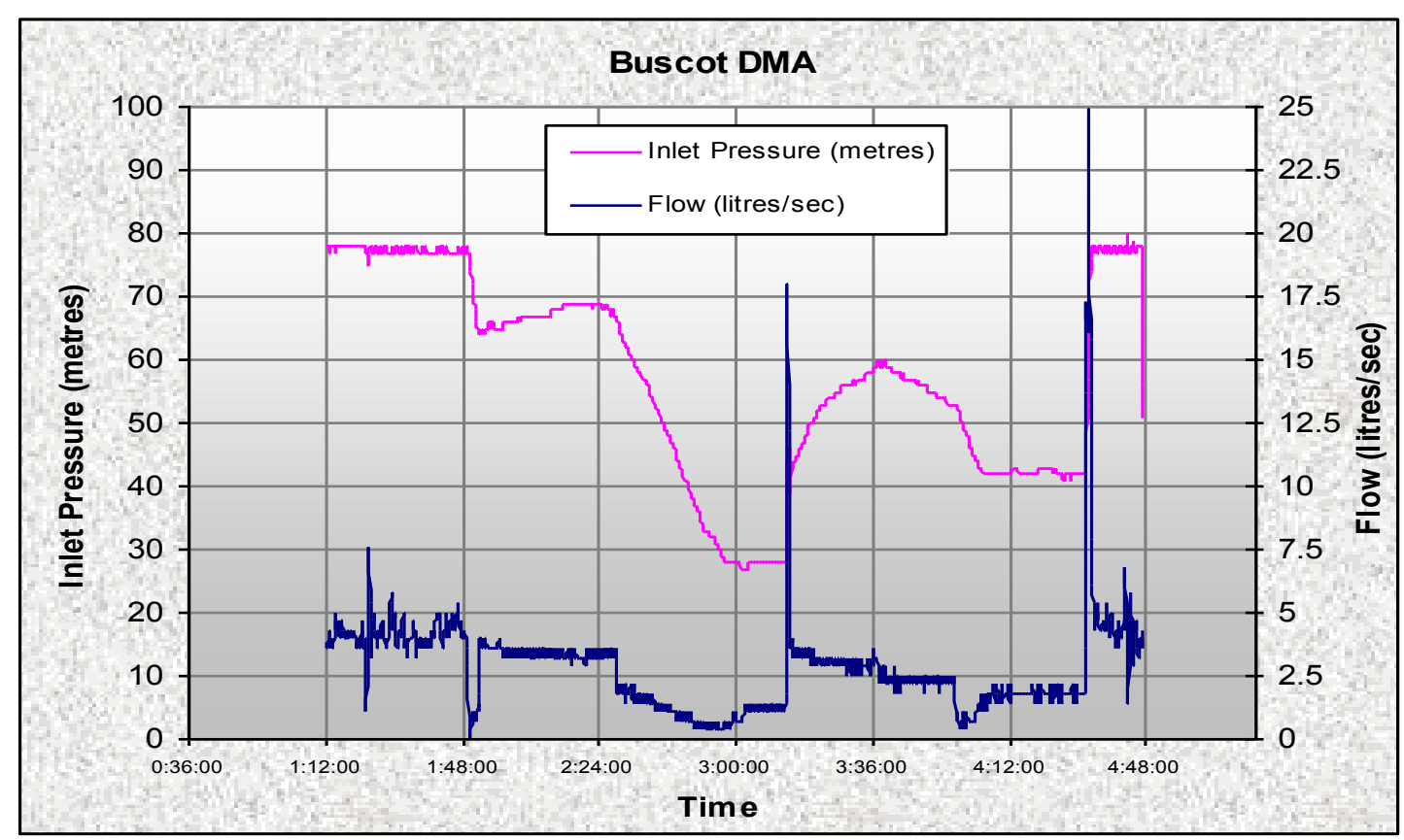

Fig. A.0.2 FAVOR Test Data. Buscot DMA.

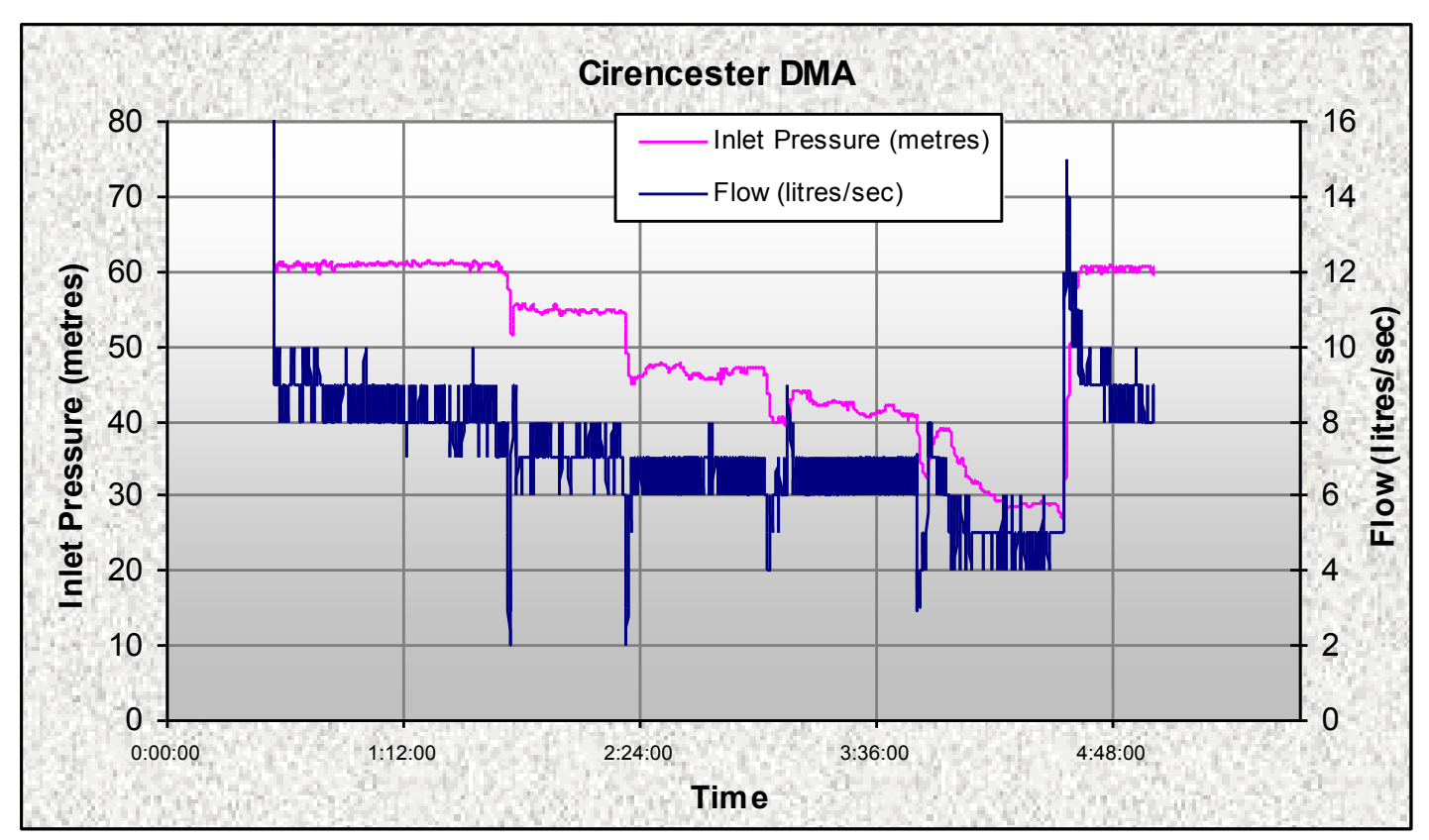

Fig. A.0.3 FAVOR Test Data. Cirencester DMA. 


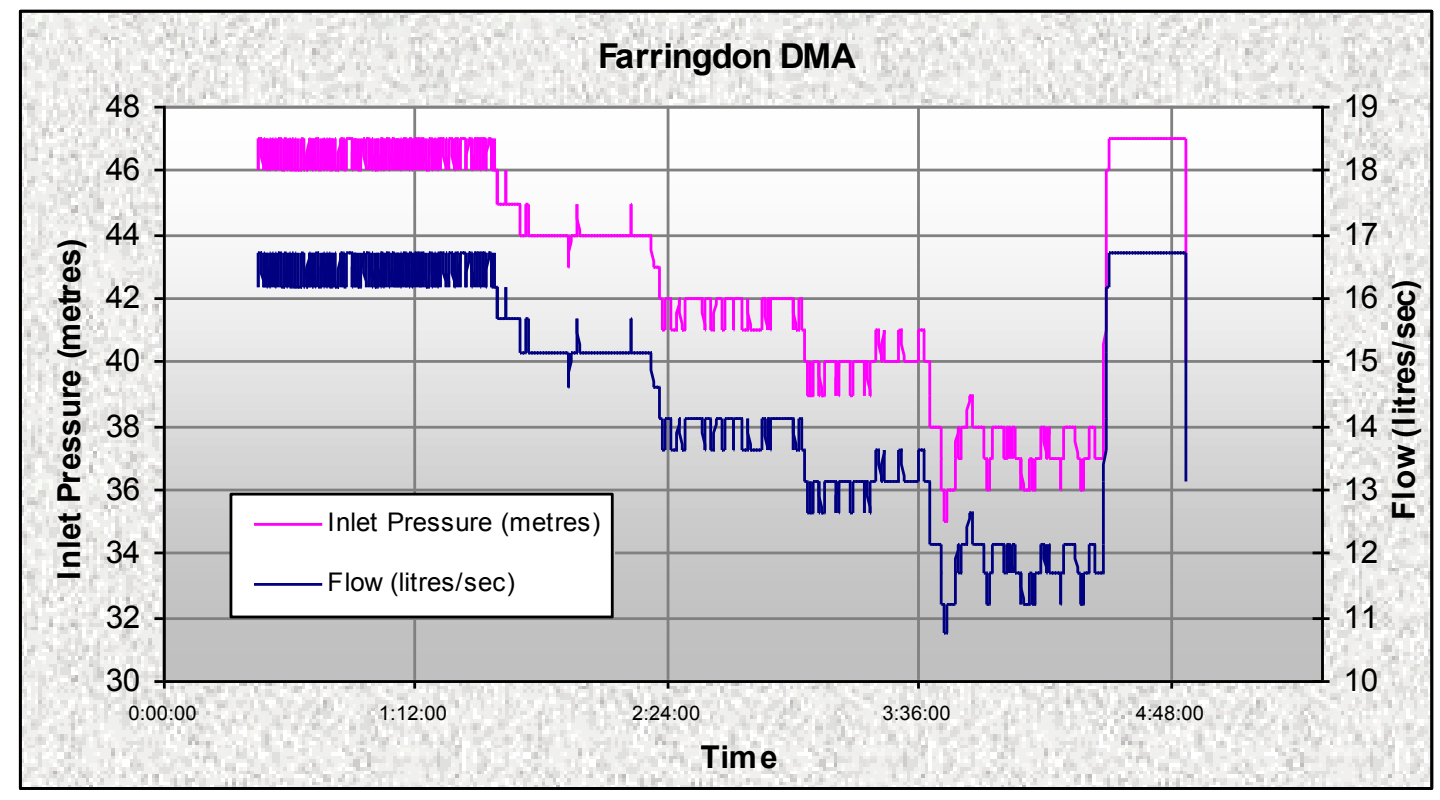

Fig. A.0.4 FAVOR Test Data. Farringdon DMA.

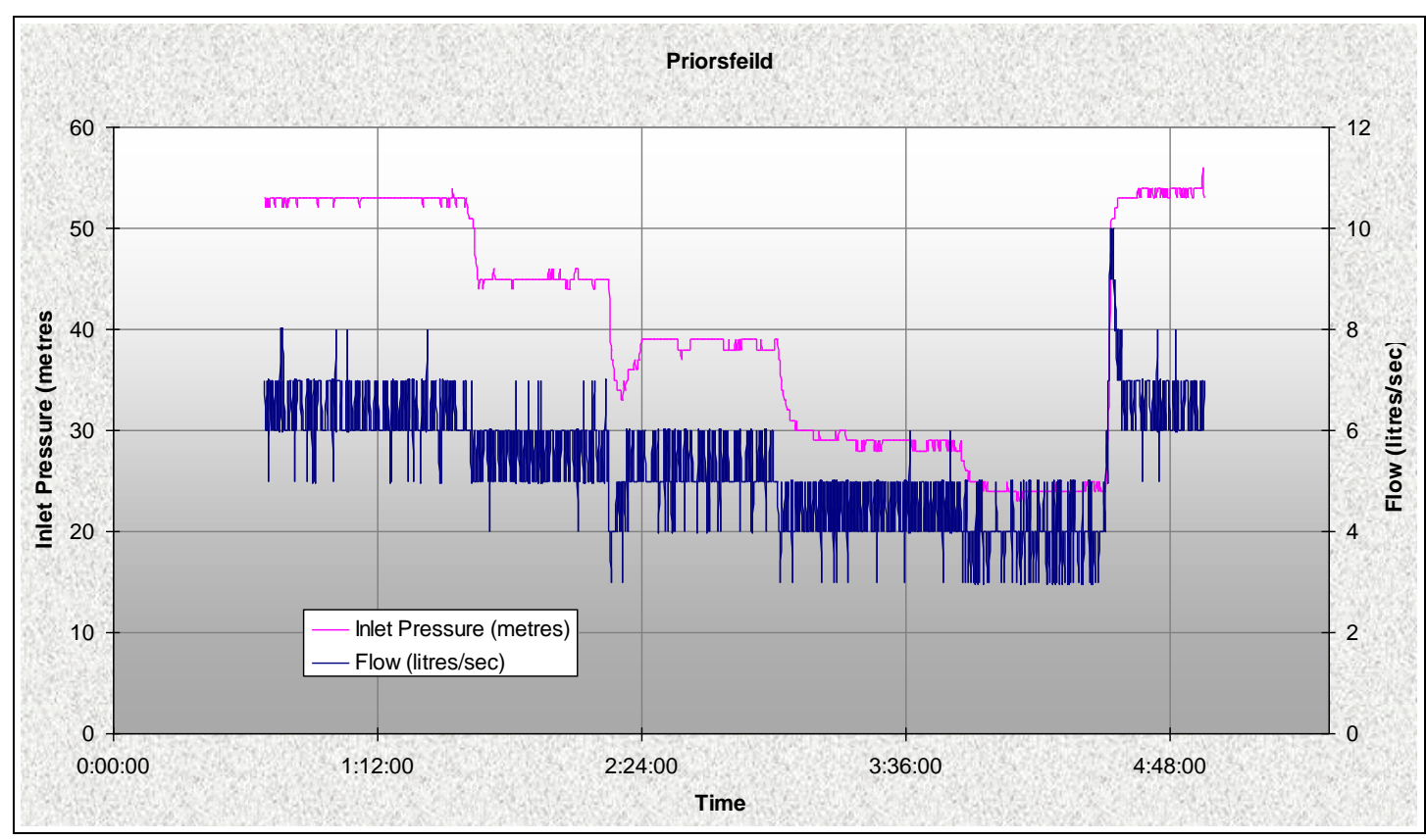

Fig. A.0.5 FAVOR Test Data. Priosfeild DMA. 


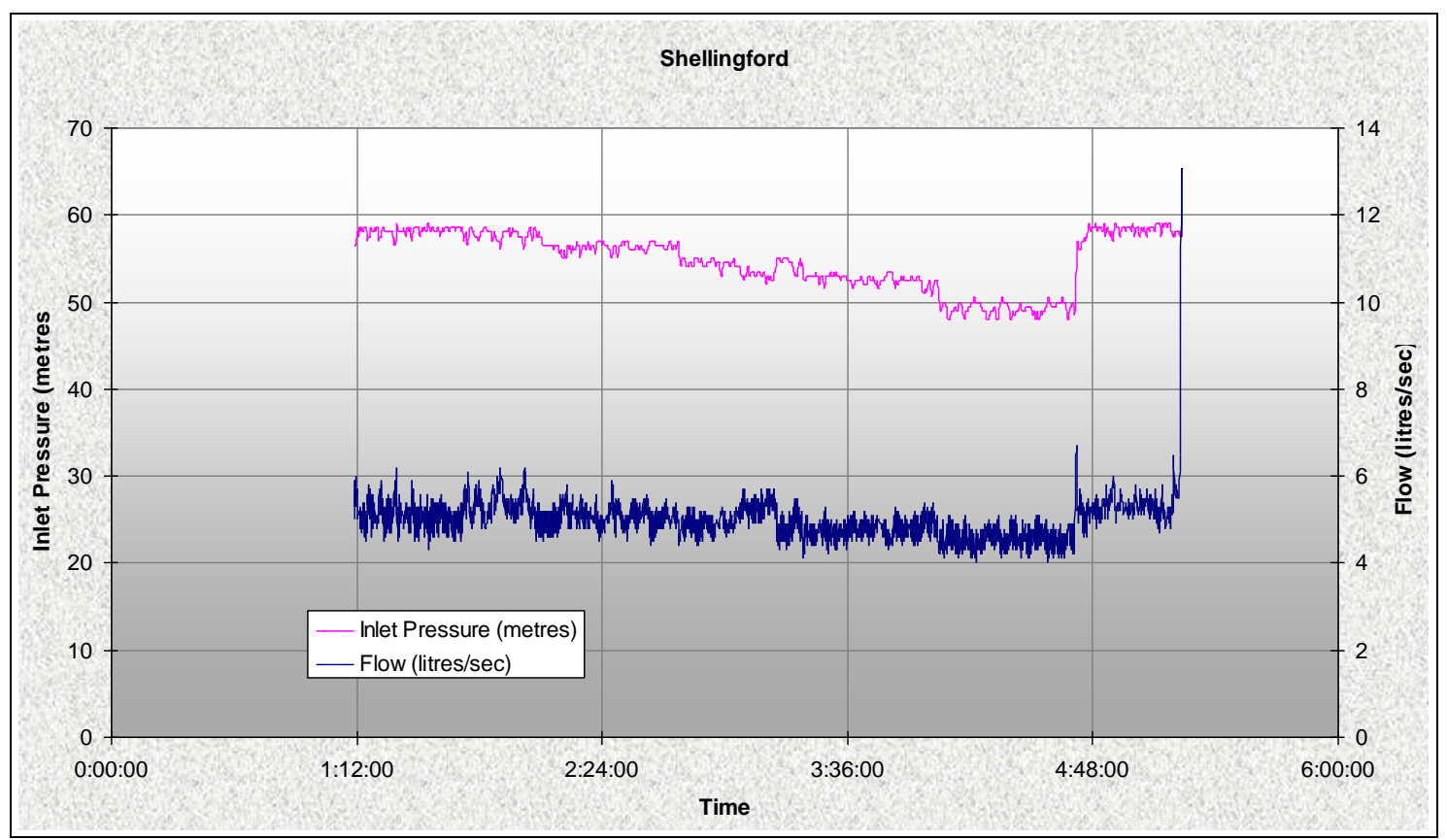

Fig. A.0.6 FAVOR Test Data. Shellingford DMA. 


\section{Appendix B - Node and Element Data for the Frizinghall DMA}

Table B.0.1 Node Data for Frizinghall DMA

\begin{tabular}{|c|c|c|c|c|c|}
\hline $\begin{array}{c}\text { Node } \\
\text { No }\end{array}$ & Node Type & $\begin{array}{l}\text { Demand } \\
\text { Factor }\end{array}$ & $\begin{array}{l}\text { Elevation } \\
\text { (m) }\end{array}$ & $\begin{array}{c}\text { Horizontal } \\
\text { Coordinate } \\
\text { of node }\end{array}$ & $\begin{array}{c}\text { Vertical } \\
\text { Coordinate } \\
\text { of node }\end{array}$ \\
\hline 5 & Source node & 0 & 148.24 & 90 & 124 \\
\hline 10 & connection node & 0 & 114 & 248 & 238 \\
\hline 15 & connection node & 0 & 114 & 264 & 222 \\
\hline 20 & connection node & 0.086216 & 113 & 292 & 210 \\
\hline 25 & connection node & 0 & 114 & 318 & 206 \\
\hline 30 & connection node & 0.068742 & 124 & 320 & 171 \\
\hline 35 & connection node & 0 & 136 & 320 & 137 \\
\hline 40 & connection node & 0.075512 & 111.339 & 364 & 197 \\
\hline 45 & connection node & 0 & 109.839 & 392 & 208 \\
\hline 50 & connection node & 0.045765 & 109 & 392 & 219 \\
\hline 55 & connection node & 0 & 110 & 425 & 207 \\
\hline 60 & connection node & 0 & 110 & 449 & 193 \\
\hline 65 & connection node & 0.057965 & 108 & 470 & 208 \\
\hline 70 & connection node & 0 & 108 & 504 & 200 \\
\hline 75 & connection node & 0.043062 & 109 & 541 & 193 \\
\hline 76 & connection node & 0 & 105 & 541 & 215 \\
\hline 77 & connection node & 0 & 102.239 & 525 & 222 \\
\hline 80 & connection node & 0.090227 & 108 & 576 & 184 \\
\hline 85 & connection node & 0 & 97 & 600 & 221 \\
\hline 90 & connection node & 0 & 95 & 617 & 252 \\
\hline 95 & connection node & 0.074389 & 96 & 645 & 235 \\
\hline 100 & connection node & 0 & 95 & 673 & 218 \\
\hline 104 & connection node & 0 & 107 & 624 & 167 \\
\hline 105 & connection node & 0.119266 & 107 & 611 & 175 \\
\hline 110 & connection node & 0.056677 & 105.519 & 655 & 145 \\
\hline 115 & connection node & 0.031842 & 104.089 & 699 & 104 \\
\hline 120 & connection node & 0.037247 & 99 & 718 & 141 \\
\hline 121 & connection node & 0 & 98 & 696 & 157 \\
\hline 125 & connection node & 0.079792 & 94 & 674 & 172 \\
\hline 130 & connection node & 0 & 93 & 745 & 185 \\
\hline 135 & connection node & 0 & 93 & 720 & 203 \\
\hline 140 & connection node & 0.153358 & 85 & 783 & 244 \\
\hline 145 & connection node & 0.066469 & 86 & 830 & 209 \\
\hline 155 & connection node & 0 & 83 & 786 & 280 \\
\hline 160 & connection node & 0 & 80.69 & 752 & 293 \\
\hline 165 & connection node & 0.184693 & 86 & 727 & 256 \\
\hline 170 & connection node & 0 & 86 & 674 & 290 \\
\hline 175 & connection node & 0.109184 & 87.48 & 644 & 328 \\
\hline
\end{tabular}




\begin{tabular}{|c|c|c|c|c|c|}
\hline $\begin{array}{l}\text { Node } \\
\text { No }\end{array}$ & Node Type & $\begin{array}{l}\text { Demand } \\
\text { Factor }\end{array}$ & $\begin{array}{l}\text { Elevation } \\
\text { (m) }\end{array}$ & $\begin{array}{c}\text { Horizontal } \\
\text { Coordinate } \\
\text { of node }\end{array}$ & $\begin{array}{c}\text { Vertical } \\
\text { Coordinate } \\
\text { of node }\end{array}$ \\
\hline 180 & connection node & 0.157161 & 85 & 695 & 367 \\
\hline 185 & connection node & 0 & 84 & 722 & 389 \\
\hline 190 & connection node & 0 & 89 & 612 & 395 \\
\hline 195 & connection node & 0.235524 & 87.8899 & 586 & 384 \\
\hline 200 & connection node & 0 & 90 & 564 & 376 \\
\hline 205 & connection node & 0 & 90 & 539 & 369 \\
\hline 210 & connection node & 0 & 92 & 596 & 309 \\
\hline 215 & connection node & 0 & 94 & 590 & 289 \\
\hline 220 & connection node & 0 & 93 & 518 & 361 \\
\hline 221 & connection node & 0 & 95 & 497 & 352 \\
\hline 225 & connection node & 0.076592 & 97 & 476 & 345 \\
\hline 226 & connection node & 0.050362 & 98.0999 & 454 & 338 \\
\hline 230 & connection node & 0.112989 & 102 & 514 & 243 \\
\hline 235 & connection node & 0 & 105 & 516 & 218 \\
\hline 240 & connection node & 0 & 110 & 284 & 236 \\
\hline 241 & connection node & 0.136793 & 108 & 304 & 260 \\
\hline 242 & connection node & 0 & 106 & 371 & 262 \\
\hline 245 & connection node & 0 & 109 & 268 & 257 \\
\hline 246 & connection node & 0 & 99.7399 & 431 & 354 \\
\hline 250 & connection node & 0.105316 & 90 & 530 & 380 \\
\hline 255 & connection node & 0.154766 & 88 & 498 & 440 \\
\hline 260 & connection node & 0 & 83.62 & 463 & 484 \\
\hline 265 & connection node & 0.118223 & 86 & 468 & 466 \\
\hline 270 & connection node & 0 & 85 & 489 & 454 \\
\hline 275 & connection node & 0 & 86 & 509 & 455 \\
\hline 280 & connection node & 0 & 82 & 818 & 438 \\
\hline 281 & connection node & 0 & 76.62 & 781 & 449 \\
\hline 285 & connection node & 0 & 82 & 564 & 502 \\
\hline 290 & connection node & 0 & 82 & 544 & 506 \\
\hline 295 & connection node & 0 & 81.33 & 506 & 531 \\
\hline 300 & connection node & 0 & 81 & 508 & 557 \\
\hline 305 & connection node & 0.0335 & 84.2699 & 305 & 610 \\
\hline 310 & connection node & 0.075 & 86.97 & 460 & 674 \\
\hline 315 & connection node & 0 & 87 & 470 & 730 \\
\hline 320 & connection node & 0.079723 & 95 & 540 & 723 \\
\hline 325 & connection node & 0 & 92 & 451 & 746 \\
\hline 330 & connection node & 0 & 95 & 412 & 744 \\
\hline 335 & connection node & 0.122334 & 95 & 452 & 766 \\
\hline 340 & connection node & 0 & 96 & 411 & 766 \\
\hline 345 & connection node & 0.1738 & 98.25 & 459 & 789 \\
\hline 350 & connection node & 0.038347 & 97 & 368 & 772 \\
\hline 351 & connection node & 0 & 88 & 196 & 711 \\
\hline 352 & connection node & 0.074923 & 87 & 145 & 732 \\
\hline 355 & connection node & 0 & 90 & 351 & 746 \\
\hline 356 & connection node & 0 & 90 & 304 & 754 \\
\hline 357 & connection node & 0 & 90 & 289 & 768 \\
\hline
\end{tabular}




\begin{tabular}{|c|c|c|c|c|c|}
\hline $\begin{array}{c}\text { Node } \\
\text { No }\end{array}$ & Node Type & $\begin{array}{c}\text { Demand } \\
\text { Factor }\end{array}$ & $\begin{array}{c}\text { Elevation } \\
(\mathrm{m})\end{array}$ & $\begin{array}{c}\text { Horizontal } \\
\text { Coordinate } \\
\text { of node }\end{array}$ & $\begin{array}{c}\text { Vertical } \\
\text { Coordinate } \\
\text { of node }\end{array}$ \\
\hline 360 & connection node & 0.055477 & 107 & 458 & 826 \\
\hline 365 & connection node & 0.135497 & 110 & 369 & 840 \\
\hline 370 & connection node & 0 & 110 & 412 & 840 \\
\hline 375 & connection node & 0.038847 & 119 & 458 & 854 \\
\hline 376 & connection node & 0 & 114.97 & 369 & 854 \\
\hline 380 & connection node & 0.038169 & 125 & 458 & 885 \\
\hline 385 & connection node & 0.090139 & 114 & 539 & 872 \\
\hline
\end{tabular}

Table B.0.2 Element Data for the Frizinghall DMA

\begin{tabular}{|c|c|c|c|c|c|c|c|c|c|}
\hline \multicolumn{2}{|c|}{$\begin{array}{l}\text { Pipe Location } \\
(\text { Node } \rightarrow \text { Node })\end{array}$} & \multirow{2}{*}{$\begin{array}{c}\begin{array}{c}\text { Length } \\
(\mathrm{m})\end{array} \\
375\end{array}$} & \multirow{2}{*}{$\begin{array}{c}\begin{array}{c}\text { Diameter } \\
(\mathrm{mm})\end{array} \\
305\end{array}$} & \multirow{2}{*}{$\begin{array}{c}\text { C-Value } \\
80\end{array}$} & \multicolumn{2}{|c|}{$\begin{array}{l}\text { Pipe Location } \\
(\text { Node } \rightarrow \text { Node) }\end{array}$} & \multirow{2}{*}{$\begin{array}{c}\begin{array}{c}\text { Length } \\
\text { (m) }\end{array} \\
90\end{array}$} & \multirow{2}{*}{$\begin{array}{c}\begin{array}{c}\text { Diameter } \\
(\mathrm{mm})\end{array} \\
100\end{array}$} & \multirow{2}{*}{$\begin{array}{c}\text { C-Value } \\
100\end{array}$} \\
\hline 5 & 10 & & & & 200 & 255 & & & \\
\hline 10 & 15 & 29 & 152 & 100 & 200 & 205 & 10 & 127 & 100 \\
\hline 10 & 245 & 60 & 305 & 80 & 205 & 210 & 101 & 102 & 70 \\
\hline 15 & 20 & 10 & 127 & 100 & 205 & 220 & 36 & 127 & 100 \\
\hline 15 & 240 & 58 & 127 & 100 & 215 & 220 & 122 & 102 & 70 \\
\hline 20 & 25 & 30 & 152 & 100 & 220 & 221 & 42 & 102 & 70 \\
\hline 20 & 45 & 196 & 102 & 100 & 221 & 225 & 10 & 127 & 100 \\
\hline 25 & 30 & 91 & 152 & 70 & 225 & 230 & 108 & 102 & 100 \\
\hline 25 & 45 & 170 & 102 & 100 & 225 & 226 & 46 & 127 & 100 \\
\hline 30 & 35 & 96 & 152 & 70 & 226 & 241 & 298 & 127 & 100 \\
\hline 30 & 40 & 230 & 102 & 70 & 230 & 235 & 70 & 76 & 70 \\
\hline 45 & 50 & 10 & 102 & 100 & 240 & 241 & 10 & 127 & 100 \\
\hline 45 & 55 & 70 & 152 & 100 & 240 & 245 & 10 & 152 & 70 \\
\hline 50 & 65 & 260 & 102 & 100 & 241 & 242 & 152 & 102 & 70 \\
\hline 55 & 60 & 51 & 76 & 70 & 245 & 246 & 275 & 305 & 80 \\
\hline 55 & 65 & 37 & 152 & 100 & 246 & 250 & 180 & 305 & 80 \\
\hline 65 & 70 & 40 & 152 & 100 & 250 & 290 & 163 & 305 & 80 \\
\hline 70 & 75 & 85 & 152 & 100 & 255 & 260 & 125 & 100 & 100 \\
\hline 75 & 76 & 43 & 102 & 100 & 255 & 275 & 52 & 100 & 100 \\
\hline 75 & 80 & 30 & 152 & 100 & 260 & 265 & 2.77 & 100 & 100 \\
\hline 76 & 77 & 56 & 102 & 100 & 270 & 275 & 2.77 & 100 & 100 \\
\hline 77 & 230 & 60 & 102 & 100 & 280 & 281 & 20 & 150 & 100 \\
\hline 80 & 85 & 72 & 102 & 70 & 281 & 285 & 455 & 150 & 100 \\
\hline 80 & 105 & 55 & 152 & 100 & 285 & 290 & 10 & 102 & 70 \\
\hline 90 & 95 & 58 & 102 & 70 & 290 & 295 & 55 & 229 & 70 \\
\hline 95 & 100 & 61 & 102 & 70 & 295 & 300 & 10 & 76 & 70 \\
\hline 95 & 105 & 86 & 102 & 70 & 295 & 310 & 210 & 229 & 75 \\
\hline 104 & 105 & 10 & 152 & 100 & 300 & 305 & 380 & 76 & 70 \\
\hline 104 & 110 & 17.3 & 152 & 70 & 310 & 315 & 22 & 229 & 75 \\
\hline 110 & 115 & 103 & 127 & 70 & 310 & 325 & 82 & 102 & 70 \\
\hline 110 & 125 & 76 & 102 & 70 & 315 & 320 & 126 & 102 & 70 \\
\hline 115 & 120 & 65 & 101 & 130 & 315 & 345 & 142 & 229 & 75 \\
\hline 120 & 121 & 52 & 73 & 120 & 325 & 330 & 70 & 102 & 70 \\
\hline
\end{tabular}




\begin{tabular}{|c|c|c|c|c|c|c|c|c|c|}
\hline \multicolumn{2}{|c|}{$\begin{array}{c}\text { Pipe Location } \\
(\text { Node } \rightarrow \text { Node })\end{array}$} & $\begin{array}{c}\text { Length } \\
(\mathrm{m})\end{array}$ & $\begin{array}{c}\text { Diameter } \\
(\mathrm{mm})\end{array}$ & C-Value & \multicolumn{2}{c|}{$\begin{array}{c}\text { Pipe Location } \\
(\text { Node } \rightarrow \text { Node })\end{array}$} & $\begin{array}{c}\text { Length } \\
(\mathrm{m})\end{array}$ & $\begin{array}{c}\text { Diameter } \\
(\mathrm{mm})\end{array}$ & C-Value \\
\hline 120 & 130 & 75 & 101 & 130 & 325 & 335 & 28 & 102 & 70 \\
\hline 121 & 125 & 52 & 102 & 70 & 335 & 340 & 70 & 102 & 70 \\
\hline 125 & 165 & 110 & 102 & 70 & 335 & 345 & 56 & 102 & 70 \\
\hline 130 & 135 & 46 & 76 & 70 & 345 & 385 & 190 & 152 & 70 \\
\hline 130 & 140 & 117 & 101 & 130 & 345 & 350 & 97 & 145 & 140 \\
\hline 140 & 145 & 65 & 73 & 120 & 345 & 360 & 58 & 152 & 70 \\
\hline 140 & 155 & 65 & 101 & 130 & 350 & 355 & 100 & 101 & 120 \\
\hline 155 & 160 & 88 & 101 & 130 & 350 & 356 & 133 & 145 & 140 \\
\hline 160 & 165 & 106 & 102 & 70 & 351 & 352 & 140 & 76 & 70 \\
\hline 160 & 180 & 140 & 102 & 70 & 351 & 356 & 225 & 145 & 140 \\
\hline 165 & 170 & 50 & 127 & 70 & 356 & 357 & 25 & 150 & 100 \\
\hline 170 & 175 & 92 & 102 & 70 & 360 & 375 & 53 & 152 & 70 \\
\hline 175 & 180 & 90 & 102 & 70 & 360 & 365 & 135 & 102 & 70 \\
\hline 175 & 195 & 120 & 102 & 70 & 365 & 370 & 52 & 38 & 100 \\
\hline 180 & 185 & 36 & 102 & 70 & 365 & 376 & 28 & 100 & 100 \\
\hline 190 & 195 & 15 & 127 & 100 & 375 & 376 & 125 & 76 & 70 \\
\hline 195 & 200 & 20 & 127 & 100 & 375 & 380 & 75 & 152 & 100 \\
\hline
\end{tabular}




\section{Appendix C - Node and Element Data for the Ocker Hill DMA}

The model of the network used by the author is stored in a separate excel file model.xls with the following fields:

A - Node number - a unique label used to identify the node.

B - Type of node - a binary value that describes the role of a node in a network: 0 for a connection node or 1 for a source node (reservoir node or PRV OUTLET node).

C - Demand factor - number of average water users allocated to a node.

D - Elevation (m) - elevation in metres above a common reference of a node. The elevation in used in the program only to compute the pressure at the node.

E - Coefficient of a burst - value of coefficient $c_{1}$ for a specific node is set in case of presence in a network of already known burst with specified characteristics.

$\mathrm{F}$ - Exponent of the burst term in the IFM=0.5.

$\mathrm{G}$ - Coefficient of known background leakages - value of coefficient $c_{2}$ for a specific node is set up in case of presence in a network with already known background leakages with specified characteristics.

$\mathrm{H}-$ Exponent of the background leakage term in the IFM $=1.5$.

I, J - Horizontal and vertical co-ordinates of a node on the map. They do not affect any other variable.

Table C.0.1 Complete nodes data for the Ocker Hill DMA

\begin{tabular}{|c|c|c|c|c|c|c|c|c|c|}
\hline $\begin{array}{l}\text { Node } \\
\text { No }\end{array}$ & $\begin{array}{l}\text { Node } \\
\text { Type }\end{array}$ & $\begin{array}{l}\text { Demand } \\
\text { Factor }\end{array}$ & $\begin{array}{c}\text { Elevation } \\
\text { (m) }\end{array}$ & $\begin{array}{c}\text { Coefficient } \\
\text { of burst }\end{array}$ & $\begin{array}{c}\text { Exponent } \\
\text { of burst } \\
\text { term }\end{array}$ & $\begin{array}{c}\text { Coefficient } \\
\text { of } \\
\text { background } \\
\text { leakage }\end{array}$ & $\begin{array}{c}\text { Exponent } \\
\text { of } \\
\text { background } \\
\text { leakage }\end{array}$ & $\begin{array}{l}\text { Horizontal } \\
\text { Coordinate } \\
\text { of node }\end{array}$ & $\begin{array}{c}\text { Vertical } \\
\text { Coordinate } \\
\text { of node }\end{array}$ \\
\hline 1 & 0 & 0 & 137.5 & 0 & 0.5 & 0 & 1.5 & 397352253 & 293887282 \\
\hline 2 & 0 & 0 & 136 & 0 & 0.5 & 0 & 1.5 & 397385856 & 293880736 \\
\hline 3 & 0 & 0 & 137.5 & 0 & 0.5 & 0 & 1.5 & 397352160 & 293889888 \\
\hline 4 & 0 & 0 & 137.5 & 0 & 0.5 & 0 & 1.5 & 397350560 & 293887808 \\
\hline 5 & 0 & 0 & 137.5 & 0 & 0.5 & 0 & 1.5 & 397349378 & 293887840 \\
\hline 6 & 0 & 0 & 139 & 0 & 0.5 & 0 & 1.5 & 397316288 & 293889696 \\
\hline 7 & 0 & 3 & 140 & 0 & 0.5 & 0 & 1.5 & 397272832 & 293889056 \\
\hline 8 & 0 & 0 & 140.5 & 0 & 0.5 & 0 & 1.5 & 397221728 & 293880480 \\
\hline 9 & 0 & 0 & 140 & 0 & 0.5 & 0 & 1.5 & 397204704 & 293876608 \\
\hline 10 & 0 & 3 & 140 & 0 & 0.5 & 0 & 1.5 & 397202976 & 293876096 \\
\hline 11 & 0 & 0 & 140 & 0 & 0.5 & 0 & 1.5 & 397196896 & 293876544 \\
\hline
\end{tabular}




\begin{tabular}{|c|c|c|c|c|c|c|c|c|c|}
\hline $\begin{array}{l}\text { Node } \\
\text { No }\end{array}$ & $\begin{array}{l}\text { Node } \\
\text { Type }\end{array} \mid$ & $\begin{array}{l}\text { Demand } \\
\text { Factor }\end{array}$ & $\begin{array}{c}\text { Elevation } \\
\text { (m) }\end{array}$ & $\begin{array}{c}\text { Coefficient } \\
\text { of burst }\end{array}$ & $\begin{array}{c}\text { Exponent } \\
\text { of burst } \\
\text { term }\end{array}$ & $\begin{array}{c}\text { Coefficient } \\
\text { of } \\
\text { background } \\
\text { leakage }\end{array}$ & $\begin{array}{c}\text { Exponent } \\
\text { of } \\
\text { background } \\
\text { leakage }\end{array}$ & $\begin{array}{l}\text { Horizontal } \\
\text { Coordinate } \\
\text { of node }\end{array}$ & $\begin{array}{l}\text { Vertical } \\
\text { Coordinate } \\
\text { of node }\end{array}$ \\
\hline 12 & 0 & 5 & 140.5 & 0 & 0.5 & 0 & 1.5 & 397277568 & 293884768 \\
\hline 13 & 0 & 0 & 140.5 & 0 & 0.5 & 0 & 1.5 & 397274624 & 293881536 \\
\hline 14 & 0 & 0 & 140 & 0 & 0.5 & 0 & 1.5 & 397200046 & 293875298 \\
\hline 15 & 0 & 0 & 140 & 0 & 0.5 & 0 & 1.5 & 397199968 & 293875232 \\
\hline 16 & 0 & 3 & 140 & 0 & 0.5 & 0 & 1.5 & 397196018 & 293874157 \\
\hline 17 & 0 & 0 & 140 & 0 & 0.5 & 0 & 1.5 & 397194848 & 293873824 \\
\hline 18 & 0 & 8 & 140 & 0 & 0.5 & 0 & 1.5 & 397178496 & 293868864 \\
\hline 19 & 0 & 0 & 139.5 & 0 & 0.5 & 0 & 1.5 & 397133696 & 293854240 \\
\hline 20 & 0 & 4 & 139.5 & 0 & 0.5 & 0 & 1.5 & 397121088 & 293850624 \\
\hline 21 & 0 & 1 & 139 & 0 & 0.5 & 0 & 1.5 & 397063360 & 293833856 \\
\hline 22 & 0 & 0 & 137 & 0 & 0.5 & 0 & 1.5 & 397052096 & 293849792 \\
\hline 23 & 0 & 0 & 137 & 0 & 0.5 & 0 & 1.5 & 397050464 & 293848576 \\
\hline 24 & 0 & 0 & 137 & 0 & 0.5 & 0 & 1.5 & 397047040 & 293852992 \\
\hline 25 & 0 & 8 & 137 & 0 & 0.5 & 0 & 1.5 & 397048960 & 293854304 \\
\hline 26 & 0 & 0 & 134 & 0 & 0.5 & 0 & 1.5 & 397349664 & 293821920 \\
\hline 27 & 0 & 0 & 130 & 0 & 0.5 & 0 & 1.5 & 397399712 & 293779808 \\
\hline 28 & 0 & 0 & 130 & 0 & 0.5 & 0 & 1.5 & 397405344 & 293779808 \\
\hline 29 & 0 & 0 & 139 & 0 & 0.5 & 0 & 1.5 & 397057440 & 293827232 \\
\hline 30 & 0 & 12 & 139 & 0 & 0.5 & 0 & 1.5 & 397053376 & 293824512 \\
\hline 31 & 0 & 0 & 139 & 0 & 0.5 & 0 & 1.5 & 397061632 & 293825408 \\
\hline 32 & 0 & 8 & 130.75 & 0 & 0.5 & 0 & 1.5 & 396959232 & 293996128 \\
\hline 33 & 0 & 19 & 132.64 & 0 & 0.5 & 0 & 1.5 & 396907232 & 293967616 \\
\hline 34 & 0 & 56 & 132.7 & 0 & 0.5 & 0 & 1.5 & 396902848 & 293965344 \\
\hline 35 & 0 & 36 & 131.56 & 0 & 0.5 & 0 & 1.5 & 396824864 & 293921728 \\
\hline 36 & 0 & 37 & 132.85 & 0 & 0.5 & 0 & 1.5 & 396761088 & 293884256 \\
\hline 37 & 0 & 0 & 133.29 & 0 & 0.5 & 0 & 1.5 & 396723328 & 293826752 \\
\hline 38 & 0 & 36 & 133.17 & 0 & 0.5 & 0 & 1.5 & 396706688 & 293809792 \\
\hline 39 & 0 & 22 & 133.15 & 0 & 0.5 & 0 & 1.5 & 396644736 & 293924736 \\
\hline 40 & 0 & 16 & 135.1 & 0 & 0.5 & 0 & 1.5 & 396536992 & 293908224 \\
\hline 41 & 0 & 15 & 135.14 & 0 & 0.5 & 0 & 1.5 & 396535360 & 293907968 \\
\hline 42 & 0 & 0 & 135.12 & 0 & 0.5 & 0 & 1.5 & 396518880 & 293905440 \\
\hline 43 & 0 & 0 & 136.7 & 0 & 0.5 & 0 & 1.5 & 396403968 & 293887744 \\
\hline 44 & 0 & 49 & 137 & 0 & 0.5 & 0 & 1.5 & 396386336 & 293885504 \\
\hline 45 & 0 & 0 & 136.2 & 0 & 0.5 & 0 & 1.5 & 396384224 & 293829632 \\
\hline 46 & 0 & 21 & 136 & 0 & 0.5 & 0 & 1.5 & 396387968 & 293816640 \\
\hline 47 & 0 & 19 & 136.2 & 0 & 0.5 & 0 & 1.5 & 396364832 & 293799104 \\
\hline 48 & 0 & 0 & 136.5 & 0 & 0.5 & 0 & 1.5 & 396356736 & 293814336 \\
\hline 49 & 0 & 0 & 137.5 & 0 & 0.5 & 0 & 1.5 & 396328576 & 293897920 \\
\hline 50 & 0 & 31 & 139 & 0 & 0.5 & 0 & 1.5 & 397128736 & 293832512 \\
\hline 51 & 0 & 0 & 137 & 0 & 0.5 & 0 & 1.5 & 397094176 & 293796640 \\
\hline 52 & 0 & 30 & 138.4 & 0 & 0.5 & 0 & 1.5 & 396963712 & 293793984 \\
\hline 53 & 0 & 29 & 138 & 0 & 0.5 & 0 & 1.5 & 396914112 & 293772352 \\
\hline 54 & 0 & 0 & 138 & 0 & 0.5 & 0 & 1.5 & 396901600 & 293766720 \\
\hline 55 & 0 & 0 & 138 & 0 & 0.5 & 0 & 1.5 & 396852736 & 293745728 \\
\hline 56 & 0 & 33 & 137.5 & 0 & 0.5 & 0 & 1.5 & 396845376 & 293742720 \\
\hline
\end{tabular}




\begin{tabular}{|c|c|c|c|c|c|c|c|c|c|}
\hline $\begin{array}{l}\text { Node } \\
\text { No }\end{array}$ & $\left|\begin{array}{c}\text { Node } \\
\text { Type }\end{array}\right|$ & $\begin{array}{l}\text { Demand } \\
\text { Factor }\end{array}$ & $\begin{array}{l}\text { Elevatior } \\
(\mathrm{m})\end{array}$ & $\begin{array}{c}\text { Coefficient } \\
\text { of burst }\end{array}$ & $\begin{array}{c}\text { Exponent } \\
\text { of burst } \\
\text { term }\end{array}$ & $\begin{array}{c}\text { Coefficient } \\
\text { of } \\
\text { background } \\
\text { leakage }\end{array}$ & $\begin{array}{c}\text { Exponent } \\
\text { of } \\
\text { background } \\
\text { leakage }\end{array}$ & $\begin{array}{l}\text { Horizontal } \\
\text { Coordinate } \\
\text { of node }\end{array}$ & $\begin{array}{l}\text { Vertical } \\
\text { Coordinate } \\
\text { of node }\end{array}$ \\
\hline 57 & 0 & 0 & 137 & 0 & 0.5 & 0 & 1.5 & 396829942 & 293735280 \\
\hline 58 & 0 & 0 & 136.8 & 0 & 0.5 & 0 & 1.5 & 396827392 & 293733952 \\
\hline 59 & 0 & 0 & 135 & 0 & 0.5 & 0 & 1.5 & 396804096 & 293722304 \\
\hline 60 & 0 & 0 & 134 & 0 & 0.5 & 0 & 1.5 & 396795232 & 293705376 \\
\hline 61 & 0 & 18 & 134 & 0 & 0.5 & 0 & 1.5 & 396786720 & 293700608 \\
\hline 62 & 0 & 0 & 134 & 0 & 0.5 & 0 & 1.5 & 396770016 & 293725568 \\
\hline 63 & 0 & 0 & 139 & 0 & 0.5 & 0 & 1.5 & 397135552 & 293830624 \\
\hline 64 & 0 & 0 & 138 & 0 & 0.5 & 0 & 1.5 & 397132992 & 293787008 \\
\hline 65 & 0 & 0 & 140 & 0 & 0.5 & 0 & 1.5 & 397179648 & 293864672 \\
\hline 66 & 0 & 9 & 137.7 & 0 & 0.5 & 0 & 1.5 & 396379360 & 293774464 \\
\hline 67 & 0 & 0 & 137.65 & 0 & 0.5 & 0 & 1.5 & 396389504 & 293778464 \\
\hline 68 & 0 & 0 & 137.13 & 0 & 0.5 & 0 & 1.5 & 396440224 & 293782208 \\
\hline 69 & 0 & 43 & 135.64 & 0 & 0.5 & 0 & 1.5 & 396518336 & 293831744 \\
\hline 70 & 0 & 0 & 136.08 & 0 & 0.5 & 0 & 1.5 & 396496096 & 293762976 \\
\hline 71 & 0 & 33 & 137 & 0 & 0.5 & 0 & 1.5 & 396413280 & 293723744 \\
\hline 72 & 0 & 0 & 137.9 & 0 & 0.5 & 0 & 1.5 & 396355232 & 293707552 \\
\hline 73 & 0 & 0 & 138.22 & 0 & 0.5 & 0 & 1.5 & 396289472 & 293696864 \\
\hline 74 & 0 & 0 & 134.7 & 0 & 0.5 & 0 & 1.5 & 396537184 & 293928128 \\
\hline 75 & 0 & 50 & 134.2 & 0 & 0.5 & 0 & 1.5 & 396539712 & 293982752 \\
\hline 76 & 0 & 0 & 136.5 & 0 & 0.5 & 0 & 1.5 & 396389344 & 293950496 \\
\hline 77 & 0 & 0 & 135.84 & 0 & 0.5 & 0 & 1.5 & 396523328 & 293716544 \\
\hline 78 & 0 & 0 & 135.2 & 0 & 0.5 & 0 & 1.5 & 396535392 & 293899648 \\
\hline 79 & 0 & 56 & 133.01 & 0 & 0.5 & 0 & 1.5 & 396650848 & 293926112 \\
\hline 80 & 0 & 0 & 132.56 & 0 & 0.5 & 0 & 1.5 & 396638720 & 293983264 \\
\hline 81 & 0 & 0 & 132.28 & 0 & 0.5 & 0 & 1.5 & 396735744 & 293950304 \\
\hline 82 & 0 & 0 & 132.6 & 0 & 0.5 & 0 & 1.5 & 396911104 & 293971584 \\
\hline 83 & 0 & 9 & 133.94 & 0 & 0.5 & 0 & 1.5 & 396780736 & 293697120 \\
\hline 84 & 0 & 0 & 134.64 & 0 & 0.5 & 0 & 1.5 & 396738880 & 293677056 \\
\hline 85 & 0 & 7 & 135.16 & 0 & 0.5 & 0 & 1.5 & 396572256 & 293664352 \\
\hline 86 & 0 & 0 & 135.26 & 0 & 0.5 & 0 & 1.5 & 396552704 & 293664000 \\
\hline 87 & 0 & 0 & 138 & 0 & 0.5 & 0 & 1.5 & 396906528 & 293786368 \\
\hline 88 & 0 & 0 & 137.5 & 0 & 0.5 & 0 & 1.5 & 396839968 & 293752384 \\
\hline 89 & 0 & 0 & 132 & 0 & 0.5 & 0 & 1.5 & 396967776 & 293855552 \\
\hline 90 & 0 & 0 & 129.58 & 0 & 0.5 & 0 & 1.5 & 396934752 & 294030144 \\
\hline 91 & 0 & 0 & 129.72 & 0 & 0.5 & 0 & 1.5 & 396869440 & 294113984 \\
\hline 92 & 0 & 20 & 129.56 & 0 & 0.5 & 0 & 1.5 & 396868736 & 294122272 \\
\hline 93 & 0 & 2 & 129.4 & 0 & 0.5 & 0 & 1.5 & 396730368 & 294258752 \\
\hline 94 & 0 & 0 & 129.74 & 0 & 0.5 & 0 & 1.5 & 396712864 & 294271232 \\
\hline 95 & 0 & 0 & 137 & 0 & 0.5 & 0 & 1.5 & 397044608 & 293767296 \\
\hline 96 & 0 & 15 & 135 & 0 & 0.5 & 0 & 1.5 & 396568256 & 293619040 \\
\hline 97 & 0 & 0 & 135 & 0 & 0.5 & 0 & 1.5 & 396550720 & 293617728 \\
\hline 98 & 0 & 0 & 136 & 0 & 0.5 & 0 & 1.5 & 396499648 & 293605440 \\
\hline 99 & 0 & 0 & 134.92 & 0 & 0.5 & 0 & 1.5 & 396564960 & 293586016 \\
\hline 100 & 0 & 0 & 133.82 & 0 & 0.5 & 0 & 1.5 & 396784128 & 293691296 \\
\hline 101 & 0 & 0 & 133 & 0 & 0.5 & 0 & 1.5 & 396808480 & 293649344 \\
\hline
\end{tabular}




\begin{tabular}{|c|c|c|c|c|c|c|c|c|c|}
\hline $\begin{array}{l}\text { Node } \\
\text { No }\end{array}$ & $\left|\begin{array}{c}\text { Node } \\
\text { Type }\end{array}\right|$ & $\begin{array}{l}\text { Demand } \\
\text { Factor }\end{array}$ & $\begin{array}{l}\text { Elevatior } \\
(\mathrm{m})\end{array}$ & $\begin{array}{c}\text { Coefficient } \\
\text { of burst }\end{array}$ & $\begin{array}{c}\text { Exponent } \\
\text { of burst } \\
\text { term }\end{array}$ & $\begin{array}{c}\text { Coefficient } \\
\text { of } \\
\text { background } \\
\text { leakage }\end{array}$ & $\begin{array}{c}\text { Exponent } \\
\text { of } \\
\text { background } \\
\text { leakage }\end{array}$ & $\begin{array}{l}\text { Horizontal } \\
\text { Coordinate } \\
\text { of node }\end{array}$ & $\begin{array}{l}\text { Vertical } \\
\text { Coordinate } \\
\text { of node }\end{array}$ \\
\hline 102 & 0 & 9 & 128.95 & 0 & 0.5 & 0 & 1.5 & 396789984 & 294302752 \\
\hline 103 & 0 & 0 & 128.77 & 0 & 0.5 & 0 & 1.5 & 396768224 & 294331744 \\
\hline 104 & 0 & 15 & 127.66 & 0 & 0.5 & 0 & 1.5 & 396835264 & 294332480 \\
\hline 105 & 0 & 39 & 127.64 & 0 & 0.5 & 0 & 1.5 & 396904704 & 294262912 \\
\hline 106 & 0 & 0 & 128.35 & 0 & 0.5 & 0 & 1.5 & 396838464 & 294243264 \\
\hline 107 & 0 & 0 & 126.02 & 0 & 0.5 & 0 & 1.5 & 397013344 & 294289408 \\
\hline 108 & 0 & 34 & 125.65 & 0 & 0.5 & 0 & 1.5 & 397025120 & 294294848 \\
\hline 109 & 0 & 0 & 125.08 & 0 & 0.5 & 0 & 1.5 & 396993824 & 294366016 \\
\hline 110 & 0 & 0 & 126.98 & 0 & 0.5 & 0 & 1.5 & 396862496 & 294352672 \\
\hline 111 & 0 & 29 & 126.68 & 0 & 0.5 & 0 & 1.5 & 396875328 & 294382368 \\
\hline 112 & 0 & 0 & 128.43 & 0 & 0.5 & 0 & 1.5 & 396759104 & 294374112 \\
\hline 113 & 0 & 0 & 129.91 & 0 & 0.5 & 0 & 1.5 & 396992480 & 294072480 \\
\hline 114 & 0 & 28 & 132 & 0 & 0.5 & 0 & 1.5 & 397119488 & 294017792 \\
\hline 115 & 0 & 0 & 132 & 0 & 0.5 & 0 & 1.5 & 397118400 & 294015168 \\
\hline 116 & 0 & 0 & 125.58 & 0 & 0.5 & 0 & 1.5 & 397026688 & 294295680 \\
\hline 117 & 0 & 0 & 125 & 0 & 0.5 & 0 & 1.5 & 397095488 & 294387776 \\
\hline 118 & 0 & 27 & 125.02 & 0 & 0.5 & 0 & 1.5 & 397093728 & 294403488 \\
\hline 119 & 0 & 35 & 125.34 & 0 & 0.5 & 0 & 1.5 & 396924608 & 294416000 \\
\hline 120 & 0 & 11 & 124.79 & 0 & 0.5 & 0 & 1.5 & 397127232 & 294430624 \\
\hline 121 & 0 & 0 & 124.91 & 0 & 0.5 & 0 & 1.5 & 397117632 & 294437504 \\
\hline 122 & 0 & 39 & 127.56 & 0 & 0.5 & 0 & 1.5 & 397067744 & 294478240 \\
\hline 123 & 0 & 0 & 127.56 & 0 & 0.5 & 0 & 1.5 & 397038624 & 294471744 \\
\hline 124 & 0 & 26 & 133 & 0 & 0.5 & 0 & 1.5 & 397273408 & 293953152 \\
\hline 125 & 0 & 0 & 134 & 0 & 0.5 & 0 & 1.5 & 397344544 & 293928800 \\
\hline 126 & 0 & 0 & 136 & 0 & 0.5 & 0 & 1.5 & 397389728 & 293887040 \\
\hline 127 & 0 & 0 & 133 & 0 & 0.5 & 0 & 1.5 & 397278016 & 293964064 \\
\hline 128 & 0 & 47 & 130.06 & 0 & 0.5 & 0 & 1.5 & 397394112 & 294175104 \\
\hline 129 & 0 & 0 & 130.1 & 0 & 0.5 & 0 & 1.5 & 397382144 & 294186144 \\
\hline 130 & 0 & 13 & 126.54 & 0 & 0.5 & 0 & 1.5 & 397286752 & 294274720 \\
\hline 131 & 0 & 0 & 128.06 & 0 & 0.5 & 0 & 1.5 & 397270912 & 294286848 \\
\hline 132 & 0 & 0 & 126.08 & 0 & 0.5 & 0 & 1.5 & 396946112 & 294328384 \\
\hline 133 & 0 & 0 & 128.18 & 0 & 0.5 & 0 & 1.5 & 397108128 & 294530112 \\
\hline 134 & 0 & 28 & 125.52 & 0 & 0.5 & 0 & 1.5 & 397141728 & 294464224 \\
\hline 135 & 0 & 0 & 126.41 & 0 & 0.5 & 0 & 1.5 & 397206720 & 294488224 \\
\hline 136 & 0 & 0 & 126.4 & 0 & 0.5 & 0 & 1.5 & 397149632 & 294485312 \\
\hline 137 & 0 & 12 & 126.39 & 0 & 0.5 & 0 & 1.5 & 397180960 & 294548992 \\
\hline 138 & 0 & 0 & 126.54 & 0 & 0.5 & 0 & 1.5 & 397173088 & 294554176 \\
\hline 139 & 0 & 26 & 127.02 & 0 & 0.5 & 0 & 1.5 & 397149216 & 294585984 \\
\hline 140 & 0 & 0 & 127.14 & 0 & 0.5 & 0 & 1.5 & 397126976 & 294594496 \\
\hline 141 & 0 & 7 & 126.03 & 0 & 0.5 & 0 & 1.5 & 397202656 & 294574624 \\
\hline 142 & 0 & 16 & 126 & 0 & 0.5 & 0 & 1.5 & 397258112 & 294505568 \\
\hline 143 & 0 & 16 & 126.34 & 0 & 0.5 & 0 & 1.5 & 397220992 & 294591232 \\
\hline 144 & 0 & 0 & 126.08 & 0 & 0.5 & 0 & 1.5 & 397210208 & 294628544 \\
\hline 145 & 0 & 0 & 126.96 & 0 & 0.5 & 0 & 1.5 & 397152160 & 294596384 \\
\hline 146 & 0 & 28 & 126.42 & 0 & 0.5 & 0 & 1.5 & 397266848 & 294617984 \\
\hline
\end{tabular}




\begin{tabular}{|c|c|c|c|c|c|c|c|c|c|}
\hline $\begin{array}{c}\text { Node } \\
\text { No }\end{array}$ & $\left|\begin{array}{c}\text { Node } \\
\text { Type }\end{array}\right|$ & $\begin{array}{l}\text { Demand } \\
\text { Factor }\end{array}$ & $\begin{array}{c}\text { Elevation } \\
(\mathrm{m})\end{array}$ & $\begin{array}{c}\text { Coefficient } \\
\text { of burst }\end{array}$ & $\begin{array}{c}\text { Exponent } \\
\text { of burst } \\
\text { term }\end{array}$ & $\begin{array}{c}\text { Coefficient } \\
\text { of } \\
\text { background } \\
\text { leakage }\end{array}$ & $\begin{array}{c}\text { Exponent } \\
\text { of } \\
\text { background } \\
\text { leakage }\end{array}$ & $\begin{array}{l}\text { Horizontal } \\
\text { Coordinate } \\
\text { of node }\end{array}$ & $\begin{array}{l}\text { Vertical } \\
\text { Coordinate } \\
\text { of node }\end{array}$ \\
\hline 147 & 0 & 0 & 126.33 & 0 & 0.5 & 0 & 1.5 & 397264096 & 294627232 \\
\hline 148 & 0 & 21 & 126 & 0 & 0.5 & 0 & 1.5 & 397319104 & 294675360 \\
\hline 149 & 0 & 0 & 125.9 & 0 & 0.5 & 0 & 1.5 & 397296032 & 294279168 \\
\hline 150 & 0 & 34 & 130 & 0 & 0.5 & 0 & 1.5 & 397474432 & 294096736 \\
\hline 151 & 0 & 0 & 130.04 & 0 & 0.5 & 0 & 1.5 & 397399104 & 294067808 \\
\hline 152 & 0 & 0 & 130 & 0 & 0.5 & 0 & 1.5 & 397516864 & 294055200 \\
\hline 153 & 0 & 0 & 126.21 & 0 & 0.5 & 0 & 1.5 & 397280736 & 294622496 \\
\hline 154 & 0 & 16 & 125.76 & 0 & 0.5 & 0 & 1.5 & 397365792 & 294587648 \\
\hline 155 & 0 & 21 & 125.16 & 0 & 0.5 & 0 & 1.5 & 397410976 & 294607616 \\
\hline 156 & 0 & 16 & 126 & 0 & 0.5 & 0 & 1.5 & 397368545 & 294690200 \\
\hline 157 & 0 & 30 & 125.9 & 0 & 0.5 & 0 & 1.5 & 397377984 & 294559104 \\
\hline 158 & 0 & 0 & 126 & 0 & 0.5 & 0 & 1.5 & 397308960 & 294568608 \\
\hline 159 & 0 & 0 & 125.06 & 0 & 0.5 & 0 & 1.5 & 397414604 & 294496136 \\
\hline 160 & 0 & 0 & 125.12 & 0 & 0.5 & 0 & 1.5 & 397441728 & 294606240 \\
\hline 161 & 0 & 41 & 125.26 & 0 & 0.5 & 0 & 1.5 & 397474175 & 294613150 \\
\hline 162 & 0 & 0 & 126 & 0 & 0.5 & 0 & 1.5 & 397435968 & 294678144 \\
\hline 163 & 0 & 14 & 126 & 0 & 0.5 & 0 & 1.5 & 397435840 & 294677856 \\
\hline 164 & 0 & 0 & 125.74 & 0 & 0.5 & 0 & 1.5 & 397510112 & 294667488 \\
\hline 165 & 1 & 0 & 137.5 & 0 & 0.5 & 0 & 1.5 & 397355488 & 293889760 \\
\hline
\end{tabular}


Table C.0.2 Complete element data for Ocker Hill DMA

\begin{tabular}{|c|c|c|c|c|c|c|c|c|c|}
\hline \multicolumn{2}{|c|}{$\begin{array}{c}\text { Pipe Location } \\
(\text { Node } \rightarrow \text { Node) }\end{array}$} & \multirow{2}{*}{$\begin{array}{c}\text { Length } \\
\text { (m) }\end{array}$} & \multirow{2}{*}{$\begin{array}{c}\begin{array}{c}\text { Diameter } \\
(\mathrm{mm})\end{array} \\
152.7 \\
\end{array}$} & \multirow{2}{*}{$\begin{array}{c}\text { C-Value } \\
70 \\
\end{array}$} & \multicolumn{2}{|c|}{$\begin{array}{c}\text { Pipe Location } \\
\text { (Node } \rightarrow \text { Node) }\end{array}$} & \multirow{2}{*}{$\begin{array}{c}\text { Length } \\
\text { (m) }\end{array}$} & \multirow{2}{*}{$\begin{array}{c}\begin{array}{c}\text { Diameter } \\
(\mathrm{mm})\end{array} \\
101.6 \\
\end{array}$} & \multirow{2}{*}{$\begin{array}{c}\text { C-Value } \\
70 \\
\end{array}$} \\
\hline 4 & 1 & & & & 47 & 48 & & & \\
\hline 4 & 3 & 3.62 & 152.4 & 70 & 48 & 49 & 91.61 & 101.6 & 70 \\
\hline 5 & 4 & 1.12 & 152.4 & 70 & 50 & 51 & 60.34 & 90 & 70 \\
\hline 5 & 6 & 33.22 & 152.4 & 35 & 50 & 63 & 9.97 & 90 & 70 \\
\hline 7 & 6 & 43.49 & 152.4 & 35 & 52 & 30 & 102.39 & 101.6 & 40 \\
\hline 7 & 8 & 51.84 & 152.4 & 45 & 53 & 52 & 54.11 & 101.6 & 40 \\
\hline 8 & 9 & 17.48 & 152.4 & 45 & 53 & 54 & 13.72 & 101.6 & 40 \\
\hline 10 & 9 & 1.8 & 125 & 40 & 54 & 55 & 53.18 & 101.6 & 40 \\
\hline 11 & 10 & 7.74 & 125 & 70 & 55 & 56 & 7.95 & 101.6 & 50 \\
\hline 11 & 16 & 3.23 & 125 & 70 & 56 & 57 & 17.12 & 101.6 & 40 \\
\hline 12 & 7 & 6.39 & 101.6 & 70 & 56 & 88 & 11.08 & 101.6 & 70 \\
\hline 12 & 13 & 4.39 & 76.2 & 70 & 57 & 58 & 2.88 & 101.6 & 70 \\
\hline 14 & 10 & 3.13 & 125 & 70 & 58 & 59 & 26.05 & 101.6 & 40 \\
\hline 15 & 16 & 3.75 & 125 & 70 & 59 & 60 & 22.42 & 101.6 & 40 \\
\hline 17 & 16 & 1.56 & 125 & 70 & 60 & 61 & 9.76 & 152.4 & 70 \\
\hline 17 & 18 & 17.09 & 152.4 & 45 & 61 & 62 & 30.04 & 101.6 & 70 \\
\hline 18 & 19 & 47.12 & 152.4 & 40 & 61 & 83 & 6.93 & 152.4 & 70 \\
\hline 18 & 65 & 4.36 & 76.2 & 70 & 62 & 38 & 105.48 & 101.6 & 70 \\
\hline 19 & 20 & 13.12 & 152.4 & 40 & 63 & 64 & 44.57 & 90 & 70 \\
\hline 20 & 21 & 61.47 & 152.4 & 40 & 66 & 47 & 28.6 & 101.6 & 70 \\
\hline 20 & 50 & 19.81 & 90 & 70 & 66 & 67 & 10.96 & 80.5 & 70 \\
\hline 21 & 22 & 19.51 & 152.4 & 40 & 67 & 68 & 51.42 & 80.5 & 70 \\
\hline 21 & 29 & 8.89 & 101.6 & 40 & 69 & 70 & 73.2 & 101.6 & 70 \\
\hline 22 & 23 & 2.02 & 101.6 & 70 & 69 & 78 & 70 & 101.6 & 70 \\
\hline 22 & 25 & 5.5 & 152.4 & 70 & 71 & 66 & 61.13 & 101.6 & 70 \\
\hline 23 & 24 & 9.06 & 101.6 & 70 & 71 & 77 & 112.57 & 101.6 & 70 \\
\hline 24 & 25 & 2.31 & 101.6 & 70 & 72 & 71 & 60.81 & 105 & 70 \\
\hline 25 & 32 & 167.94 & 152.4 & 110 & 73 & 72 & 66.66 & 100 & 70 \\
\hline 26 & 12 & 95.63 & 101.6 & 25 & 74 & 75 & 54.71 & 101.6 & 70 \\
\hline 27 & 26 & 65.51 & 101.6 & 70 & 75 & 76 & 155.83 & 101.6 & 70 \\
\hline 28 & 27 & 5.95 & 101.8 & 85.43 & 75 & 80 & 102.68 & 101.6 & 70 \\
\hline 29 & 30 & 4.91 & 101.6 & 70 & 76 & 44 & 65.1 & 101.6 & 70 \\
\hline 30 & 31 & 13.63 & 101.6 & 70 & 78 & 40 & 8.81 & 101.6 & 70 \\
\hline 32 & 90 & 44.04 & 152.4 & 100 & 79 & 39 & 6.28 & 101.6 & 70 \\
\hline 33 & 32 & 59.3 & 101.6 & 70 & 79 & 81 & 88.29 & 101.6 & 70 \\
\hline 34 & 33 & 4.94 & 101.6 & 70 & 80 & 79 & 58.45 & 101.6 & 70 \\
\hline 34 & 89 & 127.57 & 76.2 & 70 & 81 & 82 & 204.85 & 101.6 & 70 \\
\hline 35 & 34 & 89.38 & 101.6 & 70 & 82 & 33 & 6.53 & 101.6 & 70 \\
\hline 35 & 87 & 158.09 & 101.6 & 70 & 83 & 84 & 46.48 & 152.4 & 70 \\
\hline 36 & 35 & 73.97 & 101.6 & 70 & 83 & 100 & 6.74 & 101.6 & 70 \\
\hline 36 & 37 & 73.31 & 101.6 & 70 & 84 & 85 & 168.38 & 152.4 & 70 \\
\hline 37 & 38 & 24.1 & 101.6 & 70 & 85 & 86 & 19.53 & 152.7 & 70 \\
\hline 39 & 38 & 132.08 & 101.6 & 70 & 85 & 96 & 45.5 & 101.6 & 70 \\
\hline 39 & 40 & 109 & 101.6 & 70 & 87 & 53 & 15.97 & 101.6 & 70 \\
\hline 40 & 41 & 1.65 & 101.6 & 70 & 88 & 36 & 153.67 & 101.6 & 70 \\
\hline
\end{tabular}




\begin{tabular}{|c|c|c|c|c|c|c|c|c|c|}
\hline \multicolumn{2}{|c|}{$\begin{array}{c}\text { Pipe Location } \\
(\text { Node } \rightarrow \text { Node })\end{array}$} & \multirow{2}{*}{$\begin{array}{c}\begin{array}{c}\text { Length } \\
(\mathrm{m})\end{array} \\
16.68\end{array}$} & \multirow{2}{*}{$\begin{array}{c}\begin{array}{c}\text { Diameter } \\
(\mathrm{mm})\end{array} \\
101.6\end{array}$} & \multirow{2}{*}{$\frac{\text { C-Value }}{70}$} & \multicolumn{2}{|c|}{$\begin{array}{c}\text { Pipe Location } \\
(\text { Node } \rightarrow \text { Node) }\end{array}$} & \multirow{2}{*}{$\begin{array}{c}\begin{array}{c}\text { Length } \\
\text { (m) }\end{array} \\
106.31\end{array}$} & \multirow{2}{*}{$\begin{array}{c}\begin{array}{c}\text { Diameter } \\
(\mathrm{mm})\end{array} \\
101.6\end{array}$} & \multirow{2}{*}{$\frac{\text { C-Value }}{100}$} \\
\hline 41 & 42 & & & & 90 & 91 & & & \\
\hline 41 & 74 & 20.32 & 101.6 & 70 & 91 & 92 & 10.43 & 101.6 & 85.43 \\
\hline 42 & 43 & 116.24 & 101.6 & 70 & 92 & 113 & 134.22 & 152.4 & 90.09 \\
\hline 43 & 44 & 17.82 & 101.6 & 70 & 93 & 92 & 199.14 & 152.4 & 90.09 \\
\hline 45 & 44 & 55.91 & 101.6 & 70 & 93 & 102 & 88.44 & 155 & 149 \\
\hline 46 & 45 & 13.77 & 101.6 & 70 & 94 & 93 & 26.74 & 152.7 & 90.09 \\
\hline 46 & 69 & 132.39 & 101.6 & 70 & 95 & 52 & 119.36 & 80.5 & 70 \\
\hline 47 & 46 & 29.03 & 101.6 & 70 & 96 & 97 & 17.63 & 101.6 & 70 \\
\hline 96 & 99 & 33.17 & 101.8 & 70 & 128 & 150 & 112.21 & 101.6 & 85.43 \\
\hline 97 & 98 & 52.6 & 101.6 & 70 & 129 & 130 & 130.43 & 76.2 & 83.09 \\
\hline 100 & 101 & 48.5 & 101.6 & 5 & 130 & 131 & 19.95 & 76.2 & 83.09 \\
\hline 102 & 103 & 36.26 & 80.5 & 147.13 & 130 & 149 & 10.96 & 125 & 130 \\
\hline 102 & 104 & 54.21 & 155 & 149 & 134 & 135 & 111.29 & 80.5 & 147.13 \\
\hline 104 & 105 & 100.65 & 105 & 147.67 & 134 & 136 & 22.52 & 155 & 149 \\
\hline 104 & 110 & 34.39 & 155 & 149 & 136 & 137 & 71.2 & 155 & 149 \\
\hline 105 & 106 & 85.71 & 80.5 & 147.13 & 138 & 137 & 9.43 & 105 & 147.67 \\
\hline 107 & 105 & 114.7 & 105 & 147.67 & 139 & 138 & 44.63 & 105 & 147.67 \\
\hline 108 & 107 & 12.99 & 105 & 147.67 & 139 & 145 & 10.85 & 105 & 147.67 \\
\hline 108 & 109 & 78.99 & 80.5 & 147.13 & 140 & 139 & 27.58 & 80.5 & 147.13 \\
\hline 110 & 111 & 32.43 & 155 & 149 & 141 & 137 & 33.59 & 155 & 149 \\
\hline 111 & 112 & 120.25 & 80.5 & 147.13 & 141 & 142 & 93.87 & 80.5 & 147.13 \\
\hline 111 & 119 & 61.4 & 155 & 149 & 141 & 143 & 24.76 & 155 & 149 \\
\hline 113 & 114 & 138.3 & 152.4 & 90.09 & 143 & 146 & 53.24 & 155 & 149 \\
\hline 114 & 115 & 2.83 & 76.2 & 83.09 & 144 & 143 & 49.81 & 105 & 147.67 \\
\hline 116 & 108 & 1.77 & 105 & 147.67 & 145 & 144 & 72.98 & 105 & 147.67 \\
\hline 117 & 116 & 121.03 & 105 & 147.67 & 146 & 147 & 9.64 & 105 & 147.67 \\
\hline 118 & 117 & 15.86 & 105 & 147.67 & 146 & 153 & 14.61 & 155 & 149 \\
\hline 118 & 119 & 173.88 & 155 & 149 & 147 & 148 & 133.59 & 105 & 147.67 \\
\hline 118 & 120 & 44.58 & 155 & 149 & 150 & 151 & 106.22 & 76.2 & 83.09 \\
\hline 119 & 132 & 107.95 & 80.5 & 147.13 & 150 & 152 & 59.37 & 101.8 & 85.43 \\
\hline 120 & 121 & 11.79 & 105 & 147.67 & 153 & 154 & 100.85 & 155 & 149 \\
\hline 120 & 134 & 36.62 & 155 & 149 & 154 & 155 & 49.78 & 105 & 147.67 \\
\hline 121 & 122 & 65.21 & 105 & 147.67 & 154 & 157 & 31.03 & 155 & 149 \\
\hline 122 & 123 & 35.69 & 80.5 & 147.13 & 155 & 156 & 124.93 & 105 & 147.67 \\
\hline 122 & 133 & 109.82 & 105 & 147.67 & 155 & 160 & 30.86 & 105 & 147.67 \\
\hline 124 & 114 & 166.95 & 152.4 & 90.09 & 157 & 158 & 127.16 & 80.5 & 147.13 \\
\hline 124 & 125 & 76.65 & 152.4 & 90.09 & 159 & 157 & 73.2 & 150 & 149 \\
\hline 124 & 127 & 11.85 & 101.6 & 85.43 & 160 & 161 & 33.47 & 105 & 147.67 \\
\hline 126 & 2 & 7.39 & 180 & 130 & 161 & 162 & 105.86 & 105 & 147.67 \\
\hline 126 & 125 & 75.62 & 152.4 & 44.03 & 161 & 164 & 125.22 & 105 & 147.67 \\
\hline 127 & 128 & 242.38 & 101.6 & 85.43 & 162 & 163 & 0.3 & 105 & 147.67 \\
\hline 128 & 129 & 16.3 & 101.6 & 85.43 & 165 & 3 & 3.33 & 152.4 & 70 \\
\hline
\end{tabular}




\section{Appendix D - Node and Element Data for the Shenstone DMA}

The model of the network used by the author is stored in a separate excel file model.xls with the following fields:

A - Node number - a unique label used to identify the node.

B - Type of node - a binary value that describes the role of a node in a network: 0 for a connection node or 1 for a source node (reservoir node or PRV OUTLET node).

C - Demand factor - number of average water users allocated to a node.

D - Elevation $(m)$ - elevation in metres above a common reference of a node. The elevation in used in the program only to compute the pressure at the node.

E - Coefficient of a burst - value of coefficient $c_{1}$ for a specific node is set in case of presence in a network of already known burst with specified characteristics.

$\mathrm{F}$ - Exponent of the burst term in the IFM=0.5.

$\mathrm{G}$ - Coefficient of known background leakages - value of coefficient $c_{2}$ for a specific node is set up in case of presence in a network with already known background leakages with specified characteristics.

$\mathrm{H}-$ Exponent of the background leakage term in the IFM $=1.5$.

I, J - Horizontal and vertical co-ordinates of a node on the map. They do not affect any other variable.

Table D.0.1 Complete nodes data for the Shenstone DMA

\begin{tabular}{|c|c|c|c|c|c|c|c|c|c|}
\hline $\begin{array}{c}\text { Node } \\
\text { No }\end{array}$ & $\begin{array}{c}\text { Node } \\
\text { Type }\end{array}$ & $\begin{array}{c}\text { Femand } \\
\text { Factor }\end{array}$ & $\begin{array}{c}\text { Elevation } \\
(\mathrm{m})\end{array}$ & $\begin{array}{c}\text { Coefficient } \\
\text { of burst }\end{array}$ & $\begin{array}{c}\text { Exponent } \\
\text { of burst } \\
\text { term }\end{array}$ & $\begin{array}{c}\text { Coefficient } \\
\text { of } \\
\text { background } \\
\text { leakage }\end{array}$ & $\begin{array}{c}\text { Exponent } \\
\text { of } \\
\text { background } \\
\text { leakage }\end{array}$ & $\begin{array}{c}\text { Horizontal } \\
\text { Coordinate } \\
\text { of node }\end{array}$ & $\begin{array}{c}\text { Vertical } \\
\text { Coordinate } \\
\text { of node }\end{array}$ \\
\hline 1 & 0 & 2 & 91 & 0 & 0.5 & 0 & 1.5 & 411362848 & 304925728 \\
\hline 2 & 0 & 2 & 91 & 0 & 0.5 & 0 & 1.5 & 411382531 & 304927213 \\
\hline 3 & 0 & 8 & 91 & 0 & 0.5 & 0 & 1.5 & 411304768 & 304868015 \\
\hline 4 & 0 & 0 & 91.08 & 0 & 0.5 & 0 & 1.5 & 411296376 & 304921239 \\
\hline 5 & 0 & 0 & 91.4 & 0 & 0.5 & 0 & 1.5 & 411280256 & 305070883 \\
\hline 6 & 0 & 0 & 91.44 & 0 & 0.5 & 0 & 1.5 & 411279275 & 305069651 \\
\hline 7 & 0 & 0 & 91.48 & 0 & 0.5 & 0 & 1.5 & 411275752 & 304934997 \\
\hline 8 & 0 & 16 & 91.5 & 0 & 0.5 & 0 & 1.5 & 411274833 & 304917103 \\
\hline 9 & 0 & 0 & 91.54 & 0 & 0.5 & 0 & 1.5 & 411272672 & 304886400 \\
\hline 10 & 0 & 0 & 91.56 & 0 & 0.5 & 0 & 1.5 & 411271864 & 304886489 \\
\hline 11 & 0 & 0 & 91.74 & 0 & 0.5 & 0 & 1.5 & 411263223 & 304922735 \\
\hline
\end{tabular}




\begin{tabular}{|c|c|c|c|c|c|c|c|c|c|}
\hline $\begin{array}{c}\text { Node } \\
\text { No }\end{array}$ & $\begin{array}{l}\text { Node } \\
\text { Type }\end{array}$ & $\begin{array}{c}\text { Demand } \\
\text { Factor }\end{array}$ & $\begin{array}{c}\text { Elevation } \\
(\mathrm{m})\end{array}$ & $\begin{array}{c}\text { Coefficient } \\
\text { of burst }\end{array}$ & $\begin{array}{c}\text { Exponent } \\
\text { of burst } \\
\text { term }\end{array}$ & $\begin{array}{c}\text { Coefficient } \\
\text { of } \\
\text { background } \\
\text { leakage }\end{array}$ & \begin{tabular}{|c|} 
Exponent \\
of \\
background \\
leakage
\end{tabular} & $\begin{array}{c}\text { Horizontal } \\
\text { Coordinate } \\
\text { of node }\end{array}$ & $\begin{array}{c}\text { Vertical } \\
\text { Coordinate } \\
\text { of node }\end{array}$ \\
\hline 13 & 0 & 7 & 92.3528 & 0 & 0.5 & 0 & 1.5 & 411182061 & 304951420 \\
\hline 14 & 0 & 4 & 93 & 0 & 0.5 & 0 & 1.5 & 410997664 & 305024128 \\
\hline 15 & 0 & 6 & 93.18 & 0 & 0.5 & 0 & 1.5 & 411107728 & 304982497 \\
\hline 16 & 0 & 3 & 93.26 & 0 & 0.5 & 0 & 1.5 & 411048474 & 304986624 \\
\hline 17 & 0 & 6 & 93.2808 & 0 & 0.5 & 0 & 1.5 & 410995968 & 304986848 \\
\hline 18 & 0 & 6 & 93.86 & 0 & 0.5 & 0 & 1.5 & 410823583 & 304956612 \\
\hline 19 & 0 & 4 & 94.0184 & 0 & 0.5 & 0 & 1.5 & 410504128 & 304700832 \\
\hline 20 & 0 & 5 & 94.06 & 0 & 0.5 & 0 & 1.5 & 411271476 & 304724846 \\
\hline 22 & 0 & 12 & 94.304 & 0 & 0.5 & 0 & 1.5 & 411005376 & 304942112 \\
\hline 23 & 0 & 11 & 94.52 & 0 & 0.5 & 0 & 1.5 & 411090592 & 304923872 \\
\hline 24 & 0 & 4 & 94.8 & 0 & 0.5 & 0 & 1.5 & 410823224 & 304910143 \\
\hline 25 & 0 & 5 & 94.8192 & 0 & 0.5 & 0 & 1.5 & 410792477 & 304893857 \\
\hline 26 & 0 & 6 & 94.91 & 0 & 0.5 & 0 & 1.5 & 411034752 & 304914976 \\
\hline 27 & 0 & 0 & 95 & 0 & 0.5 & 0 & 1.5 & 410404352 & 304719840 \\
\hline 28 & 0 & 21 & 95.3928 & 0 & 0.5 & 0 & 1.5 & 410856420 & 304888750 \\
\hline 29 & 0 & 12 & 95.6808 & 0 & 0.5 & 0 & 1.5 & 410320515 & 304937621 \\
\hline 30 & 0 & 0 & 96 & 0 & 0.5 & 0 & 1.5 & 410315008 & 304555616 \\
\hline 31 & 0 & 0 & 96 & 0 & 0.5 & 0 & 1.5 & 410325759 & 304626559 \\
\hline 32 & 0 & 0 & 96 & 0 & 0.5 & 0 & 1.5 & 411290764 & 305669396 \\
\hline 33 & 0 & 13 & 96.06 & 0 & 0.5 & 0 & 1.5 & 410706383 & 304708933 \\
\hline 34 & 0 & 3 & 96.112 & 0 & 0.5 & 0 & 1.5 & 411289856 & 305757248 \\
\hline 35 & 0 & 25 & 96.28 & 0 & 0.5 & 0 & 1.5 & 410236282 & 304529107 \\
\hline 36 & 0 & 18 & 96.34 & 0 & 0.5 & 0 & 1.5 & 410333344 & 304722848 \\
\hline 37 & 0 & 16 & 96.48 & 0 & 0.5 & 0 & 1.5 & 411274216 & 304638683 \\
\hline 38 & 0 & 0 & 96.496 & 0 & 0.5 & 0 & 1.5 & 410639657 & 304668288 \\
\hline 39 & 0 & 3 & 96.52 & 0 & 0.5 & 0 & 1.5 & 410576262 & 304455727 \\
\hline 40 & 0 & 3 & 96.8416 & 0 & 0.5 & 0 & 1.5 & 410538979 & 304335515 \\
\hline 41 & 0 & 0 & 96.8684 & 0 & 0.5 & 0 & 1.5 & 411247108 & 305842936 \\
\hline 42 & 0 & 5 & 96.9868 & 0 & 0.5 & 0 & 1.5 & 411396608 & 305789120 \\
\hline 43 & 0 & 5 & 97 & 0 & 0.5 & 0 & 1.5 & 410556352 & 304395616 \\
\hline 44 & 0 & 10 & 97 & 0 & 0.5 & 0 & 1.5 & 410517464 & 304251778 \\
\hline 45 & 0 & 5 & 97 & 0 & 0.5 & 0 & 1.5 & 410565126 & 304325776 \\
\hline 46 & 0 & 5 & 97 & 0 & 0.5 & 0 & 1.5 & 410589705 & 304377693 \\
\hline 47 & 0 & 2 & 97 & 0 & 0.5 & 0 & 1.5 & 411250596 & 305882076 \\
\hline 48 & 0 & 10 & 97.08 & 0 & 0.5 & 0 & 1.5 & 410604128 & 304524096 \\
\hline 49 & 0 & 5 & 97.08 & 0 & 0.5 & 0 & 1.5 & 410604223 & 304450105 \\
\hline 50 & 0 & 19 & 97.12 & 0 & 0.5 & 0 & 1.5 & 410787140 & 304784071 \\
\hline 51 & 0 & 5 & 97.18 & 0 & 0.5 & 0 & 1.5 & 410558590 & 304191658 \\
\hline 52 & 0 & 0 & 97.38 & 0 & 0.5 & 0 & 1.5 & 410280963 & 304761335 \\
\hline 53 & 0 & 0 & 97.38 & 0 & 0.5 & 0 & 1.5 & 410280771 & 304737743 \\
\hline 54 & 0 & 0 & 97.41 & 0 & 0.5 & 0 & 1.5 & 410725248 & 304658752 \\
\hline 56 & 0 & 0 & 97.6 & 0 & 0.5 & 0 & 1.5 & 410630337 & 304362238 \\
\hline 57 & 0 & 4 & 97.72 & 0 & 0.5 & 0 & 1.5 & 411319087 & 304445431 \\
\hline 58 & 0 & 6 & 97.76 & 0 & 0.5 & 0 & 1.5 & 410637603 & 304505478 \\
\hline 59 & 0 & 8 & 97.96 & 0 & 0.5 & 0 & 1.5 & 410736722 & 304639328 \\
\hline
\end{tabular}




\begin{tabular}{|c|c|c|c|c|c|c|c|c|c|}
\hline $\begin{array}{l}\text { Node } \\
\text { No }\end{array}$ & $\begin{array}{l}\text { Node } \\
\text { Type }\end{array}$ & $\begin{array}{c}\text { Demand } \\
\text { Factor }\end{array}$ & $\begin{array}{c}\text { Elevation } \\
(\mathrm{m})\end{array}$ & $\begin{array}{c}\text { Coefficient } \\
\text { of burst }\end{array}$ & $\begin{array}{c}\text { Exponent } \\
\text { of burst } \\
\text { term }\end{array}$ & $\begin{array}{c}\text { Coefficient } \\
\text { of } \\
\text { background } \\
\text { leakage }\end{array}$ & \begin{tabular}{|c|}
$\begin{array}{c}\text { Exponent } \\
\text { of }\end{array}$ \\
background \\
leakage
\end{tabular} & $\begin{array}{c}\text { Horizontal } \\
\text { Coordinate } \\
\text { of node }\end{array}$ & $\begin{array}{c}\text { Vertical } \\
\text { Coordinate } \\
\text { of node }\end{array}$ \\
\hline 60 & 0 & 0 & 98 & 0 & 0.5 & 0 & 1.5 & 410661743 & 304597226 \\
\hline 61 & 0 & 0 & 98 & 0 & 0.5 & 0 & 1.5 & 410693503 & 304505214 \\
\hline 62 & 0 & 12 & 98.1 & 0 & 0.5 & 0 & 1.5 & 410902576 & 303707802 \\
\hline 63 & 0 & 38 & 98.18 & 0 & 0.5 & 0 & 1.5 & 410608832 & 304212608 \\
\hline 64 & 0 & 8 & 98.2 & 0 & 0.5 & 0 & 1.5 & 411309728 & 304429888 \\
\hline 65 & 0 & 27 & 98.26 & 0 & 0.5 & 0 & 1.5 & 410988736 & 304848352 \\
\hline 66 & 0 & 5 & 98.44 & 0 & 0.5 & 0 & 1.5 & 411135619 & 304678112 \\
\hline 67 & 0 & 40 & 98.56 & 0 & 0.5 & 0 & 1.5 & 410627763 & 304190734 \\
\hline 68 & 0 & 3 & 98.58 & 0 & 0.5 & 0 & 1.5 & 410990237 & 304830932 \\
\hline 69 & 0 & 20 & 98.64 & 0 & 0.5 & 0 & 1.5 & 410782368 & 304666496 \\
\hline 70 & 0 & 4 & 98.676 & 0 & 0.5 & 0 & 1.5 & 411180511 & 304660019 \\
\hline 71 & 0 & 36 & 98.86 & 0 & 0.5 & 0 & 1.5 & 411137088 & 304656608 \\
\hline 72 & 0 & 51 & 99.0312 & 0 & 0.5 & 0 & 1.5 & 410763165 & 304594261 \\
\hline 73 & 0 & 34 & 99.1 & 0 & 0.5 & 0 & 1.5 & 411279840 & 304434496 \\
\hline 74 & 0 & 0 & 99.14 & 0 & 0.5 & 0 & 1.5 & 410950592 & 304842336 \\
\hline 75 & 0 & 0 & 99.32 & 0 & 0.5 & 0 & 1.5 & 411283734 & 304287740 \\
\hline 76 & 0 & 0 & 99.56 & 0 & 0.5 & 0 & 1.5 & 411286272 & 304370944 \\
\hline 77 & 0 & 6 & 99.64 & 0 & 0.5 & 0 & 1.5 & 411042967 & 304640734 \\
\hline 78 & 0 & 17 & 99.852 & 0 & 0.5 & 0 & 1.5 & 410986592 & 304760224 \\
\hline 79 & 0 & 0 & 99.88 & 0 & 0.5 & 0 & 1.5 & 410406127 & 304100962 \\
\hline 80 & 0 & 35 & 99.9 & 0 & 0.5 & 0 & 1.5 & 410845216 & 304676224 \\
\hline 81 & 0 & 0 & 100.28 & 0 & 0.5 & 0 & 1.5 & 409997728 & 303515872 \\
\hline 82 & 0 & 9 & 100.444 & 0 & 0.5 & 0 & 1.5 & 411012224 & 304654592 \\
\hline 83 & 0 & 0 & 100.496 & 0 & 0.5 & 0 & 1.5 & 410021986 & 303695170 \\
\hline 84 & 0 & 0 & 101.042 & 0 & 0.5 & 0 & 1.5 & 410995328 & 304649056 \\
\hline 85 & 0 & 14 & 101.049 & 0 & 0.5 & 0 & 1.5 & 410977376 & 304649088 \\
\hline 86 & 0 & 0 & 101.286 & 0 & 0.5 & 0 & 1.5 & 411237227 & 304154713 \\
\hline 87 & 0 & 9 & 101.542 & 0 & 0.5 & 0 & 1.5 & 411082492 & 304582469 \\
\hline 88 & 0 & 0 & 102 & 0 & 0.5 & 0 & 1.5 & 410218752 & 303977728 \\
\hline 89 & 0 & 16 & 102.18 & 0 & 0.5 & 0 & 1.5 & 411153947 & 304065817 \\
\hline 91 & 0 & 100 & 97 & 0 & 0.5 & 0 & 1.5 & 411217951 & 306164501 \\
\hline 92 & 0 & 5 & 100.714 & 0 & 0.5 & 0 & 1.5 & 411142464 & 304066560 \\
\hline 93 & 0 & 16 & 102.76 & 0 & 0.5 & 0 & 1.5 & 410760043 & 304351731 \\
\hline 94 & 0 & 0 & 98 & 0 & 0.5 & 0 & 1.5 & 411219601 & 305974799 \\
\hline 95 & 1 & 0 & 94.1 & 0 & 0.5 & 0 & 1.5 & 410509041 & 304723406 \\
\hline 96 & 0 & 24 & 103.797 & 0 & 0.5 & 0 & 1.5 & 410916992 & 304578976 \\
\hline 97 & 0 & 0 & 103.8 & 0 & 0.5 & 0 & 1.5 & 410779338 & 304376098 \\
\hline 98 & 0 & 33 & 105.2 & 0 & 0.5 & 0 & 1.5 & 411156736 & 304418880 \\
\hline 99 & 1 & 0 & 100.74 & 0 & 0.5 & 0 & 1.5 & 411148846 & 304062094 \\
\hline 100 & 0 & 0 & 105.357 & 0 & 0.5 & 0 & 1.5 & 410269088 & 302952832 \\
\hline 101 & 0 & 39 & 105.38 & 0 & 0.5 & 0 & 1.5 & 411149472 & 304215968 \\
\hline 102 & 0 & 17 & 105.543 & 0 & 0.5 & 0 & 1.5 & 410757474 & 304206308 \\
\hline 103 & 0 & 0 & 105.88 & 0 & 0.5 & 0 & 1.5 & 411164520 & 304360725 \\
\hline 104 & 0 & 0 & 105.92 & 0 & 0.5 & 0 & 1.5 & 411144530 & 304424386 \\
\hline 105 & 0 & 18 & 106.26 & 0 & 0.5 & 0 & 1.5 & 410868938 & 304011281 \\
\hline
\end{tabular}




\begin{tabular}{|c|c|c|c|c|c|c|c|c|c|}
\hline $\begin{array}{c}\text { Node } \\
\text { No }\end{array}$ & $\begin{array}{c}\text { Node } \\
\text { Type }\end{array}$ & $\begin{array}{c}\text { Demand } \\
\text { Factor }\end{array}$ & $\begin{array}{c}\text { Elevation } \\
(\mathrm{m})\end{array}$ & $\begin{array}{c}\text { Coefficient } \\
\text { of burst }\end{array}$ & $\begin{array}{c}\text { Exponent } \\
\text { of burst } \\
\text { term }\end{array}$ & $\begin{array}{c}\text { Coefficient } \\
\text { of } \\
\text { background } \\
\text { leakage }\end{array}$ & $\begin{array}{c}\text { Exponent } \\
\text { of } \\
\text { background } \\
\text { leakage }\end{array}$ & $\begin{array}{c}\text { Horizontal } \\
\text { Coordinate } \\
\text { of node }\end{array}$ & $\begin{array}{c}\text { Vertical } \\
\text { Coordinate } \\
\text { of node }\end{array}$ \\
\hline 106 & 0 & 0 & 106.72 & 0 & 0.5 & 0 & 1.5 & 411130647 & 304228809 \\
\hline 107 & 0 & 29 & 107.09 & 0 & 0.5 & 0 & 1.5 & 410843840 & 304454112 \\
\hline 108 & 0 & 9 & 107.12 & 0 & 0.5 & 0 & 1.5 & 410967872 & 304536256 \\
\hline 109 & 0 & 15 & 107.356 & 0 & 0.5 & 0 & 1.5 & 411079580 & 304113381 \\
\hline 110 & 0 & 0 & 108.244 & 0 & 0.5 & 0 & 1.5 & 411065308 & 304124492 \\
\hline 111 & 0 & 11 & 108.584 & 0 & 0.5 & 0 & 1.5 & 411103232 & 304452864 \\
\hline 112 & 0 & 11 & 108.76 & 0 & 0.5 & 0 & 1.5 & 411013600 & 304512000 \\
\hline 113 & 0 & 3 & 109.144 & 0 & 0.5 & 0 & 1.5 & 411069728 & 304471712 \\
\hline 114 & 0 & 1 & 106.6 & 0 & 0.5 & 0 & 1.5 & 409880391 & 302451828 \\
\hline 115 & 0 & 18 & 106 & 0 & 0.5 & 0 & 1.5 & 410361272 & 302712532 \\
\hline 116 & 0 & 9 & 110.816 & 0 & 0.5 & 0 & 1.5 & 411059606 & 304398686 \\
\hline 117 & 0 & 10 & 110.96 & 0 & 0.5 & 0 & 1.5 & 410986567 & 304452345 \\
\hline 118 & 0 & 7 & 111.007 & 0 & 0.5 & 0 & 1.5 & 411046752 & 304444096 \\
\hline 119 & 0 & 19 & 113.704 & 0 & 0.5 & 0 & 1.5 & 410897472 & 304239488 \\
\hline 120 & 0 & 15 & 111.712 & 0 & 0.5 & 0 & 1.5 & 411059714 & 304321608 \\
\hline
\end{tabular}

Table D.0.2 Complete element data for Shenstone DMA

\begin{tabular}{|c|c|c|c|c|c|c|c|c|c|}
\hline \multicolumn{2}{|c|}{$\begin{array}{c}\text { Pipe Location } \\
(\text { Node } \rightarrow \text { Node })\end{array}$} & $\begin{array}{c}\text { Length } \\
(\mathrm{m})\end{array}$ & $\begin{array}{c}\text { Diameter } \\
(\mathrm{mm})\end{array}$ & C-Value & \multicolumn{2}{|c|}{$\begin{array}{c}\text { Pipe Location } \\
\text { (Node } \rightarrow \text { Node })\end{array}$} & $\begin{array}{c}\text { Length } \\
(\mathrm{m})\end{array}$ & $\begin{array}{c}\text { Diameter } \\
(\mathrm{mm})\end{array}$ & C-Value \\
\hline 1 & 2 & 19.75851 & 76.35 & 59.13333 & 67 & 63 & 29.30625 & 101.8 & 146.6933 \\
\hline 1 & 3 & 96.87236 & 90 & 130 & 67 & 79 & 241.588 & 101.8 & 35.42 \\
\hline 1 & 4 & 66.67503 & 76.35 & 59.13333 & 67 & 93 & 208.2561 & 101.8 & 35.42 \\
\hline 4 & 8 & 21.70503 & 76.35 & 59.13333 & 67 & 102 & 130.745 & 101.8 & 35.42 \\
\hline 5 & 32 & 598.6205 & 110 & 130 & 68 & 78 & 71.08 & 101.8 & 35.42 \\
\hline 6 & 34 & 687.6823 & 101.8 & 72.46667 & 69 & 33 & 155.9978 & 101.8 & 146.6933 \\
\hline 7 & 6 & 134.7242 & 101.8 & 72.46667 & 69 & 80 & 64.29997 & 101.8 & 72.46667 \\
\hline 8 & 7 & 17.91756 & 101.8 & 72.46667 & 71 & 66 & 21.55412 & 101.8 & 146.6933 \\
\hline 8 & 65 & 300.6921 & 76.35 & 59.13333 & 71 & 70 & 43.5567 & 101.8 & 146.6933 \\
\hline 9 & 8 & 28.74044 & 101.8 & 72.46667 & 73 & 37 & 206.0456 & 110 & 130 \\
\hline 9 & 20 & 162.0679 & 76.35 & 59.13333 & 73 & 64 & 33.745 & 76.35 & 59.13333 \\
\hline 10 & 11 & 37.41631 & 110 & 130 & 73 & 98 & 122.1518 & 101.8 & 35.42 \\
\hline 11 & 5 & 149.5353 & 110 & 130 & 74 & 65 & 39.18975 & 76.35 & 59.13333 \\
\hline 17 & 14 & 40.41073 & 90 & 130 & 75 & 76 & 83.34575 & 101.8 & 35.42 \\
\hline 17 & 16 & 64.2275 & 90 & 130 & 76 & 73 & 63.88521 & 76.35 & 39.13333 \\
\hline 19 & 38 & 139.7911 & 101.8 & 72.46667 & 78 & 85 & 140.2262 & 101.8 & 35.42 \\
\hline 20 & 10 & 166.5803 & 110 & 130 & 80 & 74 & 215.4905 & 76.35 & 59.13333 \\
\hline 22 & 17 & 48.909 & 90 & 130 & 80 & 96 & 123.6254 & 76.35 & 59.13333 \\
\hline 22 & 28 & 174.0521 & 125 & 130 & 81 & 83 & 182.5032 & 101.8 & 146.6933 \\
\hline 23 & 13 & 101.9956 & 125 & 130 & 82 & 77 & 63.4748 & 101.8 & 35.42 \\
\hline 23 & 15 & 85.4209 & 90 & 130 & 82 & 78 & 130.8103 & 101.8 & 35.42 \\
\hline 24 & 18 & 59.74524 & 90 & 130 & 82 & 84 & 17.8289 & 101.8 & 35.42 \\
\hline 24 & 25 & 51.0624 & 90 & 130 & 83 & 88 & 385.6661 & 101.8 & 146.6933 \\
\hline 26 & 22 & 43.86057 & 125 & 130 & 85 & 84 & 18.1897 & 101.8 & 35.42 \\
\hline 26 & 23 & 57.0413 & 125 & 130 & 86 & 75 & 143.3626 & 101.8 & 35.42 \\
\hline 26 & 68 & 116.7481 & 125 & 130 & 88 & 79 & 224.4458 & 101.8 & 146.6933 \\
\hline 27 & 19 & 101.3468 & 101.8 & 72.46667 & 89 & 86 & 116.7089 & 101.8 & 35.42 \\
\hline 28 & 24 & 40.5345 & 90 & 130 & 89 & 92 & 20.771 & 101.8 & 35.42 \\
\hline 28 & 50 & 177.4136 & 125 & 130 & 92 & 109 & 79.32269 & 101.8 & 35.42 \\
\hline
\end{tabular}




\begin{tabular}{|c|c|c|c|c|c|c|c|c|c|}
\hline \multicolumn{2}{|c|}{$\begin{array}{c}\text { Pipe Location } \\
\text { (Node } \rightarrow \text { Node) }\end{array}$} & \multirow{2}{*}{\begin{tabular}{|c|}
$\begin{array}{c}\text { Length } \\
(\mathrm{m})\end{array}$ \\
85.5427
\end{tabular}} & \multirow{2}{*}{$\begin{array}{c}\text { Diameter } \\
(\mathrm{mm})\end{array}$} & \multirow{2}{*}{$\frac{\text { C-Value }}{147.6667}$} & \multicolumn{2}{|c|}{$\begin{array}{c}\text { Pipe Location } \\
\text { (Node } \rightarrow \text { Node) }\end{array}$} & \multirow{2}{*}{$\begin{array}{c}\begin{array}{c}\text { Length } \\
(\mathrm{m})\end{array} \\
261.291\end{array}$} & \multirow{2}{*}{$\begin{array}{c}\text { Diameter } \\
(\mathrm{mm})\end{array}$} & \multirow{2}{*}{$\begin{array}{c}\text { C-Value } \\
130\end{array}$} \\
\hline 30 & 35 & & & & 94 & 91 & & & \\
\hline 31 & 30 & 162.6061 & 100 & 147.6667 & 95 & 19 & 16.4486 & 101.8 & 72.46667 \\
\hline 32 & 94 & 365.2932 & 110 & 130 & 96 & 85 & 94.7265 & 101.8 & 35.42 \\
\hline 34 & 41 & 98.36987 & 101.8 & 72.46667 & 96 & 108 & 66.60058 & 76.35 & 59.13333 \\
\hline 34 & 42 & 130.99 & 76.35 & 59.13333 & 97 & 93 & 31.08131 & 101.8 & 35.42 \\
\hline 36 & 27 & 71.08533 & 101.8 & 72.46667 & 97 & 107 & 101.6126 & 76.35 & 83.09333 \\
\hline 36 & 31 & 96.599 & 100 & 147.6667 & 98 & 103 & 58.67721 & 101.8 & 35.42 \\
\hline 37 & 20 & 86.6142 & 110 & 130 & 98 & 104 & 16.51672 & 101.8 & 35.42 \\
\hline 38 & 54 & 86.27027 & 101.8 & 72.46667 & 99 & 92 & 20 & 125 & 130 \\
\hline 39 & 48 & 73.88636 & 100 & 130 & 100 & 81 & 642.91 & 101.8 & 146.6933 \\
\hline 39 & 49 & 28.526 & 80 & 130 & 101 & 106 & 22.78926 & 101.8 & 35.42 \\
\hline 40 & 44 & 86.50249 & 100 & 130 & 101 & 109 & 124.1395 & 101.8 & 35.42 \\
\hline 40 & 45 & 27.902 & 80 & 130 & 102 & 105 & 240.665 & 101.8 & 35.42 \\
\hline 41 & 47 & 39.323 & 101.8 & 72.46667 & 102 & 119 & 144.3587 & 101.8 & 35.42 \\
\hline 43 & 39 & 63.32603 & 100 & 130 & 103 & 101 & 151.6336 & 101.8 & 35.42 \\
\hline 43 & 40 & 62.57467 & 100 & 130 & 104 & 111 & 50.6176 & 101.8 & 35.42 \\
\hline 43 & 46 & 38.123 & 80 & 130 & 106 & 120 & 133.7449 & 101.8 & 35.42 \\
\hline 48 & 58 & 38.424 & 80 & 130 & 107 & 72 & 161.7186 & 76.35 & 59.13333 \\
\hline 52 & 29 & 182.6855 & 125 & 130 & 107 & 108 & 158.3529 & 76.35 & 83.09333 \\
\hline 52 & 53 & 23.59628 & 101.8 & 72.46667 & 107 & 119 & 225.2091 & 76.35 & 59.13333 \\
\hline 53 & 36 & 64.42031 & 101.8 & 72.46667 & 108 & 112 & 51.77475 & 76.35 & 59.13333 \\
\hline 54 & 59 & 22.5636 & 76.35 & 59.13333 & 110 & 109 & 18.0905 & 101.8 & 35.42 \\
\hline 54 & 69 & 58.12779 & 101.8 & 72.46667 & 110 & 119 & 203.4917 & 76.35 & 39.13333 \\
\hline 56 & 61 & \begin{tabular}{|l|}
157.8994 \\
\end{tabular} & 101.8 & 146.6933 & 111 & 71 & 212.4508 & 101.8 & 146.6933 \\
\hline 59 & 72 & 52.25196 & 76.35 & 59.13333 & 111 & 113 & 38.4417 & 101.8 & 35.42 \\
\hline 60 & 48 & 94.51749 & 100 & 130 & 112 & 87 & 101.2271 & 101.8 & 35.42 \\
\hline 60 & 59 & 90.9568 & 76.35 & 83.09333 & 112 & 113 & 76.554 & 101.8 & 35.42 \\
\hline 61 & 72 & 119.2824 & 101.8 & 146.6933 & 113 & 118 & 36.659 & 101.8 & 35.42 \\
\hline 63 & 51 & \begin{tabular}{|l|}
55.03089 \\
\end{tabular} & 76.35 & 146.0267 & 114 & 115 & 558.7613 & 76.35 & 146.0267 \\
\hline 63 & 56 & 161.5005 & 101.8 & 146.6933 & 115 & 100 & 293.4016 & 101.8 & 146.6933 \\
\hline 64 & 57 & \begin{tabular}{|l|l|}
18.14639 \\
\end{tabular} & 76.35 & 59.13333 & 118 & 116 & 47.22019 & 101.8 & 35.42 \\
\hline 65 & 68 & 17.484 & 101.8 & 35.42 & 118 & 117 & 68.49815 & 101.8 & 35.42 \\
\hline 67 & 62 & 566.756 & 101.8 & 72.46667 & & & & & \\
\hline
\end{tabular}




\section{Appendix E - Node and Element Data for the E054 DMA}

The model of the network used by the author is stored in a separate excel file model.xls with the following fields:

A - Node number - a unique label used to identify the node.

B - Type of node - a binary value that describes the role of a node in a network: 0 for a connection node or 1 for a source node (reservoir node or PRV OUTLET node).

C - Demand factor - number of average water users allocated to a node.

D - Elevation $(m)$ - elevation in metres above a common reference of a node. The elevation in used in the program only to compute the pressure at the node.

E - Coefficient of a burst - value of coefficient $c_{1}$ for a specific node is set in case of presence in a network of already known burst with specified characteristics.

$\mathrm{F}$ - Exponent of the burst term in the IFM=0.5.

$\mathrm{G}$ - Coefficient of known background leakages - value of coefficient $c_{2}$ for a specific node is set up in case of presence in a network with already known background leakages with specified characteristics.

$\mathrm{H}-$ Exponent of the background leakage term in the IFM $=1.5$.

I, J - Horizontal and vertical co-ordinates of a node on the map. They do not affect any other variable.

Table E.0.1 Complete nodes data for the E054 DMA

\begin{tabular}{|c|c|c|c|c|c|c|c|c|c|}
\hline $\begin{array}{c}\text { Node } \\
\text { No }\end{array}$ & $\begin{array}{c}\text { Node } \\
\text { Type }\end{array}$ & $\begin{array}{c}\text { Demand } \\
\text { Factor }\end{array}$ & $\begin{array}{c}\text { Elevation } \\
(\mathrm{m})\end{array}$ & $\begin{array}{c}\text { Coefficient } \\
\text { of burst }\end{array}$ & $\begin{array}{c}\text { Exponent } \\
\text { of burst } \\
\text { term }\end{array}$ & $\begin{array}{c}\text { Coefficient } \\
\text { of } \\
\text { background } \\
\text { leakage }\end{array}$ & $\begin{array}{c}\text { Exponent } \\
\text { of } \\
\text { background } \\
\text { leakage }\end{array}$ & $\begin{array}{c}\text { Horizontal } \\
\text { Coordinate } \\
\text { of node }\end{array}$ & $\begin{array}{c}\text { Vertical } \\
\text { Coordinate } \\
\text { of node }\end{array}$ \\
\hline 1 & 0 & 0 & 109.52 & 0 & 0.5 & 0 & 1.5 & 430962 & 451406 \\
\hline 2 & 0 & 0 & 109.52 & 0 & 0.5 & 0 & 1.5 & 430962 & 451404 \\
\hline 3 & 0 & 0 & 108.96 & 0 & 0.5 & 0 & 1.5 & 430963 & 451403 \\
\hline 4 & 0 & 0 & 109.12 & 0 & 0.5 & 0 & 1.5 & 430964 & 451402 \\
\hline 5 & 0 & 0 & 108.89 & 0 & 0.5 & 0 & 1.5 & 430964 & 451405 \\
\hline 6 & 0 & 0 & 109.14 & 0 & 0.5 & 0 & 1.5 & 430965 & 451402 \\
\hline 7 & 0 & 0 & 109.19 & 0 & 0.5 & 0 & 1.5 & 430966 & 451402 \\
\hline 8 & 0 & 0 & 109.74 & 0 & 0.5 & 0 & 1.5 & 430968 & 451396 \\
\hline 9 & 0 & 0 & 109.09 & 0 & 0.5 & 0 & 1.5 & 430968 & 451405 \\
\hline 10 & 0 & 0 & 113.73 & 0 & 0.5 & 0 & 1.5 & 430969 & 451272 \\
\hline 11 & 0 & 0 & 110.56 & 0 & 0.5 & 0 & 1.5 & 430983 & 451389 \\
\hline
\end{tabular}




\begin{tabular}{|c|c|c|c|c|c|c|c|c|c|}
\hline $\begin{array}{c}\text { Node } \\
\text { No }\end{array}$ & $\begin{array}{l}\text { Node } \\
\text { Type }\end{array}$ & $\begin{array}{c}\text { Demand } \\
\text { Factor }\end{array}$ & $\begin{array}{c}\text { Elevation } \\
(\mathrm{m})\end{array}$ & $\begin{array}{c}\text { Coefficient } \\
\text { of burst }\end{array}$ & $\begin{array}{c}\text { Exponent } \\
\text { of burst } \\
\text { term }\end{array}$ & $\begin{array}{c}\text { Coefficient } \\
\text { of } \\
\text { background } \\
\text { leakage }\end{array}$ & $\begin{array}{c}\text { Exponent } \\
\text { of } \\
\text { background } \\
\text { leakage }\end{array}$ & $\begin{array}{c}\text { Horizontal } \\
\text { Coordinate } \\
\text { of node }\end{array}$ & $\begin{array}{c}\text { Vertical } \\
\text { Coordinate } \\
\text { of node }\end{array}$ \\
\hline 12 & 0 & 0 & 110.44 & 0 & 0.5 & 0 & 1.5 & 430984 & 451392 \\
\hline 13 & 0 & 0 & 113.47 & 0 & 0.5 & 0 & 1.5 & 431011 & 451335 \\
\hline 14 & 0 & 0 & 117.12 & 0 & 0.5 & 0 & 1.5 & 431012 & 451216 \\
\hline 15 & 0 & 0 & 113.28 & 0 & 0.5 & 0 & 1.5 & 431018 & 451348 \\
\hline 16 & 0 & 0 & 122.5 & 0 & 0.5 & 0 & 1.5 & 431082 & 451151 \\
\hline 17 & 0 & 1 & 116.95 & 0 & 0.5 & 0 & 1.5 & 431109 & 451323 \\
\hline 18 & 0 & 0 & 117.21 & 0 & 0.5 & 0 & 1.5 & 431114 & 451321 \\
\hline 19 & 0 & 0 & 117.31 & 0 & 0.5 & 0 & 1.5 & 431115 & 451319 \\
\hline 20 & 0 & 4 & 119.95 & 0 & 0.5 & 0 & 1.5 & 431127 & 451271 \\
\hline 21 & 0 & 7 & 123.42 & 0 & 0.5 & 0 & 1.5 & 431134 & 451216 \\
\hline 22 & 0 & 0 & 129.05 & 0 & 0.5 & 0 & 1.5 & 431166 & 451119 \\
\hline 23 & 0 & 0 & 129.15 & 0 & 0.5 & 0 & 1.5 & 431167 & 451118 \\
\hline 24 & 0 & 0 & 129.2 & 0 & 0.5 & 0 & 1.5 & 431168 & 451118 \\
\hline 25 & 0 & 0 & 129.13 & 0 & 0.5 & 0 & 1.5 & 431168 & 451121 \\
\hline 26 & 0 & 0 & 129.16 & 0 & 0.5 & 0 & 1.5 & 431169 & 451123 \\
\hline 27 & 0 & 2 & 129.48 & 0 & 0.5 & 0 & 1.5 & 431172 & 451117 \\
\hline 28 & 0 & 0 & 129.47 & 0 & 0.5 & 0 & 1.5 & 431174 & 451124 \\
\hline 29 & 0 & 2 & 129.47 & 0 & 0.5 & 0 & 1.5 & 431174 & 451125 \\
\hline 30 & 0 & 0 & 124.85 & 0 & 0.5 & 0 & 1.5 & 431201 & 451274 \\
\hline 31 & 0 & 7 & 136.78 & 0 & 0.5 & 0 & 1.5 & 431208 & 451063 \\
\hline 32 & 0 & 6 & 132.49 & 0 & 0.5 & 0 & 1.5 & 431209 & 451141 \\
\hline 33 & 0 & 0 & 134.31 & 0 & 0.5 & 0 & 1.5 & 431210 & 451112 \\
\hline 34 & 0 & 6 & 128.31 & 0 & 0.5 & 0 & 1.5 & 431213 & 451226 \\
\hline 35 & 0 & 2 & 134.38 & 0 & 0.5 & 0 & 1.5 & 431214 & 451118 \\
\hline 36 & 0 & 4 & 130.63 & 0 & 0.5 & 0 & 1.5 & 431236 & 451221 \\
\hline 37 & 0 & 2 & 139.46 & 0 & 0.5 & 0 & 1.5 & 431237 & 451083 \\
\hline 38 & 0 & 0 & 148.18 & 0 & 0.5 & 0 & 1.5 & 431241 & 450416 \\
\hline 39 & 0 & 4 & 139.48 & 0 & 0.5 & 0 & 1.5 & 431243 & 451095 \\
\hline 40 & 0 & 0 & 148.05 & 0 & 0.5 & 0 & 1.5 & 431244 & 450425 \\
\hline 41 & 0 & 0 & 147.97 & 0 & 0.5 & 0 & 1.5 & 431246 & 450457 \\
\hline 42 & 0 & 0 & 148.13 & 0 & 0.5 & 0 & 1.5 & 431249 & 450376 \\
\hline 43 & 0 & 0 & 148.14 & 0 & 0.5 & 0 & 1.5 & 431251 & 450371 \\
\hline 44 & 0 & 4 & 148.64 & 0 & 0.5 & 0 & 1.5 & 431253 & 450343 \\
\hline 45 & 0 & 4 & 141.35 & 0 & 0.5 & 0 & 1.5 & 431257 & 451080 \\
\hline 46 & 0 & 0 & 147 & 0 & 0.5 & 0 & 1.5 & 431258 & 450508 \\
\hline 47 & 0 & 0 & \begin{tabular}{|l|}
147.14 \\
\end{tabular} & 0 & 0.5 & 0 & 1.5 & 431266 & 450552 \\
\hline 48 & 0 & 0 & \begin{tabular}{|l|}
148.43 \\
\end{tabular} & 0 & 0.5 & 0 & 1.5 & 431269 & 450293 \\
\hline 49 & 0 & 0 & 147.99 & 0 & 0.5 & 0 & 1.5 & 431269 & 450304 \\
\hline 50 & 0 & 0 & \begin{tabular}{|l|}
146.89 \\
\end{tabular} & 0 & 0.5 & 0 & 1.5 & 431272 & 450571 \\
\hline 51 & 0 & 0 & \begin{tabular}{|l|}
146.86 \\
\end{tabular} & 0 & 0.5 & 0 & 1.5 & 431273 & 450563 \\
\hline 52 & 0 & 4 & 134.34 & 0 & 0.5 & 0 & 1.5 & 431280 & 451225 \\
\hline 53 & 0 & 0 & 148.38 & 0 & 0.5 & 0 & 1.5 & 431282 & 450272 \\
\hline 54 & 0 & 2 & \begin{tabular}{|l|}
143.57 \\
\end{tabular} & 0 & 0.5 & 0 & 1.5 & 431282 & 451071 \\
\hline 55 & 0 & 2 & 142.52 & 0 & 0.5 & 0 & 1.5 & 431284 & 451098 \\
\hline 56 & 0 & 0 & 143.95 & 0 & 0.5 & 0 & 1.5 & 431290 & 451077 \\
\hline
\end{tabular}




\begin{tabular}{|c|c|c|c|c|c|c|c|c|c|}
\hline $\begin{array}{c}\text { Node } \\
\text { No }\end{array}$ & $\begin{array}{l}\text { Node } \\
\text { Type }\end{array}$ & $\begin{array}{c}\text { Demand } \\
\text { Factor }\end{array}$ & $\begin{array}{c}\text { Elevation } \\
(\mathrm{m})\end{array}$ & $\begin{array}{c}\text { Coefficient } \\
\text { of burst }\end{array}$ & $\begin{array}{c}\text { Exponent } \\
\text { of burst } \\
\text { term }\end{array}$ & $\begin{array}{c}\text { Coefficient } \\
\text { of } \\
\text { background } \\
\text { leakage }\end{array}$ & $\begin{array}{c}\text { Exponent } \\
\text { of } \\
\text { background } \\
\text { leakage }\end{array}$ & $\begin{array}{c}\text { Horizontal } \\
\text { Coordinate } \\
\text { of node }\end{array}$ & $\begin{array}{c}\text { Vertical } \\
\text { Coordinate } \\
\text { of node }\end{array}$ \\
\hline 57 & 0 & 0 & 146.47 & 0 & 0.5 & 0 & 1.5 & 431291 & 450623 \\
\hline 58 & 0 & 4 & 143.9 & 0 & 0.5 & 0 & 1.5 & 431292 & 451081 \\
\hline 59 & 0 & 0 & 148.84 & 0 & 0.5 & 0 & 1.5 & 431292 & 450233 \\
\hline 60 & 0 & 7 & 146.41 & 0 & 0.5 & 0 & 1.5 & 431307 & 451046 \\
\hline 61 & 0 & 0 & 146.53 & 0 & 0.5 & 0 & 1.5 & 431307 & 450651 \\
\hline 62 & 0 & 0 & 147.92 & 0 & 0.5 & 0 & 1.5 & 431307 & 450200 \\
\hline 63 & 0 & 0 & 147.65 & 0 & 0.5 & 0 & 1.5 & 431308 & 450208 \\
\hline 64 & 0 & 0 & 147.8 & 0 & 0.5 & 0 & 1.5 & 431314 & 450186 \\
\hline 65 & 0 & 0 & 147.45 & 0 & 0.5 & 0 & 1.5 & 431319 & 450694 \\
\hline 66 & 0 & 4 & 146.61 & 0 & 0.5 & 0 & 1.5 & 431319 & 451059 \\
\hline 67 & 0 & 0 & 145.98 & 0 & 0.5 & 0 & 1.5 & 431320 & 451072 \\
\hline 68 & 0 & 0 & 147.24 & 0 & 0.5 & 0 & 1.5 & 431334 & 450151 \\
\hline 69 & 0 & 0 & 148.35 & 0 & 0.5 & 0 & 1.5 & 431339 & 450734 \\
\hline 70 & 0 & 0 & 148.89 & 0 & 0.5 & 0 & 1.5 & 431340 & 450748 \\
\hline 71 & 0 & 0 & 147.66 & 0 & 0.5 & 0 & 1.5 & 431341 & 451064 \\
\hline 72 & 0 & 6 & 140 & 0 & 0.5 & 0 & 1.5 & 431343 & 451219 \\
\hline 73 & 0 & 0 & 149.42 & 0 & 0.5 & 0 & 1.5 & 431353 & 450770 \\
\hline 74 & 0 & 0 & 146.96 & 0 & 0.5 & 0 & 1.5 & 431355 & 450131 \\
\hline 75 & 0 & 0 & 150 & 0 & 0.5 & 0 & 1.5 & 431357 & 450792 \\
\hline 76 & 0 & 2 & 148.85 & 0 & 0.5 & 0 & 1.5 & 431370 & 451073 \\
\hline 77 & 0 & 4 & 148.55 & 0 & 0.5 & 0 & 1.5 & 431371 & 451079 \\
\hline 78 & 0 & 0 & 150 & 0 & 0.5 & 0 & 1.5 & 431377 & 450831 \\
\hline 79 & 0 & 0 & 149.24 & 0 & 0.5 & 0 & 1.5 & 431377 & 451073 \\
\hline 80 & 0 & 0 & 150 & 0 & 0.5 & 0 & 1.5 & 431378 & 451055 \\
\hline 81 & 0 & 4 & 150 & 0 & 0.5 & 0 & 1.5 & 431378 & 451053 \\
\hline 82 & 0 & 0 & 150 & 0 & 0.5 & 0 & 1.5 & 431380 & 450872 \\
\hline 83 & 0 & 0 & 149.19 & 0 & 0.5 & 0 & 1.5 & 431380 & 450041 \\
\hline 84 & 0 & 0 & 150 & 0 & 0.5 & 0 & 1.5 & 431382 & 451053 \\
\hline 85 & 0 & 0 & 150 & 0 & 0.5 & 0 & 1.5 & 431382 & 450871 \\
\hline 86 & 0 & 0 & 150 & 0 & 0.5 & 0 & 1.5 & 431383 & 450874 \\
\hline 87 & 0 & 0 & 150 & 0 & 0.5 & 0 & 1.5 & 431383 & 450870 \\
\hline 88 & 0 & 0 & 150 & 0 & 0.5 & 0 & 1.5 & 431384 & 450870 \\
\hline 89 & 0 & 0 & 150 & 0 & 0.5 & 0 & 1.5 & 431384 & 450873 \\
\hline 90 & 0 & 0 & 150 & 0 & 0.5 & 0 & 1.5 & 431385 & 450867 \\
\hline 91 & 0 & 0 & 150 & 0 & 0.5 & 0 & 1.5 & 431385 & 450872 \\
\hline 92 & 0 & 0 & 150 & 0 & 0.5 & 0 & 1.5 & 431386 & 450853 \\
\hline 93 & 0 & 0 & 150 & 0 & 0.5 & 0 & 1.5 & 431386 & 451055 \\
\hline 94 & 0 & 0 & 150 & 0 & 0.5 & 0 & 1.5 & 431386 & 451053 \\
\hline 95 & 0 & 0 & 150 & 0 & 0.5 & 0 & 1.5 & 431386 & 450867 \\
\hline 96 & 0 & 2 & 150 & 0 & 0.5 & 0 & 1.5 & 431386 & 451046 \\
\hline 97 & 0 & 0 & 148.93 & 0 & 0.5 & 0 & 1.5 & 431387 & 451017 \\
\hline 98 & 0 & 0 & 150 & 0 & 0.5 & 0 & 1.5 & 431386 & 450868 \\
\hline \begin{tabular}{|l|}
99 \\
\end{tabular} & 0 & 0 & 150 & 0 & 0.5 & 0 & 1.5 & 431386 & 450875 \\
\hline \begin{tabular}{|l|}
100 \\
\end{tabular} & 0 & 0 & \begin{tabular}{|l}
148.93 \\
\end{tabular} & 0 & 0.5 & 0 & 1.5 & 431387 & 451022 \\
\hline 101 & 0 & 0 & 150 & 0 & 0.5 & 0 & 1.5 & 431387 & 450871 \\
\hline
\end{tabular}




\begin{tabular}{|c|c|c|c|c|c|c|c|c|c|}
\hline $\begin{array}{c}\text { Node } \\
\text { No }\end{array}$ & $\begin{array}{l}\text { Node } \\
\text { Type }\end{array}$ & $\begin{array}{l}\text { Demand } \\
\text { Factor }\end{array}$ & $\begin{array}{c}\text { Elevation } \\
(\mathrm{m})\end{array}$ & $\begin{array}{c}\text { Coefficient } \\
\text { of burst }\end{array}$ & $\begin{array}{c}\begin{array}{c}\text { Exponent } \\
\text { of burst } \\
\text { term }\end{array} \\
\text { term }\end{array}$ & $\begin{array}{c}\text { Coefficient } \\
\text { of } \\
\text { background } \\
\text { leakage }\end{array}$ & $\begin{array}{c}\text { Exponent } \\
\text { of } \\
\text { background } \\
\text { leakage }\end{array}$ & $\begin{array}{c}\text { Horizontal } \\
\text { Coordinate } \\
\text { of node }\end{array}$ & $\begin{array}{c}\text { Vertical } \\
\text { Coordinate } \\
\text { of node }\end{array}$ \\
\hline \begin{tabular}{|l|}
102 \\
\end{tabular} & 0 & 0 & 148.93 & 0 & 0.5 & 0 & 1.5 & 431388 & 451014 \\
\hline \begin{tabular}{|l|}
103 \\
\end{tabular} & 0 & 0 & 150 & 0 & 0.5 & 0 & 1.5 & 431389 & 451013 \\
\hline \begin{tabular}{|l|}
104 \\
\end{tabular} & 0 & 0 & 150 & 0 & 0.5 & 0 & 1.5 & 431389 & 451023 \\
\hline 105 & 0 & 0 & 150 & 0 & 0.5 & 0 & 1.5 & 431390 & 451016 \\
\hline \begin{tabular}{|l|}
106 \\
\end{tabular} & 0 & 0 & 150 & 0 & 0.5 & 0 & 1.5 & 431390 & 450919 \\
\hline \begin{tabular}{|l|}
107 \\
\end{tabular} & 0 & 0 & 150 & 0 & 0.5 & 0 & 1.5 & 431390 & 451020 \\
\hline \begin{tabular}{|l|}
108 \\
\end{tabular} & 0 & 2 & 150 & 0 & 0.5 & 0 & 1.5 & 431391 & 451073 \\
\hline \begin{tabular}{|l|l}
109 \\
\end{tabular} & 0 & 6 & 150 & 0 & 0.5 & 0 & 1.5 & 431391 & 451016 \\
\hline \begin{tabular}{|l|}
110 \\
\end{tabular} & 0 & 0 & 148.12 & 0 & 0.5 & 0 & 1.5 & 431394 & 450078 \\
\hline \begin{tabular}{|l|}
111 \\
\end{tabular} & 0 & 7 & 148.39 & 0 & 0.5 & 0 & 1.5 & 431395 & 451106 \\
\hline \begin{tabular}{|l|}
112 \\
\end{tabular} & 0 & 0 & 150 & 0 & 0.5 & 0 & 1.5 & 431398 & 450932 \\
\hline \begin{tabular}{|l|}
113 \\
\end{tabular} & 0 & 0 & 150 & 0 & 0.5 & 0 & 1.5 & 431399 & 450968 \\
\hline \begin{tabular}{|l|}
114 \\
\end{tabular} & 0 & 2 & 141.6 & 0 & 0.5 & 0 & 1.5 & 431401 & 451206 \\
\hline \begin{tabular}{|l|}
115 \\
\end{tabular} & 0 & 0 & 148.16 & 0 & 0.5 & 0 & 1.5 & 431402 & 450063 \\
\hline \begin{tabular}{|l|}
116 \\
\end{tabular} & 0 & 0 & 141.65 & 0 & 0.5 & 0 & 1.5 & 431402 & 451206 \\
\hline \begin{tabular}{|l|}
117 \\
\end{tabular} & 0 & 0 & 148.12 & 0 & 0.5 & 0 & 1.5 & 431402 & 450062 \\
\hline 118 & 0 & 0 & 148.09 & 0 & 0.5 & 0 & 1.5 & 431403 & 450064 \\
\hline \begin{tabular}{|l|}
119 \\
\end{tabular} & 0 & 0 & 148.04 & 0 & 0.5 & 0 & 1.5 & 431404 & 450065 \\
\hline \begin{tabular}{|l|}
120 \\
\end{tabular} & 0 & 0 & 147.98 & 0 & 0.5 & 0 & 1.5 & 431405 & 450058 \\
\hline \begin{tabular}{|l|}
121 \\
\end{tabular} & 0 & 0 & 147.96 & 0 & 0.5 & 0 & 1.5 & 431406 & 450062 \\
\hline \begin{tabular}{|l|}
122 \\
\end{tabular} & 0 & 0 & 147.87 & 0 & 0.5 & 0 & 1.5 & 431408 & 450060 \\
\hline 123 & 0 & 0 & 147.86 & 0 & 0.5 & 0 & 1.5 & 431408 & 450057 \\
\hline 124 & 0 & 0 & 147.82 & 0 & 0.5 & 0 & 1.5 & 431408 & 450058 \\
\hline \begin{tabular}{|l|}
125 \\
\end{tabular} & 0 & 0 & 147.79 & 0 & 0.5 & 0 & 1.5 & 431409 & 450058 \\
\hline 126 & 0 & 0 & 147.86 & 0 & 0.5 & 0 & 1.5 & 431409 & 450056 \\
\hline \begin{tabular}{|l|}
127 \\
\end{tabular} & 0 & 0 & 147.6 & 0 & 0.5 & 0 & 1.5 & 431413 & 450059 \\
\hline \begin{tabular}{|l|}
128 \\
\end{tabular} & 0 & 0 & 147.56 & 0 & 0.5 & 0 & 1.5 & 431414 & 450060 \\
\hline \begin{tabular}{|l|}
129 \\
\end{tabular} & 0 & 4 & 148.85 & 0 & 0.5 & 0 & 1.5 & 431425 & 451090 \\
\hline \begin{tabular}{|l|}
130 \\
\end{tabular} & 0 & 2 & 148.85 & 0 & 0.5 & 0 & 1.5 & 431426 & 451089 \\
\hline \begin{tabular}{|l|}
131 \\
\end{tabular} & 0 & 6 & 144.62 & 0 & 0.5 & 0 & 1.5 & 431442 & 451165 \\
\hline \begin{tabular}{|l|}
132 \\
\end{tabular} & 0 & 9 & 146.33 & 0 & 0.5 & 0 & 1.5 & 431455 & 450039 \\
\hline \begin{tabular}{|l|}
133 \\
\end{tabular} & 0 & 2 & 146.11 & 0 & 0.5 & 0 & 1.5 & 431461 & 450040 \\
\hline \begin{tabular}{|l|}
134 \\
\end{tabular} & 0 & 2 & 144.71 & 0 & 0.5 & 0 & 1.5 & 431465 & 451146 \\
\hline \begin{tabular}{|l|}
135 \\
\end{tabular} & 0 & 6 & 144.62 & 0 & 0.5 & 0 & 1.5 & 431468 & 451144 \\
\hline \begin{tabular}{|l|}
136 \\
\end{tabular} & 0 & 6 & 147.74 & 0 & 0.5 & 0 & 1.5 & 431470 & 451000 \\
\hline 137 & 0 & 7 & 147.7 & 0 & 0.5 & 0 & 1.5 & 431474 & 451034 \\
\hline \begin{tabular}{|l|}
138 \\
\end{tabular} & 0 & 4 & 142.02 & 0 & 0.5 & 0 & 1.5 & 431490 & 451183 \\
\hline \begin{tabular}{|l|}
139 \\
\end{tabular} & 0 & 2 & 141.83 & 0 & 0.5 & 0 & 1.5 & 431495 & 451182 \\
\hline \begin{tabular}{|l|}
140 \\
\end{tabular} & 0 & 0 & 144.05 & 0 & 0.5 & 0 & 1.5 & 431526 & 450032 \\
\hline \begin{tabular}{|l|}
141 \\
\end{tabular} & 0 & 4 & 144.03 & 0 & 0.5 & 0 & 1.5 & 431529 & 450029 \\
\hline 142 & 0 & 4 & 140 & 0 & 0.5 & 0 & 1.5 & 431537 & 451184 \\
\hline \begin{tabular}{|l|}
143 \\
\end{tabular} & 0 & 6 & 140.8 & 0 & 0.5 & 0 & 1.5 & 431539 & 451149 \\
\hline \begin{tabular}{|l|}
144 \\
\end{tabular} & 0 & 9 & 143.4 & 0 & 0.5 & 0 & 1.5 & 431547 & 451001 \\
\hline 145 & 0 & 2 & 140.07 & 0 & 0.5 & 0 & 1.5 & 431549 & 451155 \\
\hline 146 & 0 & 9 & 143.37 & 0 & 0.5 & 0 & 1.5 & 431549 & 451059 \\
\hline
\end{tabular}




\begin{tabular}{|c|c|c|c|c|c|c|c|c|c|}
\hline $\begin{array}{c}\text { Node } \\
\text { No }\end{array}$ & $\begin{array}{l}\text { Node } \\
\text { Type }\end{array}$ & $\begin{array}{c}\text { Demand } \\
\text { Factor }\end{array}$ & $\begin{array}{c}\text { Elevation } \\
(\mathrm{m})\end{array}$ & $\begin{array}{c}\text { Coefficient } \\
\text { of burst }\end{array}$ & $\begin{array}{c}\text { Exponent } \\
\text { of burst } \\
\text { term }\end{array}$ & $\begin{array}{c}\text { Coefficient } \\
\text { of } \\
\text { background } \\
\text { leakage }\end{array}$ & $\begin{array}{c}\text { Exponent } \\
\text { of } \\
\text { background } \\
\text { leakage }\end{array}$ & $\begin{array}{c}\text { Horizontal } \\
\text { Coordinate } \\
\text { of node }\end{array}$ & $\begin{array}{c}\text { Vertical } \\
\text { Coordinate } \\
\text { of node }\end{array}$ \\
\hline 147 & 0 & 0 & 140.16 & 0 & 0.5 & 0 & 1.5 & 431550 & 451151 \\
\hline 148 & 0 & 0 & 140 & 0 & 0.5 & 0 & 1.5 & 431568 & 451151 \\
\hline 149 & 0 & 0 & 140 & 0 & 0.5 & 0 & 1.5 & 431571 & 451151 \\
\hline 150 & 0 & 2 & 71.95 & 0 & 0.5 & 0 & 1.5 & 431584 & 448816 \\
\hline 151 & 0 & 11 & 71.57 & 0 & 0.5 & 0 & 1.5 & 431586 & 448793 \\
\hline 152 & 0 & 0 & 141.94 & 0 & 0.5 & 0 & 1.5 & 431587 & 450034 \\
\hline 153 & 0 & 6 & 72 & 0 & 0.5 & 0 & 1.5 & 431587 & 448833 \\
\hline 154 & 0 & 0 & 141.81 & 0 & 0.5 & 0 & 1.5 & 431590 & 450035 \\
\hline 155 & 0 & 0 & 141.77 & 0 & 0.5 & 0 & 1.5 & 431590 & 450037 \\
\hline 156 & 0 & 0 & 141.83 & 0 & 0.5 & 0 & 1.5 & 431590 & 450034 \\
\hline 157 & 0 & 0 & 141.75 & 0 & 0.5 & 0 & 1.5 & 431592 & 450034 \\
\hline 158 & 0 & 0 & 144.77 & 0 & 0.5 & 0 & 1.5 & 431595 & 450032 \\
\hline 159 & 0 & 0 & 141.57 & 0 & 0.5 & 0 & 1.5 & 431599 & 450032 \\
\hline 160 & 0 & 0 & 141.45 & 0 & 0.5 & 0 & 1.5 & 431603 & 450032 \\
\hline 161 & 0 & 0 & 71.94 & 0 & 0.5 & 0 & 1.5 & 431610 & 448859 \\
\hline 162 & 0 & 0 & 73.44 & 0 & 0.5 & 0 & 1.5 & 431651 & 448900 \\
\hline 163 & 0 & 2 & 140 & 0 & 0.5 & 0 & 1.5 & 431691 & 450032 \\
\hline 164 & 0 & 0 & 75.43 & 0 & 0.5 & 0 & 1.5 & 431692 & 448941 \\
\hline 165 & 0 & 0 & 75.68 & 0 & 0.5 & 0 & 1.5 & 431717 & 448960 \\
\hline 166 & 0 & 0 & 140 & 0 & 0.5 & 0 & 1.5 & 431735 & 449985 \\
\hline 167 & 0 & 0 & 139.22 & 0 & 0.5 & 0 & 1.5 & 431757 & 449971 \\
\hline 168 & 0 & 0 & 76.49 & 0 & 0.5 & 0 & 1.5 & 431775 & 448991 \\
\hline 169 & 0 & 0 & 137.97 & 0 & 0.5 & 0 & 1.5 & 431789 & 449957 \\
\hline 170 & 0 & 7 & 78.12 & 0 & 0.5 & 0 & 1.5 & 431834 & 449022 \\
\hline 171 & 0 & 0 & 135.4 & 0 & 0.5 & 0 & 1.5 & 431860 & 449926 \\
\hline 172 & 0 & 0 & 80.14 & 0 & 0.5 & 0 & 1.5 & 431878 & 449053 \\
\hline 173 & 0 & 0 & 80.29 & 0 & 0.5 & 0 & 1.5 & 431881 & 449055 \\
\hline 174 & 0 & 0 & 134.06 & 0 & 0.5 & 0 & 1.5 & 431896 & 449911 \\
\hline 175 & 0 & 0 & 81.37 & 0 & 0.5 & 0 & 1.5 & 431902 & 449067 \\
\hline 176 & 0 & 0 & 133.37 & 0 & 0.5 & 0 & 1.5 & 431914 & 449904 \\
\hline 177 & 0 & 0 & 132.02 & 0 & 0.5 & 0 & 1.5 & 431949 & 449892 \\
\hline 178 & 0 & 2 & 85.44 & 0 & 0.5 & 0 & 1.5 & 431981 & 449120 \\
\hline 179 & 0 & 2 & 130 & 0 & 0.5 & 0 & 1.5 & 432012 & 449870 \\
\hline 180 & 0 & 0 & 91.39 & 0 & 0.5 & 0 & 1.5 & 432065 & 449173 \\
\hline 181 & 0 & 0 & 128.67 & 0 & 0.5 & 0 & 1.5 & 432079 & 449842 \\
\hline 182 & 0 & 4 & 95.86 & 0 & 0.5 & 0 & 1.5 & 432132 & 449184 \\
\hline 183 & 0 & 4 & 125.36 & 0 & 0.5 & 0 & 1.5 & 432135 & 449816 \\
\hline 184 & 0 & 2 & 122.88 & 0 & 0.5 & 0 & 1.5 & 432182 & 449794 \\
\hline 185 & 0 & 0 & 120.47 & 0 & 0.5 & 0 & 1.5 & 432230 & 449772 \\
\hline 186 & 0 & 2 & 101.69 & 0 & 0.5 & 0 & 1.5 & 432231 & 449188 \\
\hline 187 & 0 & 4 & 117.16 & 0 & 0.5 & 0 & 1.5 & 432272 & 449753 \\
\hline 188 & 0 & 2 & 102.17 & 0 & 0.5 & 0 & 1.5 & 432307 & 449182 \\
\hline 189 & 0 & 66 & 112.3 & 0 & 0.5 & 0 & 1.5 & 432326 & 449723 \\
\hline 190 & 0 & 0 & 102 & 0 & 0.5 & 0 & 1.5 & 432328 & 449182 \\
\hline 191 & 0 & 2 & 102.53 & 0 & 0.5 & 0 & 1.5 & 432367 & 449181 \\
\hline
\end{tabular}




\begin{tabular}{|c|c|c|c|c|c|c|c|c|c|}
\hline $\begin{array}{c}\text { Node } \\
\text { No }\end{array}$ & $\begin{array}{l}\text { Node } \\
\text { Type }\end{array}$ & $\begin{array}{c}\text { Demand } \\
\text { Factor }\end{array}$ & $\begin{array}{c}\text { Elevation } \\
(\mathrm{m})\end{array}$ & $\begin{array}{c}\text { Coefficient } \\
\text { of burst }\end{array}$ & $\begin{array}{c}\text { Exponent } \\
\text { of burst } \\
\text { term }\end{array}$ & $\begin{array}{c}\text { Coefficient } \\
\text { of } \\
\text { background } \\
\text { leakage }\end{array}$ & $\begin{array}{c}\text { Exponent } \\
\text { of } \\
\text { background } \\
\text { leakage }\end{array}$ & $\begin{array}{c}\text { Horizontal } \\
\text { Coordinate } \\
\text { of node }\end{array}$ & $\begin{array}{c}\text { Vertical } \\
\text { Coordinate } \\
\text { of node }\end{array}$ \\
\hline 192 & 0 & 0 & 102.1 & 0 & 0.5 & 0 & 1.5 & 432367 & 449184 \\
\hline 193 & 0 & 2 & 102.1 & 0 & 0.5 & 0 & 1.5 & 432367 & 449186 \\
\hline \begin{tabular}{|l|}
194 \\
\end{tabular} & 0 & 0 & 110 & 0 & 0.5 & 0 & 1.5 & 432376 & 449692 \\
\hline 195 & 0 & 0 & 102.85 & 0 & 0.5 & 0 & 1.5 & 432414 & 449181 \\
\hline 196 & 0 & 12 & 106.88 & 0 & 0.5 & 0 & 1.5 & 432422 & 449661 \\
\hline \begin{tabular}{|l|}
197 \\
\end{tabular} & 0 & 4 & 103.87 & 0 & 0.5 & 0 & 1.5 & 432431 & 449185 \\
\hline 198 & 0 & 0 & 103.5 & 0 & 0.5 & 0 & 1.5 & 432442 & 449184 \\
\hline 199 & 0 & 4 & 102.88 & 0 & 0.5 & 0 & 1.5 & 432473 & 449177 \\
\hline \begin{tabular}{|l|}
200 \\
\end{tabular} & 0 & 5 & 102.69 & 0 & 0.5 & 0 & 1.5 & 432482 & 449603 \\
\hline 201 & 0 & 11 & 111.18 & 0 & 0.5 & 0 & 1.5 & 432489 & 449363 \\
\hline 202 & 0 & 0 & 102.66 & 0 & 0.5 & 0 & 1.5 & 432502 & 449568 \\
\hline 203 & 0 & 0 & 102.65 & 0 & 0.5 & 0 & 1.5 & 432503 & 449566 \\
\hline 204 & 0 & 4 & 102.63 & 0 & 0.5 & 0 & 1.5 & 432505 & 449563 \\
\hline 205 & 0 & 0 & 102.5 & 0 & 0.5 & 0 & 1.5 & 432506 & 449564 \\
\hline 206 & 0 & 0 & 102.49 & 0 & 0.5 & 0 & 1.5 & 432508 & 449561 \\
\hline 207 & 0 & 0 & 105.79 & 0 & 0.5 & 0 & 1.5 & 432519 & 449188 \\
\hline 208 & 0 & 2 & 102.79 & 0 & 0.5 & 0 & 1.5 & 432525 & 449522 \\
\hline 209 & 0 & 17 & 104.2 & 0 & 0.5 & 0 & 1.5 & 432537 & 449491 \\
\hline 210 & 0 & 0 & 104.11 & 0 & 0.5 & 0 & 1.5 & 432538 & 449491 \\
\hline 211 & 0 & 0 & 104.84 & 0 & 0.5 & 0 & 1.5 & 432548 & 449466 \\
\hline 212 & 0 & 2 & 110 & 0 & 0.5 & 0 & 1.5 & 432549 & 449330 \\
\hline 213 & 0 & 0 & 110 & 0 & 0.5 & 0 & 1.5 & 432549 & 449362 \\
\hline 214 & 0 & 7 & 110 & 0 & 0.5 & 0 & 1.5 & 432551 & 449361 \\
\hline 215 & 0 & 4 & 106 & 0 & 0.5 & 0 & 1.5 & 432552 & 449188 \\
\hline 216 & 0 & 6 & 110 & 0 & 0.5 & 0 & 1.5 & 432553 & 449344 \\
\hline 217 & 0 & 0 & 106 & 0 & 0.5 & 0 & 1.5 & 432554 & 449190 \\
\hline 218 & 0 & 4 & 110 & 0 & 0.5 & 0 & 1.5 & 432554 & 449343 \\
\hline 219 & 0 & 13 & 110 & 0 & 0.5 & 0 & 1.5 & 432554 & 449344 \\
\hline 220 & 0 & 2 & 106 & 0 & 0.5 & 0 & 1.5 & 432555 & 449185 \\
\hline 221 & 0 & 0 & 106 & 0 & 0.5 & 0 & 1.5 & 432555 & 449189 \\
\hline 222 & 0 & 2 & 105.3 & 0 & 0.5 & 0 & 1.5 & 432555 & 449453 \\
\hline 223 & 0 & 0 & 106 & 0 & 0.5 & 0 & 1.5 & 432556 & 449185 \\
\hline 224 & 0 & 4 & 110 & 0 & 0.5 & 0 & 1.5 & 432557 & 449249 \\
\hline 225 & 0 & 8 & 106 & 0 & 0.5 & 0 & 1.5 & 432557 & 449190 \\
\hline 226 & 0 & 0 & 106 & 0 & 0.5 & 0 & 1.5 & 432557 & 449190 \\
\hline 227 & 0 & 0 & 106 & 0 & 0.5 & 0 & 1.5 & 432557 & 449189 \\
\hline 228 & 0 & 0 & 106 & 0 & 0.5 & 0 & 1.5 & 432558 & 449188 \\
\hline 229 & 0 & 2 & 106.12 & 0 & 0.5 & 0 & 1.5 & 432558 & 449439 \\
\hline 230 & 0 & 11 & 110 & 0 & 0.5 & 0 & 1.5 & 432561 & 449276 \\
\hline 231 & 0 & 4 & \begin{tabular}{|l|}
106.28 \\
\end{tabular} & 0 & 0.5 & 0 & 1.5 & 432562 & 449185 \\
\hline 232 & 0 & 2 & 106.31 & 0 & 0.5 & 0 & 1.5 & 432564 & 449185 \\
\hline 233 & 0 & 0 & 106.68 & 0 & 0.5 & 0 & 1.5 & 432564 & 449188 \\
\hline 234 & 0 & 4 & \begin{tabular}{|l|}
106.69 \\
\end{tabular} & 0 & 0.5 & 0 & 1.5 & 432566 & 449188 \\
\hline 235 & 0 & 11 & \begin{tabular}{|l|}
106.99 \\
\end{tabular} & 0 & 0.5 & 0 & 1.5 & 432569 & 449415 \\
\hline 236 & 0 & 11 & 106.7 & 0 & 0.5 & 0 & 1.5 & 432597 & 449177 \\
\hline
\end{tabular}




\begin{tabular}{|c|c|c|c|c|c|c|c|c|c|}
\hline $\begin{array}{c}\text { Node } \\
\text { No }\end{array}$ & $\begin{array}{c}\text { Node } \\
\text { Type }\end{array}$ & $\begin{array}{c}\text { Demand } \\
\text { Factor }\end{array}$ & $\begin{array}{c}\text { Elevation } \\
(\mathrm{m})\end{array}$ & $\begin{array}{c}\text { Coefficient } \\
\text { of burst }\end{array}$ & $\begin{array}{c}\text { Exponent } \\
\text { of burst } \\
\text { term }\end{array}$ & $\begin{array}{c}\text { Coefficient } \\
\text { of } \\
\text { background } \\
\text { leakage }\end{array}$ & $\begin{array}{c}\text { Exponent } \\
\text { of } \\
\text { background } \\
\text { leakage }\end{array}$ & $\begin{array}{c}\text { Horizontal } \\
\text { Coordinate } \\
\text { of node }\end{array}$ & $\begin{array}{c}\text { Vertical } \\
\text { Coordinate } \\
\text { of node }\end{array}$ \\
\hline 237 & 0 & 4 & 108.61 & 0 & 0.5 & 0 & 1.5 & 432624 & 449174 \\
\hline 238 & 0 & 4 & 110 & 0 & 0.5 & 0 & 1.5 & 432676 & 449165 \\
\hline 239 & 0 & 15 & 110 & 0 & 0.5 & 0 & 1.5 & 432680 & 449167 \\
\hline 240 & 0 & 15 & 110 & 0 & 0.5 & 0 & 1.5 & 432727 & 449138 \\
\hline 241 & 0 & 2 & 110 & 0 & 0.5 & 0 & 1.5 & 432735 & 449127 \\
\hline 242 & 0 & 0 & 110 & 0 & 0.5 & 0 & 1.5 & 432756 & 449105 \\
\hline 243 & 0 & 6 & 110 & 0 & 0.5 & 0 & 1.5 & 432764 & 449108 \\
\hline 244 & 0 & 0 & 110 & 0 & 0.5 & 0 & 1.5 & 432767 & 449099 \\
\hline 245 & 0 & 0 & 110 & 0 & 0.5 & 0 & 1.5 & 432784 & 449077 \\
\hline 246 & 0 & 0 & 110 & 0 & 0.5 & 0 & 1.5 & 432788 & 449079 \\
\hline 247 & 0 & 11 & 110 & 0 & 0.5 & 0 & 1.5 & 432789 & 449080 \\
\hline 248 & 0 & 0 & 110 & 0 & 0.5 & 0 & 1.5 & 432793 & 449065 \\
\hline 249 & 0 & 0 & 110 & 0 & 0.5 & 0 & 1.5 & 432829 & 449012 \\
\hline 250 & 0 & 4 & 110 & 0 & 0.5 & 0 & 1.5 & 432838 & 449037 \\
\hline 251 & 0 & 0 & 110 & 0 & 0.5 & 0 & 1.5 & 432851 & 448974 \\
\hline 252 & 0 & 0 & 110 & 0 & 0.5 & 0 & 1.5 & 432852 & 448975 \\
\hline 253 & 0 & 0 & 110 & 0 & 0.5 & 0 & 1.5 & 432853 & 448970 \\
\hline 254 & 0 & 0 & 111.85 & 0 & 0.5 & 0 & 1.5 & 432855 & 448967 \\
\hline 255 & 0 & 0 & 110 & 0 & 0.5 & 0 & 1.5 & 432857 & 448968 \\
\hline 256 & 0 & 0 & 111.79 & 0 & 0.5 & 0 & 1.5 & 432860 & 448959 \\
\hline 257 & 0 & 4 & 110 & 0 & 0.5 & 0 & 1.5 & 432876 & 449049 \\
\hline 258 & 0 & 9 & 110 & 0 & 0.5 & 0 & 1.5 & 432884 & 449049 \\
\hline 259 & 0 & 0 & 141.4 & 0 & 0.5 & 0 & 1.5 & 431605 & 450032 \\
\hline 260 & 0 & 0 & 109.12 & 0 & 0.5 & 0 & 1.5 & 430963 & 451402 \\
\hline 262 & 0 & 0 & 110 & 0 & 0.5 & 0 & 1.5 & 432854 & 448970 \\
\hline 263 & 0 & 0 & 150 & 0 & 0.5 & 0 & 1.5 & 431389 & 451023 \\
\hline 266 & 0 & 0 & 150 & 0 & 0.5 & 0 & 1.5 & 431380 & 450871 \\
\hline 268 & 0 & 0 & 110 & 0 & 0.5 & 0 & 1.5 & 432851 & 448974 \\
\hline 269 & 0 & 0 & 150 & 0 & 0.5 & 0 & 1.5 & 431382 & 450871 \\
\hline 270 & 0 & 0 & 147.96 & 0 & 0.5 & 0 & 1.5 & 431405 & 450063 \\
\hline 271 & 0 & 0 & 109.52 & 0 & 0.5 & 0 & 1.5 & 430962 & 451405 \\
\hline 272 & 1 & 0 & 128.46 & 0 & 0.5 & 0 & 1.5 & 431173 & 451125 \\
\hline
\end{tabular}

Table E.0.2 Complete element data for E054 DMA

\begin{tabular}{|c|c|c|c|c|c|c|c|c|c|}
\hline \multicolumn{2}{|c|}{$\begin{array}{c}\text { Pipe Location } \\
(\text { Node } \rightarrow \text { Node })\end{array}$} & $\begin{array}{c}\text { Length } \\
(\mathrm{m})\end{array}$ & $\begin{array}{c}\text { Diameter } \\
(\mathrm{mm})\end{array}$ & C-Value & \multicolumn{2}{c|}{$\begin{array}{c}\text { Pipe Location } \\
(\text { Node } \rightarrow \text { Node })\end{array}$} & $\begin{array}{c}\text { Length } \\
(\mathrm{m})\end{array}$ & $\begin{array}{c}\text { Diameter } \\
(\mathrm{mm})\end{array}$ & C-Value \\
\hline 2 & 271 & 1.6 & 152 & 70 & 133 & 140 & 65.96 & 152 & 140 \\
\hline 3 & 2 & 1.23 & 152 & 70 & 134 & 131 & 69.95 & 150 & 100 \\
\hline 4 & 6 & 1.3 & 102 & 70 & 135 & 134 & 3.81 & 150 & 100 \\
\hline 4 & 260 & 1.84 & 152 & 70 & 135 & 143 & 72.82 & 150 & 100 \\
\hline 5 & 2 & 1.51 & 100 & 100 & 137 & 136 & 39.32 & 100 & 100 \\
\hline 5 & 7 & 4.45 & 100 & 100 & 138 & 139 & 4.71 & 102 & 70 \\
\hline 6 & 7 & 1.52 & 102 & 70 & 139 & 142 & 43.16 & 100 & 100 \\
\hline 8 & 4 & 7.42 & 152 & 70 & 140 & 152 & 60.83 & 152 & 140 \\
\hline 9 & 7 & 4.87 & 102 & 70 & 141 & 132 & 74.84 & 76 & 70 \\
\hline 10 & 14 & 75.07 & 154 & 140 & 142 & 145 & 30.81 & 100 & 100 \\
\hline
\end{tabular}




\begin{tabular}{|c|c|c|c|c|c|c|c|c|c|}
\hline \multicolumn{2}{|c|}{$\begin{array}{l}\text { Pipe Location } \\
\text { (Node } \rightarrow \text { Node) }\end{array}$} & \multirow{2}{*}{$\begin{array}{c}\begin{array}{c}\text { Length } \\
(\mathrm{m})\end{array} \\
16.58\end{array}$} & \multirow{2}{*}{$\begin{array}{c}\text { Diameter } \\
(\mathrm{mm})\end{array}$} & \multirow{2}{*}{$\begin{array}{c}\text { C-Value } \\
140\end{array}$} & \multicolumn{2}{|c|}{$\begin{array}{l}\text { Pipe Location } \\
\text { (Node } \rightarrow \text { Node) }\end{array}$} & \multirow{2}{*}{$\begin{array}{c}\begin{array}{c}\text { Length } \\
(\mathrm{m})\end{array} \\
67.25\end{array}$} & \multirow{2}{*}{$\begin{array}{c}\begin{array}{c}\text { Diameter } \\
(\mathrm{mm})\end{array} \\
100\end{array}$} & \multirow{2}{*}{$\begin{array}{c}\text { C-Value } \\
100\end{array}$} \\
\hline 11 & 8 & & & & 144 & 146 & & & \\
\hline 11 & 12 & 3.07 & 150 & 100 & 145 & 147 & 4.82 & 100 & 100 \\
\hline 11 & 15 & 64 & 154 & 140 & 146 & 143 & 94.29 & 100 & 100 \\
\hline 13 & 10 & 78.14 & 154 & 140 & 147 & 143 & 11.61 & 150 & 100 \\
\hline 14 & 16 & 95.85 & 154 & 140 & 147 & 148 & 18.01 & 150 & 100 \\
\hline 15 & 13 & 15.4 & 154 & 140 & 148 & 149 & 3 & 150 & 100 \\
\hline 16 & 22 & 90.33 & 154 & 140 & 150 & 151 & 23.03 & 73 & 120 \\
\hline 17 & 18 & 5.96 & 102 & 70 & 152 & 156 & 3.45 & 152 & 140 \\
\hline 18 & 19 & 1.87 & 76 & 70 & 152 & 259 & 19.29 & 152 & 70 \\
\hline 18 & 30 & 99.77 & 102 & 70 & 153 & 150 & 17.03 & 73 & 120 \\
\hline 19 & 20 & 49.54 & 76 & 70 & 154 & 155 & 1.9 & 102 & 70 \\
\hline 20 & 21 & 55.23 & 76 & 70 & 156 & 154 & 1.15 & 102 & 70 \\
\hline 22 & 23 & 1.42 & 154 & 140 & 156 & 157 & 2.25 & 152 & 140 \\
\hline 23 & 24 & 0.67 & 154 & 140 & 157 & 159 & 7.34 & 152 & 140 \\
\hline 24 & 27 & 3.85 & 154 & 140 & 158 & 141 & 66.51 & 76 & 70 \\
\hline 25 & 22 & 3.45 & 150 & 100 & 159 & 158 & 4.2 & 76 & 70 \\
\hline 26 & 24 & 5.46 & 150 & 100 & 161 & 153 & 34.99 & 73 & 120 \\
\hline 27 & 45 & 93.31 & 154 & 140 & 162 & 161 & 57.7 & 73 & 120 \\
\hline 28 & 25 & 6.96 & 150 & 100 & 163 & 259 & 48.08 & 145 & 140 \\
\hline 29 & 28 & 1.01 & 150 & 100 & 164 & 162 & 57.7 & 73 & 120 \\
\hline 29 & 33 & 38.13 & 150 & 100 & 165 & 164 & 31.69 & 73 & 120 \\
\hline 30 & 34 & 49.98 & 102 & 70 & 166 & 163 & 64.7 & 145 & 140 \\
\hline 33 & 35 & 7.57 & 80 & 90 & 167 & 166 & 26.75 & 145 & 140 \\
\hline 33 & 39 & 36.98 & 150 & 100 & 168 & 165 & 66.2 & 73 & 120 \\
\hline 34 & 36 & 25.07 & 102 & 70 & 169 & 167 & 35.16 & 145 & 140 \\
\hline 35 & 32 & 55.95 & 80 & 90 & 170 & 168 & 66.19 & 73 & 120 \\
\hline 36 & 52 & 43.82 & 102 & 70 & 171 & 169 & 77.21 & 145 & 140 \\
\hline 37 & 31 & 64.15 & 80 & 90 & 172 & 170 & 55.92 & 73 & 120 \\
\hline 38 & 41 & 41.51 & 76 & 70 & 173 & 172 & 3.54 & 73 & 120 \\
\hline 39 & 37 & 13.64 & 80 & 90 & 174 & 171 & 38.91 & 145 & 140 \\
\hline 39 & 56 & 50.18 & 150 & 100 & 175 & 173 & 23.84 & 100 & 100 \\
\hline 40 & 46 & 84.04 & 152 & 140 & 176 & 174 & 19.04 & 145 & 140 \\
\hline 41 & 47 & 97.43 & 76 & 70 & 177 & 176 & 37.33 & 145 & 140 \\
\hline 42 & 40 & 49.17 & 152 & 140 & 178 & 175 & 96.15 & 100 & 100 \\
\hline 43 & 42 & 5.49 & 152 & 140 & 179 & 177 & 66.12 & 145 & 140 \\
\hline 44 & 38 & 73.31 & 76 & 70 & 180 & 178 & 999.63 & 100 & 100 \\
\hline 45 & 54 & 26.19 & 154 & 140 & 181 & 179 & 72.97 & 145 & 140 \\
\hline 46 & 51 & 56.75 & 152 & 140 & 182 & 180 & 68.23 & 100 & 100 \\
\hline 47 & 50 & 19.65 & 100 & 100 & 183 & 181 & 61.31 & 145 & 140 \\
\hline 48 & 44 & 52.79 & 76 & 70 & 184 & 183 & 52.72 & 145 & 140 \\
\hline 49 & 43 & 69.85 & 152 & 140 & 185 & 184 & 52.73 & 145 & 140 \\
\hline 50 & 57 & 55.74 & 76 & 70 & 186 & 182 & 99.29 & 100 & 100 \\
\hline 51 & 61 & 94.93 & 152 & 140 & 187 & 185 & 46.1 & 145 & 140 \\
\hline 52 & 72 & 63.48 & 102 & 70 & 188 & 186 & 76.95 & 102 & 70 \\
\hline 53 & 49 & 34.06 & 152 & 140 & 189 & 187 & 61.62 & 145 & 140 \\
\hline 54 & 71 & 59.64 & 154 & 140 & 190 & 188 & 20.75 & 102 & 120 \\
\hline 56 & 58 & 4.56 & 80 & 90 & 191 & 190 & 38.87 & 102 & 120 \\
\hline 56 & 67 & 30.69 & 150 & 100 & 191 & 192 & 2.61 & 76 & 120 \\
\hline 57 & 65 & 76.63 & 76 & 70 & 192 & 193 & 1.91 & 76 & 120 \\
\hline 58 & 55 & 51.21 & 80 & 90 & 194 & 189 & 58.72 & 145 & 140 \\
\hline 59 & 48 & 64.02 & 76 & 70 & 195 & 191 & 47.7 & 102 & 120 \\
\hline 61 & 69 & 88.82 & 152 & 140 & 196 & 194 & 55.39 & 145 & 140 \\
\hline 62 & 59 & 36.93 & 76 & 70 & 197 & 193 & 64.41 & 76 & 120 \\
\hline 63 & 53 & 69.31 & 152 & 140 & 198 & 197 & 11.18 & 76 & 120 \\
\hline 64 & 62 & 15.43 & 76 & 70 & 199 & 195 & 59.26 & 102 & 120 \\
\hline
\end{tabular}




\begin{tabular}{|c|c|c|c|c|c|c|c|c|c|}
\hline \multicolumn{2}{|c|}{$\begin{array}{l}\text { Pipe Location } \\
\text { (Node } \rightarrow \text { Node) }\end{array}$} & \multirow{2}{*}{$\begin{array}{c}\begin{array}{c}\text { Length } \\
(\mathrm{m})\end{array} \\
57.27\end{array}$} & \multirow{2}{*}{$\begin{array}{c}\text { Diameter } \\
(\mathrm{mm})\end{array}$} & \multirow{2}{*}{$\begin{array}{c}\text { C-Value } \\
70\end{array}$} & \multicolumn{2}{|c|}{$\begin{array}{l}\text { Pipe Location } \\
\text { (Node } \rightarrow \text { Node) }\end{array}$} & \multirow{2}{*}{$\begin{array}{c}\begin{array}{c}\text { Length } \\
(\mathrm{m})\end{array} \\
83.85\end{array}$} & \multirow{2}{*}{$\begin{array}{c}\begin{array}{c}\text { Diameter } \\
(\mathrm{mm})\end{array} \\
145\end{array}$} & \multirow{2}{*}{$\begin{array}{c}\text { C-Value } \\
140\end{array}$} \\
\hline 65 & 70 & & & & 200 & 196 & & & \\
\hline 66 & 60 & 70.63 & 80 & 90 & 202 & 200 & 39.6 & 145 & 140 \\
\hline 67 & 66 & 13.09 & 80 & 90 & 203 & 202 & 2.48 & 145 & 140 \\
\hline 67 & 76 & $\begin{array}{l}49.98 \\
\end{array}$ & 150 & 100 & 203 & 204 & 4.16 & 76 & 70 \\
\hline 68 & 64 & 40.03 & 76 & 70 & 203 & 205 & 3.97 & 145 & 140 \\
\hline 69 & 73 & 38.68 & 152 & 140 & 204 & 209 & 78.68 & 76 & 120 \\
\hline 70 & 75 & 47.34 & 76 & 70 & 205 & 206 & 4.32 & 99 & 130 \\
\hline 71 & 93 & 52.49 & 154 & 140 & 206 & 208 & 41.75 & 99 & 130 \\
\hline 72 & 114 & 59.31 & 102 & 70 & 207 & 198 & 76.89 & 76 & 120 \\
\hline 73 & 78 & $\begin{array}{l}65.69 \\
\end{array}$ & 152 & 140 & 208 & 210 & 34.46 & 99 & 130 \\
\hline 74 & 63 & 90.19 & 152 & 140 & 209 & 211 & 26.77 & 76 & 120 \\
\hline 75 & 95 & 80.71 & 76 & 70 & 210 & 222 & 41.02 & 99 & 130 \\
\hline 76 & 77 & 5.74 & 80 & 90 & 211 & 229 & 29.55 & 76 & 120 \\
\hline 76 & 79 & 7.35 & 150 & 100 & 212 & 224 & 81.09 & 102 & 120 \\
\hline 77 & 111 & 76.44 & 80 & 90 & 214 & 212 & 32.18 & 102 & 120 \\
\hline 78 & 92 & 23.48 & 152 & 140 & 214 & 213 & 1.69 & 76 & 120 \\
\hline 79 & 80 & 18.53 & 150 & 100 & 215 & 199 & 79.94 & 102 & 120 \\
\hline 79 & 108 & 13.35 & 150 & 100 & 216 & 201 & 67.59 & 76 & 70 \\
\hline 80 & 81 & 2.2 & 150 & 100 & 218 & 230 & 67.21 & 76 & 120 \\
\hline 81 & 84 & 3.25 & 150 & 100 & 219 & 216 & 0.9 & 76 & 120 \\
\hline 81 & 113 & 91.02 & 150 & 100 & 219 & 218 & 1.41 & 76 & 120 \\
\hline 82 & 85 & 2.22 & 148 & 140 & 220 & 207 & 37.4 & 76 & 120 \\
\hline 82 & 266 & 9.08 & 150 & 100 & 220 & 221 & 3.2 & 76 & 120 \\
\hline 84 & 94 & 4.1 & 150 & 100 & 221 & 215 & 2.58 & 102 & 120 \\
\hline 85 & 269 & 1.64 & 148 & 140 & 222 & 214 & 95.32 & 102 & 120 \\
\hline 86 & 89 & 1.64 & 154 & 140 & 223 & 220 & 1.65 & 76 & 120 \\
\hline 87 & 88 & 0.92 & 148 & 140 & 224 & 225 & 58.48 & 102 & 120 \\
\hline 88 & 91 & 2.98 & 152 & 140 & 225 & 217 & 3 & 102 & 120 \\
\hline 89 & 91 & 1.25 & 154 & 140 & 225 & 226 & 0.75 & 102 & 120 \\
\hline 90 & 95 & 1.19 & 150 & 100 & 226 & 227 & 1.1 & 102 & 120 \\
\hline 91 & 99 & 2.75 & 152 & 140 & 227 & 221 & 2.2 & 102 & 120 \\
\hline 92 & 88 & 17.06 & 152 & 140 & 227 & 228 & 1.15 & 102 & 120 \\
\hline 94 & 93 & 2 & 154 & 140 & 228 & 233 & 6.35 & 102 & 120 \\
\hline 94 & 96 & 6.6 & 154 & 140 & 229 & 235 & 26.46 & 76 & 120 \\
\hline 95 & 98 & 1.2 & 76 & 70 & 230 & 231 & 90.72 & 76 & 120 \\
\hline 96 & 104 & 23.69 & 154 & 140 & 231 & 223 & 6 & 76 & 120 \\
\hline 97 & 102 & 5.22 & 100 & 68 & 231 & 232 & 2.05 & 76 & 120 \\
\hline 98 & 101 & 2.44 & 76 & 70 & 232 & 233 & 3.45 & 76 & 120 \\
\hline 100 & 97 & 4.54 & 100 & 68 & 232 & 236 & 33.52 & 76 & 120 \\
\hline 102 & 103 & 1.46 & 150 & 100 & 233 & 234 & 1.2 & 102 & 120 \\
\hline 102 & 105 & 1.79 & 100 & 100 & 234 & 237 & 60.03 & 102 & 120 \\
\hline 104 & 100 & 2.03 & 100 & 100 & 235 & 219 & 73.26 & 76 & 120 \\
\hline 104 & 107 & 6.45 & 154 & 140 & 236 & 239 & 84.54 & 76 & 120 \\
\hline 104 & 263 & 6.45 & 154 & 140 & 237 & 238 & 55.03 & 102 & 120 \\
\hline 105 & 109 & 1.95 & 100 & 100 & 238 & 241 & 70.37 & 102 & 120 \\
\hline 106 & 82 & 54.77 & 150 & 100 & 239 & 240 & 55.21 & 76 & 120 \\
\hline 107 & 109 & 3.61 & 154 & 140 & 240 & 243 & 47.76 & 76 & 70 \\
\hline 108 & 129 & 38.83 & 150 & 100 & 241 & 242 & 31.16 & 102 & 70 \\
\hline 109 & 112 & 85.82 & 154 & 140 & 242 & 244 & 14.96 & 99 & 130 \\
\hline 110 & 68 & 94.5 & 76 & 70 & 243 & 247 & 37.6 & 76 & 70 \\
\hline 112 & 86 & 65.33 & 154 & 140 & 244 & 245 & 28.22 & 99 & 130 \\
\hline 113 & 106 & 49.77 & 150 & 100 & 245 & 248 & 14.53 & 99 & 130 \\
\hline 114 & 116 & 1.13 & 102 & 70 & 246 & 245 & 4.41 & 76 & 70 \\
\hline 115 & 83 & 40.67 & 50 & 110 & 247 & 246 & 0.92 & 76 & 70 \\
\hline 116 & 138 & 90.92 & 102 & 70 & 247 & 250 & 67.44 & 76 & 70 \\
\hline
\end{tabular}




\begin{tabular}{|c|c|c|c|c|c|c|c|c|c|}
\hline \multicolumn{2}{|c|}{$\begin{array}{c}\text { Pipe Location } \\
(\text { Node } \rightarrow \text { Node })\end{array}$} & $\begin{array}{c}\text { Length } \\
(\mathrm{m})\end{array}$ & $\begin{array}{c}\text { Diameter } \\
(\mathrm{mm})\end{array}$ & C-Value & \multicolumn{2}{c|}{$\begin{array}{c}\text { Pipe Location } \\
(\text { Node } \rightarrow \text { Node })\end{array}$} & $\begin{array}{c}\text { Length } \\
(\mathrm{m})\end{array}$ & $\begin{array}{c}\text { Diameter } \\
(\mathrm{mm})\end{array}$ & C-Value \\
\hline 117 & 115 & 1.26 & 52 & 70 & 248 & 249 & 64.14 & 99 & 130 \\
\hline 118 & 115 & 2.03 & 52 & 70 & 249 & 251 & 47.99 & 99 & 130 \\
\hline 119 & 110 & 16.91 & 76 & 70 & 250 & 257 & 43.1 & 76 & 70 \\
\hline 119 & 118 & 1.18 & 52 & 70 & 251 & 253 & 4.03 & 99 & 130 \\
\hline 120 & 117 & 4.35 & 52 & 70 & 251 & 268 & 1.19 & 80 & 90 \\
\hline 120 & 126 & 7.14 & 50 & 110 & 252 & 255 & 11.92 & 80 & 90 \\
\hline 121 & 270 & 2.62 & 76 & 70 & 253 & 262 & 4.05 & 99 & 130 \\
\hline 122 & 120 & 3.13 & 52 & 70 & 254 & 256 & 8.76 & 99 & 130 \\
\hline 122 & 121 & 2.92 & 76 & 70 & 255 & 254 & 2.08 & 80 & 90 \\
\hline 124 & 123 & 1.03 & 52 & 70 & 257 & 258 & 9.66 & 50 & 140 \\
\hline 125 & 122 & 2.38 & 76 & 70 & 259 & 160 & 41.29 & 145 & 140 \\
\hline 125 & 124 & 0.86 & 52 & 70 & 260 & 3 & 1.84 & 152 & 70 \\
\hline 127 & 126 & 5.04 & 76 & 70 & 262 & 254 & 4.05 & 99 & 130 \\
\hline 128 & 74 & 92.93 & 152 & 140 & 266 & 90 & 9.08 & 150 & 100 \\
\hline 128 & 127 & 0.92 & 76 & 70 & 268 & 252 & 1.19 & 80 & 90 \\
\hline 128 & 133 & 52.06 & 152 & 140 & 269 & 87 & 1.64 & 148 & 140 \\
\hline 129 & 130 & 1.03 & 100 & 100 & 270 & 119 & 2.62 & 76 & 70 \\
\hline 129 & 135 & 69.61 & 150 & 100 & 271 & 1 & 1.6 & 152 & 70 \\
\hline 130 & 137 & 74.9 & 100 & 100 & 272 & 29 & 1.04 & 150 & 100 \\
\hline 132 & 125 & 50.88 & 76 & 70 & & & & & \\
\hline
\end{tabular}




\section{Appendix F - Program code}

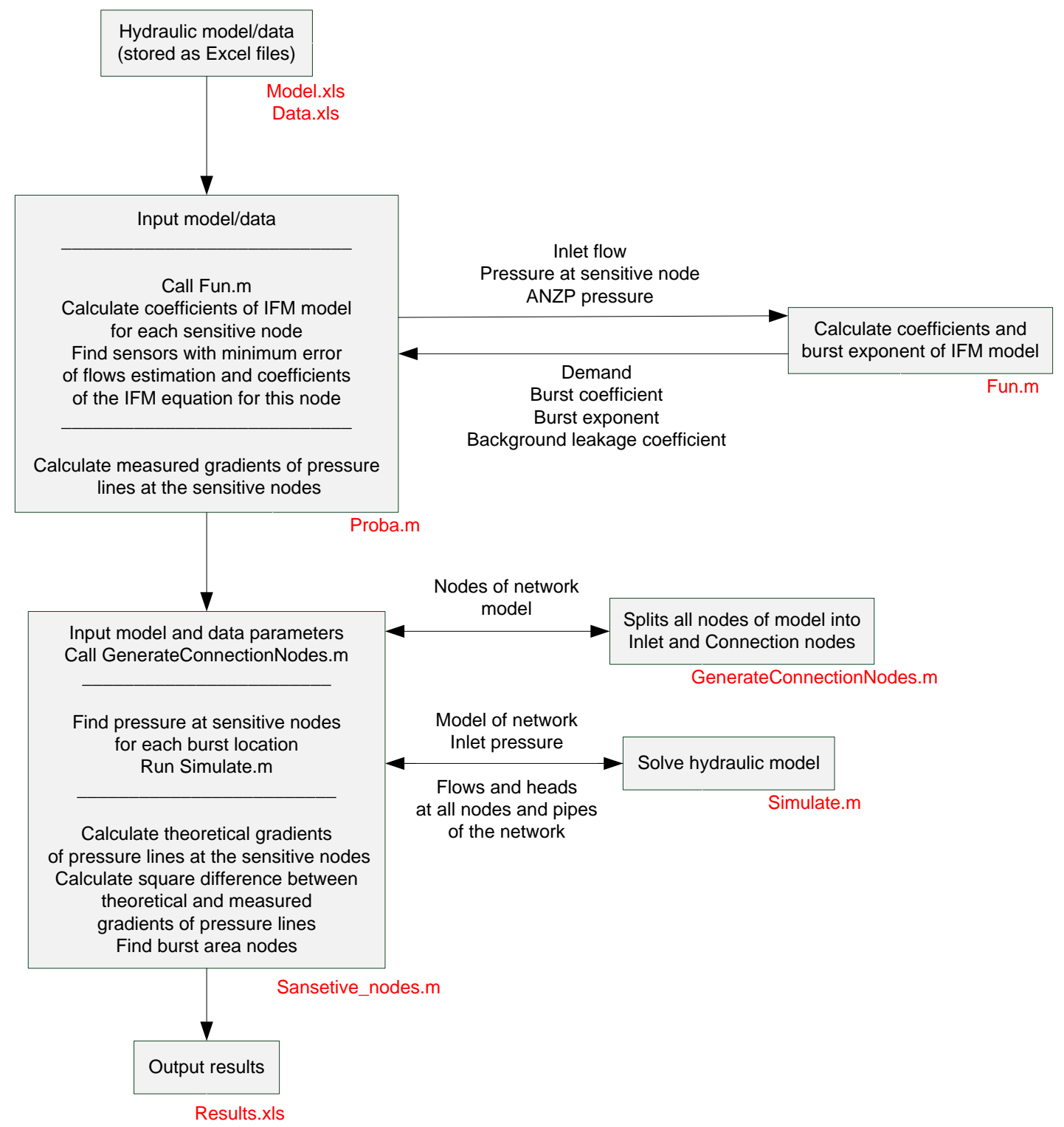


$\% \%$ Proba.m - identification of a burst size
$\% \%======================================\% \%$

$\%$ Load input data

measurements=xlsread('data','measurements');

inlet=xlsread('data','inlet');

nodes=xlsread ('model','nodes');

$\%$ Change input flows and input heads

no_input=length(inlet $(1,:))$;

for $\mathrm{i}=1: 1:$ no_input

in_flow $(:, \mathrm{i})=$ measurements $(3:$ end,i);

measurements( $3:$ end,i) $=\operatorname{inlet}(2:$ end,i);

end

heads=measurements( $3:$ end,:);

$\%$ Calculate pressures in measurements nodes from model

no_nodes $=$ measurements $(1,:)$;

for $\mathrm{i}=1: 1$ :length(nodes $(:, 1))$

for $\mathrm{j}=1: 1:$ length(no_nodes)

if no_nodes $(1, \mathrm{j})==\operatorname{nodes}(\mathrm{i}, 1)$

elevation_p $(1, \mathrm{j})=\operatorname{nodes}(\mathrm{i}, 4)$;

pressure $(:, j)=$ heads $(:, j)$-elevation_p $(1, j)$;

end

end

end

p_all=pressure';

q_all=in_flow;

NumbOfMeasurements=length(p_all(1,:));

q_first=q_all(:,1);

$\%$ q_second=q_all(:,2); $\quad \%$ if there are 2 inlets

$\%$ q_dable=q_first+q_second;

q_dable $=q \_$first; 
for $i=1: 1$ :NumbOfMeasurements

$$
\text { av_p }(1, i)=\text { mean }\left(p \_a l l(:, i)\right) \text {; }
$$

end

$\%$ Calculate coefficients

$\mathrm{lb}=\mathrm{zeros}(1,4)$;

$\mathrm{lb}(1,3)=0.5$;

$\mathrm{x}=$ ones $(1,4)$;

c_all_1=ones $(1,4)$;

c_all_2=ones $(1,4)$;

options $=$ optimset('MaxIter', 1000, 'TolX', 10.^-20);

for $\mathrm{j}=1: 1:$ length(no_nodes)

for $\mathrm{i}=1: 1$ :NumbOfMeasurements

$\operatorname{ak}(\mathrm{i}, 1)=\mathrm{q} \_$dable $(\mathrm{i}, 1)$;

$\operatorname{ak}(\mathrm{i}, 2)=\mathrm{p} \_$all $(\mathrm{j}, \mathrm{i})$;

$\operatorname{ak}(\mathrm{i}, 3)=\mathrm{av} \_\mathrm{p}(1, \mathrm{i})$;

end

save('variables.mat', 'ak');

c_all_2(j,:)=lsqnonlin(@func,x,lb);

end

r2_c_all=c_all_2;

r2_c_all(:,5)=no_nodes';

xlswrite('results',r2_c_all , 'c_all2');

$\%$ Calculate flow from coefficients with burst exponent c_all_2(3)

for $\mathrm{j}=1$ :1:length(no_nodes)

d_p=c_all_2(j,1);

$\mathrm{c} 1=\mathrm{c} \_$all_2(j,2);

c2=c_all_2(j,4);

expon2=c_all_2(j,3);

for $\mathrm{i}=1: 1$ :NumbOfMeasurements

$$
\mathrm{q} 2(\mathrm{j}, \mathrm{i})=\mathrm{d} \_\mathrm{p}+\mathrm{c} 1 * \mathrm{p} \_ \text {all }(\mathrm{j}, \mathrm{i})^{\wedge} \operatorname{expon} 2+\mathrm{c} 2 * \mathrm{av} \_\mathrm{p}(1, \mathrm{i})^{\wedge} 1.5 ;
$$




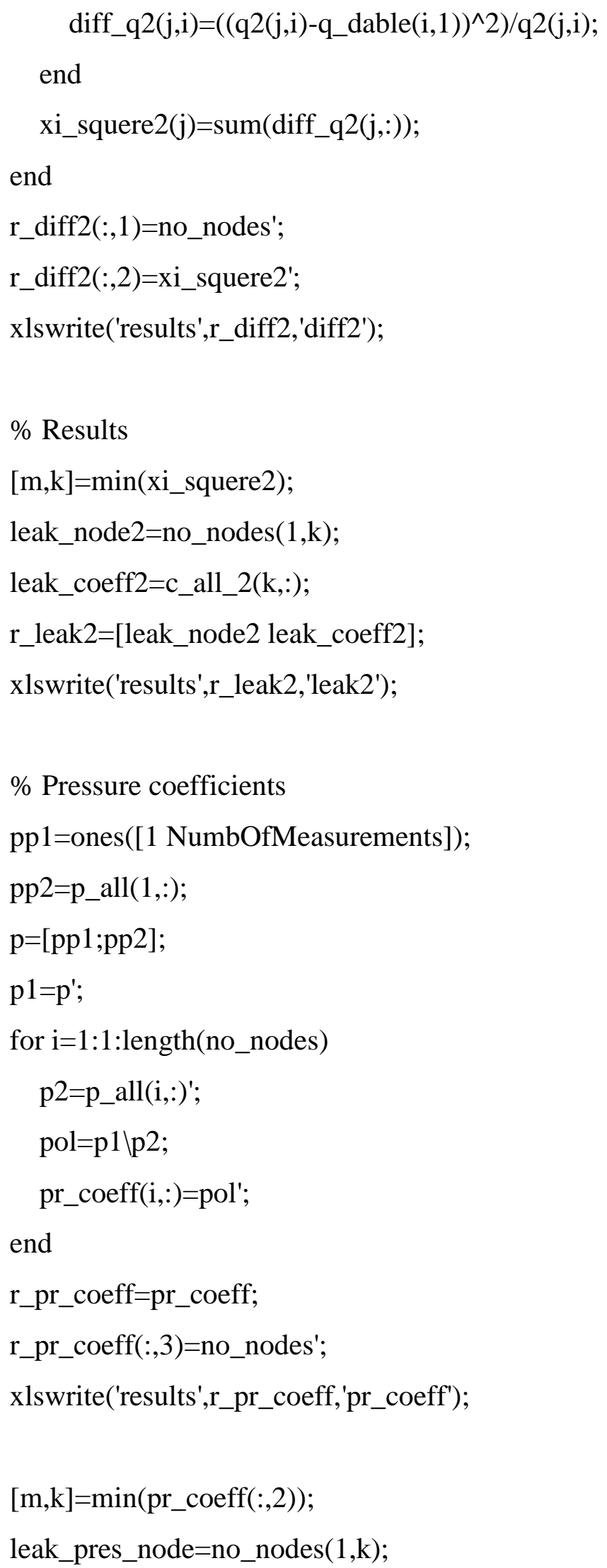


$\% \%$ sansetive_nodes.m - identification of a burst location $\% \%$

$\% \%========================================\% \%$

global lambdaf lambdac hfp d leakexp1 leakexp2 NumberPipes NumberConNodes element_resistance elevation

\% Load model

allnodes $=$ xlsread('model','nodes'); \% node data - number, type (1-inlet, 0-normal),

$\%$ demand factor, elevation, 2 leakage

$\%$ coefficients/exponents, OSgrid ref

pipes $=$ xlsread $\left(' \operatorname{model},{ }^{\prime}\right.$ pipes'); $\%$ pipe data - nodes from/to, length, diameter, $\mathrm{c}$ value

$\%$ Generate list of connection and fixed nodes

[fixnodes,connodes]=GenerateConnectionNodes(allnodes);

NumberPipes=length(pipes(:,1));

NumberNodes=length(allnodes(:,1));

NumberFixedNodes=length(fixnodes);

NumberConNodes=length(connodes(:,1));

$\%$ Create reasonable demand curve to use in simulation (load one if you have one)

S_NumberOfMeasurements=3;

DemandLevel=leak_coeff2 $(1,1)$; $\quad$ \%in $1 / \mathrm{s}$

NumberOfProperties $=\operatorname{sum}($ allnodes $(:, 3))$;

curve $=(\text { DemandLevel/NumberOfProperties })^{*}$ ones(s_NumberOfMeasurements, 1$)$;

$\%$ Exceptional demand

knowndemand=zeros(NumberConNodes,s_NumberOfMeasurements);

$\%$ Create inlet head profile for simulation (load one if you have one)

$\%$ Must be of dimension NumberFixedNodes X s_NumberOfMeasurements

elevation_res=allnodes(fixnodes,4);

$\mathrm{pf}=\left[\min \left(\mathrm{p} \_a l l(1,:)\right)\left(\left(\min \left(\mathrm{p} \_a l l(1,:)\right)+\max \left(p \_a l l(1,:)\right)\right) / 2\right) \max \left(\mathrm{p} \_a l l(1,:)\right)\right]$; 


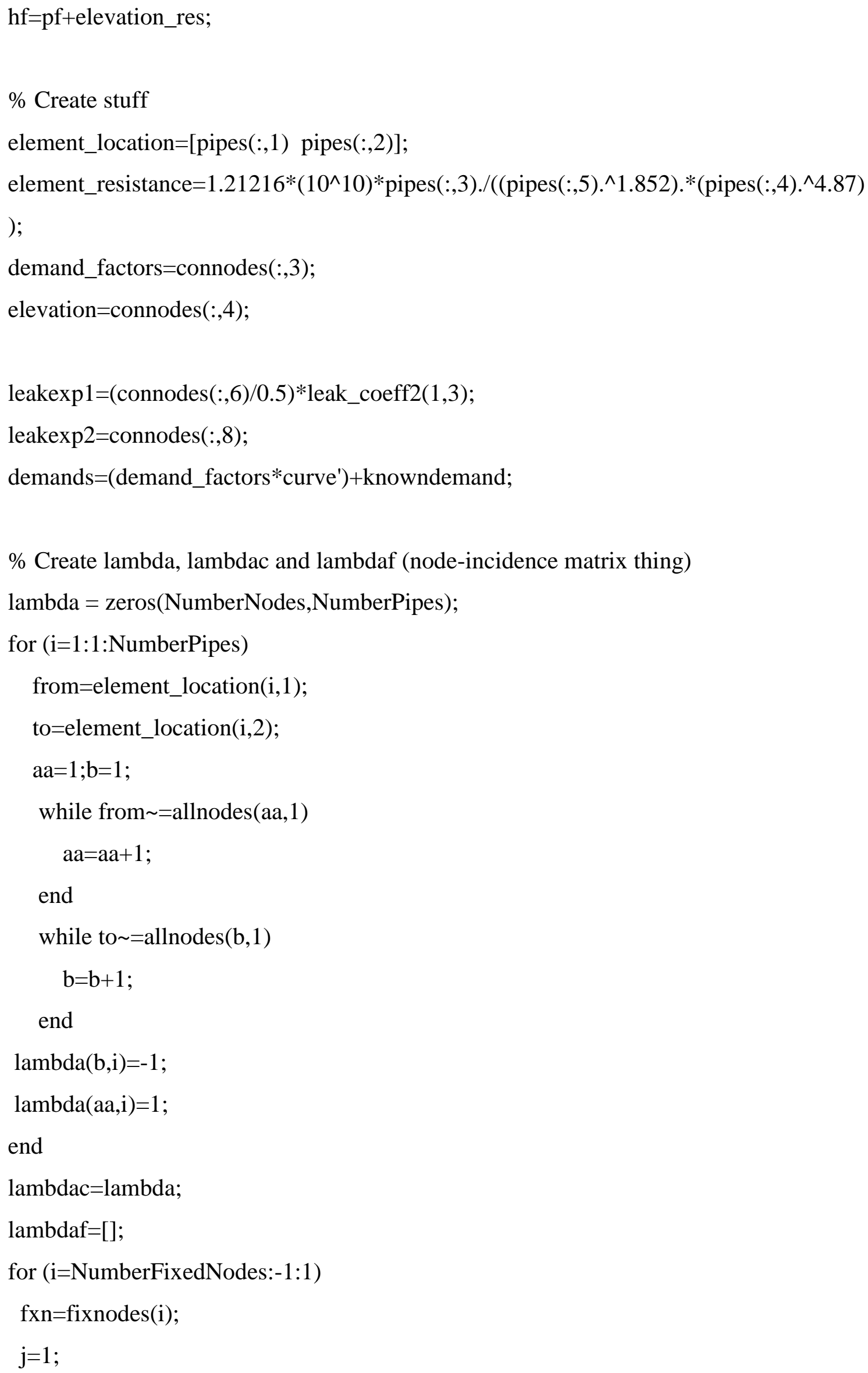




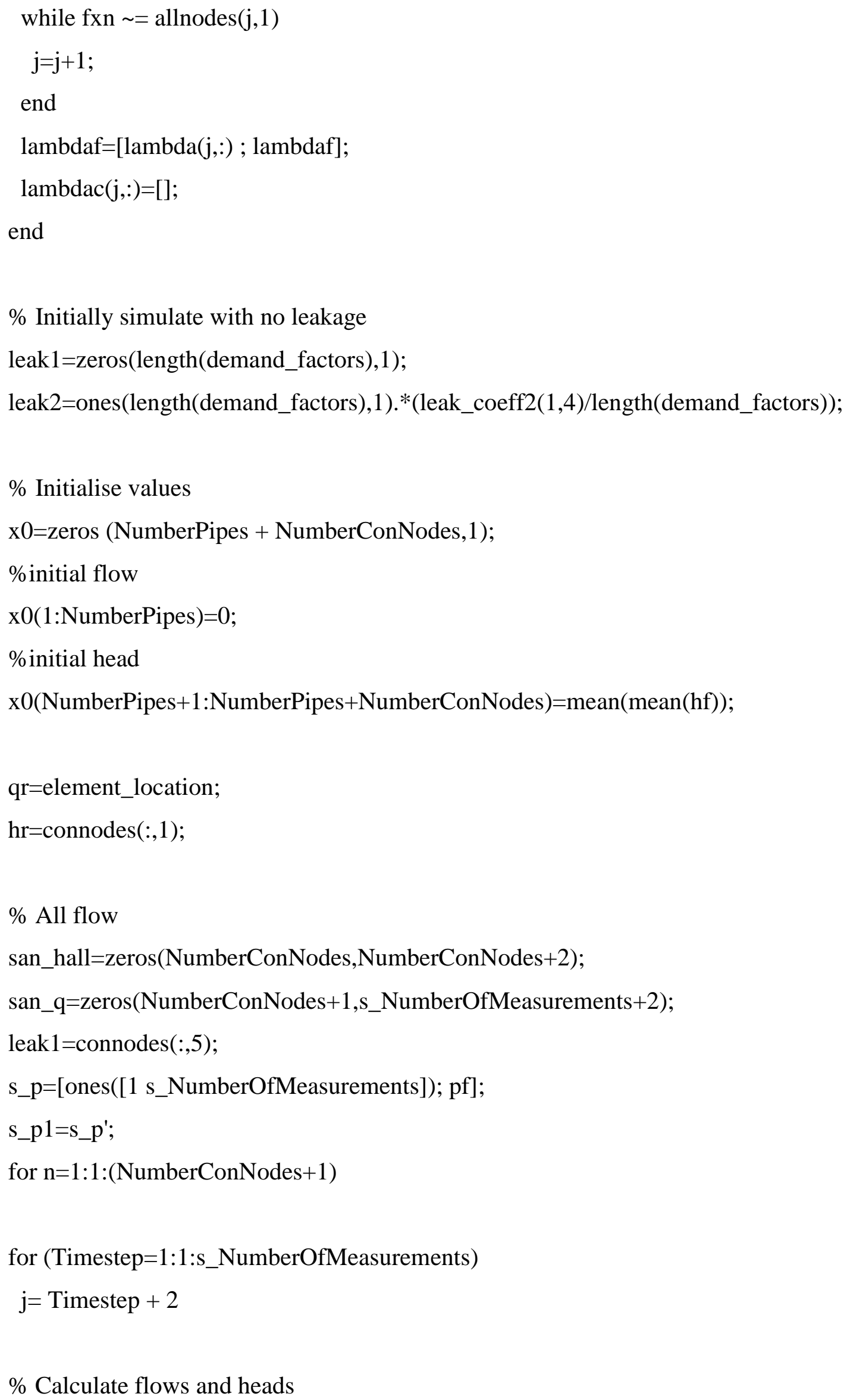




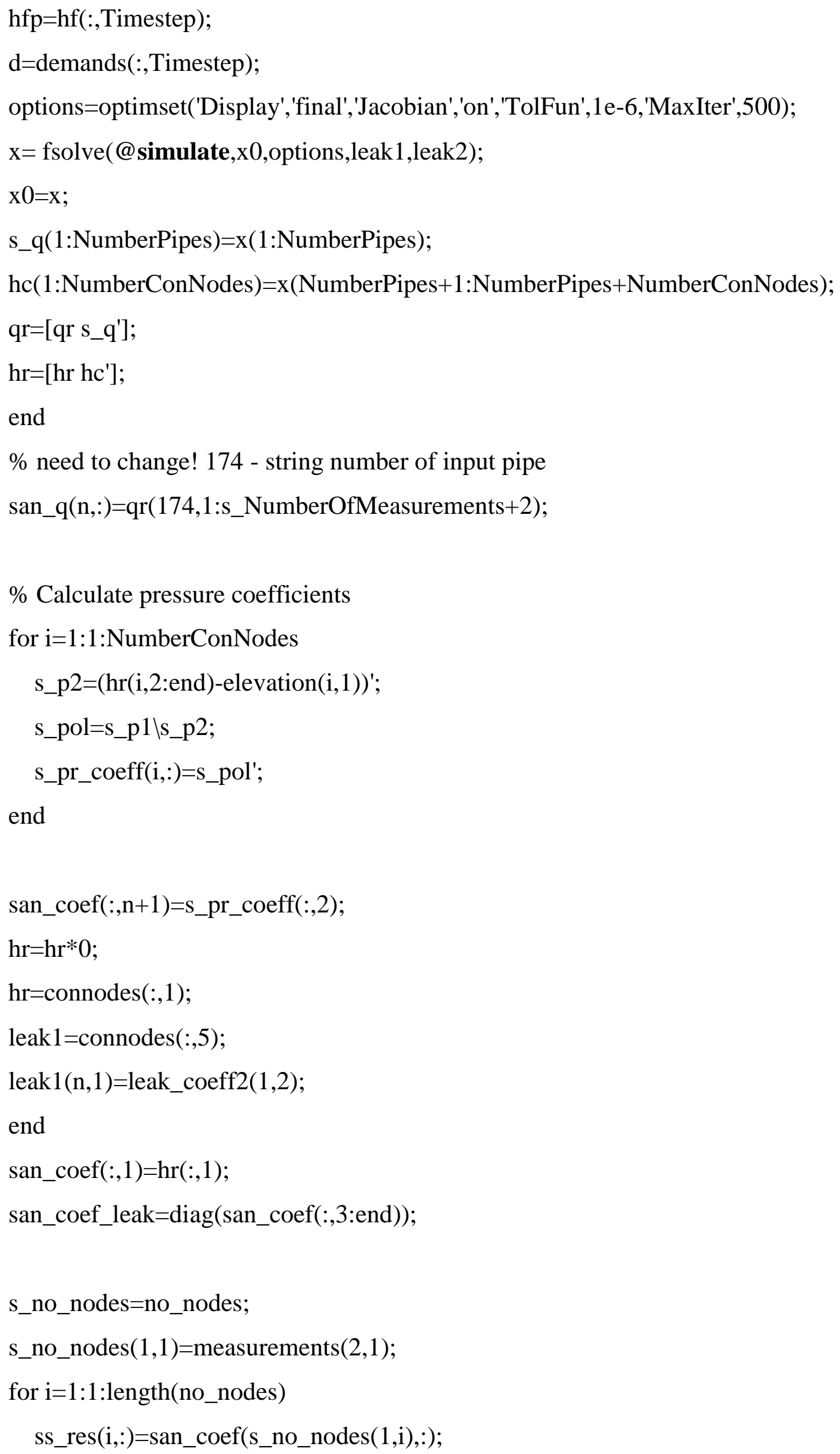


end

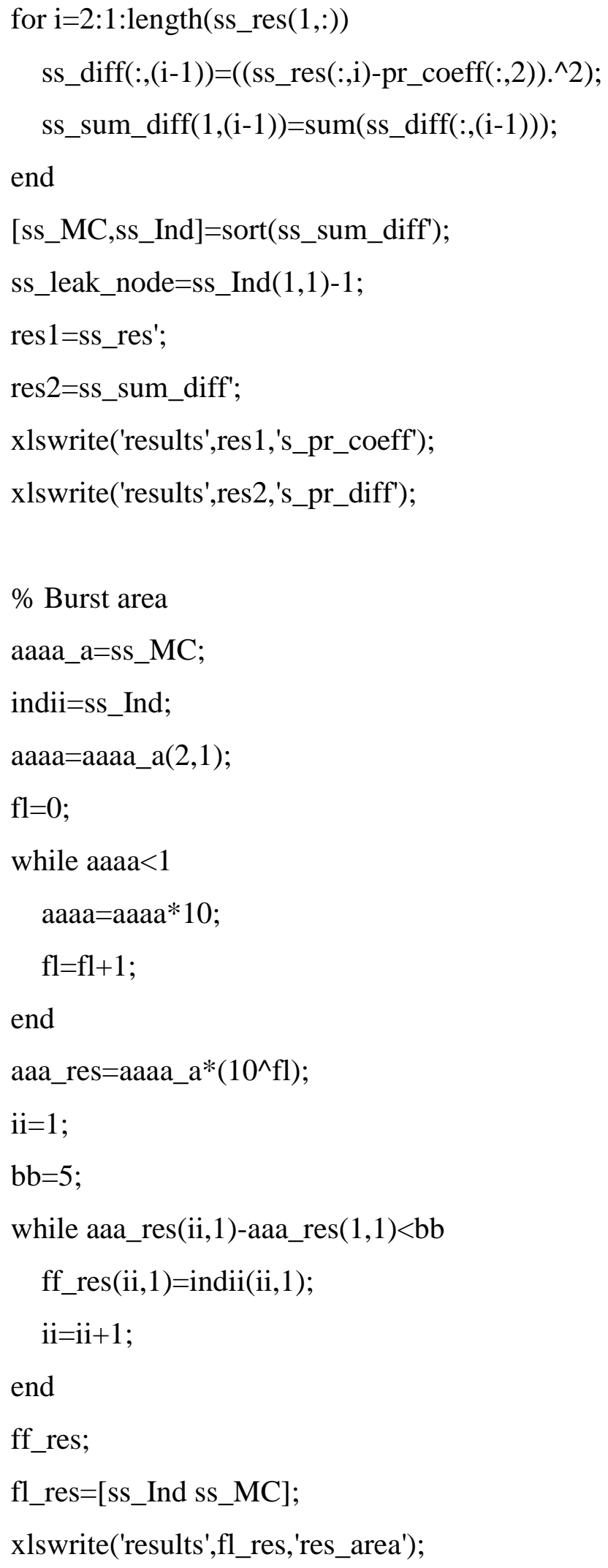




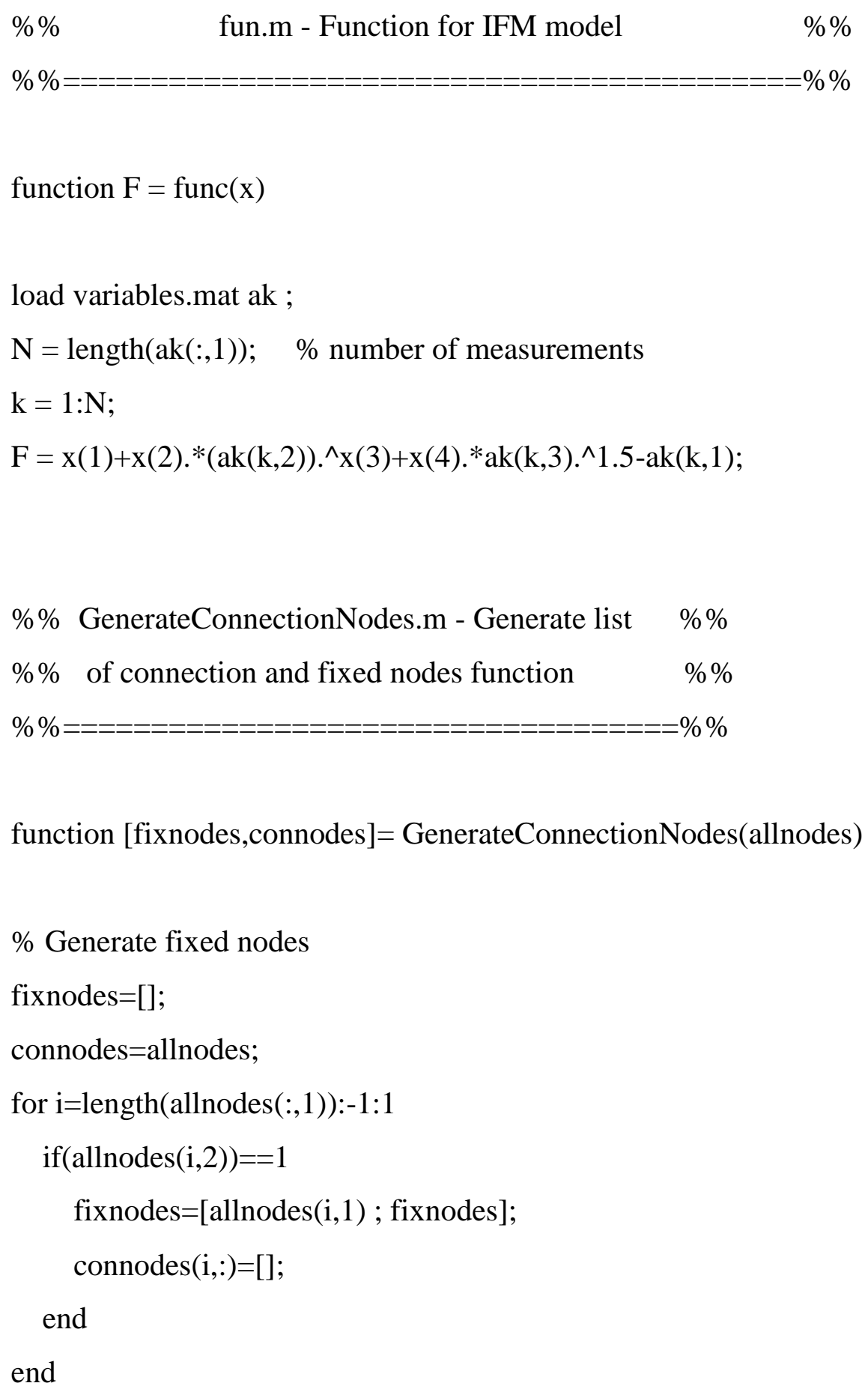


$\% \%$ simulate.m - Program of simulation of the network \%\%

$\% \%====================================\% \%$

function $[F, J]=$ simulate $(x$, leak1,leak2)

global leakexp1 leakexp2 lambdaf lambdac

global NumberPipes NumberConNodes element_resistance elevation hfp d leakage1 leakage2;

$\%$ Decoding $\mathrm{x}$ vector into 2 parts

$\mathrm{q}(1:$ NumberPipes $)=\mathrm{x}(1:$ NumberPipes $)$;

hc $(1:$ NumberConNodes $)=x($ NumberPipes +1 :NumberPipes + NumberConNodes $)$;

q=q';

hc $=$ hc';

leakage $1=\left(\right.$ leak1 $*^{*}\left((\right.$ hc-elevation $){ }^{\wedge}$ leakexp 1$\left.)\right)$;

leakage $2=($ leak2.*((hc-elevation $) .^{\wedge}$ leakexp2) $)$;

fun1= lambdac* $q+d+$ leakage $1+$ leakage 2

$\mathrm{dh}=$ element_resistance. ${ }^{*} \operatorname{abs}(\mathrm{q}) .^{\wedge} 0.852 .{ }^{*} \mathrm{q}$;

$\mathrm{a}=$ lambdac'*hc;

$\mathrm{b}=$ lambdaf'*hfp;

fun $2=d h-a-b$;

$\mathrm{F}=[$ fun $1 ;$ fun2];

leakbit1=diag(leak1.*leakexp1.*((hc-elevation).^(leakexp1-1)));

leakbit2=diag(leak2.*leakexp2.*((hc-elevation).^(leakexp2-1)));

leakbit=leakbit1 + leakbit2;

dnres $=\operatorname{diag}\left(1.852 *\left(\right.\right.$ element_resistance $\left.\left.* \operatorname{abs}(\mathrm{q}) .^{\wedge} 0.852\right)\right)$;

$\mathrm{J}=[$ lambdac leakbit;dnres -lambdac']; 


\section{Bibliography}

1. Al-Khomairi A.M. (2005), "Use of the steady state orifice equation in the computation of transient flow through pipe leaks." The Arabian Journal for Science and Engineering, 30, 1B, pp. 33-45.

2. Araujo L.S., Coelho S.T. \& Ramos H.M. (2003), "Estimation of distributed pressure-dependent leakage and consumer demand in WDSs." Advances in Water Supply Management, Swets \& Zeitlinger B.V., Lisse, The Netherlands.

3. Babich B., Prodanovich D., and Ivetich M. (2005), "Preliminary results of water losses research in sections of Belgrade water supply system and developing of technical guidelines and procedures." CCWI 2005 International Conference, Exeter University Press, Exeter, Vol.2, pp. 119-124.

4. Berardi L., Giustolisi O., Primativo F. (2007), "Exploiting multi-objective strategies for optimal rehabilitation planning", in Water Management Challenges in Global Change, (Ulanicki et al. editors), Taylor \& Francis Group, London, ISBN 978-0-415-45415-5, pp. 23-30.

5. Berardi L., Savic D. and Giustoloso O. (2005), "Investigation of burst-prediction formulas for water distribution systems by evolutionary computing." CCWI 2005 International Conference, Exeter University Press, Exeter, Vol.2, pp. 275280.

6. Borovik I. \& Pavlov Y. (2000). "Statistical methods of an estimation and the forecast of a condition of water supply systems." Computer science and control systems in XXI century, BMSTU, Moscow. (Russian)

7. Borovik I. \& Pavlov Y. (2007). "Multi-factor regression analysis in applied task to control urban water supply network." The electronic journal "Science in formation. Engineering formation ", ISSN 1994-0408 online. (English /Russian)

8. Borovik I. \& Yanov I.O. (2007). "Mathematical model of one-dimensional water supply network." The electronic journal " Science in formation. Engineering formation ", ISSN 1994-0408 online. (English /Russian)

9. Borovkov, A.A. (1976). Probability theory, publishing house "Science", Moscow. (Russian) 
10. Boxall J.B., O’Hagan A., Pooladsaz S., Saul A.J. and Unwin D.M. (2005), "Pipe level estimation of burst rates in water distribution mains." CCWI 2005 International Conference, Exeter University Press, Exeter, Vol.1, pp. 33-38.

11. Breaks and Background Estimates (BABE) (2008), Bristol Water Services Ltd. http://www.wso.us/startpage/leakagemanagement.htm, accessed on May 2008.

12. Brooke A., Kendrick, D., \& Meeraus, A. (1992). GAMS a user guide, Boyd \& Fraser - The Scientific Press Series. USA

13. Brunone B. \& Ferrante M. (2001), "Detecting leaks in pressurized pipes by means of transients." Journal of Hydraulic research, 39(5), pp. 539-547.

14. Burnell D. (2003), "Auto-validation of district meter data." Advances in Water Supply Management, Swets \& Zeitlinger B.V., Lisse, The Netherlands.

15. Buchberger, S.G. and L.Wu. (1995), "Model for instantaneous residential demands." Journal of Hydraulic Engineering, Vol. 121, No. 3, pp 232-246.

16. Buchberger, S.G. and Nadimpalli, G. (2004), "Leak Estimation in Water Distribution Systems by Statistical Analysis of Flow Readings.” Journal of Water Resources Planning and Management, Vol. 130, No. 4, pp. 321-329.

17. Bush, C.A. and Uber, J.G. (1998), "Sampling Design Methods for Water Distribution Model Calibration." Journal of Water Resources Planning and Management, Vol. 124, No. 6.

18. Cascetta, F, and Vigo, P. (1992), "Location and Assessment of Water Leakage." Measurements and Control, Vol. 25, November.

19. Chernoff H, Lehmann E.L. (1954), "The use of maximum likelihood estimates in $\chi^{2}$ tests for goodness-of-fit." The Annals of Mathematical Statistics, Vol. 25, pp. 579-586.

20. Cheung P.B., Reis L.F.R., Formiga K.T.M., Chaudhry F.H. \& Ticona W.G.C. (2003), Evolutionary algorithms applied to the rehabilitation of water distribution: A Comparative Study, Evolutionary Multi-Criterion Optimization Lecture notes in Computer Science, Heidelberg: Springer-Verlag, V.2632.

21. Coulbeck B., Orr C.H., Cunningham A.E., (1989), Computer Control of Water Supply: GINAS 5 Reference Manual, Research report $\mathrm{Nr}$ 56, School of Electronic Eng., Leicester Polytechnic. 
22. Covas D., Ramos H., Graham N. \& Maksimovic C. (2004), "Application of transient-based techniques for leak detection in water pipe systems." Proc. 4th World Water Congress and Exhibition, Marrakech, IWA.

23. Covas D., Ramos H., Graham N., Maksimovic C., Kapelan Z., Savic D. \& Walters G. (2003), “An assessment of the application of inverse transient analysis for leak detection: part II - collection and application of experimental data." Computers and Control in the Water Industry (CCWI 2003), Imperial college London, UK.

24. Covas, D. and Ramos, H. (1999), Leakage Detection in Single Pipelines Using Pressure Wave Behaviour, in Water Industry Systems: modelling and optimisation applications, edited by Savic and Walters, Research Studies Press Ltd, Baldock, England.

25. Dandy G. C. and Engelhardt M. (2001), "Optimal scheduling of water pipe replacement using genetic algorithms." Journal of Water Resources Planning and Management, Vol. 127, N 4.

26. Deb K., Agrawal S., Pratap A. \& Meyarivian T. (2000), "A fast and elitist genetic algorithm NSGAII.” Technical Report N 2000001, Indian Inst.of.Tech., Kanpur, India.

27. Devi T. \& Nam-Sik P. (2004), "Multiobjective Algorithms for decision of Water Distribution Networks." Journal of Water Resources Planning and Management, 130(1), pp. 73-82.

28. Deagle G., Green A., Scrivener J. and Tansley N. (2007), "Advanced tools for burst location", in Water Management Challenges in Global Change, (Ulanicki et al. editors), Taylor \& Francis Group, London, ISBN 978-0-415-45415-5, pp. 307-312.

29. Economou T., Kapelan Z., Bailey T. (2007), “An aggregated hierarchical Bayesian model for the prediction of pipe failures", in Water Management Challenges in Global Change, (Ulanicki et al. editors), Taylor \& Francis Group, London, ISBN 978-0-415-45415-5, pp. 13-16.

30. Farley, M., and Trow, S. (2003), Losses in Water Distribution Networks, IWA Publishing, London. 
31. Ferrante M. and Brunone B. (2003), "Pipe system diagnosis and leak detection by unsteady tests. 2. Wavelet analysis." Advances in Water Resources, 26, pp.107-116.

32. Final project report (2006). "Reduction of water losses and energy consumption using an effective process for burst detection." Sustainable Technologies Initiative EPSRC \& DTI, De Montfort University, February.

33. Garcia V., Cabrera E., Cabrera E. Jr. (2006), “The Minimum Night Flow Method Revisited." 8th Annual Water Distribution Systems Analysis Symposium, Cincinnati, Ohio, USA, August 27-30, B(1).

34. Germanopoulos, G. (1985), "A technical note in the inclusion of pressure dependent demand and leakage terms in water supply network models." Civil Engineering Systems, Vol. 2.

35. Giustolisi O. \& Berardi L. (2007), "Pipe level burst prediction using EPR and MCS-EPR", in Water Management Challenges in Global Change, (Ulanicki et al. editors), Taylor \& Francis Group, London, ISBN 978-0-415-45415-5, pp. 3946.

36. Giustolisi O. \& Laucelli D. (2007), "More realistic water distribution network design using pressure-driven demand and leakage", in Water Management Challenges in Global Change, (Ulanicki et al. editors), Taylor \& Francis Group, London, ISBN 978-0-415-45415-5, pp. 177-183.

37. Giustolisi O., Laucelli D. and Savic D. (2005), “A decision support framework for short-time rehabilitation planning in water distribution systems." CCWI 2005 International Conference, Exeter University Press, Exeter, Vol.1, 39-44.

38. Goldman, S. (1953). Information theory, Constable and company, London.

39. Guo S., Liu S. \& Chen R. (2004), “Optimisation Arrangement for Pressure Monitoring Points of Water Distribution Network." China Water \& Waste Water, Vol. 20(12), pp.82-84.

40. Hetenyi Zs., Tolnai B. and Zimmer P. (2007), "Planning reconstruction works based on risk analysis", in Water Management Challenges in Global Change, (Ulanicki et al. editors), Taylor \& Francis Group, London, ISBN 978-0-41545415-5, pp. 47-54.

41. Hirner, W.H. (1997), "Unaccounted-for Water." Conference on Water Utility Partnership for Capacity Building, Kampala, Uganda. October. 
42. Huang T. \& Cong H. (2001), "Cluster analysis for optimal locating of pressure monitoring stations in water supply network." China Water \& Waste Water, Vol. 17(11), pp. 50-52.

43. Kapelan Z., Savik D. and Walters G. (2003), “A Hybrid Inverse Transient Model for Leakage Detection and Roughness Calibration in Pipe Networks." Journal of Hydraulic Research, 41(5), pp. 481-492.

44. Kleiner Y. \& Rajani B. (2007), "Static and dynamic effects in prioritizing individual water mains for renewal", in Water Management Challenges in Global Change, (Ulanicki et al. editors), Taylor \& Francis Group, London, ISBN 978-0-415-45415-5, pp. 61-68.

45. Kleiner Y. and Rajani B. (2001), "Comprehensive review of structural deterioration of water mains: statistical models." Urban Water Journal, No 3 (3), pp. 131-150.

46. Kleiner Y., Rajani B, Sadiq R. (2004), "Management of failure risk in largediameter buried pipes using fuzzy-based techniques." 4th International Conference on Decision Making in Urban and Civil Engineering, Porto, Portugal. October.

47. Kleiner Y., Rajani B, Sadiq R. (2004), "Modelling failure risk in buried pipes using fuzzy Markov deterioration process.” ASCE International Conference of Pipeline Engineering and Construction, San Diego, CA. August.

48. Kleiner Y., Rajani B, Sadiq R. (2005), “Application of a Fuzzy Markov Model to Plan the Renewal of Large-Diameter Buried Pipes: A Case Study." CCWI 2005 International Conference, Exeter University Press, Exeter, Vol.1, pp. 4550.

49. Lambert, A., Myers, S., and Trow, S. (1998), Managing Water Leakage, Published by Financial Times Energy, London,.

50. Liggett J.A. \& Chen L.C. (1994), "Inverse transient analysis in pipe networks." Journal of Hydraulic Engineering, ASCE, 120(8), pp.934-955.

51. Magini R., Pallavicini I. \& Verde D. (2007), "Estimation of leakages in Water Distribution Systems with measurements at few nodes", in Water Management Challenges in Global Change, (Ulanicki et al. editors), Taylor \& Francis Group, London, ISBN 978-0-415-45415-5, pp. 321-328. 
52. Maksimovic, C., Butler, D., Memon, F.A. (2003), “Advances in Water Supply Management", Proceedings of the International Conference an Computing and Control for the Water Industry, London, UK, Published by Taylor and Francis group, London ISBN 9058096092, pp. 131.

53. Manual of Water Supply Practices AWWA M36 (1990). Water Audits and Leak Detection. ISBN 0898674850.

54. May, J. (1994), "Pressure-dependent Leakage" World Water and Environmental Engineering, October.

55. Mays, L.W. (2000), Water distribution systems handbook, McGraw-Hill International Editions.

56. Morrison J. (2004) "Managing leakage by District Metered Areas: a practical approach", for Water21 by the IWA Water Loss Task Force, UK.

57. Mounce S.R., Boxall J.B. \& Machell J. (2007), “An Artificial Neural Networks/Fuzzy Logic system for DMA flow meter data analysis providing burst identification and size estimation", in Water Management Challenges in Global Change, (Ulanicki et al. editors), Taylor \& Francis Group, London, ISBN 978-0-415-45415-5, pp. 313-320.

58. Mpesha W., Chaudry M.H. \& Gassman S.L. (2000), "Leak detection in pipes by frequency response method using a step excitation." Journal of hydraulic research, Vol. 40, N 1, pp. 55-62.

59. Nafi A \& Werey C. (2007), “An efficient multi-objective approach for water pipes renewal", in Water Management Challenges in Global Change, (Ulanicki et al. editors), Taylor \& Francis Group, London, ISBN 978-0-415-45415-5, pp 75-84.

60. Nash G.A. \& Karney B. (1999), "Efficient Inverse Transient Analysis in Pipe Systems.” Journal of Hydraulic Engineering, ASCE, 125(7), pp.761-764.

61. Noack C. and Ulanicki B. (2006), "Modelling of soil diffusibility on leakage characteristics of buried pipes.", 8th Annual Water Distribution Systems Analysis Symposium, Cincinnati, Ohio, USA, August 27-30.

62. Pallavicini, I., and Magini, R. (2007), "Experimental analysis of residential water demand data: Probabilistic estimation of peak coefficients at small time scales", in Water Management Challenges in Global Change, (Ulanicki et al. 
editors), Taylor \& Francis Group, London, ISBN 978-0-415-45415-5, pp.379384.

63. Plackett, R.L. (1983), "Karl Pearson and the Chi-Squared Test." International Statistical Review, Vol. 51(1), pp. 59-72.

64. Prescott, S., and Ulanicki, B. (2006), Reduction of water losses and energy consumption using an effective process for burst detection, Sustainable Technologies Initiative EPSRC (GR/S25715) \& DTI, Final Project Report, 19 February 2006.

65. Pudar, R.S. and Liggett, J.A. (1992), "Leaks in Pipe Networks.” Journal of Hydraulic Engineering, ASCE 118(7), pp.1031-1046.

66. Pudar, R.S., and Liggett, J.A. (1992). Fluid mechanics. Mass.: WCB/McGrawHill, 9th edition.

67. Puust R., Kapelan Z., Savic D. and Koppel T. (2006), "Probabilistic leak detection in pipe networks using the SCEM-UA algorithm." 8th Annual Water Distribution Systems Analysis Symposium, Cincinnati, Ohio, USA, August 27$30, A(4)$.

68. Rajani B. and Tesfamariam S. (2005), "Estimating time to failure of ageing cast iron water mains under uncertainties." CCWI 2005 International Conference, Exeter University Press, Exeter, Vol.1, pp. 57-63.

69. Rossman L.A., (2000). EPANET 2 Users Manual, U.S. Environmental Protection Agency, National Risk Management Research Laboratory, Cincinnati, $\mathrm{OH} 45268$, September.

70. Shamir U. \& Howard C.D.D. (1979), “An analytic approach to scheduling pipe replacement." Journal of American Water Works Association, N 71, pp. 248258.

71. Shmoylova R.A. editor (1999). Statistic theory, 'The finance and statistics', Moscow. (Russian).

72. Simpson, A.R. and Vitkovsky, J.P. (1997), “A Review of Pipe Calibration and Leak Detection Methodologies for Water Distribution Networks." Proc. 17th Federal Convention, Australian Water and Wastewater Association, Australia, vol. 1, pp. 680-687.

73. Skipworth P.J., Cashman A., Engelhardt M.O., Saul A.J. \& Savic D. (2001), "Quantification of mains failure behaviour in a whole life costing approach to 
distribution system management." ASCE EWRI conference, Orlando, Florida. May.

74. Soares A.K., Covas D.I.C. \& Reis L.F.R. (2007), “Inverse Transient Analysis for leak detection in a PVC pipe network", in Water Management Challenges in Global Change, (Ulanicki et al. editors), Taylor \& Francis Group, London, ISBN 978-0-415-45415-5, pp.337-344.

75. Stephens M., Misiunas D., Lambert M., Simpson A., Vitkovsky J. \& Nixon J. (2005), "Field verification of a continuous transient monitoring system for burst detection in water distribution systems." CCWI 2005 International Conference, Exeter University Press, Exeter, Vol.2, pp. 257-262.

76. Stoianov I., Karney B., Covas D., Maksimovic C. \& Graham N. (2002). Wavelet Processing of Transient Signals for pipeline Leak Location and Quantification, Roanoke, Virginia, USA.

77. Streeter, V.L., and Wylie, K.W. (1998). Fluid mechanics, Mass.: WCB/McGraw-Hill, 9th edition.

78. Tabesh M. \& Delavar M.R. (2003), "Application of integrated GIS and hydraulic models for unaccounted for water studies in water distribution systems." Advances in Water Supply Management, Swets \& Zeitlinger, Lisse, The Netherlands.

79. Tabesh M., Asadiani Yekta A.H. and Burrows R. (2005), "Evaluation of Unaccounted for Water and Real Losses in Water Distribution Networks by Hydraulic Analysis of the System Considering Pressure Dependency of Leakage." CCWI 2005 International Conference, Exeter University Press, Exeter, Vol.2, pp. 125-130.

80. Thornton J., Lambert A. (2005) "Progress in practical prediction of pressure: leakage, pressure: burst frequency and pressure: consumption relationships", in Leakage 2005 - Conference Proceedings.

81. Trifunovich N., Umar D. (2003), "Reliability assessment of the Bekasi distribution network by the method of Cullinane." Advances in Water Supply Management, Swets \& Zeitlinger, Lisse, The Netherlands.

82. Ulanicka K., Ulanicki B., Rance J.P. \& Coulbeck B., Powell R. \& Wang C. (1998), “Benchmarks for water network modelling." Hydroinformatics'98, Balkema, Rotterdam, ISBN 9054109831. 
83. Ulanicka, K, Ulanicki, B, (2003), “Computer modelling of water supply systems - pump scheduling and reservoir control", (ed), in Water \& Sewerage Journal, McMillan Pub., Issue 1/2003.

84. Ulanicki B., Bounds P.L.M., Rance L.P., Reynolds L., (2000), “Open and Closed Loop Pressure Control for Leakage Reduction." Urban Water Journal, Vol. 2, September.

85. Ulanicki, B. and Prescott, S. (2000), "Statistical Prediction of Leakage in Water Distribution Networks." Proceedings of the 45th International Scientific Colloquium, Ilmenau Technical University, October.

86. Ulanicki, B., Bounds P.L.M., Rance J.P., and Reynolds, L. (1999), “Open Loop and Closed Loop Pressure Control for Leakage Reduction." Urban Water Journal, Elsevier Science, Vol.2, pp. 105-114

87. Ulanicki, B., Prescott, S.L. and May, J. (2006). "Anatomy of leakage", unpublished notes, Water Software Systems, De Montfort University, Leicester, UK.

88. Unwin D.M., Boxall J.B. \& Saul A.J. (2003), "Data mining and relationship analysis of water distribution system databases for improved understanding of operations performance." Advances in Water Supply Management, Swets \& Zeitlinger, Lisse, The Netherland.

89. Van Zyl, J.E. \& Clayton, CRI (2005), "The effect of pressure on leakage in water distribution systems." CCWI 2005 International Conference, Exeter University Press, Exeter, Vol.2, pp. 131-136.

90. Ventcel, E.S. (1964). Probability theory, Major edition of the physical and mathematical literature, publishing house "Science", Moscow. (Russian).

91. Vairavamoorthy, K, and Lumbers, J. (1998), "Leakage Reduction in Water Distribution Systems: Optimal Valve Control." Journal of hydraulic Engineering, Vol.11, November.

92. Vitkovsky J.P., Simpson A.R. \& Lambert M.F. (1999), "Leak Detection and Calibration of Water Distribution Systems Using Transient and Genetic Algorithm." Proc. of the 26th Annual Water Resources Planning and Management Conference, June, Tempe, Arizona, USA. 
93. Vitkovsky J.P., Simpson A.R. \& Lambert M.F. (2000), "Leak Detection and Calibration Issues using Transient and Genetic Algorithm.” Journal of Water Resources Planning and Management, ASCE, 126(4), pp. 262-265.

94. Vitkovsky, J.P. and Simpson, A.R. (1997). Calibration and Leak Detection in Pipe Networks Using Inverse Transient Analysis and Genetic Algorithms. Report No. R 157, Department of Civil and Environmental Engineering, University of Adelaide, p. 97.

95. WAA - Water Authorities Association UK (1980) Leakage Control Policy \& Practice, Report 26, UK Water Authorities Association.

96. Wallingford Software (2008), www.wallingfordsoftware.com/products/infoworks_ws, accessed on July 2008.

97. Walski T.M. \& Pelliccia A. (1982), "Economic analysis of water main breaks." Journal of American Water Works Association, N 74, pp. 140-147.

98. Wang X.J., Lambert M.F., Simpson A.R., Liggett J.A. \& Vitkovsky J.P. (2002), "Leak Detection in Pipelines using Damping of Fluid Transients." Journal of Hydraulic Engineering, ASCE, 128(7), pp. 697-711.

99. WHO - World Health Organisation, (2001), Leakage Management and Control A Best Practice Manual, WHO, Geneva.

100. WRc-UK Water Industry. (1994). Managing Leakage - Summary report, Report A.

101. WRc-UK Water Industry. (1994a). Managing Leakage - Managing Water Pressure, Report G.

102. WRc-UK Water Industry. (1994b). Managing Leakage - Using Night Flow Data, Report F.

103. WSS. (1999) "FINESSE: On-line Operational Modelling and Modelling environment", [On-line], UK, available from: http://www.eng.dmu.ac.uk/wssys/software.htm. [Accessed: 7/1/00].

104. Wu Z.Y. \& Sage P. (2007), “ Pressure dependent demand optimisation for leakage detection in water distribution systems", in Water Management Challenges in Global Change, (Ulanicki et al. editors), Taylor \& Francis Group, London, ISBN 978-0-415-45415-5, pp.353-361.

105. Xi J., Bin Z.H., Jie Z. \& Fang W. (2007), “Optimal placement of pressure monitors in water supply network with elitist Genetic Algorithm", in Water 
Management Challenges in Global Change, (Ulanicki et al. editors), Taylor \& Francis Group, London, ISBN 978-0-415-45415-5, pp.115-121.

106. Zecchin A.C., White L.B., Lambert M.F. and Simpson A.R. (2005), "Frequency-Domain hypothesis testing approach to leak detection in single fluid line." CCWI 2005 International Conference, Exeter University Press, Exeter, Vol.2, pp. 149-154.

107. Zhou S. \& Xu S. (2005), "Studying Optimal Locating of Pressure Monitoring Stations in Urban. Water Distribution System.” Journal of Nanhua University (Science and Technology), Vol. 19(1), pp. 59-63. 


\section{Dictionary}

\begin{tabular}{|c|c|}
\hline AZNP & $\begin{array}{l}\text { average zonal night pressure, } \\
p_{\text {AZNP }}=\frac{\sum_{i \in \text { Nodes }} p_{i} \cdot \text { Demand_Allocation_Factor }_{i}}{\sum_{i \in \text { Nodes }} \text { Demand_Allocation_Factor }_{i}}\end{array}$ \\
\hline Background leakage & $\begin{array}{l}\text { water losses with flow rates from } 0.005 \text { litres/second to } \\
0.05 \text { litres/second which occur mainly at joints, } \\
\text { connections and fittings }\end{array}$ \\
\hline Burst & $\begin{array}{l}\text { water losses from pipe breaks or cracks with flow rates } \\
\text { from } 0.1 \text { litres/second to } 10 \text { litres/second }\end{array}$ \\
\hline Demand & node outflow representing water consumption \\
\hline Demand_Allocation_Factor & Proportion of total demand $d$ applied to node $i$ \\
\hline DMA & $\begin{array}{l}\text { District Metering Area, a part of a WDS which have closed } \\
\text { boundaries except for a small number of metered inlets and } \\
\text { outlets }\end{array}$ \\
\hline Equivalent area of a leak & $\begin{array}{l}\text { The coefficient } c \text { in the formula } q_{\text {leak }}=c(p) \times p^{0.5} \text { relating } \\
\text { leakage flow to pressure }\end{array}$ \\
\hline Experiment & $\begin{array}{l}\text { This thesis refers to simulation experiments and field } \\
\text { experiments. Unless otherwise stated 'experiment' refers } \\
\text { to simulation experiment. }\end{array}$ \\
\hline FAVOR test & $\begin{array}{l}\text { Fixed And Variable Orifice area test - the type of } \\
\text { experiment where inlet pressure of DMA is being stepped } \\
\text { down and up and the inlet flow and inlet pressure (head) } \\
\text { are measured }\end{array}$ \\
\hline Extended FAVOR test & $\begin{array}{l}\text { FAVOR test where additionally pressure (head) at a } \\
\text { number of selected internal nodes of a DMA are } \\
\text { measured }\end{array}$ \\
\hline Fixed area leakage & $\begin{array}{l}\text { leakage flow for which an equivalent leakage area is } \\
\text { constant }\end{array}$ \\
\hline
\end{tabular}




\begin{tabular}{|l|l|}
\hline IFM & $\begin{array}{l}\text { Inflow Flow Model, a three term model of the total inlet } \\
\text { flow to a DMA which comprises demand, fixed area } \\
\text { leakage and variable area leakage }\end{array}$ \\
\hline Pressure line & $\begin{array}{l}\text { a plot of a functional relationship between the inlet } \\
\text { pressure to a DMA and pressure at a selected node }\end{array}$ \\
\hline Regression pressure line & A linear regression line approximation to a pressure line \\
\hline RMS error & $\begin{array}{l}\text { Root mean square error } \\
\text { sensitive nodes } \\
\text { criterion }\end{array}$ \\
\hline Variable area leakage & $\begin{array}{l}\text { leakage flow for which an equivalent leakage area } \\
\text { changes with pressure }\end{array}$ \\
\hline$\chi^{2}$ criterion & $\begin{array}{l}\text { Water Distribution System - a general term to describe a } \\
\text { part of a clean water system from outputs of treatment } \\
\text { works to water consumers. }\end{array}$ \\
\hline
\end{tabular}




\section{List of symbols}

\begin{tabular}{|c|l|}
\hline$q$ & Flow (litres/sec), (1/s) \\
\hline$h$ & Head (metres), (m) \\
\hline$p$ & Pressure (metres), (m) \\
\hline$v$ & Acceleration due to gravity $(\mathrm{m} / \mathrm{s} / \mathrm{s})$ \\
\hline$c_{1}$ & Speed of the water $(\mathrm{m} / \mathrm{s})$ \\
\hline$c_{2}$ & Burst coefficient $(l / s / \sqrt{m})$ \\
\hline$d$ & Background leakage coefficient $(l / s / m \sqrt{m})$ \\
\hline$p_{\text {AZNP }}$ & Demand flow $(1 / \mathrm{s})$ \\
\hline$a, b$ & Coefficients \\
\hline$r$ & Resistance coefficient \\
\hline$\delta$ & Standard deviation \\
\hline$f(x)$ & Function of $x$ \\
\hline$\chi^{2}$ & The chi-square statistic \\
\hline$\varphi$ & Level of accuracy \\
\hline
\end{tabular}

